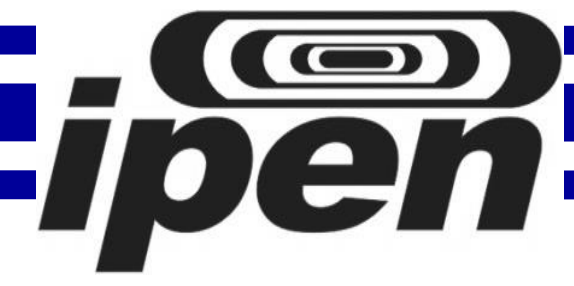

AUTARQUIA ASSOCIADA À UNIVERSIDADE DE SÃO PAULO

\title{
DESENVOLVIMENTO DE QUEIMADORES PARA ILUMINAÇÃO A GÁS À BASE DE SILICATO DE TERRAS RARAS
}

\section{SILAS CARDOSO DOS SANTOS}

Tese apresentada como parte dos requisitos para obtenção do Grau de Doutor em Ciências na Área de Tecnologia Nuclear - Materiais

\section{Orientadora:}

Profa. Dra. Sonia Regina Homem de Mello Castanho

\section{Versão Corrigida}

Versão Original disponível no IPEN

\section{SÃO PAULO}


INSTITUTO DE PESQUISAS ENERGÉTICAS E NUCLEARES

Autarquia associada à Universidade de São Paulo

\section{DESENVOLVIMENTO DE QUEIMADORES PARA ILUMINAÇÃO A GÁS À BASE DE SILICATO DE TERRAS RARAS}

\section{SILAS CARDOSO DOS SANTOS}

Tese apresentada como parte dos requisitos para obtenção do Grau de Doutor em Ciências na Área de Tecnologia Nuclear - Materiais

Orientadora:

Profa. Dra. Sonia Regina Homem de Mello Castanho

\section{Versão Corrigida}

Versão Original disponível no IPEN

\section{SÃO PAULO}

2014 


\section{DEDICATÓRIA}

Dedico este trabalho a todos que me ensinaram e contribuíram principalmente para minha formação como ser humano, a seguir:

In memoriam aos meus avós Antônio Quirino e Mariana Maria, como também a minha madrinha Ademira, que sempre me fortaleceram e conduziram no caminho da fé, perseverança e dedicação em todas as situações.

A minha irmã Cibele pelas diversas sugestões relacionadas ao meu desenvolvimento profissional.

A minha pequena e notável namorada Camila pelo carinho, comprometimento, compreensão e amor.

A minha família, principalmente a minha amada e sagrada mãe, Dona Dirce que sempre me acompanha, orienta e fortalece com sua fé, amor e carinho. Graças ao seu empenho irrestrito, tenho o privilégio de alcançar este grandioso objetivo. 


\section{AGRADECIMENTOS}

Em primeiro lugar gostaria de agradecer a Deus pela sabedoria e saúde para o desenvolvimento deste trabalho.

A São Jerônimo pela orientação, força e discernimento na elaboração desta tese.

A minha orientadora Dra. Sonia R.H.M. Castanho pela oportunidade de realizar este doutorado, orientação, confiança e consideração durante toda esta minha caminhada.

A Dra. Chieko Yamagata pelo comprometimento, paciência e apoio durante todo o desenvolvimento desta tese.

A Dra. Emília S. M. Seo pelo respeito e atenção durante todo trabalho.

A Dra. Eliana N. S. Muccillo pela gentileza em contribuir com material para os nossos primeiros ensaios de dopagem do dissilicato de ítrio.

Ao Dr. Rubens Chiba e Dr. Antônio Carlos (AC) pela amizade e consideração, ao dedicarem parte dos seus respectivos tempos para me orientar nos cálculos estequiométricos durante o projeto do material para a tese.

Ao Dr. Wilson Acchar da Universidade Federal do Rio Grande do Norte (UFRN) pela contribuição com este trabalho.

Aos pesquisadores Dr. Valter Ussui, Dr. Walter Kenji e Dra. Dolores R.R. Lazar pela gentileza de disponibilizarem o laboratório de Insumos para os primeiros ensaios desta pesquisa.

Ao Dr. Francisco J. C. Braga pelo grande auxílio no condicionamento do laboratório Químico para o desenvolvimento do experimental desta tese.

A Sra. Sandra Maria técnica do Laboratório de Insumos do CCM pela agilidade em caracterizar as amostras.

Ao MSc. Renê Ramos técnico do Laboratório de Difração de raios $\mathrm{X}$ do CCTM pela contribuição com esta pesquisa. 
Aos profissionais do Laboratório de Microscopia Eletrônica do CCTM, principalmente ao MSc. Glauson Aparecido pela caracterização microestrutural de algumas amostras.

Ao Dr. Vicente de Paulo Nicolau da Universidade Federal de Santa Catarina pelos inúmeros esclarecimentos e indicações de referências para embasamento deste estudo.

Aos respectivos professores pela oportunidade de participar do Programa de Aperfeiçoamento de Ensino pelo Estágio Supervisionado em Docência (PAE) em suas disciplinas: Dr. José Claudio Dellamano, Dr. Roberto Vicente e Dr. Julio T. Marumo (IPN004 - Introdução à Gerência de Rejeitos Radioativos); Dr. Arnaldo H. P. de Andrade (IPN0024 - Física dos Materiais Estruturais); Dr. Ricardo Leal e Dr. Cláudio José (IPN0012 - Caracterização Física de Materiais).

Ao Dr. Laércio Gomes do Centro de Lasers e Aplicações (CLA) pela indicação do grupo da Dra. Linda Caldas que posteriormente veio a contribuir muito com este trabalho.

As pesquisadoras Dra. Linda Caldas e Dra. Letícia Lucente do Centro de Metrologia das Radiações (CMR) pela humildade e gentileza em me receber, como também orientar quanto a caracterização termoluminescente dos materiais.

Aos profissionais do Centro de Tecnologia das Radiações (CTR), em particular ao técnico Sr. Paulo de Souza pelo profissionalismo e agilidade no preparo das amostras para caracterização termoluminescente.

Ao técnico Sr. Aldo Oliveira do Centro de Tecnologia das Radiações (CTR) pela dedicação em me ajudar nos primeiros ensaios termoluminescentes.

A Dra. Maíra Tiemi Yoshizumi pela distinção em me receber no laboratório, ao seu comprometimento e orientação durante a caracterização termoluminescente dos materiais.

Aos colaboradores da biblioteca do IPEN Terezine Arantes Ferraz pela atenção, educação e auxílio em todas as minhas solicitações. Gostaria de destacar também a excelência do serviço de requisição de artigos científicos internacionais desta biblioteca.

Aos profissionais do IPEN dos seguintes centros de pesquisa: Metrologia das Radiações (CMR), Tecnologia das Radiações (CTR), Combustível 
Nuclear ( $\mathrm{CCN})$, Células à Combustível e Hidrogênio $(\mathrm{CCCH})$, Química e Meio Ambiente (CQMA) e Ciências e Tecnologia dos Materiais (CCTM) pela gentileza em me receber nos respectivos laboratórios e auxílio na caracterização das amostras para o desenvolvimento desta tese.

Ao Instituto de Pesquisas Energéticas e Nucleares (IPEN) pela oportunidade deste doutorado.

A Coordenação de Aperfeiçoamento de Pessoal de Nível Superior (CAPES) pelo apoio financeiro para esta pesquisa.

Ao Dr. Antônio Carlos (AC), Dr. Thomaz Augusto, Dr. Luiz Fernando pelas inúmeras sugestões quanto ao procedimento experimental deste trabalho.

Ao Dr. Thomaz Augusto pelas orientações quanto a caracterização das amostras para análise térmica, interpretação de determinados resultados experimentais e redação das publicações internacionais.

Aos amigos MSc. William Naville e MSc. Douglas Will Leite da Faculdade de Engenharia Industrial (FEI) por colaborarem com a caracterização microestrutural das réplicas cerâmicas.

A todos os colaboradores do IPEN que sempre me trataram com muita atenção e respeito.

A minha grande amiga, escritora e professora Angela Braga pelo carinho, respeito e apoio em todos os momentos.

Ao meu eterno e querido professor Durigan pelos inúmeros conselhos profissionais e pessoais.

A minha namorada Camila, pelo carinho, amor, atenção e comprometimento em toda minha caminhada.

A minha família, em especial a minha querida mãe pelo amor, dedicação, incentivo, acompanhamento, força e orientação desde o início da minha vida. 
"O homem que ajunta letras e livros,

teorias e valores científicos

sem distribuí-los a benefício dos outros,

é irmão infortunado daquele que

amontoa moedas e apólices,

títulos e objetos preciosos,

sem ajudar a ninguém.

O mesmo prato lhes serve

na balança da vida." 


\title{
DESENVOLVIMENTO DE QUEIMADORES PARA ILUMINAÇÃO A GÁS À BASE DE SILICATO DE TERRAS RARAS
}

\author{
Silas Cardoso dos Santos
}

\section{RESUMO}

$\mathrm{O}$ dissilicato de ítrio $\left(\mathrm{Y}_{2} \mathrm{Si}_{2} \mathrm{O}_{7}\right)$ por apresentar propriedades luminescentes consideráveis, é um potencial substituto dos óxidos de terras raras na tecnologia de queimadores de gás para iluminação. Em processos de conformação a partir de suspensões, o controle da estabilidade das partículas em meio líquido consiste em uma importante etapa para a produção de componentes com microestrutura homogênea e estabilidade estrutural. Neste sentido, este trabalho apresenta estudos sobre o comportamento de superfície, de estabilidade e reológico de suspensões aquosas de $\mathrm{Y}_{2} \mathrm{Si}_{2} \mathrm{O}_{7}$ e $\beta-\mathrm{Y}_{1,95} \mathrm{Dy}_{0,05} \mathrm{Si}_{2} \mathrm{O}_{7}$ com o objetivo de preparar suspensões compatíveis para o processo de conformação por réplica, usando-se fibras vegetais como matriz para a confecção de componentes reticulados para queimadores de gás. Neste estudo foram avaliados parâmetros determinantes na estabilidade e comportamento de fluxo das suspensões, como também a luminescência estimulada pela temperatura desses materiais na forma de pó e a eficiência radiante do protótipo de queimador de gás. Os resultados obtidos para o $\beta-\mathrm{Y}_{1,95} \mathrm{Dy}_{0,05} \mathrm{Si}_{2} \mathrm{O}_{7}$ comparados com a ítria $\left(\mathrm{Y}_{2} \mathrm{O}_{3}\right)$ e concentrado de terras raras contento ítria (YTR) mostram-se promissores. Desenvolveu-se por processamento coloidal do $\beta-Y_{1,95} \mathrm{Dy}_{0,05} \mathrm{Si}_{2} \mathrm{O}_{7}$ e utilizando-se o processo de conformação por réplica a partir da esponja vegetal Lufa Cylindrica, um protótipo de lâmpada de queimador de gás com boa resistência mecânica ao manejo, emissividade espectral no visível ( $\lambda=580 \mathrm{~nm}$ ) e eficiência radiante de $13 \%$, com grande potencial para iluminação de ambientes internos de acordo com as recomendações da Comissão Internacional de lluminação (CIE). 


\title{
DEVELOPMENT OF RARE EARTH SILICATE BURNERS FOR GAS LIGHTING
}

\author{
Silas Cardoso dos Santos
}

\begin{abstract}
Yttrium disilicate $\left(\mathrm{Y}_{2} \mathrm{Si}_{2} \mathrm{O}_{7}\right)$ shows luminescent proprieties and is a potential material to replace rare earth oxides in porous burner technology for lighting. In conformation process from suspensions the control of stability of particles in aqueous medium is an important step to produce ceramic components that show homogeneous microstructure and structural stability. This work presents studies about surface behavior, stability and rheological behavior of aqueous suspensions of $\mathrm{Y}_{2} \mathrm{Si}_{2} \mathrm{O}_{7}$ and $\beta-\mathrm{Y}_{1,95} \mathrm{Dy}_{0,05} \mathrm{Si}_{2} \mathrm{O}_{7}$ and aims to prepare suitable suspensions for replica method, and vegetable fibers were used as template to produce porous components for gas burners. In this study key parameters on stability and rheological behavior of suspensions were evaluated, as well as the stimulated luminescence of powders by increasing temperature and radiant efficiency of gas burner prototype. The results as compared with yttria and rare earth concentrate containing yttria are very promising. By colloidal processing of $\beta-Y_{1,95} \mathrm{Dy}_{0,05} \mathrm{Si}_{2} \mathrm{O}_{7}$ and using replica method from Luffa Cylindrica vegetable sponge a prototype of gas burner lamp showing good handle strength, visible spectral emissivity $(\lambda=580 \mathrm{~nm})$, radiant efficiency of $13 \%$, and great potential to be used for lighting internal spaces according to the International Commission on Illumination (CIE).
\end{abstract}




\section{SUMÁRIO}

PÁGINA

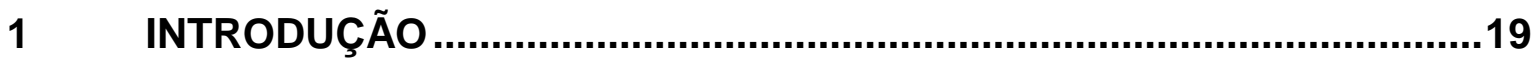

2 OBJETIVO

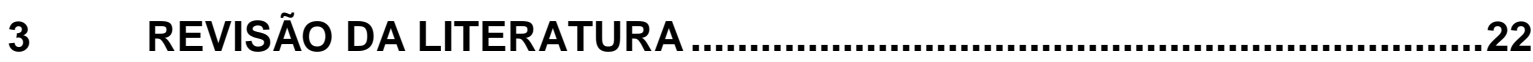

3.1 Competitividade, a força motriz para o desenvolvimento do Brasil ...........22

3.2 Biogás: biomassa moderna como fonte de energia distribuída ..................24

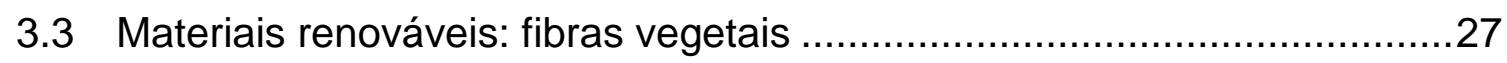

3.4 Componentes cerâmicos porosos para iluminação à gás .........................29

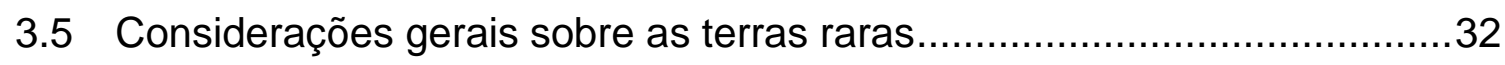

3.5.1 Propriedades químicas e físicas das terras raras ................. 35

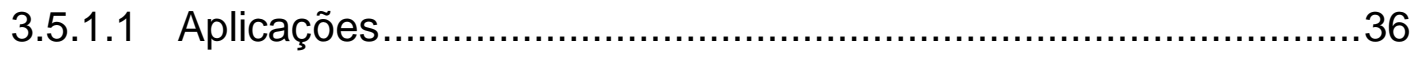

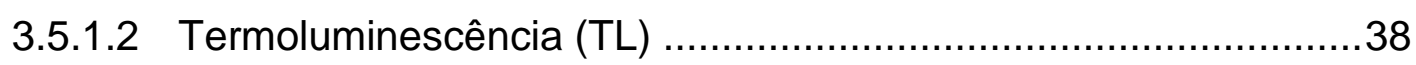

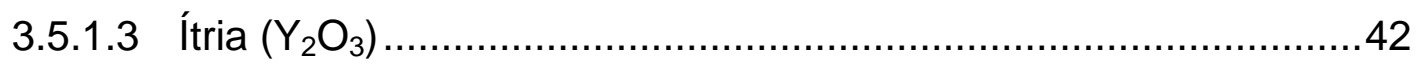

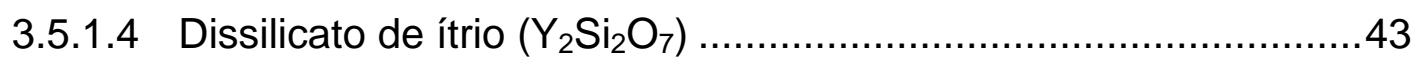

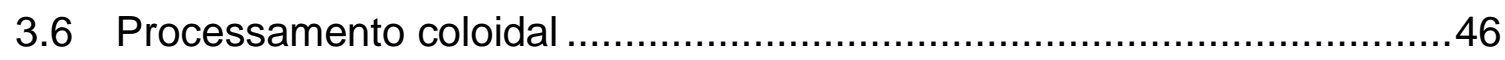

3.6.1 Aspectos gerais do processamento cerâmico a partir de suspensões

3.6.1.1 Mecanismos de estabilização de suspensões ............................51

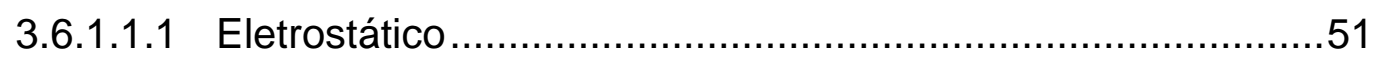

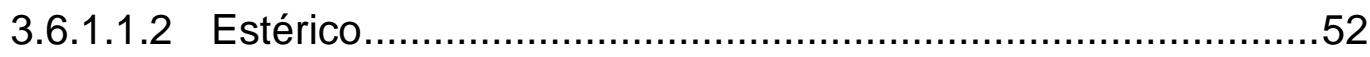

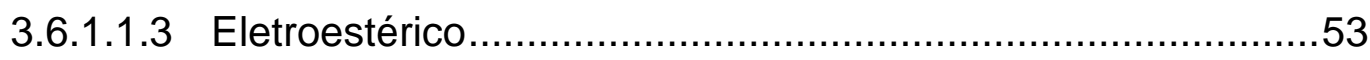

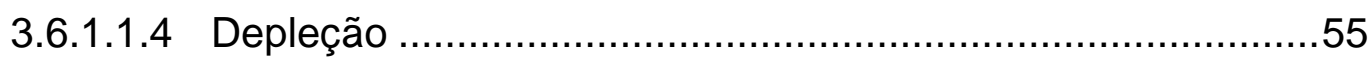

3.6.1.2 Reologia das suspensões cerâmicas........................................56

3.6.1.2.1 Viscosidade ...............................................................

3.6.1.2.2 Tensão $(\tau)$ e taxa de cisalhamento $(\gamma)$..............................57

3.6.1.2.3 Curvas de Fluxo.............................................................. 59

3.6.1.2.4 Tipos de comportamentos reológicos ...................................60

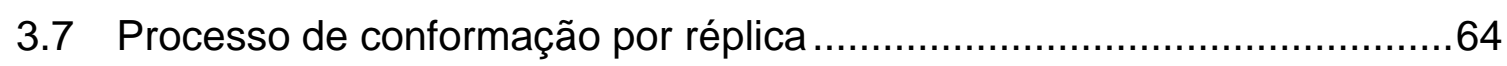




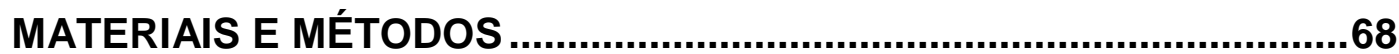

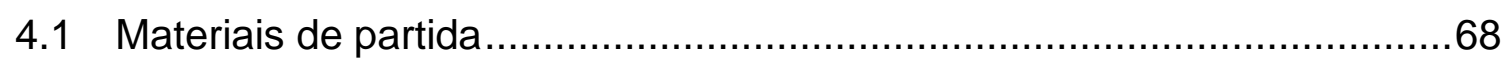

4.2 Síntese do dissilicato de ítrio..............................................................

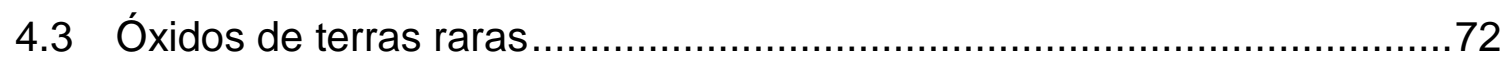

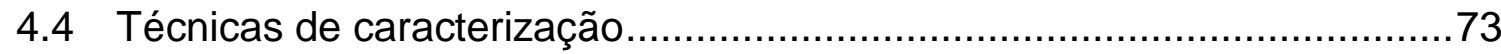

4.4.1 Picnometria de gás hélio ................................................... 73

4.4.2 Espectroscopia de correlação de fótons (PCS) …………..... 73

4.4.3 Área de superfície específica pelo método de BET $\left(\mathrm{S}_{\mathrm{M}}\right)$, diâmetro médio de partícula teórico $\left(\mathrm{d}_{\mathrm{BET}}\right)$ e fator de aglomeração $\left(\mathrm{F}_{\mathrm{AG}}\right)$........... 74

4.4.4 Difração de raios X (DRX)................................................ 76

4.4.5 Microscopia Eletrônica de Varredura (MEV) ......................... 76

4.4.6 Fluorescência de raios X (FRX) ....................................... 77

4.4.7 Análise termogravimétrica e análise térmica diferencial

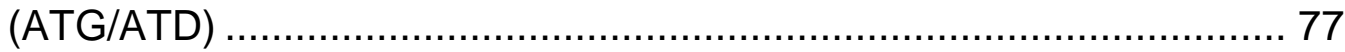

4.4.8 Emissão de luz termicamente estimulada (TL) .................... 78

4.4.9 Estabilidade das partículas em suspensão - potencial Zeta (ろ)78

4.4.10 Preparo das suspensões cerâmicas .................................... 79

4.4.11 Caracterização reológica das suspensões cerâmicas ............ 80

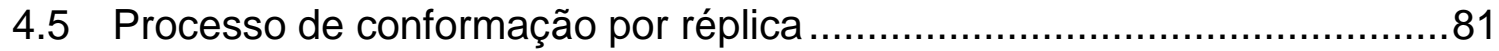

4.5.1 Condicionamento da superfície das fibras vegetais ............... 81

4.5.2 Confecção do protótipo de manta de gás ............................. 82

4.5.3 Ensaios de impregnação das amostras ............................... 83

4.5.4 Ensaios de tratamento térmico das amostras impregnadas .. 83

4.5.5 Determinação da eficiência radiante do protótipo ................... 83

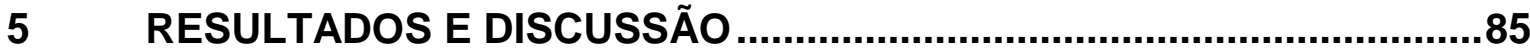

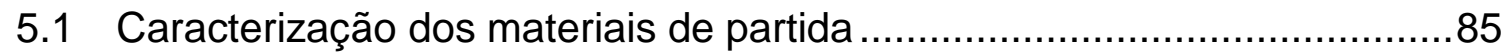

5.1.1 Óxido de ítrio $\left(\mathrm{Y}_{2} \mathrm{O}_{3}\right)$, óxido de disprósio $\left(\mathrm{Dy}_{2} \mathrm{O}_{3}\right)$ e concentrado

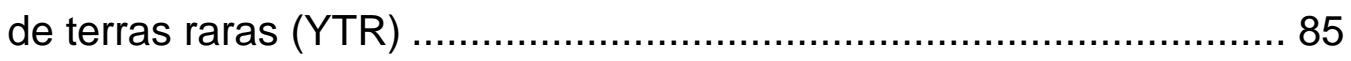

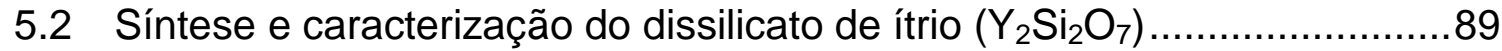

5.2.1 Caracterização do dissilicato de ítrio dopado com disprósio.. 94

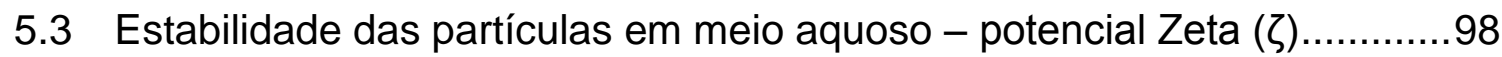

5.4 Reologia das suspensões cerâmicas .................................................101

5.4.1 Estabilidade das suspensões pelo ajuste de $\mathrm{pH}$................. 101 
5.4.2 Curvas de defloculação para ajuste de dispersante 102

5.4.3 Influência da concentração de sólidos no comportamento de fluxo das suspensões 105

5.4.4 Determinação da concentração do ligante CMC 107

5.5 Condicionamento da superfície das fibras vegetais para impregnação ..112

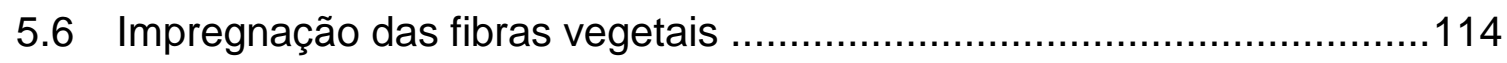

5.7 Tratamento térmico das amostras impregnadas .................................115

5.8 Caracterização microestrutural dos protótipos ………………..............118

5.9 Luminescência estimulada pela temperatura ......................................124

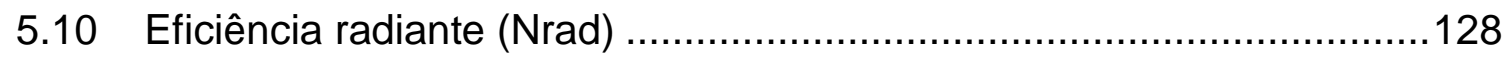

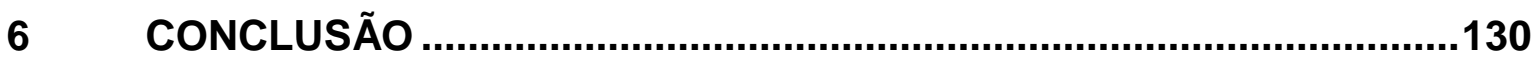

7 REFERÊNCIAS BIBLIOGRÁFICAS ................................................131 


\section{ÍNDICE DE TABELAS}

\section{PÁGINA}

TABELA 1 - Vantagens do uso do biogás como fonte de energia .26

TABELA 2 - Exemplos de materiais que apresentam característica termoluminescente reportados na literatura

TABELA 3 - Principais estudos de processamento coloidal dos compostos $\mathrm{Y}_{2} \mathrm{O}_{3} \mathrm{e}$ $\mathrm{Y}_{2} \mathrm{O}_{3}: \mathrm{SiO}_{2}$ encontrados na literatura. .47

TABELA 4 - Principais modelos reológicos. 63

TABELA 5 - Principais materiais utilizados como matriz de réplica. .66

TABELA 8 - Especificações dos gases combustíveis utilizados para os ensaios de desempenho do protótipo de queimador de gás .84

TABELA 9 - Resultados de Fluorescência de raios $X$ das amostras $\mathrm{Y}_{2} \mathrm{O}_{3}, \mathrm{Dy}_{2} \mathrm{O}_{3} \mathrm{e}$ YTR. .88

TABELA 10 - Resultados de caracterização dos pós de $\mathrm{Y}_{2} \mathrm{O}_{3}, \mathrm{Dy}_{2} \mathrm{O}_{3}$ e YTR .......89 TABELA 11 - Resultados de caracterização dos pós de $\mathrm{Y}_{2} \mathrm{Si}_{2} \mathrm{O}_{7}$ tratados

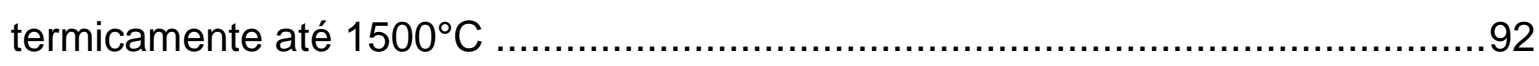

TABELA 12 - Resultados de caracterização física dos pós de $\beta-Y_{2} \mathrm{Si}_{2} \mathrm{O}_{7}$ e $\quad \beta$ $\mathrm{Y}_{1,95} \mathrm{Dy}_{0,05} \mathrm{Si}_{2} \mathrm{O}_{7}$

TABELA 13 - Parâmetros de processamento determinados para as suspensões selecionadas para os ensaios de impregnação das fibras vegetais LCy.

TABELA 14 - Condições de tratamento térmico propostas para as amostras de LCy impregnadas. 


\section{ÍNDICE DE FIGURAS}

\section{PÁGINA}

FIGURA 1 - Os doze pilares da competitividade segundo o Fórum Econômico Mundial. Colunas em verde correspondem aos índices do Brasil, colunas em azul representam a média aritmética dos indicadores dos países do grupo TOP10 ...23 FIGURA 2 - Diagrama geral de geração de biogás: sólidos domésticos, resíduos animais e efluentes líquidos. O produto da biodigestão é utilizado como fertilizante ${ }^{[11-13]}$ .25

FIGURA 3 - Comparativo do poder calorífico do biogás com as demais fontes de energia convencionais. 25

FIGURA 4 - Luffa Cylindrica. Em (a) frutos (buchas) em condição para colheita; (b) região interna da bucha à verde em corte transversa; (c) buchas descascadas secando ao sol; (d) buchas secas e cortadas; micrografias por Microscopia Eletrônica de Varredura (MEV) das (e) fibras da bucha natural e (f) detalhe da superfície celular da fibra vegetal ${ }^{[30-35]}$ 29

FIGURA 5 - Esquema do processo de circulação de calor num meio poroso, idealizado como um tubo refratário ${ }^{[4]}$.

FIGURA 6 - Principais aplicações dos queimadores de gás, tratamento térmico de (a) peças com geometria complexa e (b) materiais laminados; (c) processamento de papel; (d) secagem de pinturas, (e) aquecimento de ambientes (estádio de futebol), (f) secagem de matérias primas depositadas em vagões (transporte ferroviário $)^{[48]}$

FIGURA 7 - Principais fabricantes de queimadores de gás para iluminação: (a) GasLiteAmerica, (b) Mr. Heater, (c) The Outdor Great Room e (d)Gallery Series Lighting $^{[49-52]}$

FIGURA 8 - Estimativa da disponibilidade dos elementos TR na crosta terrestre.

FIGURA 9 - Principais reservas de terras raras no mundo ${ }^{[75]}$ 
FIGURA 10 - Número de publicações brasileiras sobre materiais à base de TR em periódicos internacionais registradas no ano de 2000 até 31 de maio de 2014 segundo a plataforma Scopus.

FIGURA 11- Variação dos raios iônicos os lantanídeos trivalentes em função dos números atômicos (contração lantanídica). .36

FIGURA 12 - Aplicações das terras raras no mercado americano. 37

FIGURA 13 - Representação de um modelo de bandas de energia ${ }^{[103]}$.... 39 FIGURA 14 - Espectro de emissão de luz característico de um material (a) termoluminescente e (b) corpo negro (espectro de referência). .40

FIGURA 15 - Estrutura cristalina cúbica de corpo centrado do $\mathrm{Y}_{2} \mathrm{O}_{3}$. 42 FIGURA 16 - Principais elementos lantanídeos utilizados como dopantes e seus respectivos espectros de emissão luminescente ${ }^{[121]}$ 43

FIGURA 17 - Diagrama de equilíbrio de fases do sistema $\mathrm{Y}_{2} \mathrm{O}_{3}-\mathrm{SiO}_{2[136]}$ 45 FIGURA 18 - Representação da dupla camada elétrica segundo a teoria de Stern. Em (a) arranjo espacial dos íons que constituem a dupla camada elétrica de uma partícula em meio líquido; (b) disposição dos planos de carga que constituem a dupla camada e (c) variação do potencial elétrico em função da distância da superfície da partícula ${ }^{[158]}$ .50

FIGURA 19 - Mecanismo de estabilização eletrostático a partir da formação da dupla camada elétrica. .52

FIGURA 20 - Mecanismo de estabilização estérica[ ${ }^{163]}$. 53

FIGURA 21 - Mecanismo de estabilização eletroestérica[ ${ }^{163]}$.... .53

FIGURA 22 - Efeito da adição do polieletrólito aniônico PMMA na variação do potencial zeta em função do $\mathrm{pH}$ das suspensões de $\mathrm{Al}_{2} \mathrm{O}_{3}{ }^{[164]}$. .54 FIGURA 23 - Configuração geral do polímero aniônico adsorvido na superfície da partícula em função do $\mathrm{pH}$. Normalmente a condição que favorece melhor configuração é estabelecida a $\mathrm{pH} \geq 9$. .55 FIGURA 24 - Condição dos polímeros em dissolução. Em (a) estabilização por depleção (b) exclusão do polímero durante a aproximação das partículas, favorecendo a floculação por depleção.

FIGURA 25 - Representação do modelo misto de estabilização estérica e depleção. .56

FIGURA 26 - Representação de fluxo entre duas placas paralelas .59 
FIGURA 27 - Representação da curva de fluxo tensão por taxa de cisalhamento controlada $(\mathrm{CR})$.

FIGURA 28 - Comportamento reológico de um fluído Newtoniano. Em (a) curva de fluxo e (b) curva de viscosidade.

FIGURA 29 - Representação da estrutura da suspensão na condição (a) em repouso e (b) durante o fluxo.

FIGURA 30 - Representação dos diferentes tipos de comportamento reológico dos fluídos. Em (a) curvas de fluxo e (b) curvas de viscosidade. 62

FIGURA 31 - Esquema do processo de conformação por réplica. .65

FIGURA 32 - Fotografia óptica de (a) esponja vegetal Lufa Cylindrica e (b) cerâmica porosa obtida por réplica a partir dessa matriz natural.

FIGURA 33 - Estruturas reticuladas das esponjas (a) sintética de poliuretano e (b) vegetal da espécie Luffa Cylindrica.

FIGURA 34 - Esponja vegetal Luffa Cylindrica. Em (a) fruto verde no pé; (b) esponja descascada e seca (c) secção transversal da esponja e (d) estrutura fibrosa constituinte da esponja.

FIGURA 35 - Processo de síntese hidrotermal utilizado para produzir os pós de dissilicato de ítrio. Em (a) suspensão do precursor; (b) precursor em balão volumétrico; (c) sistema condensador para tratamento hidrotérmico; (d) filtragem e lavagem do precursor após refluxo; (e) precursor em gel e (f) pós de dissilicato de ítrio obtidos por tratamento térmico a $1000^{\circ} \mathrm{C}$ por $2 \mathrm{~h}$ em atmosfera ambiente. ....72 FIGURA 36 - Parâmetros utilizados para as curvas de fluxo: (C1) curva de subida, $0-1000 \mathrm{~s}^{-1}$ por $300 \mathrm{~s}$; (C2) patamar à $1000 \mathrm{~s}^{-1}$ por $120 \mathrm{~s}$; (C3) curva de descida, $1000-0 s^{-1}$ por 300 s.

FIGURA 37 -Tratamento das fibras vegetais da matriz LCy com solução de $2 \%$ massa de $\mathrm{NaOH}$ a $60^{\circ} \mathrm{C}$ por $2 \mathrm{~h}$. Em (a) LCy imersa em solução alcalina; (b) vista superior da amostra LCy imersa; (c) solução sobrenadante extraída das fibras.

FIGURA 38 - Esquema de confecção do protótipo de manta de gás a partir da esponja vegetal LCy. .82

FIGURA 39 - Padrões de difração de raios $X$ dos óxidos de terras raras $\mathrm{Y}_{2} \mathrm{O}_{3} \mathrm{e}$ $\mathrm{Dy}_{2} \mathrm{O}_{3}$ 86

FIGURA 40 - Padrões de difração de raios $X$ do carbonato de terras raras $\mathrm{TR}_{2}\left(\mathrm{CO}_{3}\right)_{3}$ e concentrado de terras raras YTR 
FIGURA 41 - Micrografias dos materiais de partida em pó. $\mathrm{Em}$ (a) $\mathrm{Y}_{2} \mathrm{O}_{3}$, (b) $\mathrm{Dy}_{2} \mathrm{O}_{3}$ e (c) YTR obtidas por MEV.

FIGURA 42 - Análise termogravimétrica e termo diferencial do PDY tratado a $10^{\circ} \mathrm{C} \cdot \mathrm{min}^{-1}$ até $1400^{\circ} \mathrm{C}$ em atmosfera ambiente.

FIGURA 43 - Padrões de difração de raios $X$ das amostras do precursor de $\mathrm{Y}_{2} \mathrm{Si}_{2} \mathrm{O}_{7}$ tratadas até $1500^{\circ} \mathrm{C}$ por $2 \mathrm{~h}$ em atmosfera ambiente. .93

FIGURA 44 - Micrografias obtidas por MEV dos pós de $\mathrm{Y}_{2} \mathrm{Si}_{2} \mathrm{O}_{7}$ tratados por $2 \mathrm{~h}$ em atmosfera ambiente a (a) $975^{\circ} \mathrm{C}$; (b) $1000^{\circ} \mathrm{C}$; (c) $1200^{\circ} \mathrm{C}$; (d) $1300^{\circ} \mathrm{C}$; (e) $1400^{\circ} \mathrm{C}$ e (f) $1500^{\circ} \mathrm{C}$ .94

FIGURA 45 - Padrões de difração de raios $X$ das amostras $\beta-Y_{2} \mathrm{Si}_{2} \mathrm{O}_{7}$ e $\mathrm{Y}_{1,95} \mathrm{Dy}_{0,05} \mathrm{Si}_{2} \mathrm{O}_{7}$ obtidas por tratamento térmico a $1400^{\circ} \mathrm{C}$ por $2 \mathrm{~h}$ em atmosfera ambiente. .95

FIGURA 46 - Curvas de distribuição granulométrica de partículas das amostras $\beta$ $\mathrm{Y}_{2} \mathrm{Si}_{2} \mathrm{O}_{7}$ e $\beta-\mathrm{Y}_{1,95} \mathrm{Dy}_{0,05} \mathrm{Si}_{2} \mathrm{O}_{7}$ por PCS, obtidas por tratamento térmico a $1400^{\circ} \mathrm{C}$ por duas horas em atmosfera ambiente. .96

FIGURA 47 - Micrografias dos pós de (a) $\mathrm{Y}_{2} \mathrm{Si}_{2} \mathrm{O}_{7}$ e (b) $\beta-\mathrm{Y}_{1,95} \mathrm{Dy}_{0,05} \mathrm{Si}_{2} \mathrm{O}_{7}$ obtidas por MEV, após tratamento térmico a $1400^{\circ} \mathrm{C}$ por duas horas em atmosfera ambiente. .96

FIGURA 48 - Curvas de potencial zeta em função do $\mathrm{pH}$ das suspensões cerâmicas de $\beta-Y_{2} \mathrm{Si}_{2} \mathrm{O}_{7} \quad(\mathrm{PIE}=7,8), \quad \beta-\mathrm{Y}_{1,95} \mathrm{Dy}_{0,05} \mathrm{Si}_{2} \mathrm{O}_{7} \quad(\mathrm{PIE}=8,3)$ e $\mathrm{Y}_{2} \mathrm{O}_{3}$ $(\mathrm{PIE}=8,5)$ .99

FIGURA 49 - Variação do potencial zeta do $\beta-\mathrm{Y}_{2} \mathrm{Si}_{2} \mathrm{O}_{7}$ em função do $\mathrm{pH}$ e da concentração em massa de dispersante PAA. 100

FIGURA 50 - Variação do potencial zeta do $\beta-Y_{1,95} D y_{0,05} S_{2} \mathrm{O}_{7}$ em função do $\mathrm{pH}$ e da concentração em massa de dispersante PAA. 101 FIGURA 51 - Correlação entre pH e viscosidade aparente a $500 \mathrm{~s}^{-1}$ das suspensões aquosas de $\beta-\mathrm{Y}_{2} \mathrm{Si}_{2} \mathrm{O}_{7}, \beta-\mathrm{Y}_{1,95} \mathrm{Dy}_{0,05} \mathrm{Si}_{2} \mathrm{O}_{7}, \mathrm{Y}_{2} \mathrm{O}_{3}$ e YTR. 102 FIGURA 52 - Variação da viscosidade aparente em função da taxa de cisalhamento controlado até $1000 s^{-1}$ das suspensões aquosas de $\beta-Y_{2} \mathrm{Si}_{2} \mathrm{O}_{7}$ preparadas com até $3 \%$ em massa de PAA. 104 FIGURA 53 - Curvas de viscosidade aparente em função da taxa de cisalhamento controlado até $1000 s^{-1}$ das suspensões aquosas de $\beta-Y_{2} \mathrm{Si}_{2} \mathrm{O}_{7}$, $\beta$ - 
$\mathrm{Y}_{1,95} \mathrm{Dy}_{0,05} \mathrm{Si}_{2} \mathrm{O}_{7}, \mathrm{Y}_{2} \mathrm{O}_{3}$ e YTR preparadas nas melhores condições de estabilidade. 105

FIGURA 54 - Curvas de fluxo das suspensões de $\beta-\mathrm{Y}_{2} \mathrm{Si}_{2} \mathrm{O}_{7}$ com até $25 \%$ vol de sólidos em modo de taxa de cisalhamento controlado até $1000 \mathrm{~s}^{-1}$. 106

FIGURA 55 - Curvas de fluxo das suspensões aquosas de $\beta-Y_{2} \mathrm{Si}_{2} \mathrm{O}_{7}$, $\mathrm{Y}_{1,95} \mathrm{Dy}_{0,05} \mathrm{Si}_{2} \mathrm{O}_{7}, \mathrm{Y}_{2} \mathrm{O}_{3}$ e YTR com $25 \%$ vol de sólidos em modo de taxa de cisalhamento controlado até $1000 \mathrm{~s}^{-1}$. 107

FIGURA 56 - Curvas de fluxo das suspensões de $\beta-\mathrm{Y}_{2} \mathrm{Si}_{2} \mathrm{O}_{7}$ com $25 \%$ vol de sólidos e até $0,6 \%$ em massa de CMC. 109

FIGURA 57 - Curvas de viscosidade aparente das suspensões de $\beta-\mathrm{Y}_{2} \mathrm{Si}_{2} \mathrm{O}_{7}$ preparadas com $25 \%$ vol de sólidos e com até $0,6 \%$ massa de CMC 109 FIGURA 58 - Curvas de viscosidade aparente das suspensões aquosas de .....111 FIGURA 59 - Esponja vegetal Luffa Cylindrica (LCy). Em (A) perspectiva macroscópica da esponja; (B) micrografia das fibras da LCy dispostas em arranjo matricial e aleatório; micrografias das superfícies das fibras (C) como recebido e (D) após o tratamento com $2 \%$ massa de $\mathrm{NaOH}$, onde as ranhuras e micro canais estão indicados pelas setas.

FIGURA 60 - Detalhe da superfície das fibras vegetais (a) sem tratamento e (b) com tratamento alcalino, ilustrando a adesão da suspensão na superfície das mesmas. 114

FIGURA 61 - Análises térmicas das fibras da LCy à taxa de aquecimento de $10^{\circ} \mathrm{C} \cdot \mathrm{min}^{-1}$ até $800^{\circ} \mathrm{C}$ em atmosfera ambiente.

FIGURA 62 - Padrões de difração de raios X das fibras vegetais LCy. Em (a) LCy in natura e (b) cinzas da LCy resultantes da calcinação com taxa de aquecimento de $10^{\circ} \mathrm{C} / \mathrm{min}$ até $800^{\circ} \mathrm{C} / 1 \mathrm{~h}$ em atmosfera ambiente. 116 FIGURA 63 - Protótipo de queimador de gás à base de $\beta-\mathrm{Y}_{2} \mathrm{Si}_{2} \mathrm{O}_{7}$ sinterizado à $1500^{\circ} \mathrm{C}$ por $7 \mathrm{~h}$ em atmosfera ambiente. Em (a) protótipo em forma de bulbo à partir da réplica LCy; (b) disposição aleatória das fibras constituintes do bulbo; (c) microestrutura porosa do bulbo; (d) superfície da fibra e (e) superfície interna da fibra de estrutura reticulada com poros de tamanho inferior a $2 \mu \mathrm{m}$; (f) superfície interna da fibra constituída de grãos de tamanho e formato heterogêneos. 119 FIGURA 64 - Protótipo de queimador de gás à base de $\beta-Y_{1,95} D y_{0,05} \mathrm{Si}_{2} \mathrm{O}_{7}$ sinterizado a $1500^{\circ} \mathrm{C}$ por $7 \mathrm{~h}$ em atmosfera ambiente. Em (a) protótipo em forma de bulbo; (b) fibras; (c) microestrutura porosa do bulbo; (d) detalhe do poro 
presente na superfície da fibra e (e) superfície porosa da fibra; (f) superfície interna da fibra.

FIGURA 65 - Protótipo de queimador de gás à base de Y2O3 sinterizado a $1600^{\circ} \mathrm{C}$ por $2 \mathrm{~h}$ em atmosfera ambiente. Em (a) protótipo em forma de bulbo à partir da réplica LCy; (b) disposição aleatória das fibras constituintes do bulbo; (c) micrografia da estrutura reticulada do bulbo; (d) microestrutura porosa da superfície da fibra (e) camada interna da fibra constituída de grãos de tamanho e formato heterogêneos; (f) superfície interna da fibra em fratura de modo intergranular.

FIGURA 66 - Protótipo de queimador de gás à base de YTR sinterizado a $1600^{\circ} \mathrm{C}$ por $2 \mathrm{~h}$ em atmosfera ambiente. Em (a) protótipo em forma de bulbo à partir da réplica LCy; (b) disposição aleatória das fibras constituintes do bulbo; (c) microestrutura porosa do bulbo; (d) superfície da fibra e (e) superfície de fratura da fibra de estrutura reticulada com poros de tamanho inferior a $2 \mu \mathrm{m}$; (f) superfície interna da fibra em fratura de modo transgranular .123 FIGURA 67 - Termoluminescência da amostra $\beta-\mathrm{Y}_{2} \mathrm{Si}_{2} \mathrm{O}_{7}$. Em (a) espectro de emissão de luz à taxa de $10^{\circ} \mathrm{C} . \mathrm{s}^{-1}$ até $400^{\circ} \mathrm{C}$ em atmosfera ambiente, com emissão de luz análoga ao corpo negro; (b) espectro padrão de emissão do corpo negro. 124

FIGURA 68 - Termoluminescência da amostra $\beta-Y_{1,95} \mathrm{Dy}_{0,05} \mathrm{Si}_{2} \mathrm{O}_{7}$ à taxa de $10^{\circ} \mathrm{C} / \mathrm{s}$ até $350^{\circ} \mathrm{C}$ em atmosfera ambiente, com emissão no comprimento de onda visível $(\lambda=580 \mathrm{~nm})$, correspondente à cor amarela.

FIGURA 69 - Termoluminescência da amostra $\mathrm{Y}_{2} \mathrm{O}_{3}$ à taxa de $10^{\circ} \mathrm{C} . \mathrm{s}^{-1}$ até $350^{\circ} \mathrm{C}$ em atmosfera ambiente, com emissão no comprimento de onda visível $(\lambda=550 \mathrm{~nm})$, correspondente à cor verde

FIGURA 70 - Termoluminescência da amostra YTR. Em (a) espectro de emissão de luz à taxa de $10^{\circ} \mathrm{C} . \mathrm{s}^{-1}$ até $400^{\circ} \mathrm{C}$ em atmosfera ambiente, com emissão de luz análoga ao corpo negro; (b) espectro padrão de emissão do corpo negro. 127 FIGURA 71 - Eficiência radiante do queimador de gás à base de $\beta$ $\mathrm{Y}_{1,95} \mathrm{Dy}_{0,05} \mathrm{Si}_{2} \mathrm{O}_{7}$ em função da temperatura e do tipo de gás combustível utilizado.

FIGURA 72 - Protótipo de lâmpada de queimador de gás à base de $\beta$ $\mathrm{Y}_{1,95} \mathrm{Dy}_{0,05} \mathrm{Si}_{2} \mathrm{O}_{7}$ durante ensaio de queima de gás metano a temperatura de $600^{\circ} \mathrm{C}$ 


\section{INTRODUÇÃO}

O Brasil da atualidade é considerado uma potência ascendente na América Latina, sendo sua política internacional definida como "poder brando" ${ }^{[1]}$, baseada em diplomacia, desenvolvimento econômico e interesses comuns. Para continuar neste processo de desenvolvimento é importante estabelecer um programa sustentável de segurança energética, onde o projeto de materiais e componentes avançados para conversão de energia é essencial.

No panorama global, universalizar o acesso à energia é um dos maiores desafios deste século segundo o relatório, Pobreza energética: Como estabelecer o acesso a energia moderna universal? $(2010)^{[2]}$, da Organização das Nações Unidas (ONU). Cerca de 2 bilhões de pessoas ainda não tem acesso a este recurso, o qual é requisito básico para cidadania. De acordo com a Agência Internacional de Energia (AIE), apenas o serviço de iluminação consome $20 \%$ do total gerado ${ }^{[3]}$.

No contexto de eficiência energética, a iluminação a partir de biogás utilizando-se componentes porosos pode ser mais eficaz se comparada à queima por chama livre. O queimador de gás para iluminação apresenta uma estrutura reticulada que favorece maior contenção do gás em seu volume interno e atua como um sistema de circulador de calor. Esta arquitetura proporciona melhor condição de combustão, estabilidade a chama, emissividade espectral do material constituinte do queimador, eficiência radiante e menor emissão de poluentes ${ }^{[4]}$.

Os materiais cerâmicos mostram-se como uma opção interessante para o desenvolvimento de componentes para queimadores de gás, devido as suas propriedades intrínsecas como estabilidade estrutural em alta temperatura. O material ainda há poucas décadas utilizado para esta aplicação, a tória $\left(\mathrm{ThO}_{2}\right)$, foi substituída pela ítria dopada com elementos terras raras $\left(\mathrm{Y}_{2} \mathrm{O}_{3}: T R\right)$. A $\mathrm{Y}_{2} \mathrm{O}_{3}$, embora tenha excelentes propriedades ópticas e estruturais, apresenta um elevado custo. Por outro lado, devido à forte característica de uso da $\mathrm{Y}_{2} \mathrm{O}_{3}$ como dopante, ou matriz para compostos luminescentes, pouca atenção tem- 
se dedicado as pesquisas em processamento cerâmico massivo deste material. Por este razão, notam-se poucos trabalhos referentes ao comportamento reológico e ao processamento da $\mathrm{Y}_{2} \mathrm{O}_{3}$. Até o presente momento, observa-se também para o dissilicato de ítrio $\left(\mathrm{Y}_{2} \mathrm{Si}_{2} \mathrm{O}_{7}\right)$, material proposto neste trabalho, poucos estudos relacionados ao processamento do mesmo. Baseado neste contexto, considera-se uma importante contribuição para estas questões, fazer um estudo detalhado do processamento coloidal da $\mathrm{Y}_{2} \mathrm{O}_{3}$ e $\mathrm{Y}_{2} \mathrm{Si}_{2} \mathrm{O}_{7}$ visando a obtenção de queimadores de gás com boas propriedades mecânicas e termoluminescentes. Neste sentido, muitas questões referentes ao processamento coloidal destes materiais precisam ser avaliadas. Adicionalmente, o uso das fibras naturais como matrizes em substituição aos materiais sintéticos contribui para uma tecnologia ambientalmente sustentável destes componentes.

Este trabalho inova a tecnologia de fabricação de queimadores de gás para iluminação por dois aspectos: (1) apresenta um produto com potencial para substituir a ítria utilizada como material luminescente pelo dissilicato de ítrio sintético e (2) utiliza estruturas naturais como matrizes em substituição aos materiais industrializados e derivados de petróleo.

Teve-se como meta deste estudo reduzir o teor de ítrio presente nos queimadores de gás. Neste sentido, foram utilizados e avaliados quanto ao desempenho termoluminescente quatro materiais distintos: ítria $\left(\mathrm{Y}_{2} \mathrm{O}_{3}\right)$, concentrado de terras raras com alto teor de ítria (YTR), dissilicato de ítrio sintético puro $\left(\mathrm{Y}_{2} \mathrm{Si}_{2} \mathrm{O}_{7}\right)$ e dopado com disprósio $\left(\beta-\mathrm{Y}_{1,95} \mathrm{Dy}_{0,05} \mathrm{Si}_{2} \mathrm{O}_{7}\right)$. O protótipo de queimador de gás à base do material de melhor resposta termoluminescente foi caracterizado quanto a sua eficiência radiante, utilizando-se dois tipos de gases combustível: metano e butano.

Ao determinar parâmetros de projeto e processamento de materiais, como também de conformação de componentes porosos à partir de suspensões cerâmicas, esta tese representa uma importante contribuição para o desenvolvimento da tecnologia nacional de queimadores de gás para iluminação. 


\section{OBJETIVO}

Obter componentes porosos e luminescentes à base de $\mathrm{Y}_{2} \mathrm{Si}_{2} \mathrm{O}_{7}$ para aplicação em queimadores de gás. Neste sentido, as principais metas são:

- Sintetizar pelo processo hidrotermal os pós de $\mathrm{Y}_{2} \mathrm{Si}_{2} \mathrm{O}_{7}$ e caracterizálos visando o uso em queimadores de gás;

- Estudar os parâmetros envolvidos no processamento coloidal do dissilicato de ítrio para conformação por réplica a partir de estruturas orgânicas naturais;

- Avaliar o comportamento do $\mathrm{Y}_{2} \mathrm{Si}_{2} \mathrm{O}_{7}$ para aplicações luminescentes, como potencial substituto da ítria dopada com terras raras. 


\section{REVISÃO DA LITERATURA}

\subsection{Competitividade, a força motriz para o desenvolvimento do Brasil}

Política de desenvolvimento consiste em disponibilidade de recursos naturais, educação-profissionalização, investimento produtivo, saúde e inovação tecnológica ${ }^{[5]}$. O Índice de Competitividade Global (ICG) é um parâmetro utilizado para avaliar a economia de um país e sua capacidade de desenvolvimento. $O$ Fórum Econômico Mundial define competitividade como, "um conjunto de instituições, políticas e fatores que determinam o nível de produtividade de um país"[6].

Na FIG. 1 é apresentado o comparativo da competitividade do Brasil com as dez nações de maior ICG, denominadas como TOP10 (Suíça, Suécia, Singapura, Estados Unidos, Alemanha, Japão, Finlândia, Holanda, Dinamarca e Canadá). O Brasil figura na $53^{\circ}$ posição do ICG (total de 142 países) ${ }^{[6]}$. Dentre os pilares mostrados na FIG. 1, a inovação apresenta a menor pontuação. Este indicativo revela que profundas reformas estruturais são necessárias para alavancar o Brasil para posições mais favoráveis e consolidá-lo como um agente importante no mercado global altamente competitivo. As seguintes reformas podem ser resumidas em quatro pontos chaves como, política, ideologia, economia e tecnologia.

Devido ao aumento populacional e da expectativa de vida do brasileiro, o investimento em tecnologias renováveis compete politicamente com outros temas de interesse nacional como reforma da previdência social, reajuste do salário mínimo, educação, saúde pública e reforma trabalhista. Neste cenário, os projetos de tecnologias renováveis recebem pouca atenção das autoridades políticas. 


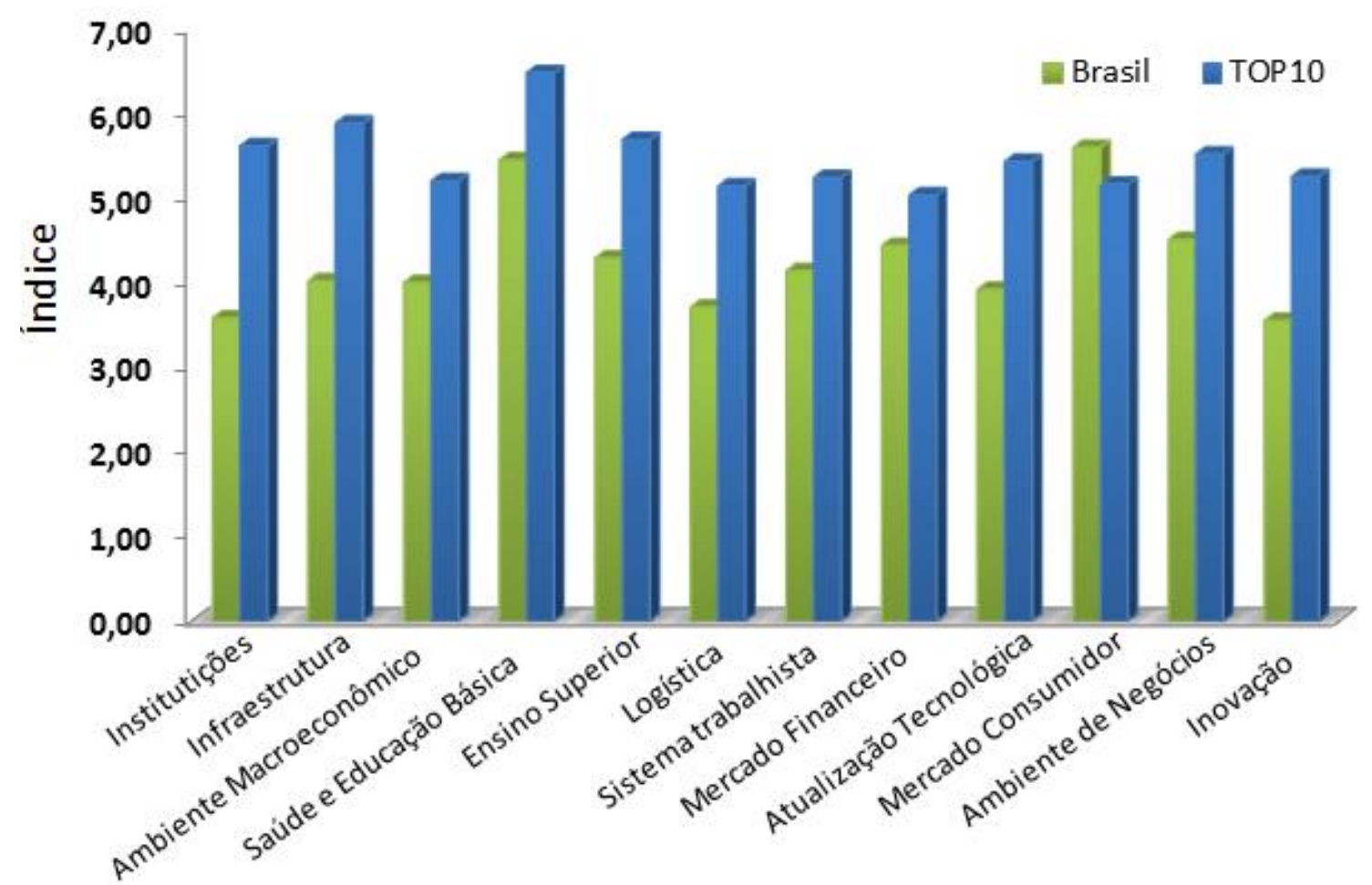

FIGURA 1 - Os doze pilares da competitividade segundo o Fórum Econômico Mundial. Colunas em verde correspondem aos índices do Brasil, colunas em azul representam a média aritmética dos indicadores dos países do grupo TOP10.

Há um grande consenso na indústria referente à falta de incentivos fiscais para pequenas e médias empresas para investirem em tecnologias renováveis. Neste contexto, apenas as empresas transnacionais são capazes de aplicar recursos em pesquisa, desenvolvimento, inovação e implantação de novas tecnologias. Um caminho promissor para o desenvolvimento de novas tecnologias para as pequenas e médias empresas é o trabalho conjunto com centros de pesquisas e universidades.

No Brasil a produção de matérias primas elaboradas e em especial dos compostos de Terras Raras (TR) é um dos setores de tecnologia que carecem de maior investimento. Atualmente o Brasil não possui tecnologia economicamente competitiva para produção de compostos terras raras para suprir a demanda interna. Muitos óxidos têm sido importados, como óxido de ítrio $\left(\mathrm{Y}_{2} \mathrm{O}_{3}\right)$, óxido de cério $\left(\mathrm{CeO}_{2}\right)$, óxido de disprósio $\left(\mathrm{Dy}_{2} \mathrm{O}_{3}\right)$ e até ligas metálicas à base de $\mathrm{Ce}^{[7]}$. As terras raras são materiais muito utilizados em produtos de alta tecnologia, como 
ligas metálicas, componentes para armamento, lasers, painéis de alta resolução e fibra óptica ${ }^{[8]}$.

Uma das aplicações de destaque das terras raras é na composição de produtos para iluminação, devido ao seu alto desempenho luminescente (elevada resolução de cor). O setor de iluminação consome cerca de $20 \%{ }^{[9]}$ do total de energia gerada no mundo, portanto a busca por novas fontes de energia, associada ao desenvolvimento de produtos de menor consumo energético e maior eficiência luminosa são metas cada vez mais desafiadoras ${ }^{[10]}$.

Perante este panorama aqui apresentado, este trabalho inova ao apresentar uma proposta para o desenvolvimento de queimadores de gás à base de terras raras para iluminação. Teve-se como meta diminuir a concentração de ítrio presente no material a partir do uso do dissilicato de ítrio sintetizado puro $\left(\mathrm{Y}_{2} \mathrm{Si}_{2} \mathrm{O}_{7}\right)$ e dopado com disprósio $\left(\mathrm{Y}_{2} \mathrm{Si}_{2} \mathrm{O}_{7}: \mathrm{Dy}^{3+}\right)$. Além disso, o uso de biomassa como combustível para queima nesses componentes pode contribuir para o desenvolvimento de um sistema de energia renovável e distribuída, favorecendo o bem estar e conforto da sociedade a partir de um programa sustentável de energia.

\subsection{Biogás: biomassa moderna como fonte de energia distribuída}

O biogás é um gás produzido a partir da digestão anaeróbia de resíduos animais, agroindustriais, sólidos domésticos e efluentes líquidos, conforme mostrado na FIG. $2^{[11-13]}$. De modo geral, apresenta como constituintes principais o $\mathrm{CH}_{4}(50 \%)$ e $\mathrm{CO}_{2}(45 \%)$, tendo $5 \%$ de componentes minoritários $\left(\mathrm{H}_{2}\right.$, $\left.\mathrm{N}_{2}, \mathrm{O}_{2}, \mathrm{NH}_{3}, \mathrm{H}_{2} \mathrm{~S}, \mathrm{CO}\right)^{[14]}$. Comparado às outras fontes de energia, o biogás apresenta poder calorífico considerável, sendo superior à lenha $\left(6.200 \mathrm{kcal} \mathrm{kg}^{-1}\right) \mathrm{e}$ bem próximo ao do etanol $\left(6.700 \mathrm{kcal}^{\mathrm{kg}}{ }^{-1}\right)$, como ilustrado na FIG. 3. No sentido de potencializar o biogás como fonte de energia, estudos recentes mostram duas vertentes, uma relacionada às rotas químicas complementares ao processo de biodigestão ${ }^{[15-17]}$, e outra à projetos de biodigestores com sistemas de cogeração ${ }^{[18-22]}$.

Para captação do biogás em aterros sanitários são utilizados drenos que permitem a extração do gás e o escoamento do chorume. Os drenos são 
conectados a sopradores que realizam a sucção do biogás 24hs por dia. Quanto ao resíduo rural, é utilizado o biodigestor - equipamento fechado sem entrada de ar, onde os resíduos são armazenados e fermentam, transformando a biomassa em biogás. O material resultante do processo de biodigestão pode ser utilizado como fertilizante, pois é rico em nitrogênio e fósforo ${ }^{[23]}$.

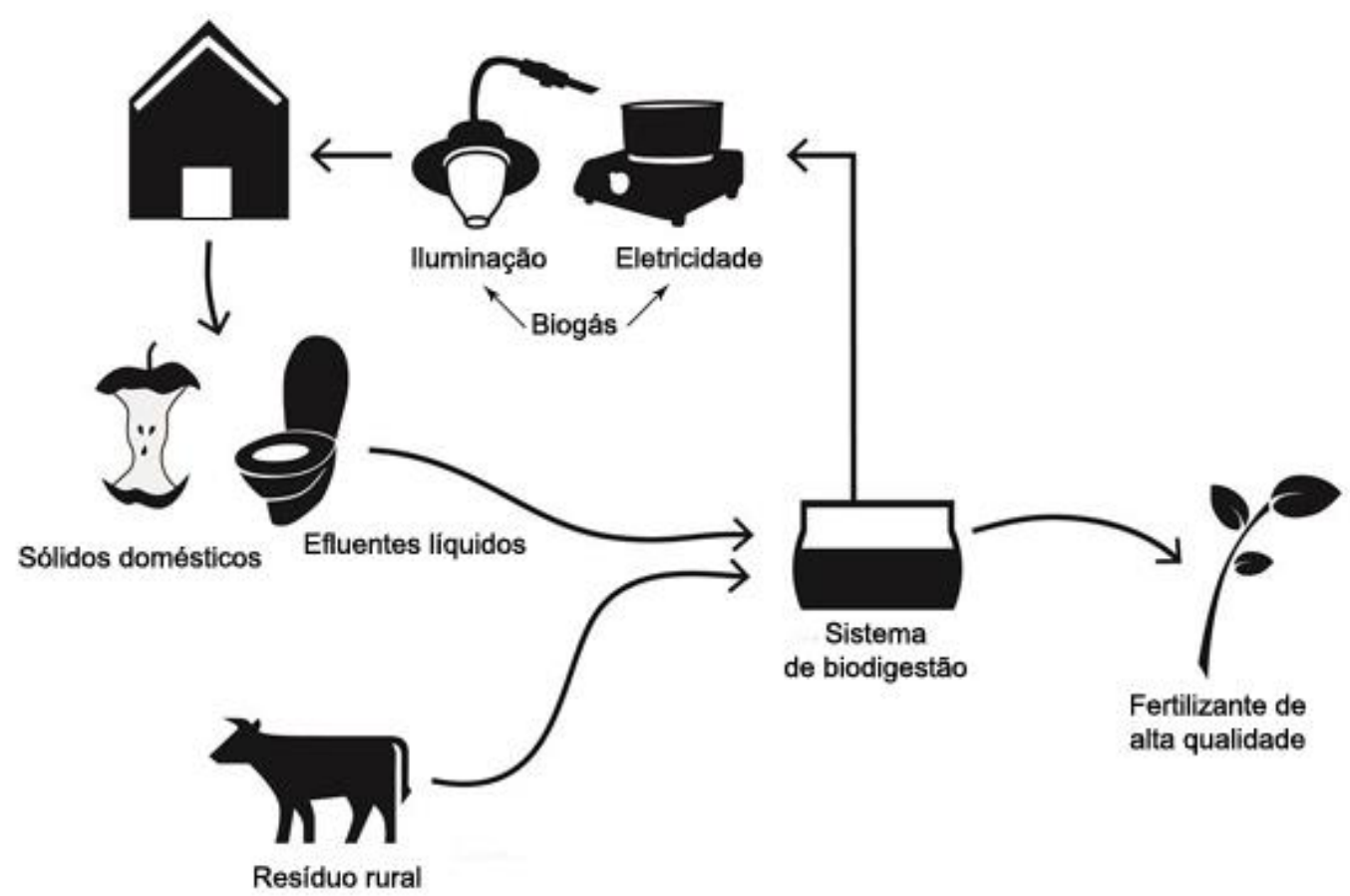

FIGURA 2 - Diagrama geral de geração de biogás: sólidos domésticos, resíduos animais e efluentes líquidos. O produto da biodigestão é utilizado como fertilizante ${ }^{[11-13]}$.

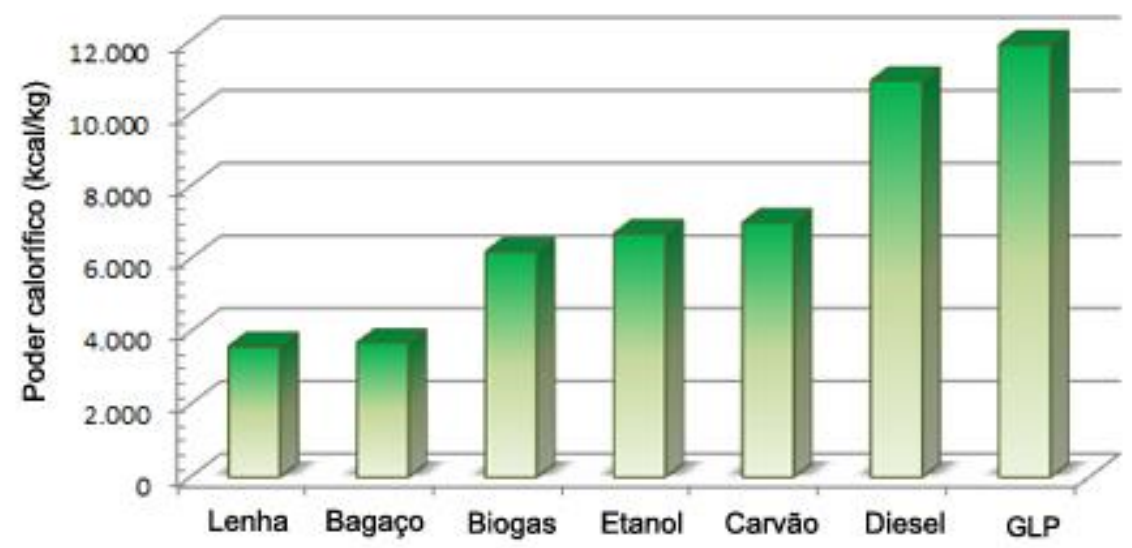

FIGURA 3 - Comparativo do poder calorífico do biogás com as demais fontes de energia convencionais. 
Baseado no Programa de Incentivo às Fontes Alternativas de Energia $(P R O I N F A)^{[24]}$, o uso do biogás como fonte de energia certamente irá contribuir na oferta de energia, diversificar a matriz energética atual (dependente da hidroeletricidade), reduzir os impactos ambientais e auxiliar a promoção de um mercado energético sustentável. Portanto, o biogás apresenta vantagens nas áreas ambiental, social e econômica, conforme indicado na TAB. $1^{[23,25-29]}$.

TABELA 1 - Vantagens do uso do biogás como fonte de energia

\begin{tabular}{|c|c|}
\hline Aspectos & Vantagens \\
\hline Ambiental & $\begin{array}{l}\text { - Menor emissão dos gases efeito estufa } \\
\text { - } \text { Diversificação da matriz energética nacional } \\
\text { - Melhora na qualidade do ar } \\
\text { - Política efetiva de gestão de resíduos }\end{array}$ \\
\hline Social & $\begin{array}{l}\text { - Aprimoramento dos programas de saneamento básico. } \\
\text { - Maior oferta de energia. } \\
\text { - Menor fluxo migratório para os grandes centros. } \\
\text { - Melhor qualidade de vida. }\end{array}$ \\
\hline Econômico & $\begin{array}{l}\text { - Novas oportunidades de empregos formais. } \\
\text { - Aprimoramento da política de venda de Créditos de } \\
\text { Carbono. } \\
\text { - Desenvolvimento regional. } \\
\text { - Aumento da renda familiar. }\end{array}$ \\
\hline
\end{tabular}

O uso do biogás como fonte de energia é uma tecnologia promissora, cujas projeções atendem as condições do PROINFA. Neste sentido também, a busca por materiais naturais em substituição aos sintéticos no processo tecnológico de confecção de queimadores de gás é uma contribuição importante deste trabalho. O Brasil reúne uma grande variedade de fibras vegetais, onde a bucha vegetal da espécie Luffa Cylindrica apresenta propriedades interessantes para esta tecnologia. 


\subsection{Materiais renováveis: fibras vegetais}

As fibras vegetais estão disponíveis em praticamente toda parte do mundo. Constituindo a classe de materiais renováveis, as fibras vegetais apresentam aspectos importantes que podem contribuir no processo de transição da economia fóssil para a economia verde, como biodegradabilidade, abundância e baixo custo.

Em geral, as fibras vegetais são materiais constituídos de fibrilos aglomerados pela resina do tecido da planta. As principais fibras são: sisal, bucha, linho, rami, abacá, kenaf, algodão, palmira, bambu, mesta, henequen, tampico, paina, cânhamo, crotalária, piaçava, madeira, banana, kusha, gramíneas Sawai e abacaxi. Algumas fibras vegetais como algodão, sisal, coco, piaçava, juta e abacá são muito utilizadas na confecção de tecidos, mantas, carpetes, vassouras, enchimento de assentos veiculares, esteiras, cordas, embalagens e reforço estrutural.

Dentre as diversas variedades de fibras vegetais, a esponja vegetal (FIG. 4) ${ }^{[30-35]}$, fruto da Luffa Cylindrica (família da Curcubitacea), apresenta morfologia semelhante a um cone, onde as fibras estão dispostas aleatoriamente, formando uma estrutura emaranhada e de comprimento variando de $15-150 \mathrm{~cm}^{[36]}$. GIANPRIETO ${ }^{[37]}$ et al. em seus estudos determinaram que as fibras da bucha natural possuem cerca de $60 \%$ celulose, $30 \%$ hemicelulose e $10 \%$ de lignina.

Basicamente a bucha natural é utilizada como esponja de banho e para fins medicinais (espécie Acutangulla) ${ }^{[38]}$. Estudos recentes de caracterização e condicionamento buscam potencializar a bucha vegetal para outras aplicações tecnológicas. TANOBE et.al ${ }^{[39]}$ modificaram a superfície das fibras a partir de soluções de $\mathrm{NaOH}$ e metacrilamida em diferentes tempos de imersão, onde o tratamento com $\mathrm{NaOH}$ proporcionou aumento da área de superfície das fibras e maior estabilidade térmica. SHEN et al.. ${ }^{[40]}$ determinaram a resistência à compressão das fibras em diferentes taxas de compressão, onde observaram que a capacidade de absorção de energia por unidade de massa em altas taxas de compressão das fibras vegetais foi maior que de muitas esponjas metálicas, destacando este material para aplicações de absorção de impacto, isolamento acústico e de vibração. DEMIR et al.. ${ }^{[41]}$ avaliaram as fibras vegetais quanto ao potencial de absorção de corantes azuis à base de metileno em soluções aquosas 
em diferentes concentrações e condições de tratamento térmico. Neste estudo verificaram que a capacidade de absorção das fibras é independente da temperatura e as mesmas apresentaram absorção média de $49 \mathrm{mg}^{-1}{ }^{-1}$, resultado significativamente superior às demais fibras à base de celulose como o sisal e a juta. Outro potencial tecnológico da bucha natural, porém pouco explorado, é como molde para confecção de componentes cerâmicos porosos, substituindo as matrizes sintéticas à base de poliuretano e nylon. Neste sentido, Silva et al.. ${ }^{[30]}$ desenvolveram cerâmicas porosas à base de argila e feldspato a partir da bucha vegetal como matriz de réplica. As peças sinterizadas à $1175^{\circ} \mathrm{C}$ por $2 \mathrm{~h}$ apresentaram morfologia idêntica à bucha vegetal, sem nenhuma trinca ou defeito aparente. Portanto, determinar e avaliar as propriedades da bucha vegetal possibilitam novas oportunidades de aplicação tecnológica.

A crescente preocupação quanto à mudança climática, segurança energética e os preços dos combustíveis fósseis têm proporcionado um grande interesse na pesquisa de fontes de energia alternativas renováveis. Processos baseados no reaproveitamento energético de combustíveis de baixo poder calorífico como o biogás e o reuso dos gases de exaustão provenientes de sistemas de combustão (cogeração) são considerados alternativas tecnológicas com grande potencial para contribuir na transição do panorama econômico atual para a economia verde. O queimador de gás apresenta uma estrutura porosa que possibilita a passagem da mistura gás + ar e favorece o processo de combustão. A bucha vegetal é caracterizada pela sua estrutura de fibras dispostas aleatoriamente, formando uma arquitetura reticulada. Esta particularidade destaca a bucha vegetal como um insumo potencial para a confecção de queimadores de gás. 

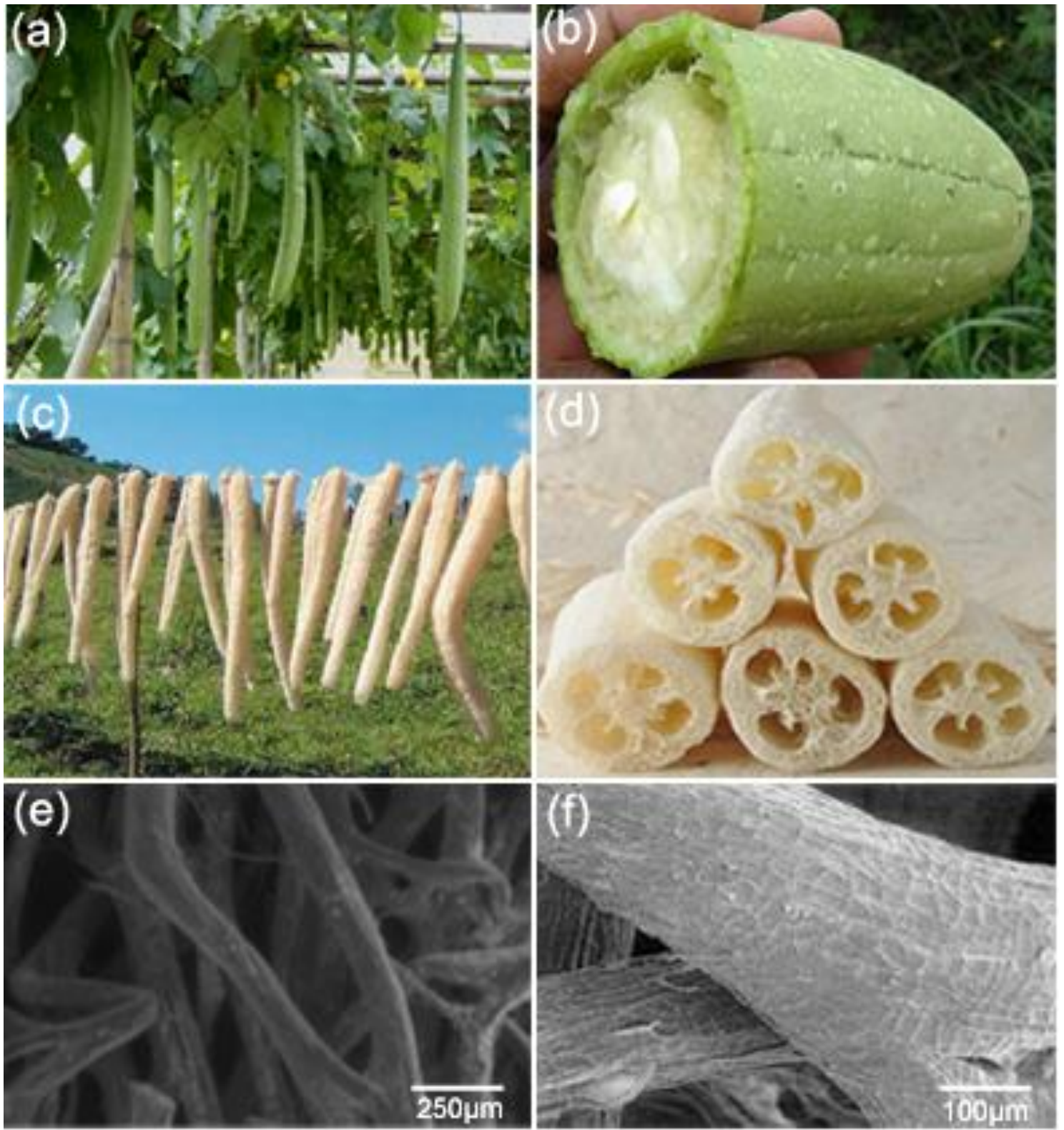

FIGURA 4 - Luffa Cylindrica. Em (a) frutos (buchas) em condição para colheita; (b) região interna da bucha à verde em corte transversa; (c) buchas descascadas secando ao sol; (d) buchas secas e cortadas; micrografias por Microscopia Eletrônica de Varredura (MEV) das (e) fibras da bucha natural e (f) detalhe da superfície celular da fibra vegetal ${ }^{[30-35]}$.

\subsection{Componentes cerâmicos porosos para iluminação à gás}

O conceito de queimador poroso foi primeiramente apresentado por TAKENO e SATO ${ }^{[42,43]}$ que a partir de um componente poroso conseguiram manter a chama do queimador com baixo fluxo de combustível, onde na condição de chama livre, isso não seria possível. Os componentes cerâmicos porosos são 
constituídos de uma estrutura celular (rede), que favorece a retenção do gás em seu volume interno e possibilita a troca de calor entre a parede da estrutura cerâmica e o gás ${ }^{[44]}$. Este modelo favorece estabilidade a chama, potencializa a queima do combustível, emissão de luz e uniformidade de calor, resultando em baixa emissão de gases poluentes ${ }^{[4,44-47]}$. Nestas condições, a tecnologia de queimadores porosos contribui também para o cumprimento das recomendações do Plano de Emissão de Baixo Carbono das Nações Unidades (ONU) ${ }^{[10]}$.

Na FIG. $5^{[4]}$ é apresentado o processo de circulação de calor durante a queima do combustível em um componente cerâmico poroso. A partir da combustão, o calor é conduzido por convecção da região de combustão para a estrutura cerâmica, pois o gás está mais quente que a matriz sólida. O reticulado cerâmico conduz e irradia o fluxo de calor para a região de entrada do gás (região mais fria). Nesta condição, os gases de entrada são aquecidos e seu deslocamento para a região de queima é favorecido por expansão. Portanto, esta configuração favorece também estabilidade a chama e melhora a eficiência de queima do gás ${ }^{[4]}$.

Os queimadores de gás são utilizados em diversas aplicações tecnológicas, como aquecimento de água e de ambientes (campos de futebol e galpões), secagem de pinturas e matérias primas, processamento de materiais cerâmicos, metálicos, vidros, papéis, madeira e alimentos, conforme ilustrado na

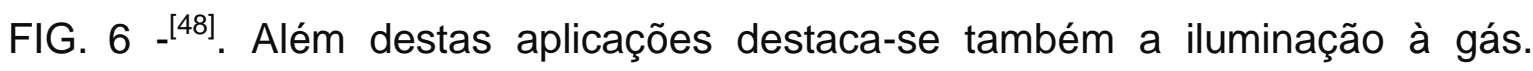
Atualmente não foi encontrada no mercado nenhuma empresa brasileira fabricante de componentes cerâmicos para queima de gás para iluminação (mantas). Os principais fabricantes são particularmente norte americanos como GasliteAmerica $^{[49]}$,The Outdoor GreatRoom ${ }^{[50]}$, Mr. Heater ${ }^{[51]}$ e Gallery Series Lighting $^{[52]}$. Portanto, este trabalho tem como meta contribuir para o desenvolvimento tecnológico nacional deste produto. Na FIG. $7^{[49-52]}$ são apresentados alguns modelos de queimadores de gás desenvolvidos pelas empresas citadas anteriormente. 


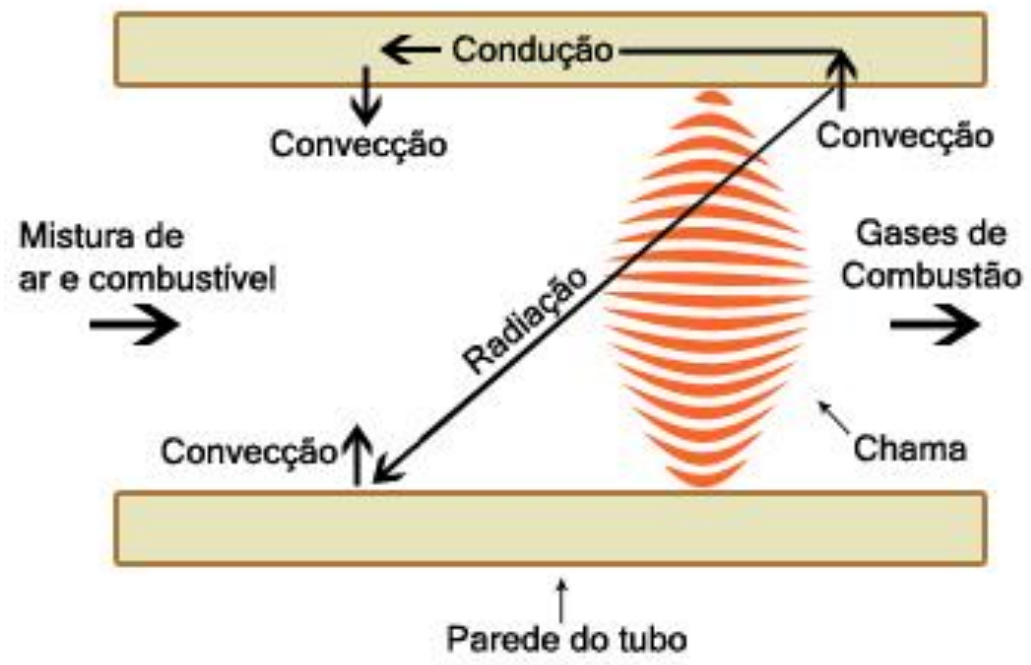

FIGURA 5 - Esquema do processo de circulação de calor num meio poroso, idealizado como um tubo refratário ${ }^{[4]}$.
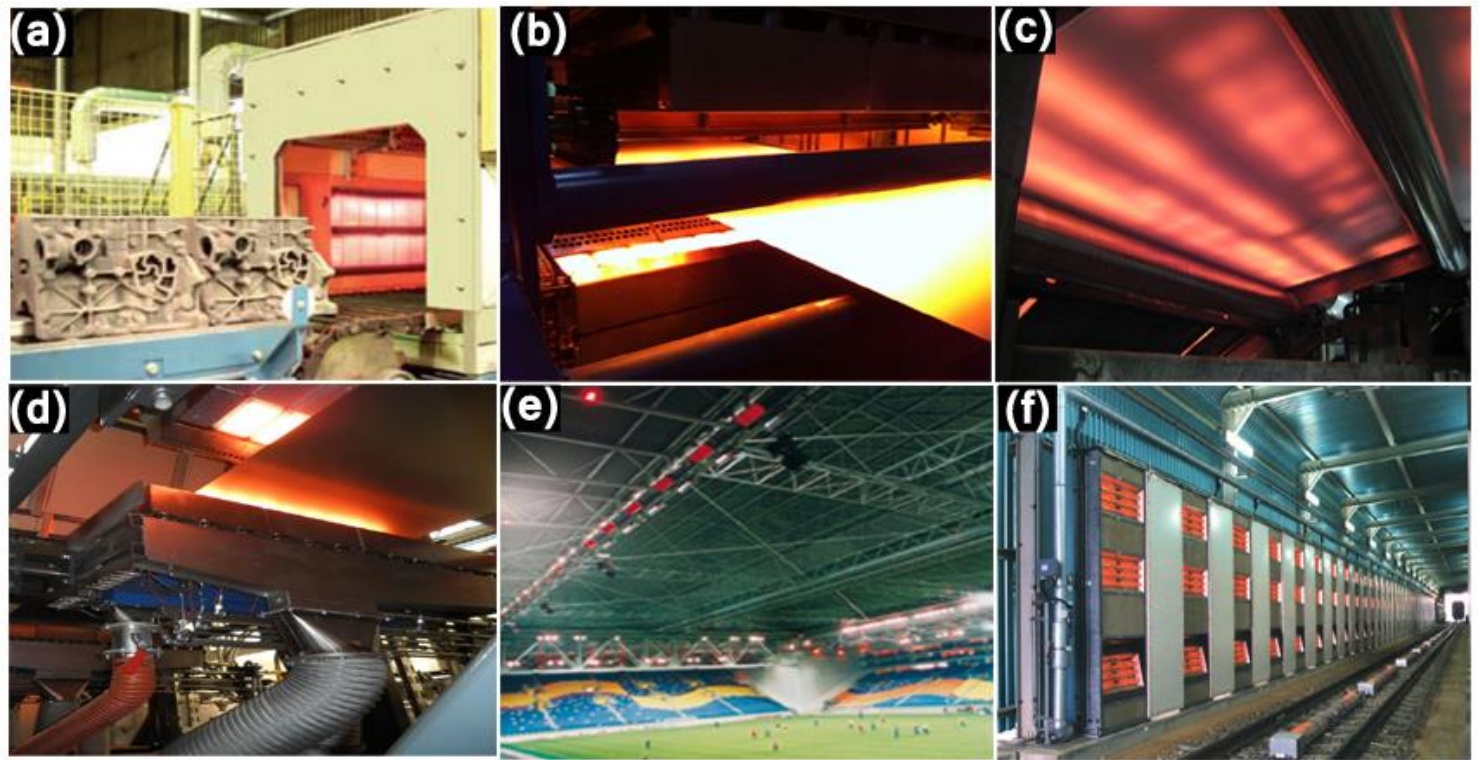

FIGURA 6 - Principais aplicações dos queimadores de gás, tratamento térmico de (a) peças com geometria complexa e (b) materiais laminados; (c) processamento de papel; (d) secagem de pinturas, (e) aquecimento de ambientes (estádio de futebol), (f) secagem de matérias primas depositadas em vagões (transporte ferroviário) ${ }^{[48]}$. 


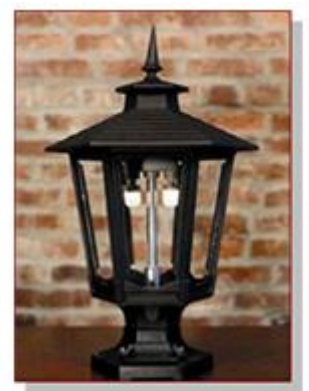

(a)

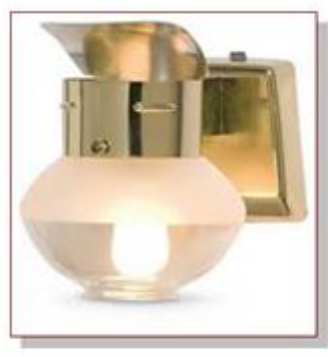

(b)
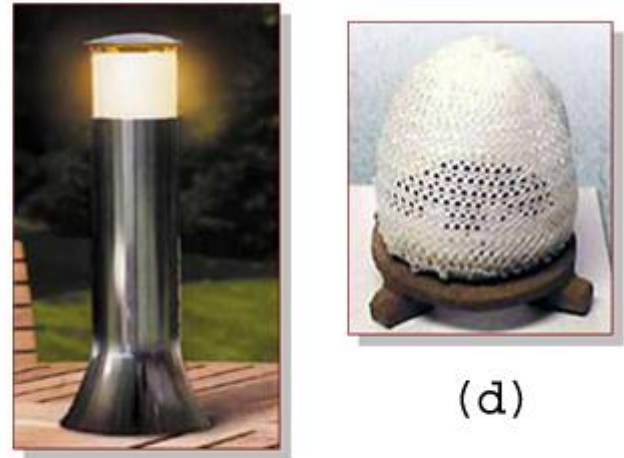

(d)

(c)

FIGURA 7 - Principais fabricantes de queimadores de gás para iluminação: (a) GasLiteAmerica, (b) Mr. Heater, (c) The Outdor Great Room e (d)Gallery Series Lighting ${ }^{[49-52]}$.

No projeto de queimadores de gás a seleção de materiais é uma etapa muito importante, onde os parâmetros como estabilidade química e física em alta temperatura são determinantes na escolha do material. Dentre a classe de materiais disponíveis, os materiais cerâmicos destacam-se por suas propriedades particulares, como elevada temperatura de fusão, resistência a corrosão e ao desgaste $^{[53]}$. Na tecnologia de queimadores de gás para aquecimento, os materiais cerâmicos geralmente são os denominados refratários como: alumina $\left(\mathrm{Al}_{2} \mathrm{O}_{3}\right)^{[54-56]}$, carbeto de silício $(\mathrm{SiC})^{[57-59]}$ e zircônia estabilizada com os seguintes aditivos: ítria-magnésia $(P S Z)^{[60-62]}$, ítria-alumina $(Y Z A)^{[63,64]}$, mulita $(Z T M)^{[65]}$ e alumina $(Z T A)^{[66]}$.

Para uso como queimador de gás para iluminação, além das propriedades intrínsecas das cerâmicas tradicionalmente utilizadas, é essencial que o material apresente emissividade espectral, ou seja, emissão de luz no comprimento de onda visível ( $\lambda=350-750 \mathrm{~nm})$. Os elementos terras raras devido as suas particularidades físicas e químicas exibem excelentes propriedades luminescentes, por isso são muito utilizados na tecnologia de fontes emissoras de luz.

\subsection{Considerações gerais sobre as terras raras}

O termo terras raras (TR) é designado ao conjunto de elementos químicos da série dos lantanídeos ( $\mathrm{La}$ ao $\mathrm{Lu}$ ) e os elementos Sc e Y. Os 
elementos TR são classificados de acordo com o número atômico em: leves (La, Ce, Pr e Nd); médias (Sm, Eu, Gd, Tb e Dy) e pesadas (Ho, Er, Yb e Lu) ${ }^{[67-70]}$.

$\mathrm{Na}$ natureza os elementos terras raras estão associados em misturas e devido as suas similaridades químicas são difíceis de separar. Nesta condição, a obtenção de compostos de alta pureza é um processo complexo e trabalhoso. Primeiramente é estabelecida uma separação dos elementos por classes de pesos molecular, classificados em leves, médios e pesados. A partir de cada concentrado é realizada a separação individual. Por isso, as terras raras são materiais de alto custo.

Os elementos denominados terras raras são moderadamente abundantes na crosta terrestre. Pela estimativa apresentada por TAYLOR ${ }^{[71]}$, o cério $(\mathrm{Ce})$ é o mais abundante entre todos os elementos terras raras, com cerca de 60ppm, sendo também mais abundante que o cobre $(\mathrm{Cu})$, com estimativa de 50 ppm. Comparativamente, o elemento lutécio (Lu) é o menos abundante entre os lantanídeos, com cerca de 0,5ppm. Na FIG. 8 é mostrada a estimativa de disponibilidade dos elementos terras raras na crosta terrestre ${ }^{[71]}$. Os elementos Sc e Pm não estão indicados na FIG. 8, pois o Sc não ocorre em quantidades consideráveis e o Pm é sintético ${ }^{[71-73]}$.

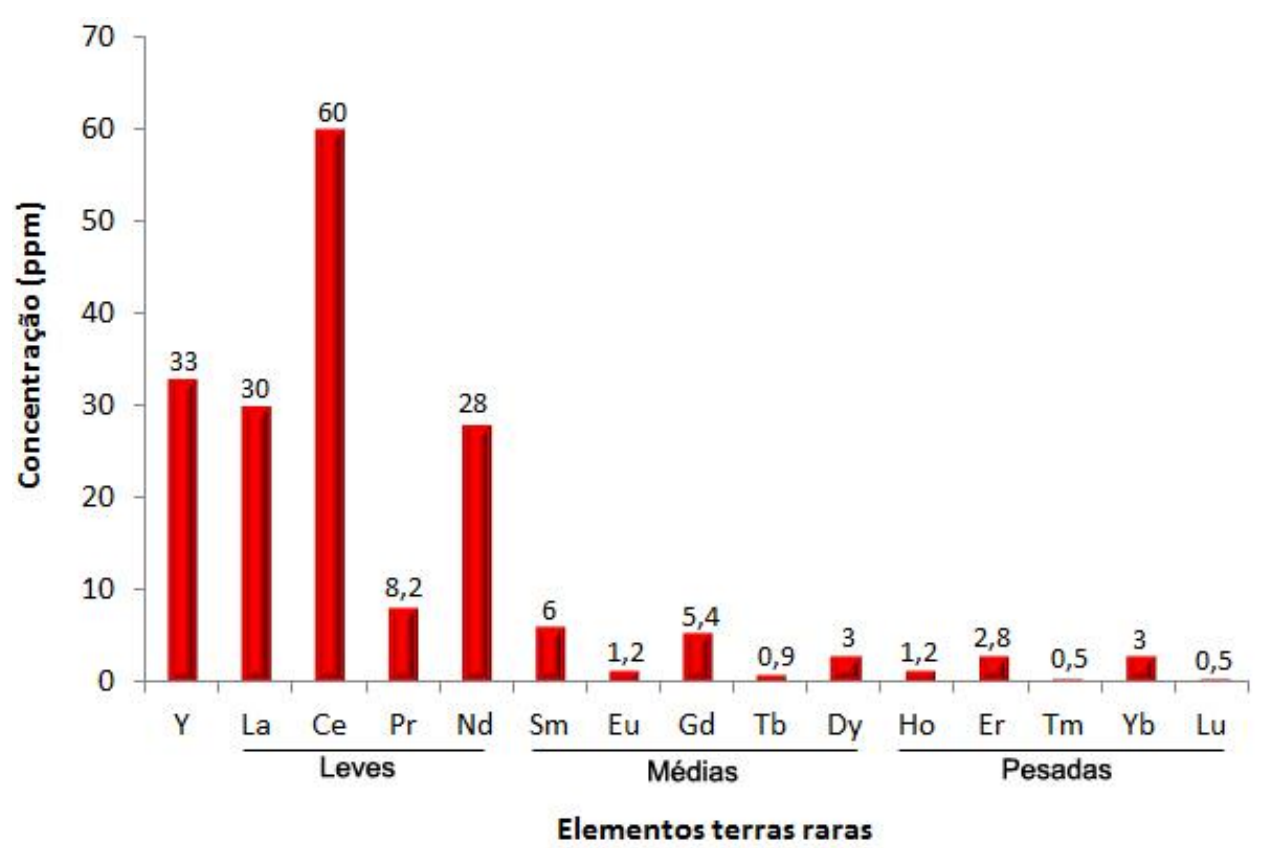

FIGURA 8 - Estimativa da disponibilidade dos elementos TR na crosta terrestre. 
As principais reservas de TR encontram-se na China, Estados Unidos, Austrália, Malásia, Índia e na Comunidade dos Estados Independentes - $\mathrm{CEI}^{[74]}$ (Armênia, Azerbaijão, Belarus, Geórgia, Cazaquistão, Quirguistão, Moldova, Rússia, Tajiquistão, Turcomenistão, Ucrânia e Uzbequistão), como indicado na FIG. $9^{[75]}$. Neste cenário, a China possui as maiores reservas $(48,34 \%)$ como também tecnologia competitiva para o processamento dos compostos TR. O Brasil detêm apenas $0,03 \%$ do total.

Ainda que o mercado brasileiro de TR não esteja consolidado, muitos esforços têm sido feitos pelos institutos de pesquisas e universidades para desenvolver processos competitivos para o projeto de materiais e componentes à base de $\operatorname{TR}^{[76-84]}$. Conforme apresentado na FIG. 10, nos últimos anos os pesquisadores brasileiros publicaram 2676 trabalhos referentes aos materiais à base de TR, segundo a plataforma Scopus (palavras chave: "rare earth", "phosphors", "lanthanides" e "luminescence") ${ }^{[85]}$.

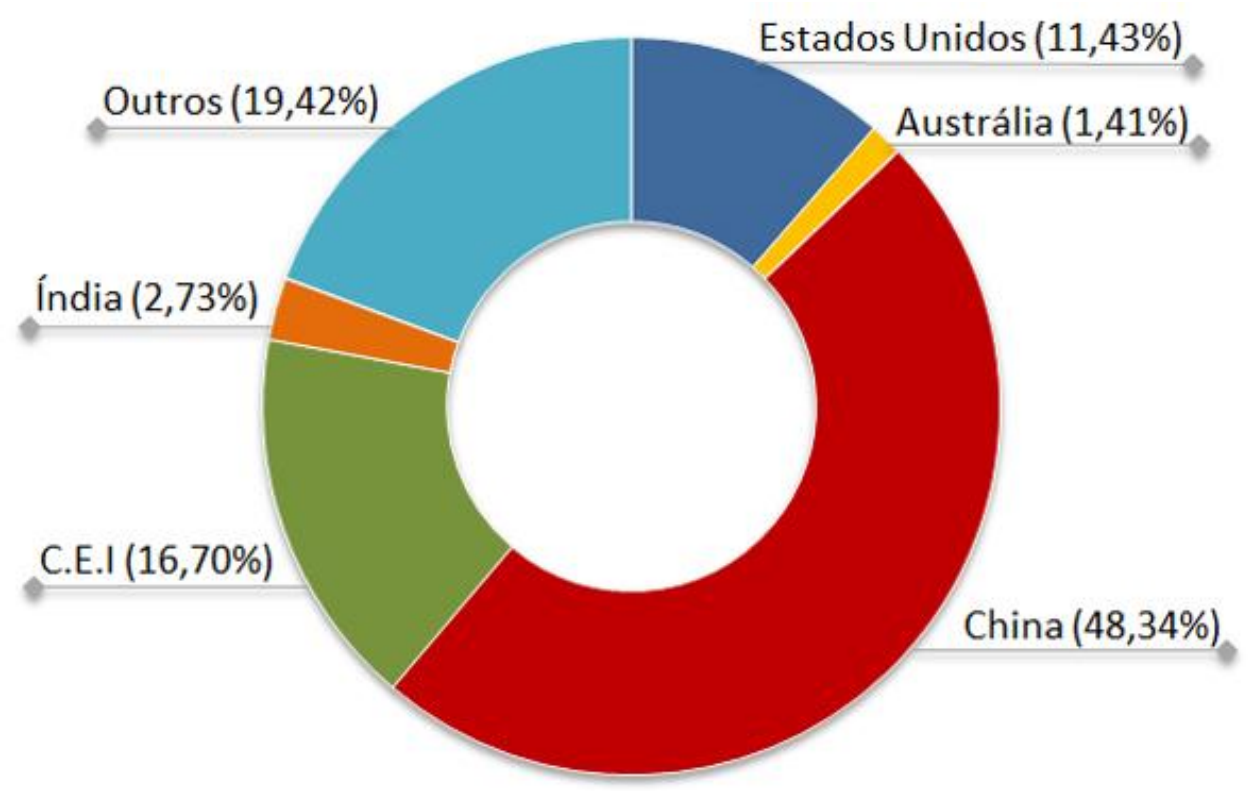

FIGURA 9 - Principais reservas de terras raras no mundo ${ }^{[75]}$. 


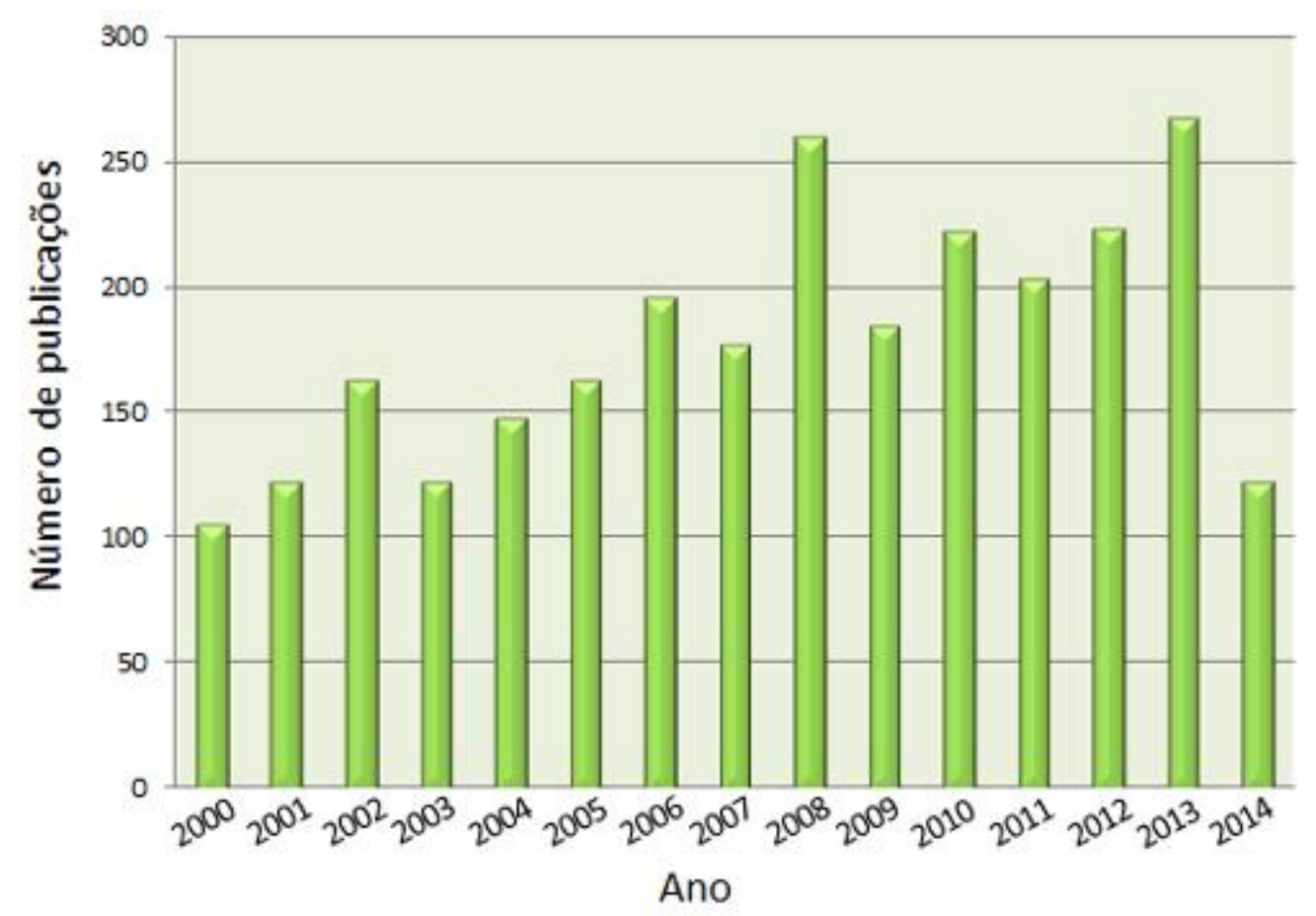

FIGURA 10 - Número de publicações brasileiras sobre materiais à base de TR em periódicos internacionais registradas no ano de 2000 até 31 de maio de 2014 segundo a plataforma Scopus.

\subsubsection{Propriedades químicas e físicas das terras raras}

As terras raras têm como caracterísitica uma grande similaridade química e física entre seus elementos, exibindo uma estrutura semelhante das camadas eletrônicas externas $5 \mathrm{~d}$ e $6 \mathrm{~s}$. Como consequência do preenchimento progressivo do subnível $4 f$ ocorre a diminuição do raio atômico e iônico dos elementos que pertencem a este grupo, definido como contração lantanídica. Esta característica se reflete nas propriedades dos átomos e íons dos elementos deste grupo, como aumento na estabilidade de formação de complexos, menor tendência de oxidação dos metais, facilidade da hidrólise e aumento no grau de convalência ${ }^{[68,86]}$. Para ilustrar este fenônemo, é apresentado na FIG. 11 a variação dos raios iônicos dos lantanídeos trivalentes em função dos números atômicos. Os elementos TR são classificados de acordo com o número atômico em: leves (La, Ce, Pr e Nd); médias (Sm, Eu, Gd, Tb e Dy) e pesadas (Ho, Er, Yb e Lu) ${ }^{[67,69,70,87]}$. 


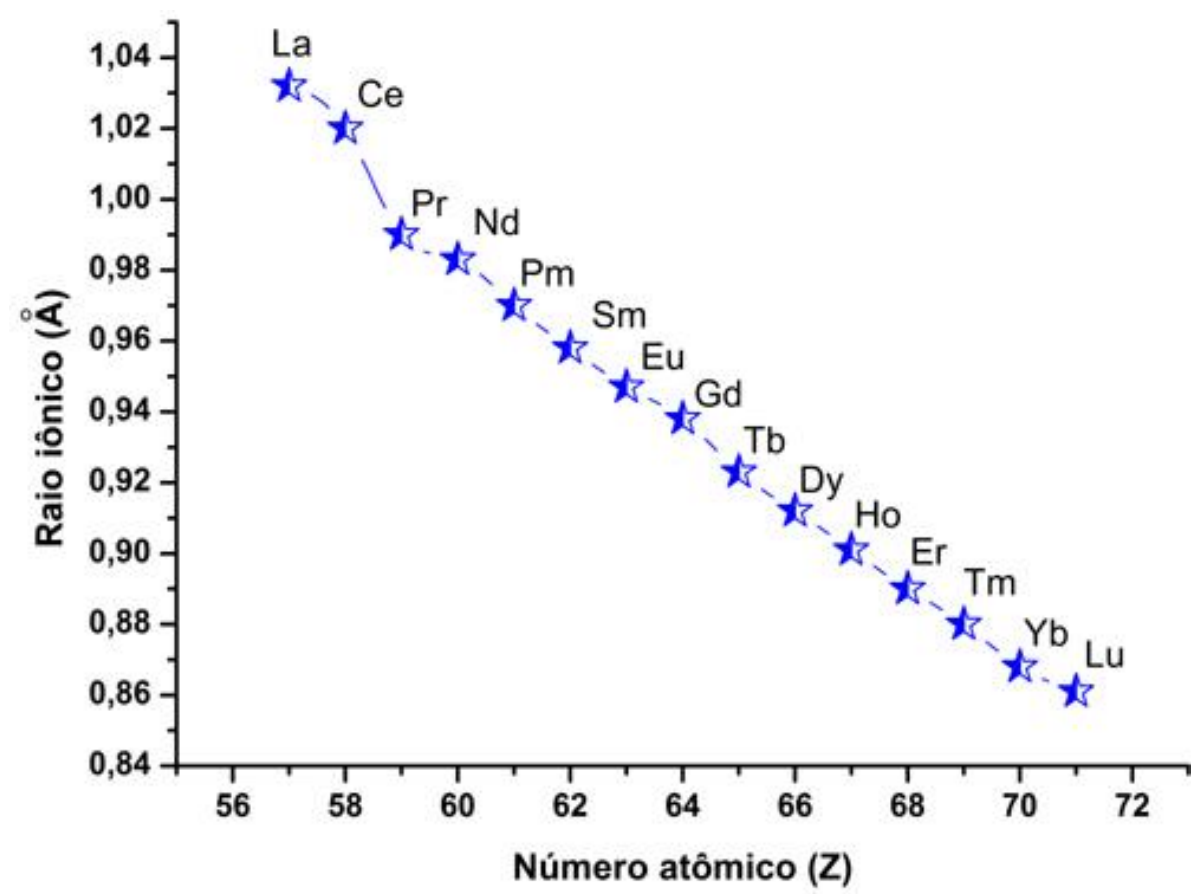

FIGURA 11- Variação dos raios iônicos os lantanídeos trivalentes em função dos números atômicos (contração lantanídica).

\subsubsection{Aplicações}

Os compostos de terras raras são utilizados em diversas aplicações tecnológicas como: ligas especiais, pigmento para vidros, fibras ópticas, lentes, abrasivos, filmes finos, aditivos de sinterização para cerâmicas avançadas, lâmpadas, telas de celular, tablets, marcadores ópticos, semicondutores, capacitores, leds, sensores de oxigênio, catalisadores de craqueamento e automotivos, tratamento de câncer e odontológico ${ }^{[73,88-92]}$.

Os Estados Unidos são os maiores importadores e exportadores de produtos à base de TR. O valor estimado de importação de materiais refinados à base de terras raras nos dois últimos anos é de $\$ 780$ milhões de dólares. $\mathrm{Na}$ FIG. 12 estão indicadas as principais aplicações das terras raras no mercado americano $^{[93]}$. 


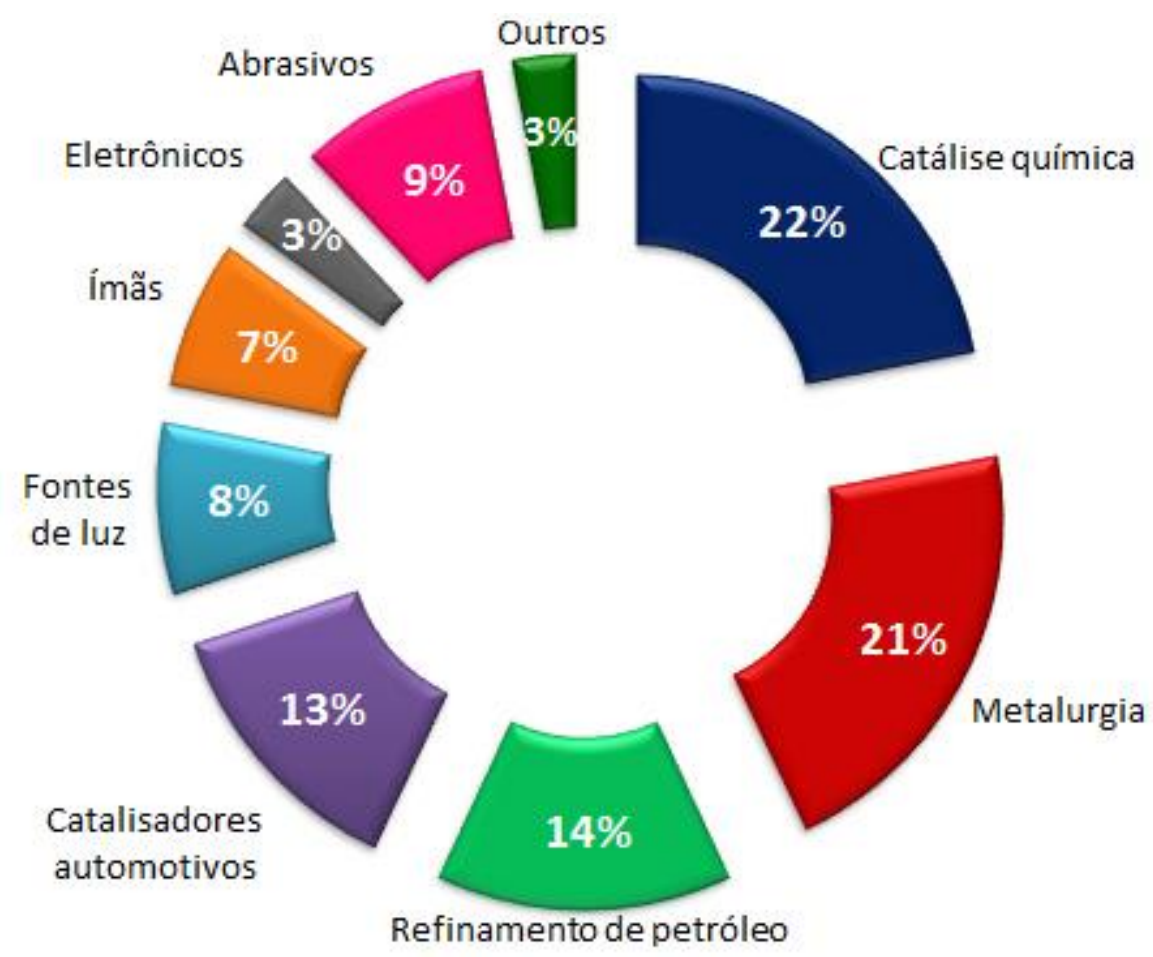

FIGURA 12 - Aplicações das terras raras no mercado americano.

Do grupo dos materiais à base de terras raras, a Ítria $\left(\mathrm{Y}_{2} \mathrm{O}_{3}\right)$ é um dos compostos mais importantes na atualidade. É utilizada em distintas aplicações

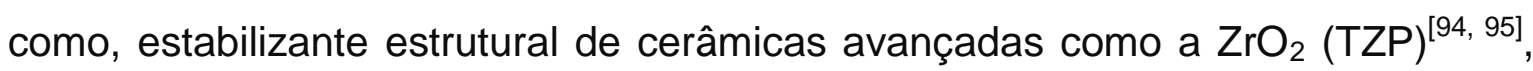
na composição de ligas metálicas à base de $\mathrm{Al} \mathrm{e} \mathrm{Mg}^{[96]}$, biomateriais ${ }^{[97]}$, ímãs permanentes $^{[98]}$, laser (YAG ${ }^{[99]}$ e outros materiais luminescentes ${ }^{[100]}$.

Alguns materiais têm a capacidade de absorver energia quando expostos a radiação eletromagnética ou ionizante e posteriormente liberá-la na forma de luz visível a partir de um estímulo. Pela teoria das bandas de energia, a luz emitida pelo material é decorrente das transições eletrônicas no sólido. Quando um elétron é promovido para um estado mais energizado ocorre absorção de energia. A energia liberada pelo material na forma de luz é resultado do decaimento do elétron para um estado de menor energia ${ }^{[101]}$. Os materiais que absorvem energia pela radiação ionizante e posteriormente emitem luz visível quando estimulados pela temperatura são caracterizados como materiais termoluminescentes ${ }^{[102]}$. 


\subsubsection{Termoluminescência (TL)}

Um material termoluminescente tem como característica absorver energia durante sua exposição à radiação ionizante e quando aquecido libera esta energia armazenada na forma de luz visível. Portanto, a luminescência do material é estimulada pela temperatura, mas a excitação do sólido ocorre pela radiação ionizante.

Para que ocorra emissão de luz por termoluminescência é necessário atender a três condições: propriedade específica do material, energia de ativação para o processo e temperatura adequada. Neste caso, o material pode ser isolante ou semicondutor (os metais não apresentam propriedades termoluminescentes).

Baseado no modelo de bandas de energia, a presença de impurezas (naturais ou intencionais), vacâncias e outros defeitos cristalinos na estrutura de um sólido favorece o desenvolvimento de níveis de energia na banda proibida (região de separação entre as bandas de valência e condução). Estes níveis de energia são denominados armazenadores de carga, pois são capazes de reter os carregadores de carga (elétrons e lacunas), antes da recombinação dos mesmos nos centros de luminescência e consequentemente, retardam a emissão de luz do material.

Na FIG. 13 ${ }^{[103]}$ mostra-se uma representação simplificada do modelo de bandas de energia. Durante a irradiação, um centro de luminescência C1 pode ser elevado para um nível excitado C2 (transição 1), onde seu retorno para a posição original resultará na emissão de um fóton (transição 2). Se um elétron localizado na banda de valência, ou no centro de luminescência é transferido para a banda de condução (transições 3 e 4), este estará livre para se mover e possivelmente será armazenado no nível de energia $T$ (transição 5). O elétron pode permanecer um período $(\mathrm{t})$ neste nível e depois ser transferido para a banda de condução (transição 6) e se recombinar no centro de luminescência C. Neste modelo de bandas de energia, as lacunas apresentam o mesmo comportamento de transição eletrônica dos elétrons: armazenamento (transição 7), retorno ao estado fundamental (transição 8) e recombinação no centro de luminescência (transição 9). Devido a espaçamento entre as bandas de valência e condução 
característico dos materiais isolantes e semicondutores, a possibilidade de recombinação direta de elétrons e lacunas é pouco provável ${ }^{[103]}$.

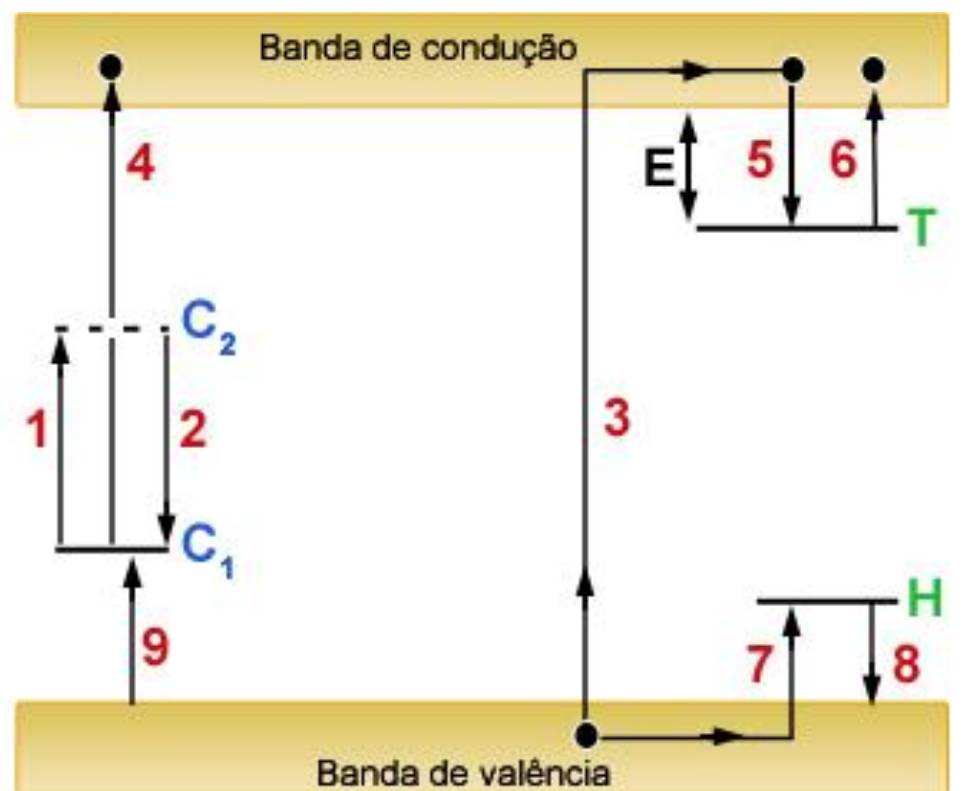

FIGURA 13 - Representação de um modelo de bandas de energia ${ }^{[103]}$.

Para um material termoluminescente, a intensidade de luz emitida é decorrente da transição dos carregadores de carga de um nível de energia mais elevado para outro de menor energia pelo estímulo da temperatura. Quanto maior a concentração $(n)$ de elétrons e lacunas armazenados, maior a intensidade emitida (FIG. 14a) em determinada temperatura. Baseado neste contexto, a termoluminescência difere da incandescência, que consiste na emissão espontânea de luz das substâncias quando aquecidas. Neste caso, em temperaturas superiores a $200^{\circ} \mathrm{C}$, um sólido emite radiação infravermelho, cuja intensidade de luz (I) e comprimento de onda $(\lambda)$ aumentam com a temperatura, segundo a Lei de Planck (radiação térmica ou emissão de corpo negro), como indicado na FIG. 14b. 


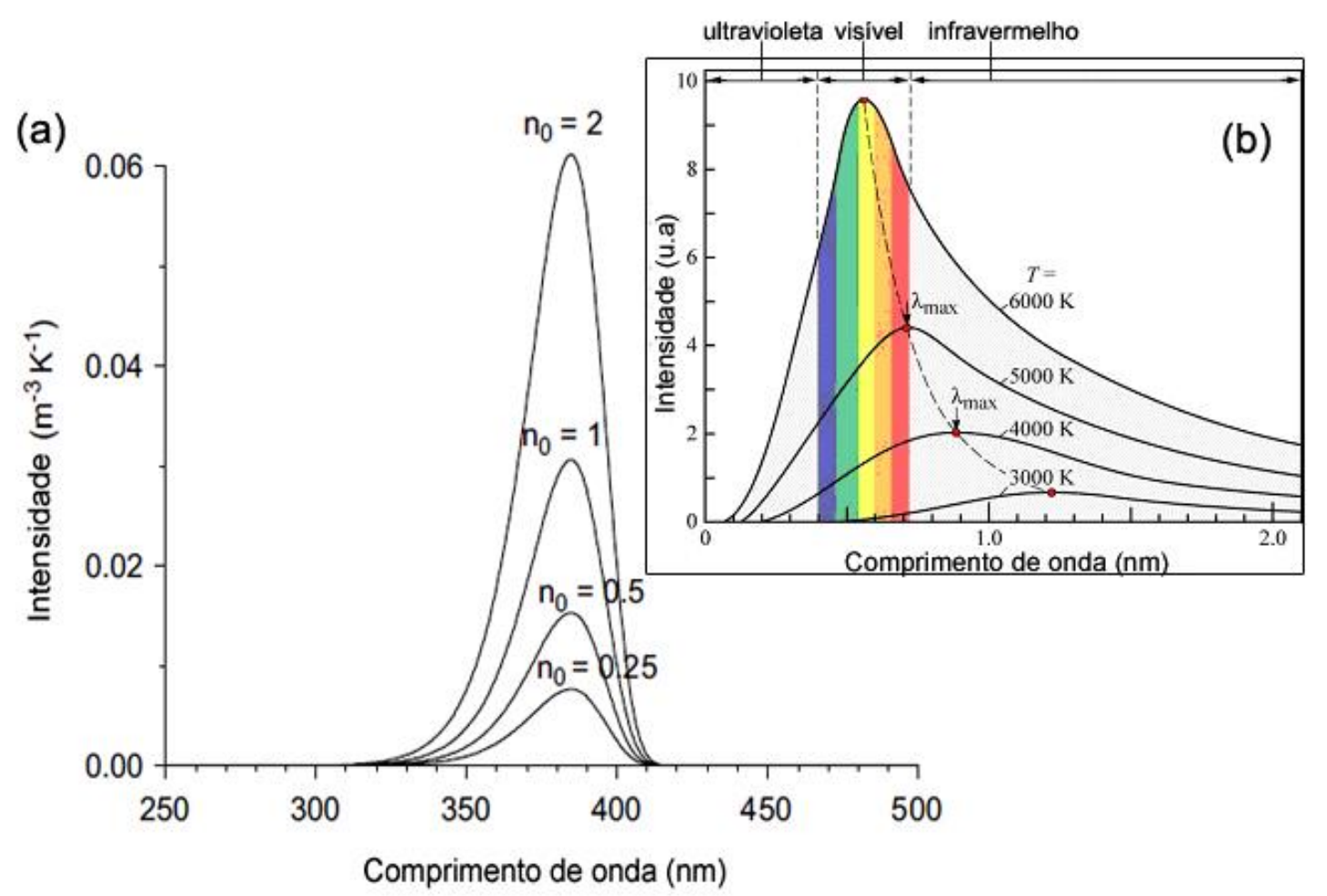

FIGURA 14 - Espectro de emissão de luz característico de um material (a) termoluminescente e (b) corpo negro (espectro de referência).

A intensidade de luz (I) pelo mecanismo termoluminescente em fótons por segundo em um determinado tempo (t) durante o aquecimento é proporcional à taxa de recombinação de lacunas e elétrons em $(\mathrm{C})$. Se $(\mathrm{m})$ é a concentração de lacunas armadilhadas em (C), a intensidade (I) pode ser calculada conforme a equação 1, onde o sinal negativo indica a diminuição de lacunas pelo tempo:

$$
I(t)=-\frac{d m}{d t}
$$

HOOGENBOOM et al. ${ }^{[104]}$ a partir de ajustes matemáticos do modelo proposto por RANDALL et al. ${ }^{[105,106]}$, determinaram que a intensidade máxima $\left(I_{m}\right)$ emitida pelo material pode ser calculada conforme a equação 2:

$$
I_{m}=n_{0} \frac{\beta E}{k T_{m}^{2}} e^{-g_{m}}\left[\mathrm{~m}^{-3} \cdot \mathrm{K}^{-1}\right]
$$


Onde:

- $\mathrm{I}_{\mathrm{m}}$ : intensidade máxima $\left(\mathrm{m}^{-3} \cdot \mathrm{K}^{-1}\right)$;

- $\mathrm{n}_{0}$ : número total de elétrons armadilhados $\left(\mathrm{m}^{-3}\right)$;

- $\beta$ : taxa de aquecimento $\left(K^{-1} s^{-1}\right)$;

- $\mathrm{E}$ : energia de ativação $(\mathrm{eV})$;

- $g_{m}$ : função exponencial de segunda ordem.

A termoluminescência tem sido utilizada nas áreas de física médica para detecção de radiação ultravioleta e ionizante, determinação da idade de materiais arqueológicos e formações geológicas. Na TAB. 2 estão relacionados alguns trabalhos precursores referentes aos materiais que apresentam resposta termoluminescente. No geral, a emissividade espectral varia de acordo com o elemento dopante (Dy, Tb, Mn, Cu, Si).

TABELA 2 - Exemplos de materiais que apresentam característica termoluminescente reportados na literatura

\begin{tabular}{cccc}
\hline Material & Temperatura $\left({ }^{\circ} \mathrm{C}\right)$ & $\lambda(\mathbf{n m})$ & Ref. \\
\hline $\mathrm{CaF}_{2}: \mathrm{Mn}$ & 260 & $450-600$ & {$[107]$} \\
$\mathrm{CaF}_{2}: \mathrm{Dy}$ & $120 ; 140 ; 200 ; 240 ; 340 ; 400$ & $460 ; 484 ; 577$ & {$[108]$} \\
$\mathrm{CaSO}_{4}: \mathrm{Mn}$ & 110 & 495 & {$[109]$} \\
$\mathrm{CaSO}_{4}: \mathrm{Tm}$ & 220 & 450 & {$[110]$} \\
$\mathrm{Li}_{2} \mathrm{~B}_{4} \mathrm{O}_{7}: \mathrm{Cu}$ & 205 & 605 & {$[111]$} \\
$\mathrm{BeO}$ & $200-210$ & $200 ; 450$ & {$[112]$} \\
$\mathrm{Mg}_{2} \mathrm{SiO}: \mathrm{Tb}$ & 190 & $380 ; 552$ & {$[113]$} \\
$\mathrm{Al}_{2} \mathrm{O}_{3}: \mathrm{Si}: \mathrm{Ti}$ & 250 & 410 & {$[114]$}
\end{tabular}

$\lambda$ : comprimento de onda da luz do material termicamente estimulado; Ref: referência. 


\subsubsection{3 Ítria $\left(\mathrm{Y}_{2} \mathrm{O}_{3}\right)$}

A $\mathrm{Y}_{2} \mathrm{O}_{3}$ apresenta ponto de fusão de $2400^{\circ} \mathrm{C}$, estabilidade térmica, baixo coeficiente de expansão térmica, alta condutividade térmica, índice de refração de 1,9 e estrutura cristalina cúbica de corpo centrado ${ }^{[115]}$, conforme ilustrado na FIG. 15 ${ }^{[116]}$. Segundo HOEKSTRA et al. ${ }^{[117]}$ todos os sesquioxides, como $\mathrm{Dy}_{2} \mathrm{O}_{3}, \mathrm{Th}_{2} \mathrm{O}_{3}, \mathrm{Ga}_{2} \mathrm{O}_{3}$ e $\ln _{2} \mathrm{O}_{3}$ apresentam essa estrutura. Entretanto, três tipos de estruturas cristalinas diferentes do $\mathrm{Y}_{2} \mathrm{O}_{3}$ são relatadas na literatura. GOURLAOUEN et al. ${ }^{[118]}$ obtiveram a ítria de estrutura monoclínica nas condições de temperatura de $997^{\circ} \mathrm{C}$ e à pressão de 2GPa. NAVROTSKY et al.. ${ }^{[119]}$ reportaram que a ítria de estrutura cúbica de corpo centrado apresentou duas transformações polimórficas, à $2308^{\circ} \mathrm{C}$ de cúbica para tipo fluorita, e de fluorita para hexagonal à temperatura de $2325^{\circ} \mathrm{C}$. QIN et al. ${ }^{[120]}$ observaram que nanopartículas de ítria de diâmetro médio inferior a 10nm exibiram estrutura cristalina monoclínica.

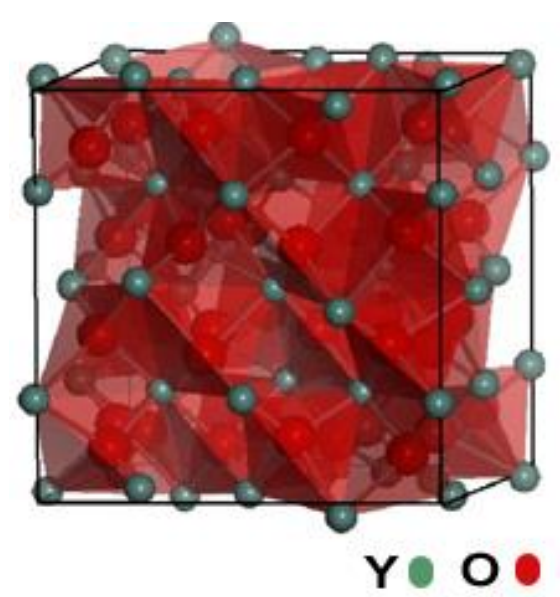

FIGURA 15 - Estrutura cristalina cúbica de corpo centrado do $\mathrm{Y}_{2} \mathrm{O}_{3}$.

A $\mathrm{Y}_{2} \mathrm{O}_{3}$ possui propriedades químicas e físicas muito semelhantes aos elementos lantanídeos, por isso é muito utilizada como matriz na composição de materiais luminescentes, onde o espectro de emissão varia de acordo com o elemento TR dopante (FIG. 16) ${ }^{[121]}$. WANG et al.. ${ }^{[84]}$ mostraram que a emissão de luz do composto $\mathrm{Y}_{2} \mathrm{O}_{3}: \mathrm{Eu}^{3+}$ aumentou em função do tamanho do cristalito e do tamanho de partícula da ítria. ZHANG et al.. ${ }^{[79]}$ observaram um aumento 
significativo da luminescência do composto $\mathrm{Y}_{2} \mathrm{O}_{3}: \mathrm{Eu}^{3+}$ sintetizado por reação de combustão e sinterizado em atmosfera de vácuo. GOLDBURT et al. ${ }^{[122]}$ reportaram que o composto $\mathrm{Y}_{2} \mathrm{O}_{3}: \mathrm{Tb}$ com diâmetro de partícula de $10 \AA$ exibiu maior eficiência luminescente que aqueles compostos de partículas com diâmetro de $100 \AA$. Neste cenário, nota-se que o composto $\mathrm{Y}_{2} \mathrm{O}_{3}$ é um material muito importante para composição de materiais luminescentes.

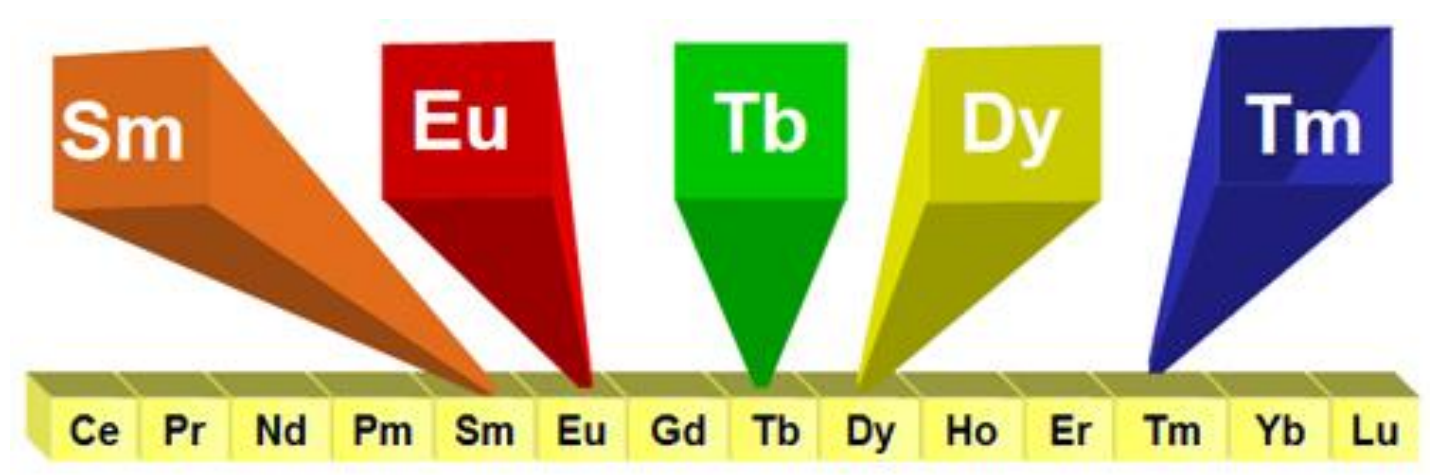

FIGURA 16 - Principais elementos lantanídeos utilizados como dopantes e seus respectivos espectros de emissão luminescente ${ }^{[121]}$.

Conforme discutido no item 3.1, o Brasil importa grande parte dos insumos de terras raras, como a $\mathrm{Y}_{2} \mathrm{O}_{3}$. Nesta condição, o custo dos produtos à base deste material é alto o que inviabiliza economicamente também o desenvolvimento de novos componentes. Por isso, esta tese tem como objetivo diminuir a concentração de ítrio na composição de materiais para queimadores de gás para iluminação, a partir do uso do dissilicato de ítrio sintetizado puro $\left(\mathrm{Y}_{2} \mathrm{Si}_{2} \mathrm{O}_{7}\right)$ e dopado com disprósio $\left(\mathrm{Y}_{2} \mathrm{Si}_{2} \mathrm{O}_{7}: \mathrm{Dy}^{3+}\right)$.

\subsubsection{Dissilicato de ítrio $\left(\mathrm{Y}_{2} \mathrm{Si}_{2} \mathrm{O}_{7}\right)$}

Os dissilicatos do tipo $\mathrm{TR}_{2} \mathrm{Si}_{2} \mathrm{O}_{7}$ ( $\mathrm{TR}=$ terra rara), têm sido muito estudados devido as suas características magnéticas, elétricas e ópticas. $\mathrm{O}$ dissilicato de ítrio $\left(\mathrm{Y}_{2} \mathrm{Si}_{2} \mathrm{O}_{7}\right)$ ocorre na natureza juntamente com outros silicatos de terras raras, cujo minério recebe o nome de "yttrialita". Este composto também 
aparece com frequência como fase cristalina secundária resultante da sinterização do $\mathrm{Si}_{3} \mathrm{~N}_{4}$ e do $\mathrm{SiC}$ quando o $\mathrm{Y}_{2} \mathrm{O}_{3}$ é utilizado como aditivo ${ }^{[123,124]}$.

$\mathrm{O} \mathrm{Y}_{2} \mathrm{Si}_{2} \mathrm{O}_{7}$ apresenta cinco fases polimórficas $(\mathrm{y}, \alpha, \beta, \gamma, \delta)$. Segundo BATALIEV et al. ${ }^{[25]}$ a fase itrialita $(y)$ é estável até $1200^{\circ} \mathrm{C}$ quando estabilizada com $\mathrm{Na}^{+}, \mathrm{Mg}^{2+}, \mathrm{Mn}^{2+}, \mathrm{Fe}^{2+}, \mathrm{Fe}^{3+}, \mathrm{Al}^{3+}, \mathrm{Th}^{4+}, \mathrm{Zr}^{4+}$. ITO et al. ${ }^{[126]}$ classificaram as demais quatro fases conforme suas estabilidades em função da temperatura a seguir em: $\alpha \stackrel{1225^{\circ} \mathrm{C}}{\longrightarrow} \beta \stackrel{1445^{\circ} \mathrm{C}}{\longrightarrow} \gamma \stackrel{1535^{\circ} \mathrm{C}}{\longrightarrow} \delta$. Contudo, obtê-lo com propriedades bem definidas em uma de suas estruturas constitui um grande desafio. A formação e estabilidade das fases polimórficas têm sido estudadas por diversos autores ${ }^{[126-}$ 129]. Tem-se destacado que o início da cristalização está relacionado à natureza dos materiais de partida, temperatura e rota de síntese, onde as comumente utilizadas são reação em estado sólido da mistura de óxidos de ítrio e sílica ${ }^{[130]}$, sol-gel ${ }^{[131]}$ e síntese hidrotermal ${ }^{[132]}$.

Os trabalhos referentes à síntese do $\mathrm{Y}_{2} \mathrm{Si}_{2} \mathrm{O}_{7}$ via estado sólido têm demostrado que a obtenção deste composto por esta rota é possível somente com temperaturas e tempos extremamente elevados $\left(1800^{\circ} \mathrm{C} \text { por } 100 \mathrm{~h}\right)^{[131]}$. Por outro lado, rotas alternativas como o processo hidrotérmico ou sol-gel, que utilizam misturas homogeneizadas de precursores químicos têm sido propostas por reduzir o tempo e a temperatura necessários para se formar o dissilicato de ítrio $^{[133-135]}$. MOYA et al. ${ }^{[135]}$ a partir do método hidrotermal à pressão atmosférica, obtiveram um precursor que permitiu a formação de dissilicato de ítrio após tratamento térmico de $1 \mathrm{~h}$ a temperatura de $975^{\circ} \mathrm{C}$.

Analisando-se o diagrama de equilíbrio do sistema binário $\mathrm{Y}_{2} \mathrm{O}_{3}-\mathrm{SiO}_{2}$ (FIG.17) ${ }^{[136]}$, observa-se que fora a composição estritamente estequiométrica, este composto coexiste de forma estável juntamente com o monosilicato de ítrio $\left(\mathrm{Y}_{2} \mathrm{Si}_{2} \mathrm{O}_{5}\right)$ ou com a sílica $\left(\mathrm{SiO}_{2}\right)$ em temperaturas inferiores a $1650^{\circ} \mathrm{C}$. Portanto independente do método de síntese, a formação de uma mistura de silicatos, dissilicatos e óxidos é bastante favorecida. Portanto, a precisão na formulação do composto e a homogeneidade dos componentes precursores na síntese do material são etapas fundamentais na obtenção do $\mathrm{Y}_{2} \mathrm{Si}_{2} \mathrm{O}_{7}$ cristalino, monofásico e com propriedades condizentes para a aplicação final. 


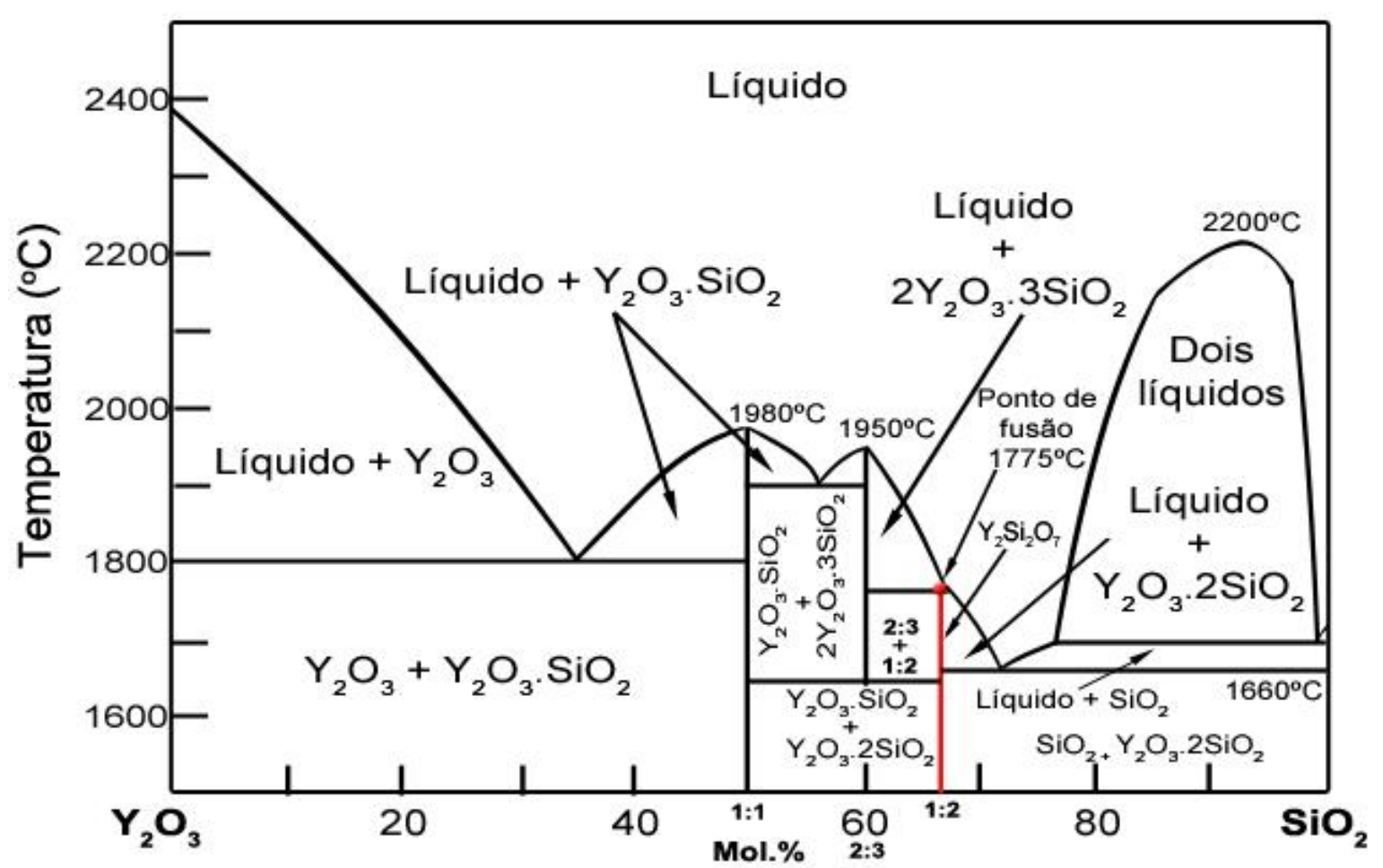

FIGURA 17 - Diagrama de equilíbrio de fases do sistema $\mathrm{Y}_{2} \mathrm{O}_{3}-\mathrm{SiO}_{2[136]}$

Trabalhos recentes mostram que as propriedades luminescentes deste composto estão relacionadas às rotas de síntese e as fases polimórficas. KIM et al. ${ }^{[137]}$ obtiveram por reação em estado sólido as fases $(\alpha, \beta, \gamma, \delta)$ do $\mathrm{Y}_{2} \mathrm{Si}_{2} \mathrm{O}_{7}$, onde a fase alfa apresentou a melhor emissão de luz (626nm). DIAZ et al. ${ }^{[138]}$ compararam a eficiência luminosa das fases $\alpha$ e $\beta$, ambas dopadas com Dy e obtidas pelo processo hidrotermal. Foi observado que a fase $\beta$ apresentou uma eficiência luminosa maior, correspondendo a $40 \%$ da emissão do composto $\mathrm{Y}_{2} \mathrm{O}_{3}: \mathrm{Eu}^{3+}$, considerado um dos compostos de melhor emissão luz. Este resultado confirma a grande potencialidade do dissilitato de ítrio para aplicações luminescentes, em particular quando dopado com Dy, visto que o componente amarelo é uma das cores mais adequadas para iluminação. Considerando esta particularidade, esta proposta inovadora de trabalho contribuirá para definir parâmetros importantes para o desenvolvimento de componentes cerâmicos com propriedades luminescentes.

Até o presente foram encontrados poucos trabalhos referentes ao processamento coloidal da $\mathrm{Y}_{2} \mathrm{O}_{3}$ e do $\mathrm{Y}_{2} \mathrm{Si}_{2} \mathrm{O}_{7}$. A falta de literatura possivelmente é decorrente do alto custo da ítria, complexidade da síntese do dissilicato de ítrio 
e especificidade das aplicações destes materiais. Seguindo uma estratégia de produzir componentes cerâmicos pelo método de réplica, recentemente nosso grupo de pesquisa publicou três trabalhos em periódicos internacionais: (1) SANTOS et al. ${ }^{[139]}$, Yttria nettings by colloidal processing, Journal of the European Ceramic Society, 2014; (2) SANTOS et al. ${ }^{[140]}$, Yttrium Disilicate Micro-Cellular Architecture from Biotemplating of Luffa Cylindrica, Journal of Ceramic Science and Technology, 2014; (3) SANTOS et al. ${ }^{[141]}$ Perspectives on the development of porous burners in Brazil, Journal of Materials Sciences and Applications, 2014.

\subsection{Processamento coloidal}

O processamento coloidal é um dos métodos usualmente utilizados para a confecção de peças cerâmicas a partir do preparo de suspensões de partículas com diâmetro médio $(\varnothing \mathrm{m})$ entre $0,001 \mu \mathrm{m} \leq \varnothing \mathrm{m} \leq 1 \mu \mathrm{m}$. Suspensões estáveis geralmente proporcionam corpos cerâmicos com alta densidade à verde e microestrutura homogênea após sinterização. O adequado empacotamento das partículas favorece controle dimensional e menor concentração de defeitos das peças $^{[142]}$.

$\mathrm{Na}$ TAB. 3 são apresentados alguns estudos referentes ao processamento coloidal dos compostos de $\mathrm{Y}_{2} \mathrm{O}_{3}$ e $\mathrm{Y}_{2} \mathrm{O}_{3}: \mathrm{SiO}_{2}$. Verifica-se que a maioria dos estudos de processamento coloidal dos compostos de $\mathrm{Y}_{2} \mathrm{O}_{3}$ e $\mathrm{Y}_{2} \mathrm{O}_{3}: \mathrm{SiO}_{2}$ referem-se a avaliações pontuais de condicionamento das suspensões para o processo de colagem em molde de gesso. Em geral esses estudos mostram que as melhores condições de estabilidade das suspensões baseiam-se em $\mathrm{pH}$ alcalino e adição máxima de $2 \%$ massa de polieletrólito aniônico.

Em uma suspensão de partículas coloidais a área de contato entre a partícula e o meio em que ela se encontra é grande. Portanto, as forças de superfície são determinantes na estabilidade das partículas e consequentemente no comportamento reológico das suspensões. 
TABELA 3 - Principais estudos de processamento coloidal dos compostos $\mathrm{Y}_{2} \mathrm{O}_{3}$ e $\mathrm{Y}_{2} \mathrm{O}_{3}: \mathrm{SiO}_{2}$ encontrados na literatura

\begin{tabular}{|c|c|c|c|c|c|c|}
\hline Ref. & Suspensão & $\%$ Vol & $\mathrm{pH}$ & $\begin{array}{c}\text { Dispersante } \\
\text { (\%massa) }\end{array}$ & $\begin{array}{c}\text { Ligante } \\
\text { (\%massa) }\end{array}$ & Processo \\
\hline [139] & $\mathrm{Y}_{2} \mathrm{O}_{3}$ & $30 \%$ & 10 & $1 \% \mathrm{PAA}$ & $0,3 \% \mathrm{CMC}$ & Réplica \\
\hline [140] & $\mathrm{Y}_{2} \mathrm{Si}_{2} \mathrm{O}_{7}$ & $30 \%$ & 10 & $2 \%$ PAA & $0,4 \% \mathrm{CMC}$ & Réplica \\
\hline [141] & $\mathrm{Y}_{2} \mathrm{O}_{3}: \mathrm{TR}$ & $25 \%$ & 10 & $1 \%$ PAA & 0,3\%CMC & Réplica \\
\hline [143] & $\mathrm{Y}_{2} \mathrm{O}_{3}: \mathrm{Al}_{2} \mathrm{O}_{3}$ & $86 \%$ & 10 & $1,5 \%$ PAA & - & Colagem \\
\hline [144] & $\mathrm{Y}_{2} \mathrm{O}_{3}$ & $30 \%$ & 10 & $1 \%$ PAA & $0,3 \% \mathrm{CMC}$ & Réplica \\
\hline [145] & $\mathrm{Y}_{2} \mathrm{O}_{3}: \mathrm{CeO}_{2}$ & $40 \%$ & $9-11$ & $2 \%$ PAA & - & Colagem \\
\hline [146] & $\mathrm{Y}_{2} \mathrm{O}_{3}$ & $30 \%$ & 10 & $1 \% \mathrm{PAA}$ & 0,3\%CMC & Réplica \\
\hline [147] & $\mathrm{Y}_{2} \mathrm{O}_{3}$ & $30 \%$ & 10 & $1,5 \%$ PMAA & - & Colagem \\
\hline [148] & $\mathrm{Y}_{2} \mathrm{O}_{3}: \mathrm{Al}_{2} \mathrm{O}_{3}$ & $20 \%$ & $7-8$ & $0,1 \%$ PAA & 0,5\%PEG & Colagem \\
\hline [149] & $\mathrm{Y}_{2} \mathrm{O}_{3}$ & $45 \%$ & - & $1,45 \%$ PAA & - & $\begin{array}{c}\text { Gel- } \\
\text { casting }\end{array}$ \\
\hline [150] & $\mathrm{Y}_{2} \mathrm{O}_{3}: \mathrm{SiO}_{2}$ & $60 \%$ & 11 & $2 \%$ PMAA & - & Colagem \\
\hline [151] & $\mathrm{Y}_{2} \mathrm{O}_{3}: \mathrm{SiO}_{2}$ & $25 \%$ & 11 & $2 \%$ PAA & - & Réplica \\
\hline
\end{tabular}

Ref: referência; \%vol: porcentagem em volume de sólidos; CMC:

Carboximetilcelulose; PAA: Poliacrilato de Amônia; PEG: Polietileno Glicol.

\subsubsection{Aspectos gerais do processamento cerâmico a partir de suspensões}

Basicamente uma suspensão cerâmica consiste em partículas sólidas dispostas em meio líquido. As propriedades desta mistura (partículas e meio líquido) dependerão das características do líquido, dos pós (tamanho, morfologia e condição de superfície) e da interface partícula-meio líquido ${ }^{[152-155]}$. 
O comportamento da partícula em suspensão e a estabilidade da mesma podem ser definidos utilizando-se o conceito da Dupla Camada ${ }^{[156]}$ ou teoria DLVO (Derjaguin, Landau, Verwey e Overbeek) ${ }^{[157]}$. De acordo com este modelo, a estabilidade das suspensões aquosas pode ser controlada ajustandose a condição de superfície das partículas a partir da variação do $\mathrm{pH}$ da suspensão.

O potencial elétrico formado na superfície da partícula (FIG. 18a $)^{[158]}$ atrai diversos íons de carga oposta presentes na solução (contra - íons), que permanecem ao redor da partícula. Como esta possui uma dimensão finita, apenas uma determinada quantidade de íons é adsorvida em sua superfície. Esses contra-íons adsorvidos formam uma película protetora, definida como camada de Stern. Os demais íons que não foram adsorvidos não conseguem se aproximar da partícula porque são repelidos pelos íons da camada de Stern. A concentração de contra-íons diminui conforme o aumento da distância em relação à partícula, resultando então numa segunda camada, a difusa. Os íons de carga igual a da partícula são chamados de co-íons e são atraídos pelos contra-íons da camada de Stern, porém, ao mesmo tempo são fortemente repelidos pela partícula que possui a mesma carga. A concentração dos co-íons intensifica-se em função do aumento da distância em relação à partícula (FIG. 18b) ${ }^{[158]}$. A região que engloba a camada de Stern e a camada difusa é chamada de dupla camada elétrica. Essa nuvem iônica tende a acompanhar a partícula conforme o fluxo da suspensão e mantê-la dispersa em meio líquido ${ }^{[159-161]}$.

Baseado na teoria de Stern (FIG. 18c ${ }^{[158]}$, o potencial elétrico varia da superfície da partícula $\left(\Psi_{0}\right)$ para o plano de Stern $\left(\Psi_{\mathrm{d}}\right)$ e decai para 0 em função da distância da superfície da partícula. O potencial elétrico no plano de Stern é medido por técnicas experimentais, como por exemplo, a eletroforese. Por esta técnica, é aplicado um campo elétrico na suspensão e medida a velocidade de deslocamento das partículas (mobilidade eletroforética). Com estes valores é possível calcular pela equação 3 o potencial zeta $(\zeta)$, que representa o potencial elétrico no plano de cisalhamento. Este plano é definido como o limite de separação entre os contra-íons da dupla camada que conseguem ou não se manter ao redor da partícula durante a aplicação de um campo elétrico ${ }^{[160,162]}$. 


$$
\zeta=\frac{6 \pi \eta \mu_{e}}{\varepsilon f(k \alpha)}[\mathrm{mV}]
$$

Onde:

- $\varepsilon=$ permissividade elétrica;

- $\eta$ = viscosidade do meio [mPa.s];

- $\mu_{e}=$ mobilidade eletroforética $\left[\mu . s^{-1} \cdot V^{-1} . c m\right]$;

- $f(k \alpha)=1,5$ (meio aquoso).

Conforme a teoria DLVO ${ }^{[157]}$, a estabilidade das partículas em meio aquoso pode ser estabelecida pela variação do $\mathrm{pH}$, ou seja, da força iônica do meio. Geralmente, considera-se condição de estabilidade de uma suspensão quando o valor do $|\zeta| \geq 25 \mathrm{mV}$. Para $\zeta=0$, tem-se o estado de neutralidade das partículas, onde não há formação da dupla camada elétrica. Neste caso, as partículas tendem a aglomerar e sedimentar. A condição de $\mathrm{pH}$ em que este fenômeno ocorre é definida como ponto isoelétrico (PIE). Portanto, para o preparo de suspensões estáveis $(|\zeta| \geq 25 \mathrm{mV})$ é recomendável ajustar o $\mathrm{pH}$ a valores distantes do PIE.

Suspensões estáveis são importantes sob o ponto de vista de processamento, pois as partículas encontram-se individualizadas e devido às suas dimensões nanométricas são pouco influenciadas pela ação da gravidade, mantendo boa homogeneidade e estabilidade por um maior período de tempo.

Quanto às propriedades da peça conformada e sinterizada, suspensões dispersas geralmente proporcionam corpos cerâmicos com alta densidade à verde e após sinterização, como também microestrutura homogênea, em virtude do bom empacotamento das partículas, o que facilita o controle dimensional e menor concentração de defeitos. 
(a)

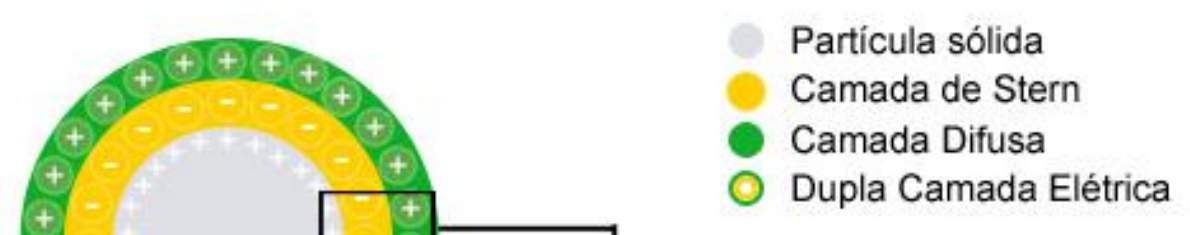

(b)

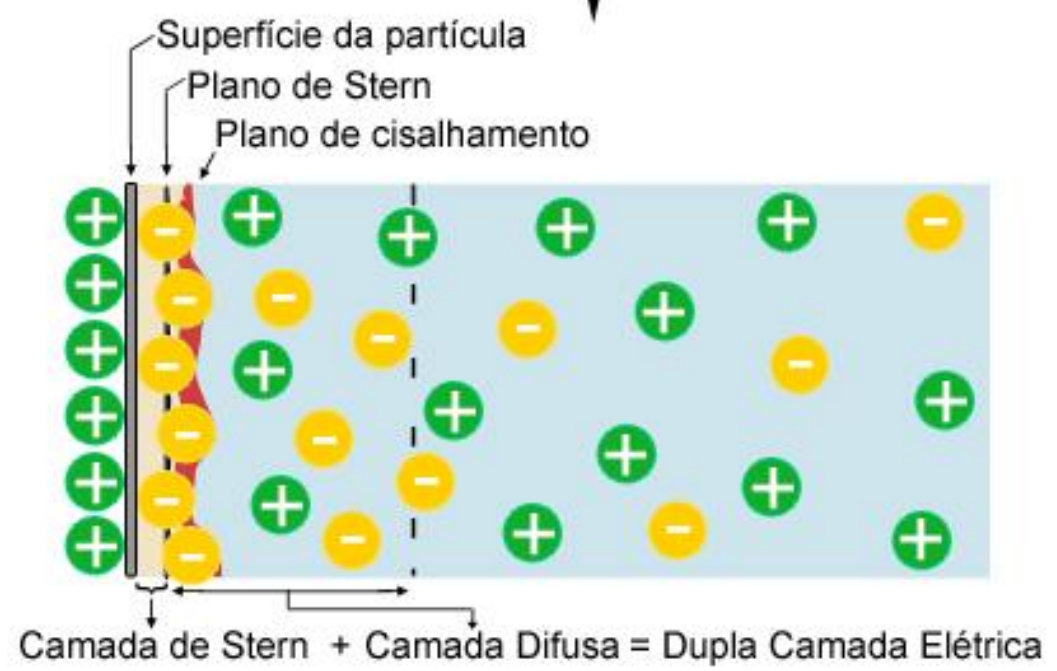

(c)

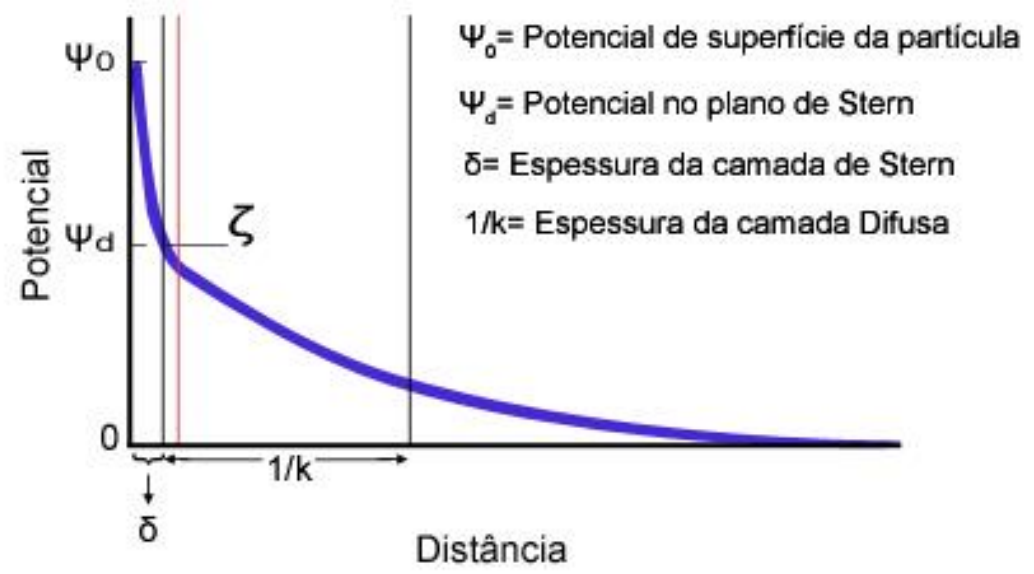

FIGURA 18 - Representação da dupla camada elétrica segundo a teoria de Stern. Em (a) arranjo espacial dos íons que constituem a dupla camada elétrica de uma partícula em meio líquido; (b) disposição dos planos de carga que constituem a dupla camada e (c) variação do potencial elétrico em função da distância da superfície da partícula ${ }^{[158]}$. 
O princípio da estabilidade das suspensões cerâmicas consiste em reduzir a intensidade das forças de atração entre as partículas e prolongar o período de dispersão delas no meio. Para isso, são utilizadas técnicas que introduzem forças de repulsão entre as partículas. Esta repulsão pode ocorrer basicamente por cargas eletrostáticas (estabilização eletrostática), repulsão por moléculas poliméricas (estabilização estérica), ou (depleção) e pela combinação dos mecanismos eletrostático e estérico (estabilização eletroestérica).

\subsubsection{Mecanismos de estabilização de suspensões}

\subsection{Eletrostático}

A estabilização eletrostática (FIG. 19) ${ }^{[163]}$ consiste na formação de cargas elétricas na superfície das partículas. No caso dos óxidos, a formação de cargas superficiais geralmente ocorre pela reação dos grupos $\left(\mathrm{OH}^{-}\right)$superficiais com os íons hidroxônio $\left(\mathrm{H}_{3} \mathrm{O}^{+}\right)$e hidroxila $\left(\mathrm{OH}^{-}\right)$do meio líquido, de acordo com as equações 4 e $5^{[158]}$. Esse processo depende do $\mathrm{pH}$ da suspensão. $\mathrm{O}$ desenvolvimento de cargas superficiais negativas é favorecido em valores de $\mathrm{pH} \geq 7$. A condição de $\mathrm{pH}<7$ contribui para o desenvolvimento de cargas superficiais positivas. Portanto, a origem de cargas na superfície das partículas resulta numa diferença de potencial elétrico. Para que as partículas encontrem-se dispersas em meio líquido, as forças de repulsão devem se sobrepor às de $\operatorname{atração}^{[142,158,160]}$.

$$
\begin{gathered}
\mathrm{MOH}+\mathrm{H}^{+}=\mathrm{MOH}_{2}^{+} \\
\mathrm{MOH}+\mathrm{OH}^{-}=\mathrm{MO}^{-}+\mathrm{H}_{2} \mathrm{O}
\end{gathered}
$$

Onde

- $\mathrm{H}_{+}$: íon determinante de potencial elétrico positivo (+);

- $\mathrm{OH}^{-}$: íon determinante de potencial elétrico negativo (-); 


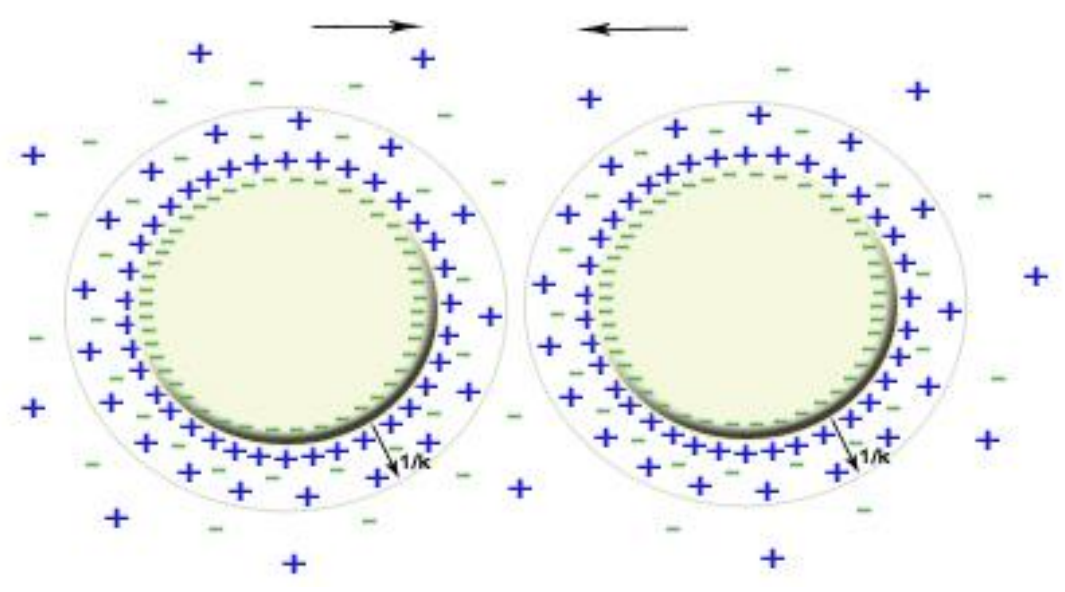

FIGURA 19 - Mecanismo de estabilização eletrostático a partir da formação da dupla camada elétrica.

\subsection{Estérico}

Em determinados sistemas cerâmicos não é possível elaborar suspensões estáveis apenas ajustando $\mathrm{o} \mathrm{pH}$, pois a adição de grandes concentrações de ácido ou base pode resultar na dissolução das partículas, ou num aumento da força iônica do meio, a qual comprime a dupla camada elétrica, favorecendo a floculação e sedimentação das partículas. Neste caso, os dispersantes poliméricos são utilizados para promover a estabilidade da suspensão pelo impedimento físico, ou seja, pela adsorção de cadeias poliméricas na superfície das partículas ${ }^{[160]}$.

A estabilização estérica (FIG. 20) ${ }^{[163]}$ consiste na utilização de um polímero como forma de separar fisicamente as partículas em suspensão. Para que o processo de estabilização seja eficiente, o polímero deve ser adsorvido na superfície da partícula de forma que a ligação polímero - superfície seja intensa, evitando o fenômeno da dessorção. A espessura da camada polimérica adsorvida deve ser maior que a distância de atuação das forças de van Der Waals. Contudo, as cadeias poliméricas não podem ser muito longas para não acarretar no fenômeno conhecido como pontes, onde uma mesma cadeia polimérica é adsorvida por duas partículas ${ }^{[160]}$.

A interação entre as camadas de polímero adsorvidas à superfície das partículas é influenciada pela distância entre as mesmas. Quando essa distância (D) é maior que duas vezes a espessura $(L)$ da camada polimérica $(D>2 L)$, não há 
repulsão entre as partículas por este mecanismo. Caso essa distância seja $(L<D<2 L)$, as cadeias poliméricas podem penetrar umas nas outras de forma a expulsar o líquido que separa as partículas (pressão osmótica). Na situação em que a distância entre as partículas estiver $(\mathrm{D}<\mathrm{L})$, haverá uma compressão das cadeias poliméricas durante o momento da colisão entre as partículas e assim, ocorrerá uma forte repulsão entre elas.

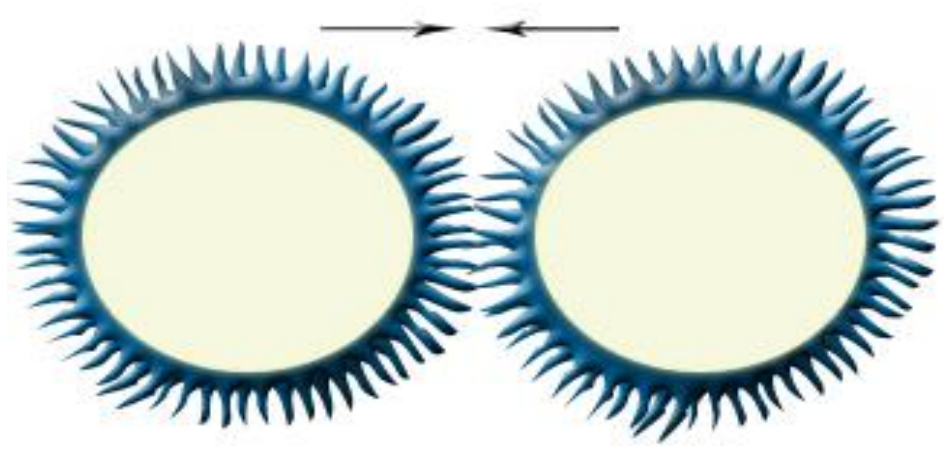

FIGURA 20 - Mecanismo de estabilização estérica[ [ ${ }^{163]}$

\subsection{Eletroestérico}

Esse processo resulta da soma dos dois últimos processos de estabilização, o eletrostático e estérico. Nesse mecanismo são utilizadas moléculas poliméricas ionizáveis, definidas como os polieletrólitos. Os íons resultantes da dissociação das moléculas favorecem a dispersão das partículas pelo mecanismo estérico e a eletrostático, como ilustrado na FIG. $21^{[163]}$.

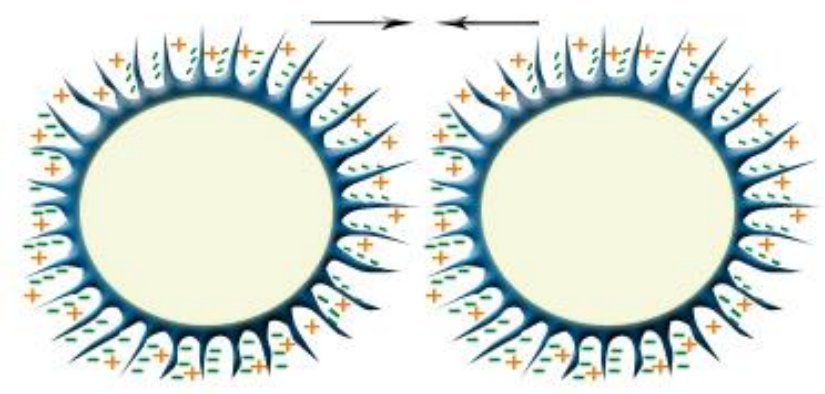

FIGURA 21 - Mecanismo de estabilização eletroestérica[ ${ }^{163]}$ 
Para exemplificar o efeito da adição de polieletrólito na estabilidade das partículas e deslocamento do ponto isoelétrico (PIE), na FIG. $22^{[164]}$ mostra-se a variação nas curvas de potencial zeta $(\zeta)$ das suspensões de $\mathrm{Al}_{2} \mathrm{O}_{3}$ em função da concentração em massa do dispersante polimetacrilato de amônio (PMAA) e do pH. O uso de polieletrólitos aniônicos como o PMAA permite dispersar as partículas a valores de $\mathrm{pH}$ moderados, onde na ausência de dispersante esta condição possivelmente favoreceria a floculação e sedimentação das partículas por estar próxima ao PIE. A adição de polieletrólitos catiônicos como hidróxido de amônio quaternário, ou polietilenimina provoca o deslocamento do PIE a valores de $\mathrm{pH}$ mais elevados. Ao utilizar polieletrólitos, deve-se considerar também a condição de $\mathrm{pH}$. A adsorção das moléculas do polieletrólito na superfície das partículas e a disposição das mesmas (alongada, ou enovelada) são dependentes das condições do meio líquido como $\mathrm{pH}$ e força iônica. Em geral, para os polieletrólitos aniônicos esta condição é estabelecida a valores de $\mathrm{pH} \geq 9^{[160]}$, conforme apresentado na FIG. 23.

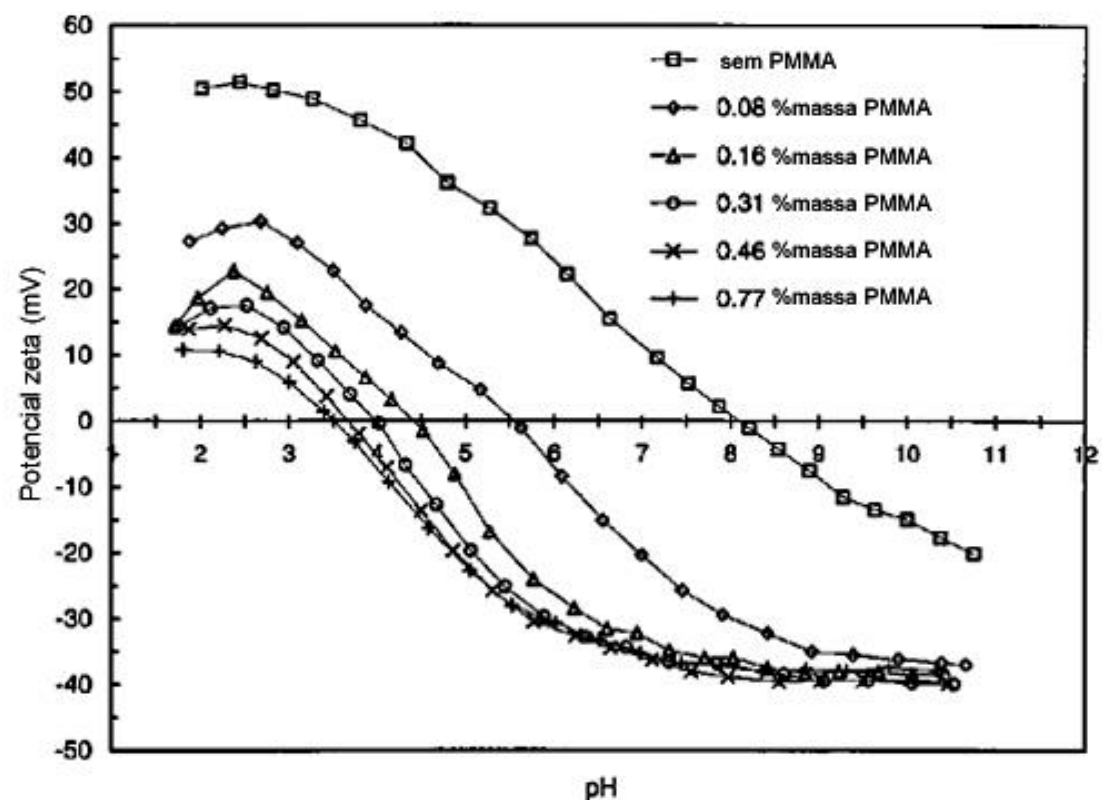

FIGURA 22 - Efeito da adição do polieletrólito aniônico PMMA na variação do potencial zeta em função do $\mathrm{pH}$ das suspensões de $\mathrm{Al}_{2} \mathrm{O}_{3}{ }^{[164]}$. 


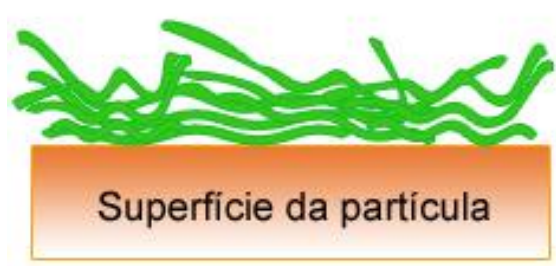

$\mathrm{pH}<9$

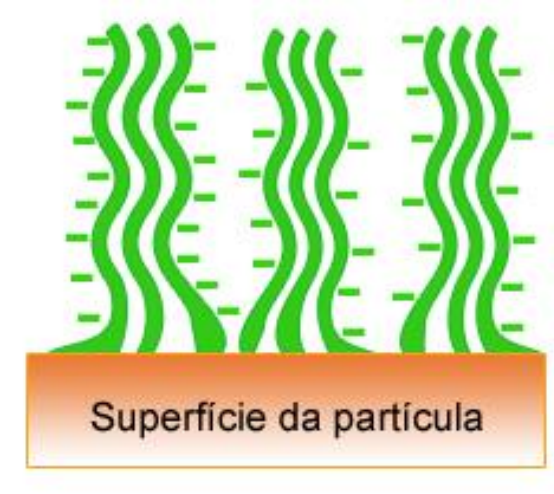

$\mathrm{pH} \geq 9$

FIGURA 23 - Configuração geral do polímero aniônico adsorvido na superfície da partícula em função do $\mathrm{pH}$. Normalmente a condição que favorece melhor configuração é estabelecida a $\mathrm{pH} \geq 9$.

\subsection{Depleção}

A estabilização das partículas pode ser realizada também pelos polímeros que não se adsorvem na superfície e permanecem em dissolução. Neste caso, o mecanismo de estabilização é definido como depleção. Segundo AZAKURA et al. ${ }^{[165]}$, a medida que as partículas se aproximam o polímero livre é excluído da região entre as partículas e provoca a floculação das mesmas (FIG 24).

(a)

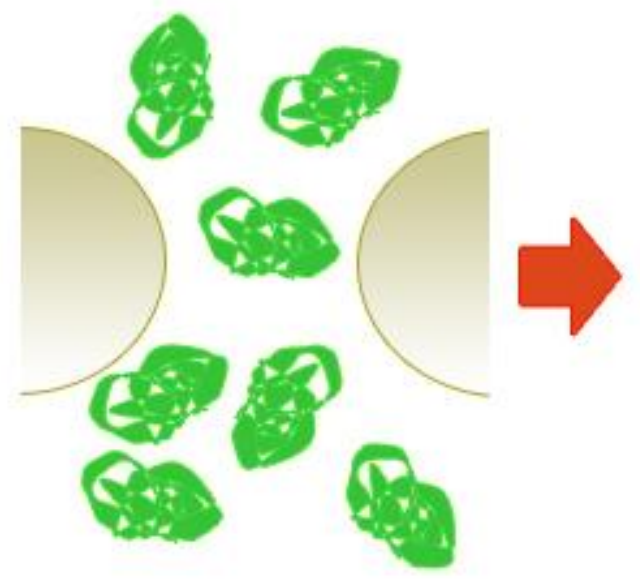

(b)

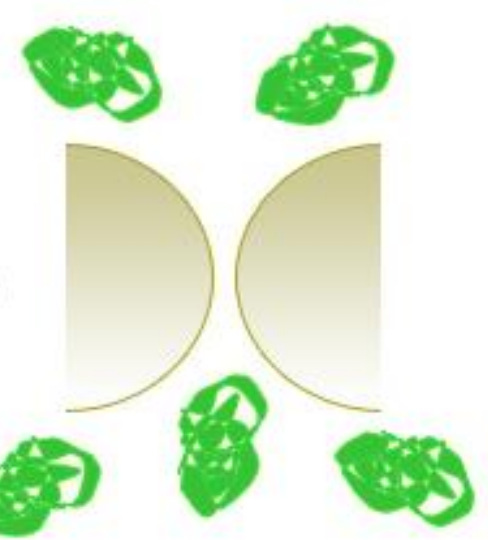

FIGURA 24 - Condição dos polímeros em dissolução. Em (a) estabilização por depleção (b) exclusão do polímero durante a aproximação das partículas, favorecendo a floculação por depleção. 
VINCENT et al. ${ }^{[166]}$ propuseram outro modelo para a floculação por depleção. Este modelo baseia-se em um mecanismo misto de estabilização estérica e depleção, onde a camada de polímero adsorvida (L) na superfície das partículas interage com as moléculas do polímero em dissolução, conforme representado na FIG. 25. As cadeiais do polímero livre colidem com o polímero adsorvido, mas quando as partículas se aproximam, as cadeiais do polímero em solução são excluídas da região de separação entre as partículas (D). Supõe-se um mecanismo frágil de repulsão. Por este modelo, quando a distância de separação é $D=2 L$ ocorre atração por depleção e para $D<2 L$, ocorre a repulsão estérica.

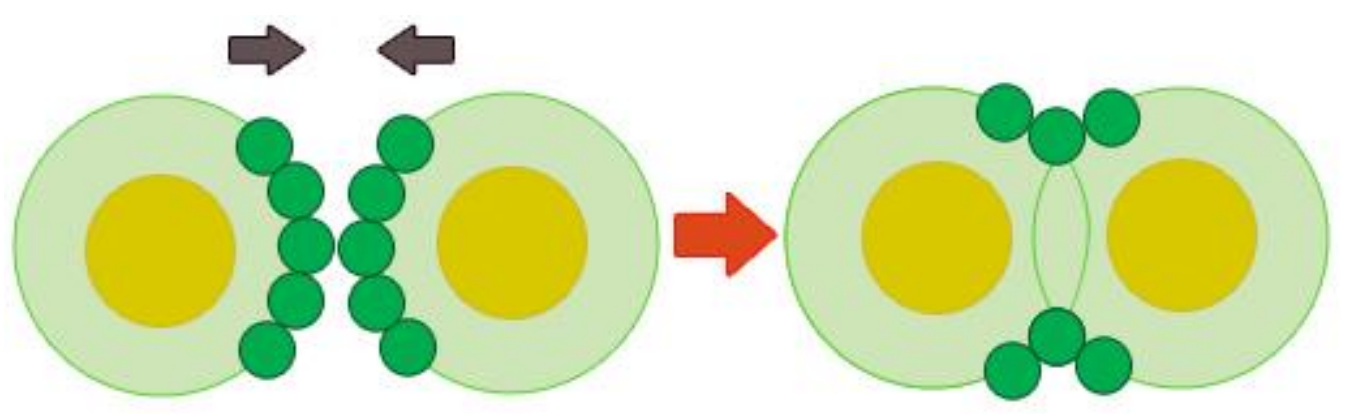

FIGURA 25 - Representação do modelo misto de estabilização estérica e depleção.

O controle da estabilidade das partículas possibilita condicionar as suspensões cerâmicas para os mais distintos processos de conformação como: colagem em molde de gesso, réplica, extrusão, injeção, dip coating e tape casting. Neste contexto, o comportameno reológico é uma das propriedades mais importantes no processamento cerâmico a partir de suspensões. De modo geral, a reologia caracteriza o comportamento de fluxo de fluídos, suspensões de partículas e emulsões em resposta a uma tensão aplicada. Parâmetros como viscosidade, temperatura, taxa e tensão de cisalhamento são variáveis essenciais para o processamento de materiais à partir de suspensões.

\subsubsection{Reologia das suspensões cerâmicas}

Reologia é a ciência que estuda a relação entre a deformação e o fluxo de matéria ${ }^{[160]}$, ou ainda segundo a IUPAC ${ }^{[167]}$, é o estudo da deformação e do 
fluxo da matéria pela influência de uma força mecânica aplicada. A palavra proposta pela primeira vez por Bingham em 1928, tem origem grega e é composta por duas palavras, que significam: Rheo = fluir e Logos = estudo. A reologia tem por finalidade determinar a força necessária para causar uma dada deformação ou escoamento num corpo, ou reciprocamente, a deformação ou escoamento resultante da aplicação de um dado sistema de forças em um corpo.

No estudo do comportamento reológico os parâmetros importantes a serem observados são: viscosidade, taxa de cisalhamento, concentração de sólidos e meios utilizados (aquoso ou não aquoso). A variação destes fatores se faz necessária na medida em que as condições especificadas para cada processo de conformação também variem ${ }^{[168]}$.

\subsection{Viscosidade}

No caso de suspensões diluídas, ou substâncias puras como a água, a viscosidade é a constante de proporcionalidade entre a tensão necessária para o escoamento em função da velocidade de escoamento. Quanto às suspensões mais concentradas, essa relação de proporcionalidade não é observada, ou seja, a determinação da viscosidade engloba outros parâmetros ${ }^{[160,169]}$.

A viscosidade constitui a principal característica reológica de uma suspensão. Suspensões estáveis tendem a escoar com maior facilidade se comparadas àquelas instáveis. Quanto maior o número de partículas numa dispersão, mais difícil é mantê-la dispersa, uma vez que a distância entre as partículas é menor, o que facilita a atuação das forças de atração de curta distância de Van Der Waals e a formação de aglomerados de partículas, os quais retêm em seu interior parte do meio líquido, o que resulta num atrito mais intenso entre as partículas e aumento da viscosidade ${ }^{[160]}$.

\subsection{Tensão $(\tau)$ e taxa de cisalhamento $(\gamma)$}

A viscosidade pode ser definida como a resistência do líquido quanto ao fluxo. No modelo proposto por Newton (FIG. $26^{[163]}$ ), duas placas paralelas 
estão separadas a uma distância $(x)$ e entre elas está um líquido. A placa inferior (base) é fixa. Uma força $(F)$ é aplicada no disco superior de área $(A)$ numa direção tangencial, onde a placa se move a uma velocidade constante (V) na direção paralela a placa inferior. As moléculas do líquido próximas a placa superior irão se mover com uma velocidade (V), a qual diminui gradualmente conforme o distanciamento das moléculas do líquido com relação a placa superior, chegandose a zero para aquelas próximas a placa inferior (base ${ }^{[169]}$.

Esta força tangencial $(F)$ que atua por unidade de área $(A)$ é definida como tensão de cisalhamento $(\tau)$, grandeza necessária para favorecer 0 escoamento de um fluido e expressa conforme a equação $6^{[169]}$ :

$$
\tau=\frac{F_{[N]}}{A_{\left[m^{2}\right]}}[\mathrm{Pa}]
$$

O gradiente de velocidade das camadas do líquido define a taxa de cisalhamento $(\dot{\gamma})$, que é expressa pela equação $7^{[169]}$ :

$$
\dot{\gamma}=\frac{d V}{d x}\left[s^{-1}\right]
$$

Definidas as duas grandezas ( $\tau$ e $\dot{\gamma}$ ), pode-se calcular a viscosidade de suspensões diluídas, como a água, conforme a equação $8^{[169]}$. Para suspensões mais complexas, outros parâmetros também são considerados para se determinar a viscosidade. Neste caso, modelos matemáticos mais complexos são utilizados.

$$
\eta=\frac{\tau}{\gamma}[\mathrm{Pa} . \mathrm{s}]
$$




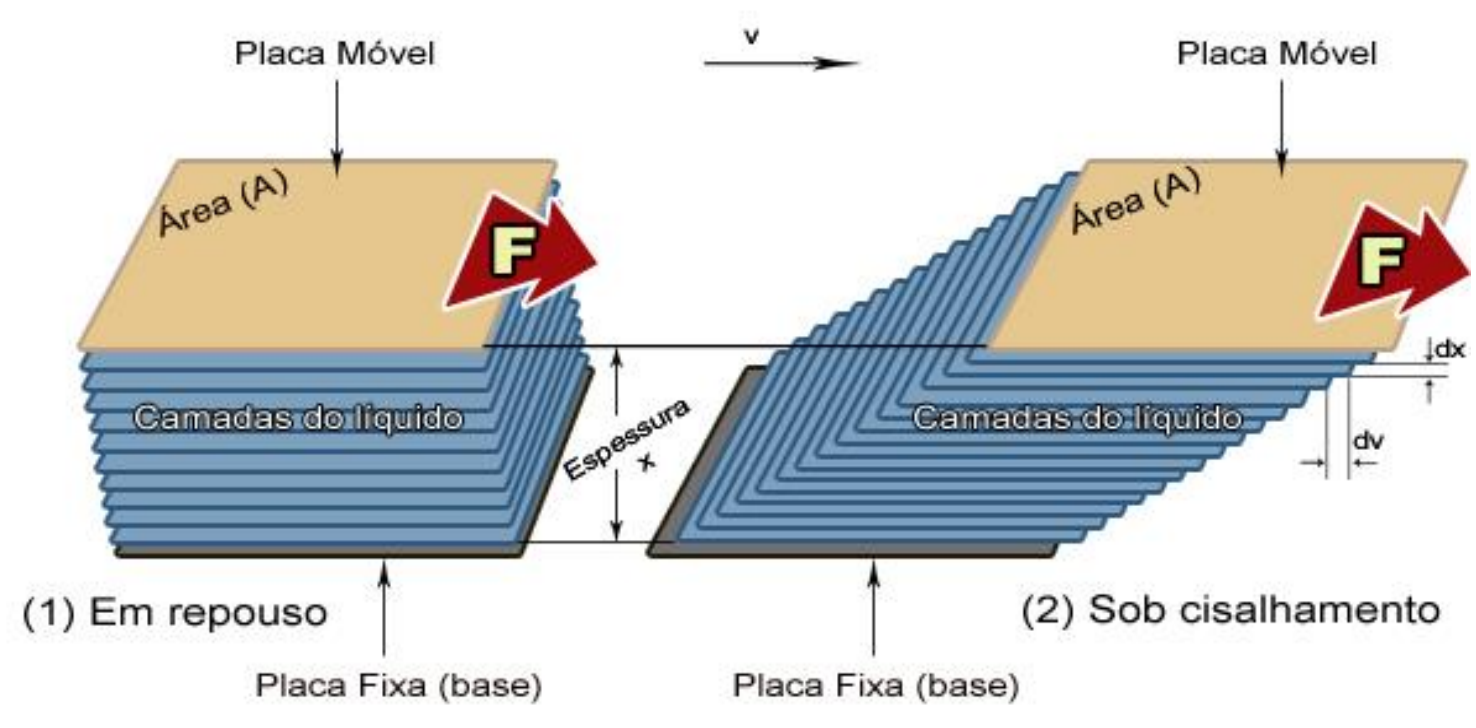

Onde:
$v=$ velocidade de fluxo
$F=$ força

FIGURA 26 - Representação de fluxo entre duas placas paralelas

A viscosidade das suspensões pode ser afetada por variáveis como composição, temperatura, pressão, velocidade de cisalhamento, campo elétrico e magnético. Dentre esses parâmetros, o mais importante sob o ponto de vista reológico é a velocidade de cisalhamento $(\dot{\gamma})$. A representação gráfica da $(\tau)$ em função da $(\dot{\gamma})$ é a curva de fluxo ${ }^{[160]}$.

\subsection{Curvas de Fluxo}

As curvas de fluxo são muito utilizadas em estudos de comportamento de viscosidade quando um fluido, ou suspensão de sólidos em meio líquido estão em movimento. Neste caso, pode-se determinar o comportamento de fluxo da suspensão pela variação da tensão de cisalhamento $(\tau)$, ou da taxa de cisalhamento $(\dot{\gamma})$ em função do tempo. Geralmente os gráficos de fluxo (FIG. $27)^{[163]}$ são constituídos de duas curvas, uma de subida e outra de descida, as quais correspondem respectivamente ao aumento e diminuição da taxa de cisalhamento $(\dot{\gamma})$ em função do tempo. De acordo com o aspecto apresentado pelas curvas de fluxo, o comportamento reológico da suspensão pode ser classificado em: newtoniano, de Bingham, dilatante ou pseudoplástico ${ }^{[160]}$. 


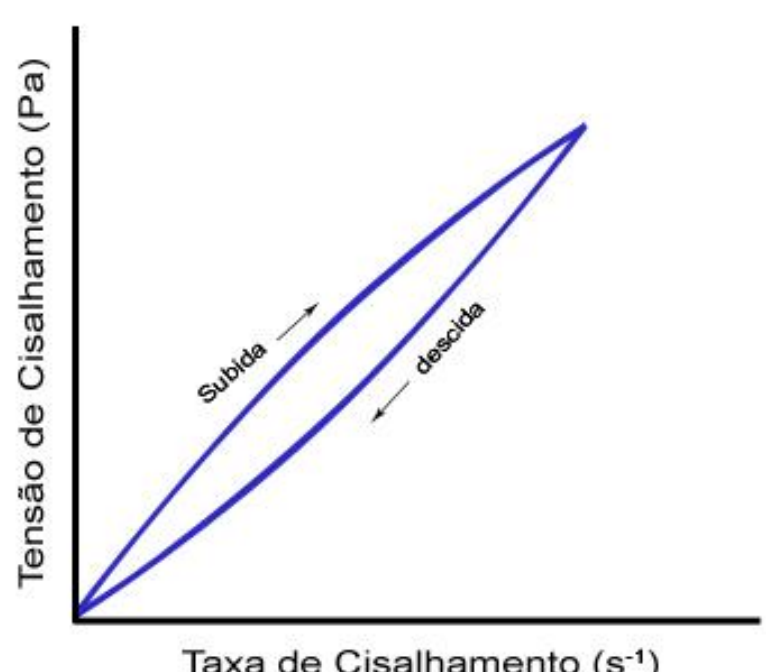

FIGURA 27 - Representação da curva de fluxo tensão por taxa de cisalhamento controlada (CR).

\subsection{Tipos de comportamentos reológicos}

Os fluidos Newtonianos apresentam viscosidade ( $\eta$ ) independente da taxa de cisalhamento $(\dot{\gamma})$, ou seja, a viscosidade é a constante de proporcionalidade entre tensão e taxa de cisalhamento, conforme indicado na FIG. 28. Este tipo de comportamento é característico de líquidos puros e suspensões bem diluídas, como água, óleos minerais, betumem ${ }^{[160,169]}$.

O comportamento pseudoplástico caracteriza-se pela diminuição da viscosidade do fluido com o aumento da taxa de cisalhamento. Alguns produtos que apresentam este comportamento são: shampoos, xaropes e tintas. Os fatores que podem contribuir para o comportamento pseudoplástico são: quebra dos aglomerados de partículas, orientação e deformação das partículas e alongamento das cadeias poliméricas, como ilustrado na FIG. 29. Caso a diminuição da viscosidade também seja dependente do tempo, o fluido é caracterizado como tixotrópico ${ }^{[160,169]}$. 


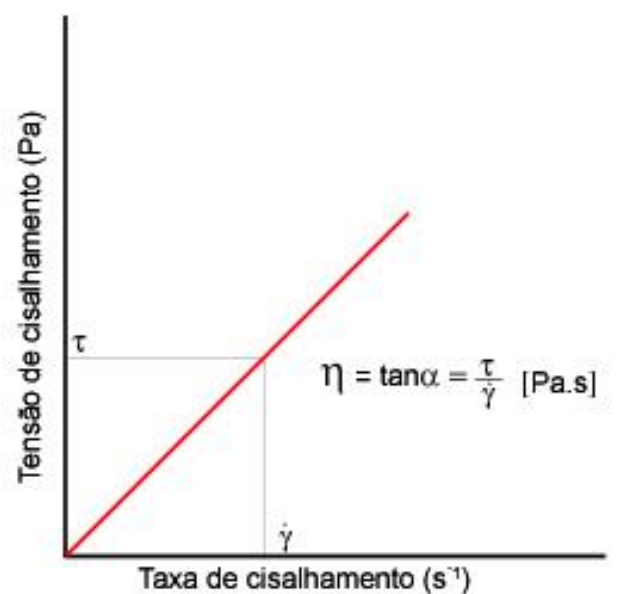

(a)

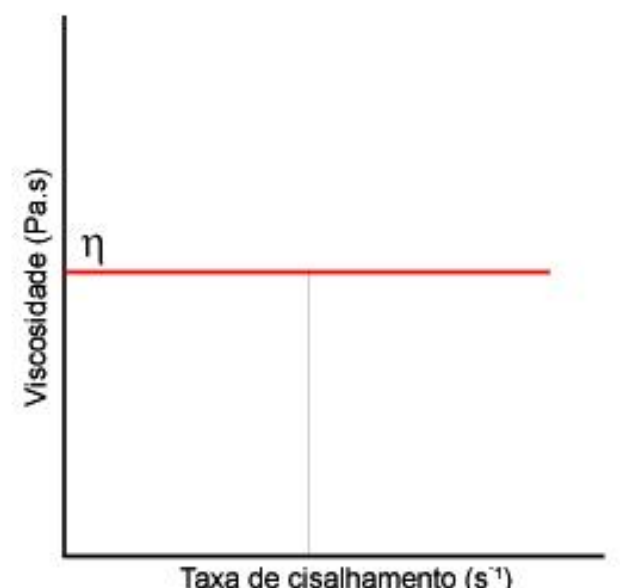

(b)

FIGURA 28 - Comportamento reológico de um fluído Newtoniano. Em (a) curva de fluxo e (b) curva de viscosidade.

(a) Suspensão em repouso
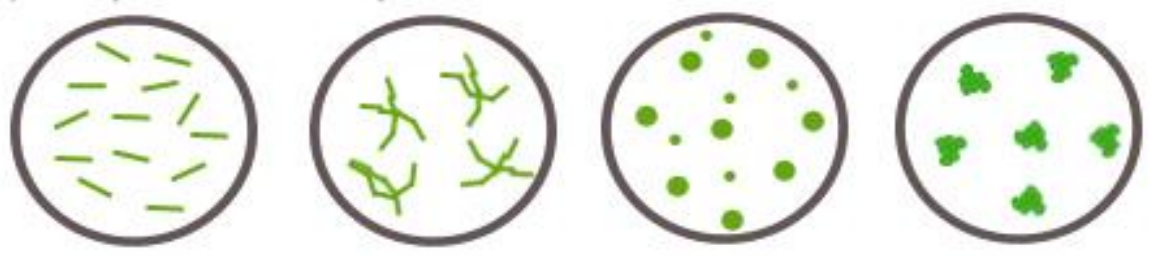

(b) Suspensão fluindo

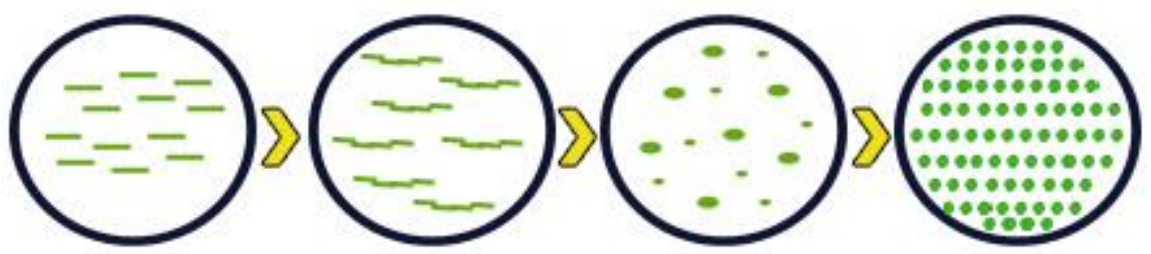

FIGURA 29 - Representação da estrutura da suspensão na condição (a) em repouso e (b) durante o fluxo.

O comportamento dilatante é oposto ao pseudoplástico, ou seja, a viscosidade aumenta conforme o crescimento da taxa de cisalhamento. Suspensões comumente utilizadas não apresentam este comportamento. A dilatância pode ocorrer em suspensões altamente concentradas e estabilizadas, como também em suspensões constituídas de partículas dispersas no meio que contem plastificantes. Neste caso, as partículas estão separadas apenas por um 
filme líquido muito fino. Para que as partículas possam se movimentar é necessária uma distância maior entre elas para o líquido passar entre elas. Isso é possível apenas a baixas taxas de cisalhamento. Para taxas de cisalhamento muito elevadas, a fina camada de líquido não é suficiente para lubrificar a superfície das partículas e a viscosidade aumenta. Para as suspensões que apresentam plastificante, este aditivo preenche os vazios entre as partículas e atua também como lubrificante na superfície das mesmas. Durante o esforço de cisalhamento, o comportamento da suspensão é análogo ao descrito anteriormente. Se o aumento da viscosidade for também dependente do tempo, o fluido é denominado reopéxico ${ }^{[160]}$.

Os fluidos de Bingham são sistemas onde o fluxo se desenvolve após a aplicação de uma tensão de cisalhamento superior a tensão mínima de escoamento. A partir daí, o fluido pode apresentar um ou mais dos comportamentos reológicos descritos anteriormente (FIG. 30) ${ }^{[160]}$.

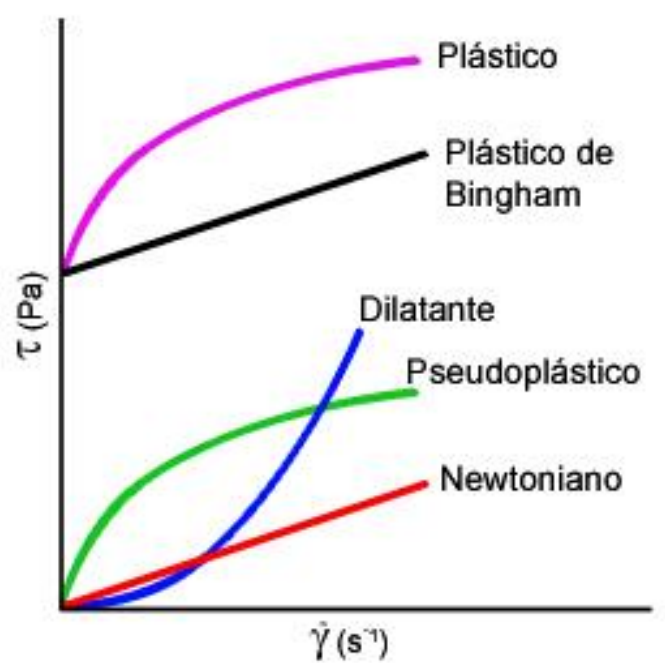

(a)

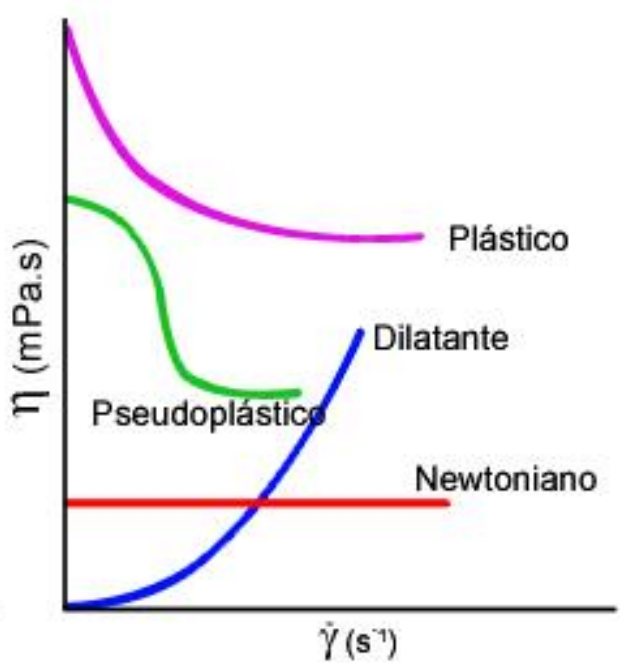

(b)

FIGURA 30 - Representação dos diferentes tipos de comportamento reológico dos fluídos. Em (a) curvas de fluxo e (b) curvas de viscosidade.

As suspensões utilizadas industrialmente podem apresentar um ou mais tipos de comportamentos reológicos em função das condições de tensão e cisalhamento aplicados, das condições de processo e do material. Neste sentido, 
desenvolveram-se os modelos matemáticos $(\text { TAB. 4 })^{[160]}$ para descrever 0 comportamento reológico das suspensões pelo ajuste de equações matemáticas.

TABELA 4 - Principais modelos reológicos

\begin{tabular}{cc} 
Modelo & Equação \\
\hline Newton & $\tau=\eta \dot{\gamma}$ \\
Bingham & $\tau=\tau_{0}+\eta_{p} \dot{\gamma}$ \\
Ostwald - de - Waele & $\tau=k(\dot{\gamma})^{n}$ \\
Herschel-Bulkley & $\tau=\tau_{0}+k(\dot{\gamma})^{n}$ \\
Casson & $\tau^{1 / 2}=\left(\tau_{0}\right)^{1 / 2}+k_{1}(\dot{\gamma})^{1 / 2}$ \\
Casson modificado & $\tau^{1 / 2}=\left(\tau_{0}\right)^{1 / 2}+k_{1}(\dot{\gamma})^{n_{1}}$ \\
Ellis & $\dot{\gamma}=k_{1} \tau+k_{2}(\tau)^{n_{1}}$ \\
Herschel-Bulkley modificado & $\tau^{n_{1}}=\left(\tau_{0}\right)^{n_{1}}+k_{1}(\dot{\gamma})^{n_{2}}$ \\
Séries de Potência & $\tau=k_{1} \tau+k_{2} \tau^{3}+k_{3} \tau^{5} \ldots$ \\
Cross & $\frac{\eta_{0}-\eta}{\eta-\eta_{\infty}}$ \\
Carreau & $\frac{\eta}{\eta_{0}-\eta_{\infty}}$ \\
&
\end{tabular}

$\mathrm{K}_{1}, \mathrm{~K}_{2}, \mathrm{~K}_{3}, \mathrm{n}_{1}$ e $\mathrm{n}_{2}$ são constantes arbitrárias e índices de potência determinados mediante dados experimentais.

Muitos processos são utilizados para conformar peças cerâmicas a partir de suspensões com média e elevada concentração de sólidos, como: colagem a partir de barbotinas, colagem em filme, colagem sob pressão, extrusão, injeção em moldes, calandragem, réplica, entre outros. Cada um destes processos de conformação está sujeito a diferentes solicitações de esforços e para cada caso, as suspensões devem apresentar características específicas, as quais são influenciadas por fatores característicos dos materiais como, tamanho e formato das partículas, estado de agregação e densidade. Desta forma, são 
parâmetros específicos de cada processo: a estabilidade e reologia das suspensões, a temperatura, secagem, dimensões e forma geométrica da peça a ser conformada. Dentre os processos de conformação citados, a técnica de réplica mostra-se vantajosa, pois possibilita a fabricação de peças cerâmicas de geometria complexa de maneira mais simplificada ${ }^{[170,171]}$.

\subsection{Processo de conformação por réplica}

A técnica de réplica, proposta por SCHWARTZWALDER et al. ${ }^{[172]}$, consiste basicamente em imergir e emergir uma matriz (sintética ou natural) em uma suspensão contendo o material que se deseja conformar. Em função das condições da suspensão e do meio, o material fica retido na superfície da matriz após a imersão. A matriz impregnada é submetida a um processo de secagem, calcinação (para eliminar a pré-forma e outros constituintes orgânicos) e sinterização (FIG. 31). A principal vantagem deste processo consiste na possibilidade de utilizar qualquer material cerâmico disperso em uma suspensão $0^{[170,173,174]}$.

Os materiais geralmente utilizados como matrizes de réplica são esponja polimérica, esponja de carbono e fibras sintéticas (TAB. 5). A esponja polimérica ainda é a pré-forma mais utilizada, devido a possibilidade de controle do tamanho de poros, reprodutibilidade, disponibilidade deste insumo no mercado, preço competitivo e também pelo conhecimento consolidado das propriedades deste material.

Com a crescente preocupação quanto ao desenvolvimento de processos e componentes de menor impacto ambiental, busca-se substituir materiais sintéticos por estruturas vegetais disponíveis na biodiversidade brasileira. Nesta direção, este estudo propõe o uso da esponja vegetal Luffa Cylindrica como matriz de réplica para confecção de componentes reticulados para queimadores de gás. Nos estudos de SILVA, et al. ${ }^{[30]}$, cerâmicas porosas à base de argila e feldspato foram obtidas por réplica da esponja vegetal Lufa Cylindrica. As peças sinterizadas a $1175^{\circ} \mathrm{C}$ por $2 \mathrm{~h}$ apresentaram morfologia idêntica à matriz vegetal (FIG. 32), sem nenhuma trinca ou deformação aparente. 


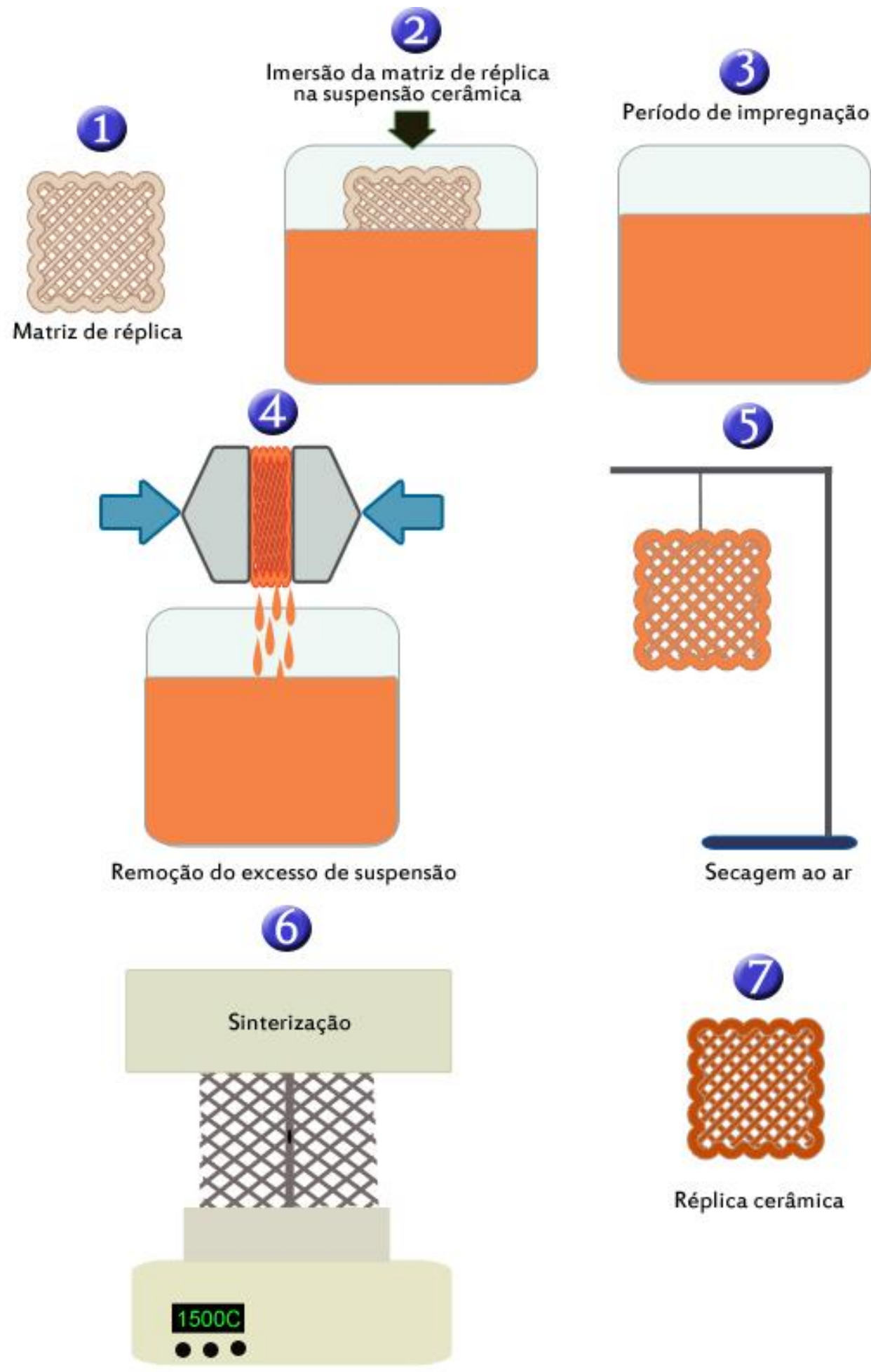

FIGURA 31 - Esquema do processo de conformação por réplica 
TABELA 5 - Principais materiais utilizados como matriz de réplica

\begin{tabular}{|c|c|c|}
\hline Pré-forma & Suspensão & Referência \\
\hline & $\mathrm{Al}_{2} \mathrm{O}_{3}$ & {$[171,175-177]$} \\
\hline & $\mathrm{ZrO}_{2}$ & {$[178-180]$} \\
\hline \multirow[t]{4}{*}{ Esponja polimérica } & $\mathrm{Si}_{3} \mathrm{~N}_{4}$ & {$[181,182]$} \\
\hline & $\mathrm{TiO}_{2}$ & {$[183]$} \\
\hline & $\mathrm{SiC}$ & [184-187] \\
\hline & $\mathrm{ZrO}_{2}$ & {$[188]$} \\
\hline \multirow[t]{3}{*}{ Esponja de carbono } & $\mathrm{SiC}$ & [189] \\
\hline & $\mathrm{SiO}_{2}$ & [190] \\
\hline & $\mathrm{TiO}_{2}$ & [191-193] \\
\hline \multirow[t]{3}{*}{ Madeira } & $\mathrm{Al}_{2} \mathrm{O}_{3}$ & [194-197] \\
\hline & $\mathrm{SiC}$ & {$[198,199]$} \\
\hline & $\mathrm{Si}_{3} \mathrm{~N}_{4}$ & {$[200]$} \\
\hline \multirow[t]{3}{*}{ Coral } & $\mathrm{MgO}$ & {$[201]$} \\
\hline & Hidroxiapatita & [202] \\
\hline & $\mathrm{Y}_{2} \mathrm{O}_{3}$ & {$[139]$} \\
\hline \multirow[t]{2}{*}{ Tecido de algodão } & $\mathrm{Y}_{2} \mathrm{O}_{3}: \mathrm{TR}$ & {$[141]$} \\
\hline & $\mathrm{Al}_{2} \mathrm{O}_{3}$ & [203] \\
\hline \multirow[t]{2}{*}{ Esponja vegetal } & $\mathrm{Y}_{2} \mathrm{Si}_{2} \mathrm{O}_{7}$ & {$[140]$} \\
\hline & Argila & [30] \\
\hline
\end{tabular}



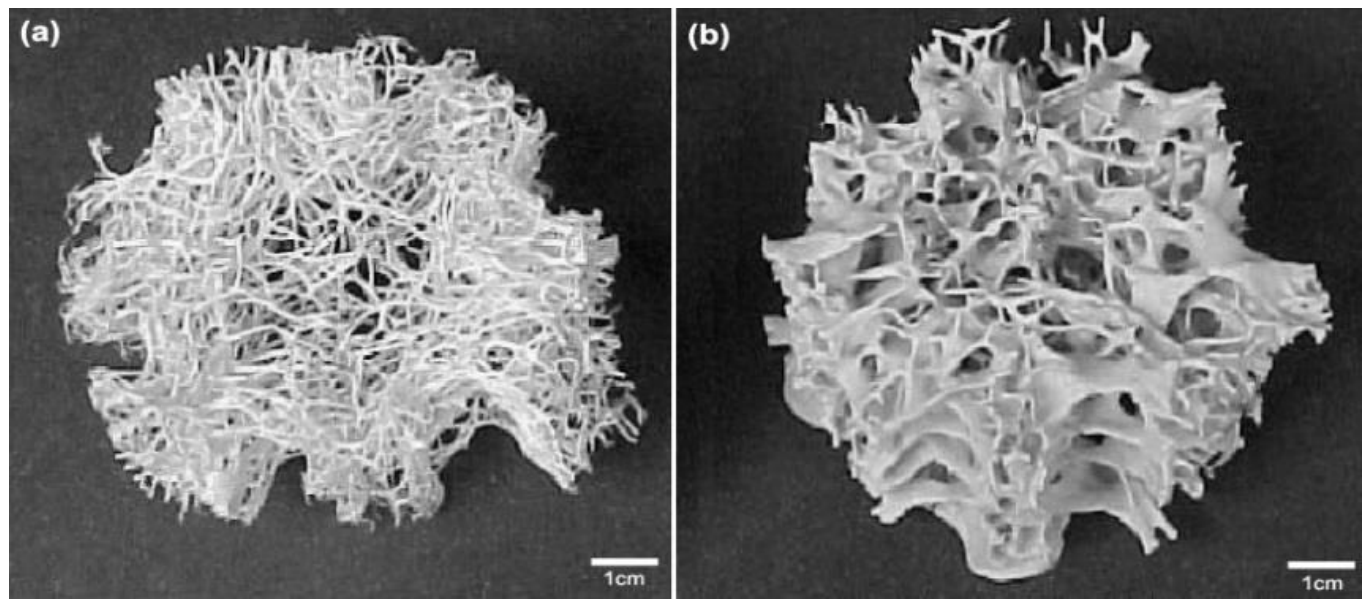

FIGURA 32 - Fotografia óptica de (a) esponja vegetal Lufa Cylindrica e (b) cerâmica porosa obtida por réplica a partir dessa matriz natural.

Muitas contribuições têm sido apresentadas para aprimorar o processo

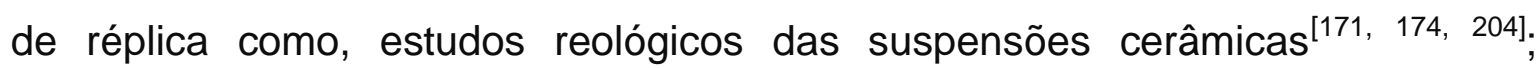
impregnação em etapas, com o objetivo de cobrir as possíveis trincas dos

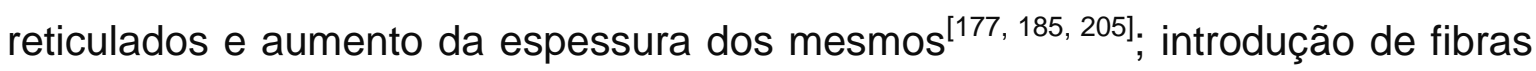
ou aditivos para aumentar a resistência mecânica da peça ${ }^{[206]}$, a avaliação da decomposição térmica das matrizes de réplica ${ }^{[163]}$.

Até o presente, foram encontrados poucos trabalhos referentes ao processamento coloidal da ítria e nenhum quanto ao dissilicato de ítrio, com exceção do trabalho realizado pelo nosso grupo ${ }^{[140]}$. A falta de literatura possivelmente é decorrente do alto custo da ítria, complexidade da síntese do dissilicato de ítrio e especificidade das aplicações destes materiais. 


\section{MATERIAIS E MÉTODOS}

Para o desenvolvimento de bulbos cerâmicos porosos com características luminescentes e com boa resistência mecânica, teve-se como meta reduzir a concentração de ítrio presente no material. Para este estudo foram utilizados quatro tipos de materiais contendo ítrio, óxido de ítrio comercial, concentrado de óxidos de terras raras, dissilicato de ítrio sintético puro e dopado com disprósio. Constitui-se também como meta deste trabalho substituir os materiais sintéticos geralmente utilizados como matriz de réplica, por estruturas vegetais reticuladas, como a esponja vegetal Luffa Cylindrica.

\subsection{Materiais de partida}

- Água deionizada

- Óxido de ítrio 99,9\%; $\mathrm{Y}_{2} \mathrm{O}_{3}$ (Alfa Aesar $\mathrm{GmbH}$ )

- Óxido de disprósio 99,9\%; $\mathrm{Dy}_{2} \mathrm{O}_{3}$ (Alfa Aesar $\mathrm{GmbH}$ )

- Ortosilicato de tetraetilo 98\% - TEOS, $\left(\mathrm{C}_{4} \mathrm{H}_{5} \mathrm{O}\right)_{4} \mathrm{Si}$ (Merck)

- Ácido nítrico $54 \% \mathrm{PA}, \mathrm{HNO}_{3}$ (Synth)

- Álcool etílico 99,5\% PA, $\mathrm{C}_{2} \mathrm{H}_{5} \mathrm{OH}$ (CRQ Química)

- Hidróxido de amônio $30 \% \mathrm{PA}, \mathrm{NH}_{4} \mathrm{OH}$ (Casa Americana)

- Carboximetilcelulose (262,19g.mol-1) - CMC (Veta Química)

- Hidróxido de tetrametilamônio 25\% - HTMA (Sigma-Aldrich)

- Poliacrilato de amônio 35\% - PAA (Duramax D-3005) 
Como matéria prima utilizou-se também carbonato de terras raras $\mathrm{TR}_{2}\left(\mathrm{CO}_{3}\right)_{3}$, obtido a partir do processamento da monazita brasileira (Nuclemon Nuclebrás de Monazita e Associados Ltda, Brasil). Em estudo anterior ${ }^{[163]}$, ao condicionar o $\mathrm{TR}_{2}\left(\mathrm{CO}_{3}\right)_{3}$ para forma de óxido (YTR), verificou-se que este material apresentou alto teor de óxido de ítrio e significativa concentração de óxido de disprósio. Uma das características das terras raras consiste no seletivo espetro de emissão de luz. O disprósio apresenta emissão no comprimento de onda correspondente ao amarelo $(\lambda \approx 580 \mathrm{~nm})$. Segundo a Comissão Internacional de Iluminação $(\mathrm{CIE})^{[207]}$, a fonte de luz amarela favorece melhor acomodação da retina do olho humano. Portanto, essa cor é adequada para iluminação de espaços internos destinados, onde se busca estabelecer um ambiente de repouso ou lazer.

\section{- Matriz de réplica}

Neste estudo foi selecionada como matriz de réplica a esponja vegetal da Luffa Cylindrica (LCy). Este insumo apresenta estrutura reticulada semelhante às esponjas sintéticas de poliuretano usualmente utilizadas como matrizes de réplica, conforme mostrado na FIG. 33. A disposição aleatória das fibras vegetais constitui uma arquitetura compatível para confecção de bulbos cerâmicos porosos pelo processo de réplica.

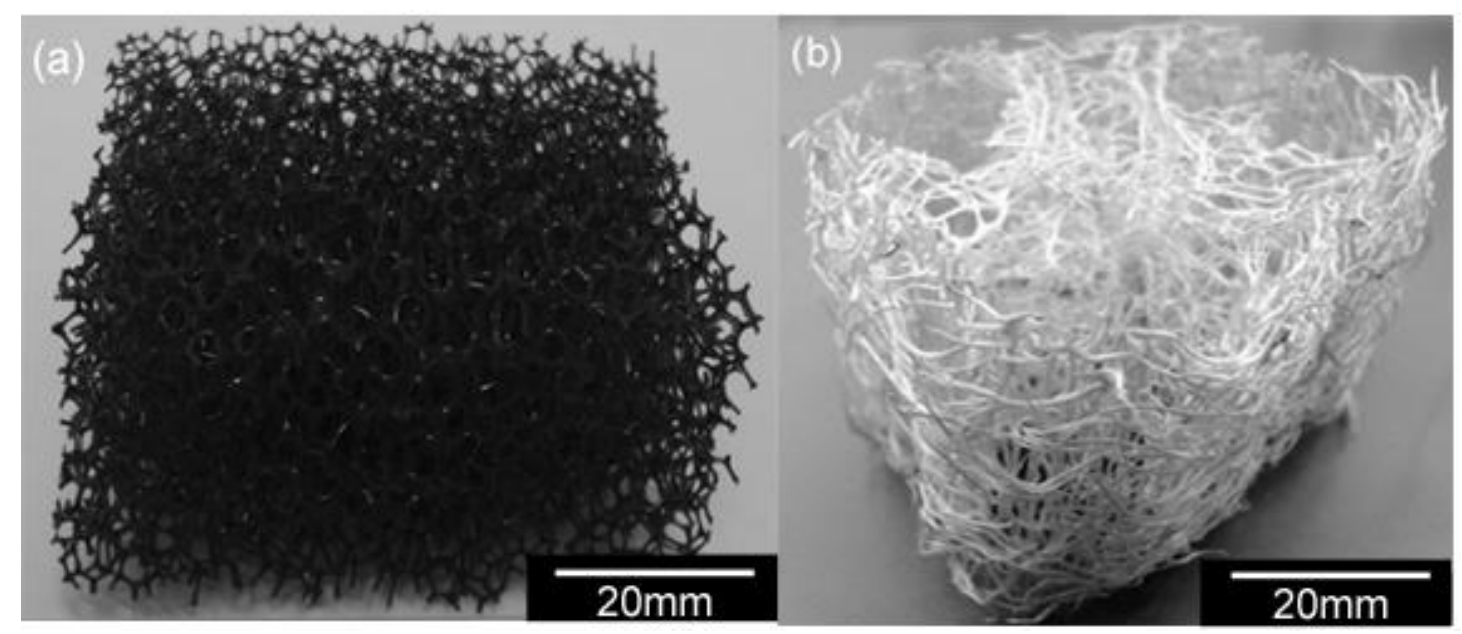

FIGURA 33 - Estruturas reticuladas das esponjas (a) sintética de poliuretano e (b) vegetal da espécie Luffa Cylindrica. 
A esponja LCy foi obtida pelo cultivo da planta Luffa Cylindrica em suporte (FIG. 34a) durante o ano de 2011. Alguns aspectos da esponja são ilustrados a seguir: fruto descascado, seco e cortado (FIG. 34b); secção transversal do fruto seco e descascado, que ilustra a formação de cavidades características de forma triangular em uma estrutura reticulada (FIG. 34c); retículos das fibras vegetais $\left(\varnothing_{\mathrm{fibra}}=150 \mu \mathrm{m}\right)$ da Luffa Cylindrica (FIG. 34d).
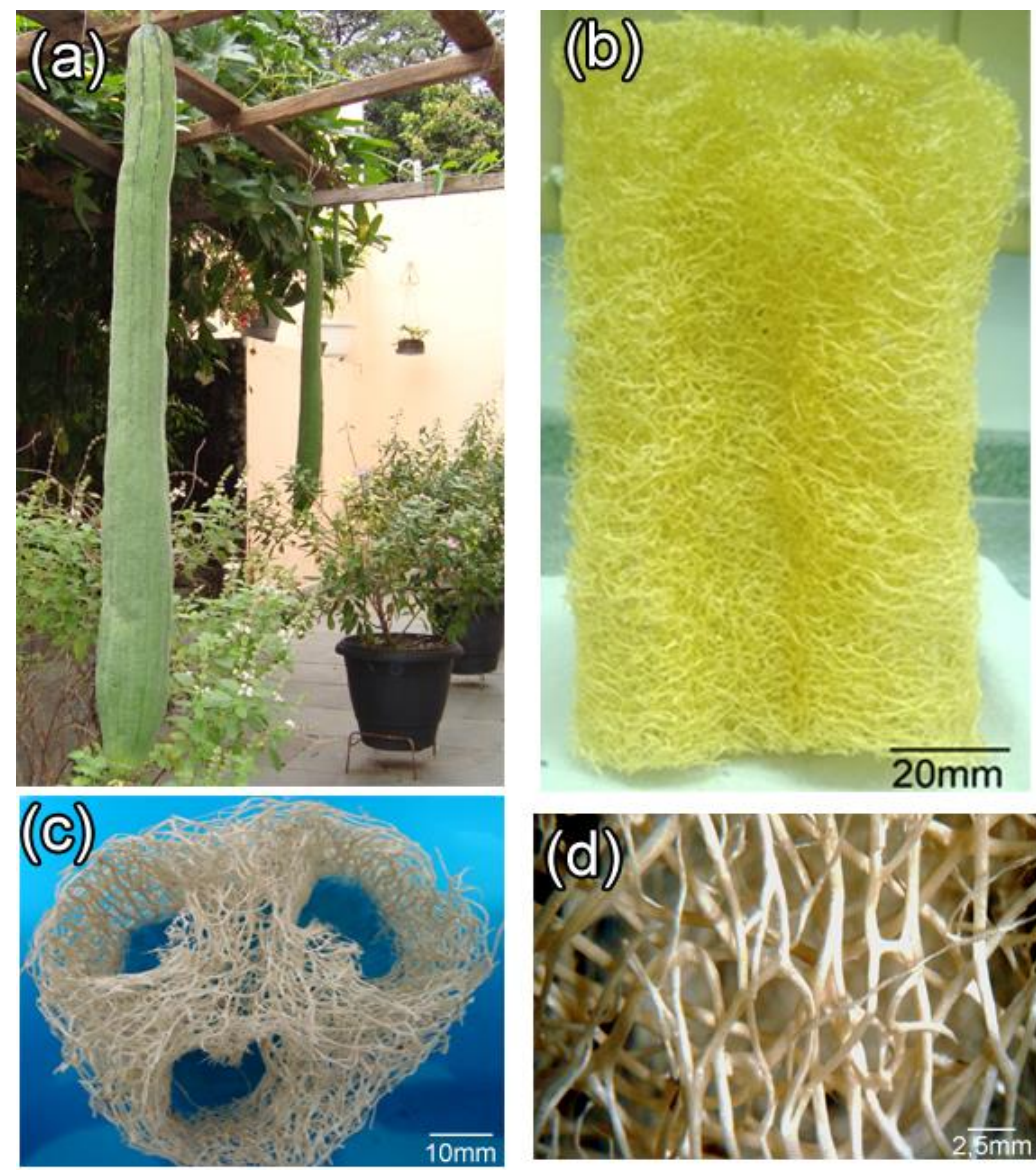

FIGURA 34 - Esponja vegetal Luffa Cylindrica. Em (a) fruto verde no pé; (b) esponja descascada e seca (c) secção transversal da esponja e (d) estrutura fibrosa constituinte da esponja.

\subsection{Síntese do dissilicato de ítrio}

Para obter componentes reticulados pelo processo de réplica, foram utilizados 0 dissilicato de ítrio puro $\left(\mathrm{Y}_{2} \mathrm{Si}_{2} \mathrm{O}_{7}\right)$ e dopado com disprósio $\left(\mathrm{Y}_{2} \mathrm{Si}_{2} \mathrm{O}_{7}: \mathrm{Dy}^{3+}\right)$ sintetizados em laboratório. Para o estudo de comportamento e 
dopagem destes materiais foi necessário maior rigor para se assegurar a formação do dissilicato estequiométrico. Conforme indicado no diagrama de equilíbrio de fases do sistema $\mathrm{Y}_{2} \mathrm{O}_{3}-\mathrm{SiO}_{2}$ (FIG. 17), a região de estequiometria deste composto é muito estreita.

A síntese do dissilicato de ítrio $\left(\mathrm{Y}_{2} \mathrm{Si}_{2} \mathrm{O}_{7}\right)$ foi desenvolvida via processo hidrotermal de acordo com estudo anterior do grupo ${ }^{[138]}$. Os pós de $\mathrm{Y}_{2} \mathrm{O}_{3}$ foram dissolvidos em solução aquosa de ácido nítrico (razão volumétrica 1:1), formandose a solução de nitrato de ítrio. A solução de TEOS foi diluída em álcool etílico (razão volumétrica 1:5) e adicionada em solução de nitrato de ítrio. A mistura foi homogeneizada em agitador magnético por 5 minutos. A solução final permaneceu em agitação, onde nesta condição foi adicionado hidróxido de amônio para ajuste de $\mathrm{pH}$ até a condição favorável para a formação do precipitado. Conforme reportado por TRUSTY et al. ${ }^{[132,208]}$ a suspensão do precursor do $\mathrm{Y}_{2} \mathrm{Si}_{2} \mathrm{O}_{7}$ preparada em $\mathrm{pH}$ alcalino favorece a formação deste material com maior homogeneidade de fase. $\mathrm{Na}$ condição de $\mathrm{pH}=10$ foi observado a precipitação de um composto branco e gelatinoso corresponde ao hidróxido de ítrio e sílica gel. Nesta condição, toda a suspensão foi colocada sob refluxo à temperatura de $70^{\circ} \mathrm{C}$ por $6 \mathrm{~h}$, a pressão atmosférica e sob agitação. $\mathrm{O}$ precursor do dissilicato de ítrio formado foi filtrado e lavado repetidas vezes com água deionizada e posteriormente seco em estufa a $60^{\circ} \mathrm{C}$ por 12h. Na FIG. 35 são apresentadas algumas etapas desenvolvidas para síntese do $\mathrm{Y}_{2} \mathrm{Si}_{2} \mathrm{O}_{7}$.

Conforme apresentado no capítulo anterior, o dissilicato de ítrio pode apresentar diferentes formas cristalinas em função da temperatura de tratamento térmico. Visando-se obter o $\beta-\mathrm{Y}_{2} \mathrm{~S}_{2} \mathrm{O}_{7}$ que é a fase que apresentou melhor desempenho luminescente ${ }^{[138]}$, neste trabalho estudou-se o comportamento de cristalização do precursor em função da temperatura na formação do composto para obter esta fase em particular. Para estes estudos foram propostos tratamentos térmicos nas seguintes condições: intervalos de temperatura entre 900- $1500^{\circ} \mathrm{C}$, com patamar de 2 horas em cada temperatura considerada no intervalo, velocidade de aquecimento de $2^{\circ} \mathrm{C} \cdot \mathrm{min}^{-1}$ e atmosfera ambiente. Os equipamentos utilizados foram forno tipo mufla (EDG 1100, EDG, BR) e forno vertical resistivo (Lindbergh Blue $\mathrm{M}$, Thermo Scientific, USA). 


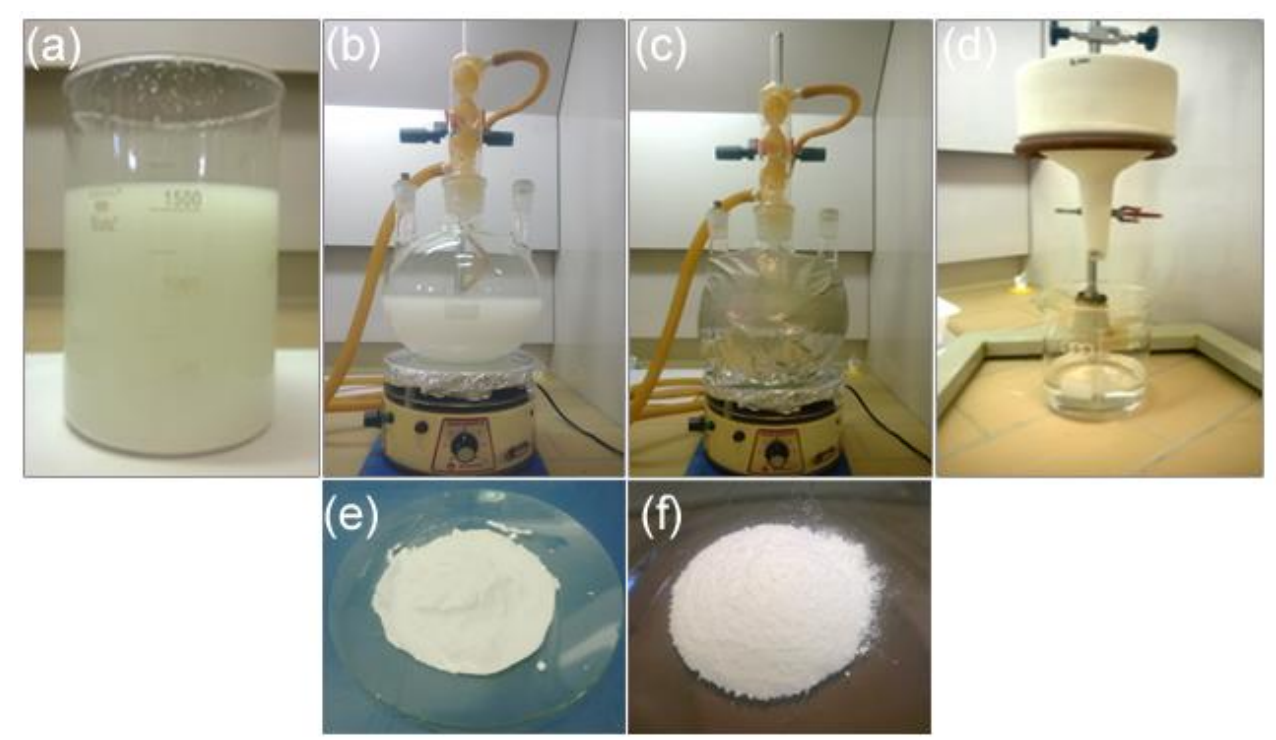

FIGURA 35 - Processo de síntese hidrotermal utilizado para produzir os pós de dissilicato de ítrio. Em (a) suspensão do precursor; (b) precursor em balão volumétrico; (c) sistema condensador para tratamento hidrotérmico; (d) filtragem e lavagem do precursor após refluxo; (e) precursor em gel e (f) pós de dissilicato de ítrio obtidos por tratamento térmico a $1000^{\circ} \mathrm{C}$ por $2 \mathrm{~h}$ em atmosfera ambiente.

Além de diminuir a quantidade de ítrio presente nos materiais constituintes das mantas de gás para iluminação, utilizando-se o dissilicato de ítrio, tem-se como meta também potencializar a emissão deste composto a partir da dopagem com disprósio. O mesmo procedimento de síntese hidrotermal foi realizado para o dissilicato de ítrio dopado com disprósio $\quad \beta-Y_{1,95} \mathrm{Dy}_{0,05} \mathrm{Si}_{2} \mathrm{O}_{7}$.

\section{3 Óxidos de terras raras}

Para fins comparativos de processamento e desempenho termoluminescente com o dissilicato de ítrio puro e dopado com disprósio, neste trabalho foram utilizados também outros dois materiais: ítria $\left(\mathrm{Y}_{2} \mathrm{O}_{3}\right)$ e concentrado de terras com elevada concentração de ítria (YTR) obtido a partir de um carbonato de terras raras $\mathrm{TR}_{2}\left(\mathrm{CO}_{3}\right)_{3}$.

Os pós de $\mathrm{TR}_{2}\left(\mathrm{CO}_{3}\right)_{3}$ foram calcinados para formação do óxido de terras raras com alto teor de ítria (YTR), de acordo com as condições determinadas em estudo anterior ${ }^{[163]}$ : velocidade de aquecimento de $10^{\circ} \mathrm{C} \cdot \mathrm{min}^{-1}$ até $750^{\circ} \mathrm{C}$, com patamar de 3 horas, em atmosfera ambiente. A calcinação foi 
realizada em forno mufla marca Flyever (FE50RPN, Fortlab Eequipamentos, Brasil).

\subsection{Técnicas de caracterização}

\subsubsection{Picnometria de gás hélio}

Para determinação da densidade real por Picnometria de gás hélio dos pós de $\mathrm{Y}_{2} \mathrm{O}_{3}, Y T R, \mathrm{Y}_{2} \mathrm{Si}_{2} \mathrm{O}_{7}$ e $\beta-\mathrm{Y}_{1,95} \mathrm{Dy}_{0,05} \mathrm{Si}_{2} \mathrm{O}_{7}$, das fibras LCy à verde e das réplicas sinterizadas, as amostras foram previamente secas em estufa à $100^{\circ} \mathrm{C}$ por 24h. O equipamento utilizado foi o picnômetro de $\mathrm{He} / \mathrm{Ar}$ (Micromeritics, modelo 1330, USA).

\subsubsection{Espectroscopia de correlação de fótons (PCS)}

A distribuição granulométrica das amostras em pó de $\mathrm{Y}_{2} \mathrm{O}_{3}, \mathrm{YTR}$, $\mathrm{Y}_{2} \mathrm{Si}_{2} \mathrm{O}_{7}$ e $\beta-\mathrm{Y}_{1,95} \mathrm{Dy}_{0,05} \mathrm{Si}_{2} \mathrm{O}_{7}$ foi determinada utilizando-se 0 analisador de partículas acoplado ao zetâmetro modelo ZetaPlus (Brookhaven Instruments Corporation, USA), com fonte de laser He-Ne de $25 \mathrm{~mW}, \lambda=678 \mathrm{~nm}$ e ângulo de incidência do feixe $\theta_{1}=90^{\circ}$. Por esta técnica pode-se determinar o tamanho médio e a curva de distribuição de tamanho de partículas, a partir do espalhamento dinâmico de luz proporcionado pelo movimento browniano das partículas dispersas em meio líquido. O diâmetro hidrodinâmico da partícula, $d_{h}$ (diâmetro da partícula + dupla camada elétrica) é determinado pela equação 9 de StokesEinstein [209-211].

$$
d_{h}=\frac{K_{B T}}{3 \pi \eta D_{t}}[\mathrm{~nm}]
$$

Onde: 
$\mathrm{T}=$ Temperatura $(\mathrm{K}) ; \eta=$ viscosidade do líquido(cP); $\mathrm{Dt}=$ coeficiente de difusão da partícula $\left(\mathrm{cm}^{2} \cdot \mathrm{s}^{-1}\right) ; \mathrm{K}_{\mathrm{BT}}=$ constante de Boltzman $\left(1,38 \cdot 10^{-23} \mathrm{~J} \cdot \mathrm{K}^{-1}\right)$.

Para as medidas de diâmetro médio de partícula foram preparadas suspensões cerâmicas em meio aquoso com concentração de sólidos de 0,1\%vol, estabilizadas com hidróxido de tetrametilamônio (HTMA) e homogeneizadas em moinho de bolas por 24h. Para cada amostra foram realizadas 10 medidas com tempo de contagem de 30s cada uma. A distribuição granulométrica de partículas e o diâmetro médio $\left(d_{50}\right)$ foram determinados pelo valor médio das medidas.

\subsection{3 Área de superfície específica pelo método de $B E T\left(S_{M}\right)$, diâmetro médio de partícula teórico $\left(\mathrm{d}_{\mathrm{BET}}\right)$ e fator de aglomeração $\left(\mathrm{F}_{\mathrm{AG}}\right)$}

As áreas de superfícies específicas dos pós de $\mathrm{Y}_{2} \mathrm{O}_{3}, \mathrm{YTR}, \mathrm{Y}_{2} \mathrm{Si}_{2} \mathrm{O}_{7} \beta$ $\mathrm{Y}_{1,95} \mathrm{Dy}_{0,05} \mathrm{Si}_{2} \mathrm{O}_{7}$ e das fibras LCy foram determinadas pelo método de adsorção gasosa BET(Bruaner, Emmett e Teller), que consiste em determinar o volume ocupado por uma monocamada de gás inerte na superfície das partículas. A área de superfície específica por unidade de massa $\left(S_{M}\right)$ é expressa pela equação $10^{[212]}$ :

$$
S_{M}=\frac{N_{A} V_{M} A_{M}}{V_{m o l} M_{s}}\left[\mathrm{~m}^{2} \cdot \mathrm{g}^{-1}\right]
$$

Onde:

- $\mathrm{N}_{\mathrm{A}}=$ Constante de Avogadro $\left(6,023 \cdot 10^{23}\right)$;

- $\mathrm{A}_{\mathrm{M}}=$ Área ocupada por uma molécula de gás adsorvido

- $\left(16,2 \cdot 10^{-20} \mathrm{~m}^{2}\right.$ para $\left.\mathrm{N}_{2}\right)$;

- $\mathrm{V}_{\mathrm{M}}=$ Volume da molécula de gás adsorvida $\left(\mathrm{cm}^{3}\right)$;

- $\mathrm{V}_{\mathrm{mol}}=$ volume de $1 \mathrm{~mol}$ de gás a temperatura ambiente $\left(\mathrm{cm}^{3}\right)$;

- $\mathrm{M}_{\mathrm{S}}=$ massa da amostra $(\mathrm{g})$. 
Para determinar a área de superfície específica das amostras foi utilizado um analisador BET da marca Micromeritics, modelo ASAP2010 (USA).

A partir do valor da área de superfície específica $\left(S_{M}\right)$, determinou-se o tamanho médio das partículas das amostras utilizando-se a equação $11^{[155]}$. Nesta relação, considera-se que as partículas apresentam morfologia esférica e homogênea.

$$
d_{B E T}=\frac{6}{\rho_{t} \cdot S_{M}}[\mu \mathrm{m}]
$$

Onde:

$$
\begin{aligned}
& d_{B E T}=\text { diâmetro médio da partícula }(\mu \mathrm{m}) ; \\
& \rho_{\mathrm{t}}=\text { densidade teórica do material }\left(\mathrm{g} \cdot \mathrm{cm}^{-3}\right) ; \\
& \mathrm{S}_{\mathrm{M}}=\text { área de superfície específica da partícula }\left(\mathrm{m}^{2} \cdot \mathrm{g}^{-1}\right) \text {. }
\end{aligned}
$$

O grau de aglomeração das partículas ou fator de aglomeração $F_{A G}$ (equação 12) indica o quanto o material, ou o sistema de partículas se encontra aglomerado. É avaliado pela razão entre o diâmetro medido por técnicas físicas, tais como feixe de laser $\left(d_{50}\right.$, item 4.4.2) e calculado a partir dos dados de BET $\left(d_{B E T}\right)$.

$$
F_{a g}=\frac{d_{50}}{d_{B E T}}
$$

Neste caso é importante destacar que $F_{a g}=1$ indica partículas individualizadas e homogêneas (situação ideal); $F_{a g}<1$ pode ser atribuído as partículas com fator de forma elevado (comprimento/raio); $F_{a g}>1$ as partículas se encontram aglomeradas. Quanto maior esta relação, maior será o estado de aglomeração $^{[155]}$. 


\subsubsection{Difração de raios X (DRX)}

As fases cristalinas dos óxidos de terras raras $\mathrm{Y}_{2} \mathrm{O}_{3}, Y T R$ e 0 comportamento de cristalização do precursor do dissilicato de ítrio puro e dopado em função da temperatura, foram analisados por difração de raios $X$ (DRX),

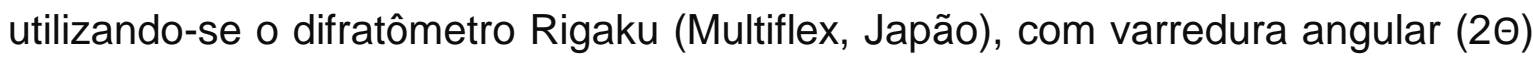
no intervalo de 20 a $80^{\circ}$, com passo de varredura $(\Delta 2 \Theta)$ de $0,5^{\circ} \mathrm{min}^{-1}$ e fonte $\mathrm{Cu}$ Ka. Para identificar as fases cristalinas existentes nas amostras estudadas, utilizou-se o banco de dados do software Crystallographica Search-Match (Versão 2.1.1.1, Oxford Cryosystems).

$\mathrm{Na}$ literatura ${ }^{[39,213,214]}$ é reportado que a estrutura das fibras vegetais LCy apresenta cristalinidade à curto alcance, a qual é associado as substâncias constituintes, como celulose e elementos metálicos. Portanto, por esta técnica e nas mesmas condições apresentadas anteriormente, foram analisadas amostras das fibras vegetais LCy à verde e as cinzas deste insumo após calcinação com velocidade de aquecimento de $10^{\circ} \mathrm{C} \cdot \mathrm{min}^{-1}$ até $800^{\circ} \mathrm{C}$, com patamar de $1 \mathrm{~h}$, em atmosfera ambiente (forno mufla EDG 1100, EDG, BR). Nestas condições, podese determinar o padrão de difração de curto alcance das fibras LCy e os picos de difração dos constituintes remanescentes das cinzas.

\subsubsection{Microscopia Eletrônica de Varredura (MEV)}

As morfologias e tamanhos das partículas dos pós de $\mathrm{Y}_{2} \mathrm{Si}_{2} \mathrm{O}_{7}, \beta$ $\mathrm{Y}_{1,95} \mathrm{Dy}_{0,05} \mathrm{Si}_{2} \mathrm{O}_{7}, \mathrm{Y}_{2} \mathrm{O}_{3}$ e YTR foram observadas em microscópios eletrônicos de varreduras, Philips (XL30, Holanda) e Oxford Instruments (InCax-act, UK). As amostras em suspensão foram pulverizadas em porta amostras de alumínio polido e recobertas com ouro pelo método de sputering.

As análises de superfície e morfologia das fibras vegetais como recebido, após tratamento químico e impregnadas com as suspensões cerâmicas foram realizadas utilizando-se microscópio eletrônico de varredura Hitachi (TM 3000, Japão). As amostras foram fixadas com fita de carbono em porta amostras de alumínio polido sem recobrimento. 
As microestruturas de superfície e de fratura das réplicas cerâmicas sinterizadas à base de $\mathrm{Y}_{2} \mathrm{Si}_{2} \mathrm{O}_{7}, \beta-\mathrm{Y}_{1,95} \mathrm{Dy}_{0,05} \mathrm{Si}_{2} \mathrm{O}_{7}, \mathrm{Y}_{2} \mathrm{O}_{3}$ e $\mathrm{YTR}$ foram observadas em microscópio eletrônico de varredura Oxford Instruments (InCax-act, UK). As amostras foram fixadas com fita de carbono em porta amostras de alumínio polido e recobertas com filme de ouro.

\subsubsection{Fluorescência de raios X (FRX)}

A caracterização química das amostras de $\mathrm{Y}_{2} \mathrm{O}_{3}$ e $\mathrm{YTR}$ foi realizada pela técnica de Espectrometria de Fluorescência de raios $X$ (FRX), no espectrofotômetro de Fluorescência de raios X Rigaku (RIX 3000, Japão), baseando-se no Método de Parâmetros Fundamentais ${ }^{[215]}$.

\subsubsection{Análise termogravimétrica e análise térmica diferencial (ATG/ATD)}

Trabalhos anteriores ${ }^{[125,216]}$ mostram que o precursor do dissilicato de ítrio pode cristalizar e apresentar uma ou mais fases em função da temperatura do e tempo. Baseado nestes estudos, utilizou-se a análise termogravimétrica (ATG) para determinar alterações na massa do precursor de dissilicato de ítrio em função da temperatura e do tempo. Por análise térmica diferencial (ATD), pode-se definir as mudanças de fase do material em função da temperatura e do tempo. As análises ATG/ATD do precursor de dissilicato de ítrio foram realizadas no analisador termogravimétrico Setaram (S60/38336, França), com termopar de $\mathrm{Pt} / \mathrm{R}$ th, nas seguintes condições: velocidade de aquecimento de $10^{\circ} \mathrm{C} \cdot \mathrm{min}^{-1}$ até a temperatura de $1400^{\circ} \mathrm{C}$ e em atmosfera.

No processo de conformação por réplica, uma etapa importante consiste no tratamento térmico das amostras impregnadas. Neste caso, deve-se estabelecer parâmetros de processamento compatíveis para eliminar a matriz de réplica e consolidar a fase cerâmica de forma a conservar o corpo cerâmico íntegro. Neste sentido, o comportamento termo cinético das fibras LCy foi avaliado por análise termogravimétrica (ATG) para determinar alterações na massa do material em função da temperatura e do tempo. Simultaneamente, as fibras LCy foram avaliadas por análise térmica diferencial (ATD) para definir as 
condições de decomposição dos constituintes orgânicos da amostra em função da temperatura e do tempo. As análises ATG/TD das fibras LCy foram realizadas no analisador termogravimétrico Setaram (S60/38336, França), com termopar de $\mathrm{Pt} / \mathrm{Rh}$, nas seguintes condições: velocidade de aquecimento de $10^{\circ} \mathrm{C} \cdot \mathrm{min}^{-1}$ até a temperatura de $800^{\circ} \mathrm{C}$ e atmosfera ambiente.

\subsubsection{Emissão de luz termicamente estimulada ( $T L)$}

Conforme anteriormente discutido, a função do queimador cerâmico poroso, neste estudo é apresentar resistência mecânica, proporcionar maior tempo de residência do gás na zona de combustão, potencializar a emissão de luz pela queima do combustível e pela luminescência emitida inerente ao material que o constitui. Neste caso, um dos fenômenos luminescentes que podem ser determinados é a termoluminescência ( $T L)$, que consiste na emissão de luz de um material isolante, ou semicondutor durante o aquecimento posterior a exposição da amostra à radiação ionizante ${ }^{[217]}$.

O efeito termoluminescente dos materiais estudados a partir de amostras em pó foi determinado em leitor combinado de TL/OSL Risoe DTU (Ris $\varnothing$ TL/OSL-DA-20, Dinamarca) equipado com sistema de aquecimento até $700^{\circ} \mathrm{C}$. O conjunto de detecção de luminescência emitida consiste no espectrômetro Ocean Optics (QE65 Pro), com sensibilidade espectral na faixa de 200 a 950nm e resolução em comprimento de onda de 6,5nm. Para caracterização termoluminescente, as amostras foram previamente irradiadas com dose de $2 \mathrm{KGy}$ em fonte ${ }^{60} \mathrm{Co}$ e posteriormente aquecidas à taxa de $5^{\circ} \mathrm{C} . \mathrm{s}^{-1}$ até $700^{\circ} \mathrm{C}$ em atmosfera ambiente. A luz emitida pelas amostras foi analisada em função da temperatura $(T)$ e comprimento de onda $(\lambda)$.

\subsubsection{Estabilidade das partículas em suspensão - potencial Zeta (ろ)}

A estabilidade das partículas em suspensão aquosa foi avaliada

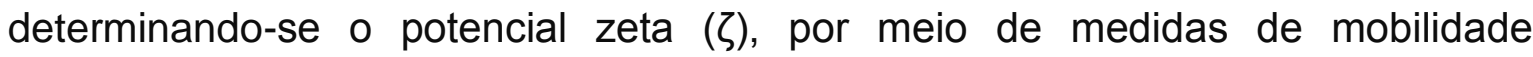
eletroforética das partículas $\left(\mu_{\mathrm{e}}\right)$ e o modelo matemático de Smoluchowski ${ }^{[218]}$, 
conforme indicado na equação $13^{[218]}$. O equipamento utilizado foi o zetâmetro modelo ZetaPlus (Brookhaven Instruments Corporation, USA).

Para as análises de mobilidade eletroforética foram preparadas suspensões aquosas com $0,01 \% \mathrm{vol}$ de sólidos e $10^{-3} \mathrm{M}$ de $\mathrm{NaCl}$ como eletrólito. As amostras foram dispersas em ultrassom por 2 minutos. Os posteriores ajustes de $\mathrm{pH}$ das suspensões foram realizados a partir de soluções de $\mathrm{KOH}$ e $\mathrm{HCl}$ $(0,25 \mathrm{M}$ e $0,5 \mathrm{M})$. Estudou-se também, a estabilidade das suspensões e deslocamento do ponto isoelétrico (PIE) dos materiais em função da adição de dispersante, o polieletrólito Duramax D3005 ${ }^{\circledR}$ (poliacrilato de amônio - PAA, 3,500g.mol ${ }^{-1}$, Rohm and Hass Company, Philadelphia, USA).

$$
\zeta=\left(\frac{\eta \cdot \mu_{e}}{\varepsilon}\right)[\mathrm{mV}]
$$

Onde: $\eta$ : viscosidade do líquido $\left[\mathrm{g} \cdot \mathrm{cm}^{-1} \cdot \mathrm{s}^{-1}\right] ; \mu_{\mathrm{e}}:$ mobilidade eletroforética da partícula $\left[\mathrm{m}^{2} \cdot \mathrm{s}^{-1} \mathrm{~V}^{-1}\right] ; \varepsilon$ : permissividade do líquido $\left[J . \mathrm{V}^{-2} \cdot \mathrm{m}^{-1}\right]$.

\subsubsection{Preparo das suspensões cerâmicas}

Neste estudo foi avaliado o comportamento reológico das suspensões cerâmicas à base dos materiais estudados em função dos seguintes parâmetros: concentração de sólidos, dispersante, ligante e pH.

Para todas as condições estudadas, suspensões com até $25 \%$ vol de sólidos foram homogeneizadas em moinho de bolas por $24 \mathrm{~h}$, utilizando-se como meio de moagem esferas de alumina $\left(\varnothing_{\text {esfera }}=10 \mathrm{~mm}\right)$. $O$ ajuste de $\mathrm{pH}$ foi realizado com hidróxido de tetrametilamônio (HTMA). A concentração em massa de dispersante foi baseada na quantidade em massa do pó cerâmico, variando-se de $0,5 \%$ a $3 \%$. A concentração de ligante $\mathrm{CMC}$ foi estabelecida em relação a massa total da suspensão. A seleção dos aditivos HTMA, PAA e CMC foi baseada em trabalhos anteriores do grupo ${ }^{[139,163,219,220] .}$

A determinação das melhores condições, sob o ponto de vista reológico, foi realizada para o dissilicato de ítrio. As condições de processamento 
para a ítria $\left(\mathrm{Y}_{2} \mathrm{O}_{3}\right)$ e óxido de terras raras com alto teor de ítria (YTR) foram estabelecidas em estudo anterior ${ }^{[163]}$ e utilizadas neste trabalho para fins comparativos.

\subsubsection{Caracterização reológica das suspensões cerâmicas}

O estudo reológico das suspensões aquosas foi realizado utilizando-se o reômetro RS600 (HAAKE, Alemanha), com sensor de duplo cone. As curvas de fluxo foram analisadas em função das condições de tensão e taxa de cisalhamento, utilizando-se o método de Controle de velocidade de cisalhamento ("Controlled Rate" - CR). A caracterização reológica no modo CR consistiu em três etapas: $\left(C_{1}\right)$ curva de subida, $0-1000 s^{-1}$ por $300 s ;\left(C_{2}\right)$ patamar à $1000 s^{-1}$ por 120s e $\left(\mathrm{C}_{3}\right)$ curva de descida, $1000-0 \mathrm{~s}^{-1}$ por 300s, conforme indicado na FIG. 36. Para cada etapa $C R\left(\mathrm{C}_{1}-\mathrm{C}_{3}\right)$ foram medidos 200 pontos. A caracterização das curvas de fluxo foi determinada a partir dos modelos reológicos disponíveis no banco de dados do software do reômetro, Haake RheoWin Data Manager (versão 3.61.0000, 2007).

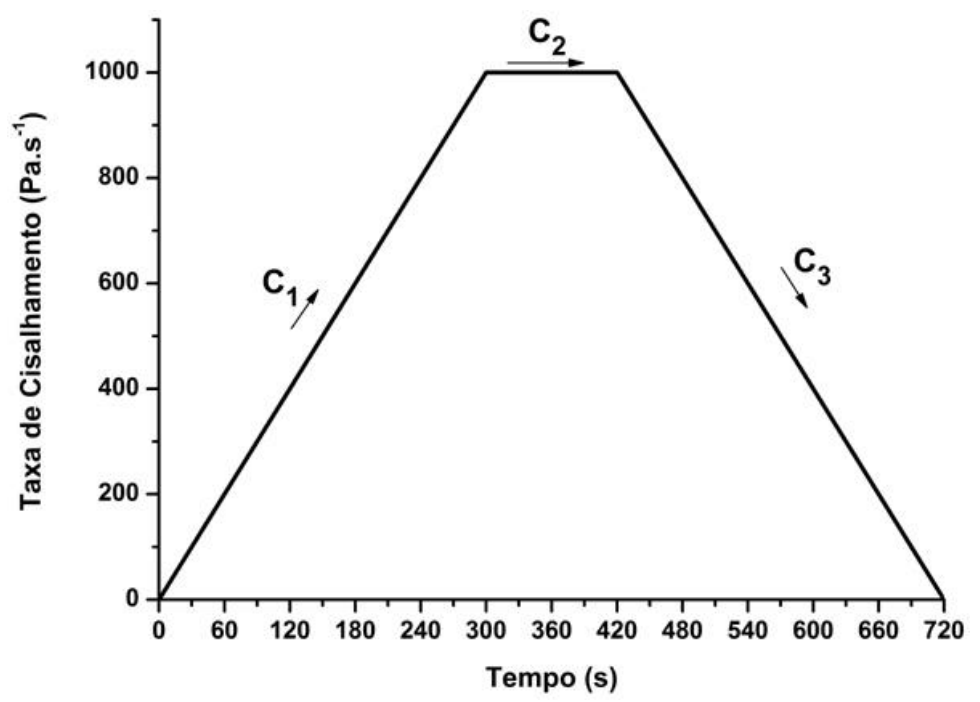

FIGURA 36 - Parâmetros utilizados para as curvas de fluxo: (C1) curva de subida, 0$1000 \mathrm{~s}^{-1}$ por $300 \mathrm{~s}$; (C2) patamar à $1000 \mathrm{~s}^{-1}$ por $120 \mathrm{~s}$; (C3) curva de descida, $1000-0 \mathrm{~s}^{-1}$ por 300s. 


\subsection{Processo de conformação por réplica}

\subsubsection{Condicionamento da superfície das fibras vegetais}

As fibras vegetais, como a esponja Lufa Cylindrica, ainda que bem atrativas devido à facilidade de obtenção e cultivo, constituindo uma classe de materiais renováveis que apresentam morfologias promissoras para diversas aplicações, apresentam substâncias em sua superfície que dificultam a adesão de qualquer outra substância $\left.{ }^{[35}, 39,221-223\right]$. Estudos de caracterização e processamento da esponja vegetal Lufa Cylindrica mostram ${ }^{[35,221]}$ que o tratamento à base de $\mathrm{NaOH}$ remove da superfície das fibras substâncias como lignina e celulose que dificultam adesão de outras substâncias.

Para condicionamento da superfície das fibras vegetais, este estudo baseou-se nas condições estabelecidas no trabalho de TANOBE et al. ${ }^{[224]}$. As amostras de LCy foram imersas em solução aquosa com $2 \%$ massa de $\mathrm{NaOH}$ a $60^{\circ} \mathrm{C}$ por $2 \mathrm{~h}$ e posteriormente lavadas com água deionizada (FIG 37). As amostras foram secas à temperatura ambiente por $24 \mathrm{~h}$.

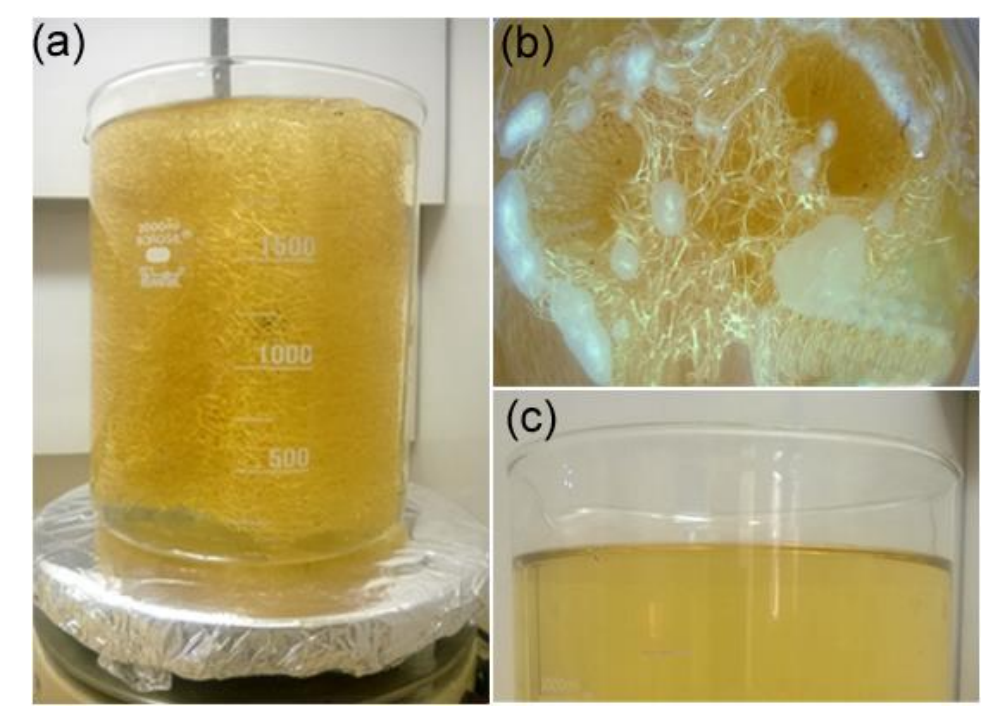

FIGURA 37 -Tratamento das fibras vegetais da matriz LCy com solução de $2 \%$ massa de $\mathrm{NaOH}$ a $60^{\circ} \mathrm{C}$ por $2 \mathrm{~h}$. Em (a) LCy imersa em solução alcalina; (b) vista superior da amostra LCy imersa; (c) solução sobrenadante extraída das fibras. 


\subsubsection{Confecção do protótipo de manta de gás}

O protótipo de manta de gás foi baseado na morfologia dos bulbos de lâmpadas tradicionais de bulbo de filamento incandescente. Esta morfologia pode favorecer a contenção do gás, estabilidade da chama, condução de calor, potencializar a queima do combustível e a emissividade do material.

Conforme indicado na FIG. 38, o esquema de confecção do protótipo a partir da esponja vegetal LCy pode ser dividido em sete etapas, (1) seleção da esponja; (2) corte da seção transversal da esponja; (3) retirada do cerne da LCy; (4-5) dobra da amostra LCy em retângulo e recorte em formato de bulbo de lâmpada; (6-7) junção das extremidades laterais e superior da amostra LCy, constituindo-se um bulbo com cavidade na parte inferior para entrada de gás. Por este método foram confeccionados protótipos de manta de gás com dimensões de $85 \times 110 \mathrm{~mm}$ (largura $\mathrm{x}$ altura).
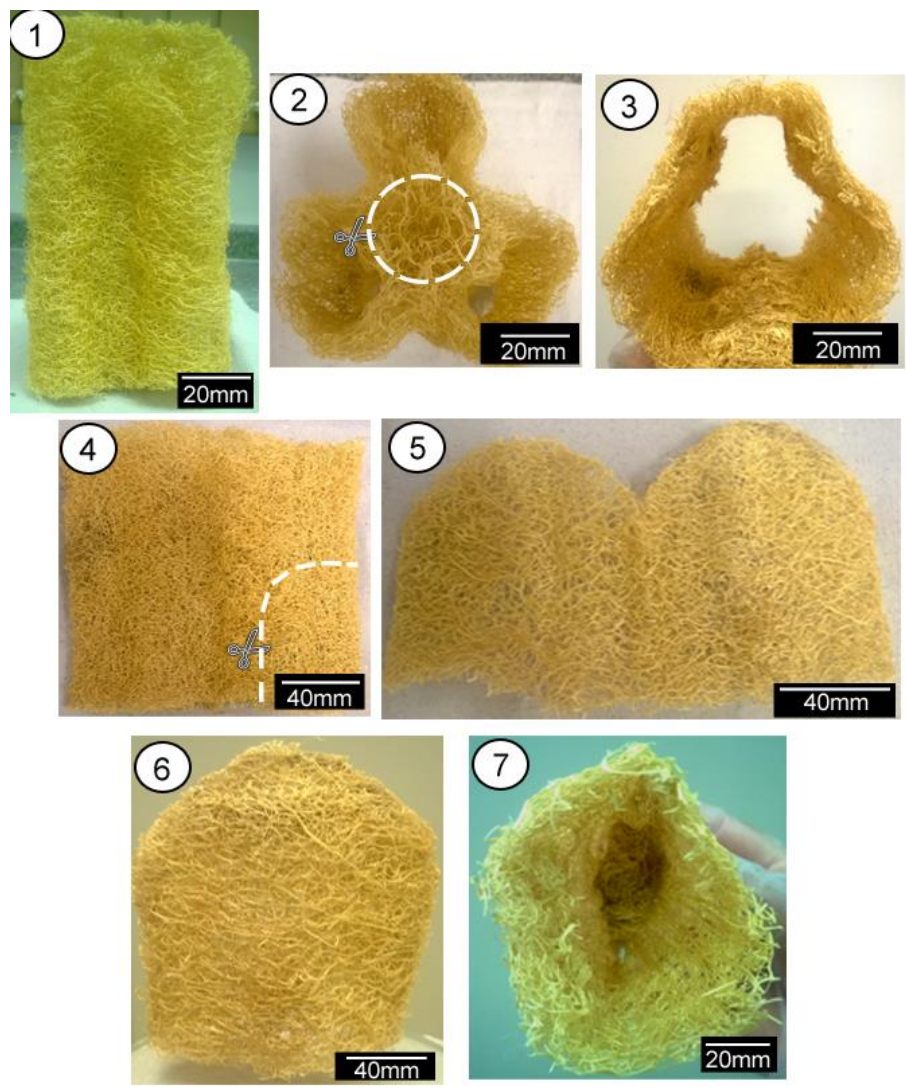

FIGURA 38 - Esquema de confecção do protótipo de manta de gás a partir da esponja vegetal LCy. 


\subsubsection{Ensaios de impregnação das amostras}

As fibras tratadas foram imersas uma vez nas suspensões cerâmicas por 30 minutos[146], submetidas a secagem e tratamento térmico controlado antes da sinterização. A secagem foi realizada à temperatura ambiente por $24 \mathrm{~h}$. A caracterização a verde foi realizada medindo -se a massa impregnada em balança analítica AG 204 (Mettler Toledo) e observando-se a morfologia das amostras em esteroscópio Jena (GSZ, Carl Zeiss, Alemanha).

\subsubsection{Ensaios de tratamento térmico das amostras impregnadas}

As amostras impregnadas foram submetidas a diferentes condições de tratamento térmico visando a eliminação total da fibra, conservando a integridade da réplica.

As condições propostas para os ensaios de tratamento térmico foram baseadas nos resultados das ATG/ATD da matriz vegetal LCy. O comportamento termo cinético da amostra LCy foi acompanhado utilizando-se 0 analisador termogravimétrico S60/38336 (Setaram, França), com taxa de aquecimento de $10^{\circ} \mathrm{C} \cdot \mathrm{min}^{-1}$ até $800^{\circ} \mathrm{C}$.

Os equipamentos utilizados para tratamento térmico das amostras impregnadas foram: mufla (EDG 3000) e forno vertical (Lindberg/Blue M), cujas temperaturas máximas de trabalho são respectivamente $1100^{\circ} \mathrm{C}$ e $1650^{\circ} \mathrm{C}$. Todos os ensaios foram realizados em atmosfera ambiente.

\subsubsection{Determinação da eficiência radiante do protótipo}

O desempenho do protótipo de queimador foi avaliado quanto a eficiência radiativa $\left(N_{\text {rad }}\right)$, que consiste na razão entre a energia fornecida pelo combustível pela energia radiante emitida pelo material na forma de calor, conforme indicado na equação 14. Para o ensaio de queima foi selecionado o gás metano $\left(\mathrm{CH}_{4}\right.$, White Martins) como combustível e para fins comparativos, usou-se também o gás butano $\left(\mathrm{C}_{4} \mathrm{H}_{10}\right.$, White Martins). As especificações dos 
respectivos gases são apresentadas na TAB. 6. Para este ensaio foram utilizados bico de bunsen, pirômetro óptico (Minipa, MP 350) com limite de determinação de temperatura de até $700^{\circ} \mathrm{C}\left( \pm 2^{\circ} \mathrm{C}\right)$.

$$
\operatorname{Nrad}=\left(\frac{\text { Qrad }}{\mathrm{v}_{\mathrm{g}} \cdot \Delta \mathrm{H}_{\mathrm{L}}}\right) \times 100[\%]
$$

Onde,

- $Q \mathrm{Qrad}=\tau . \mathrm{T}^{4}\left[\mathrm{~W} \cdot \mathrm{m}^{-2}\right]$;

- $\tau=5,6697 \cdot 10^{-8} \mathrm{~W} \cdot \mathrm{m}^{-2} \cdot \mathrm{K}^{-4}$ (constante de Boltzmann);

- $\mathrm{T}=$ Temperatura $[\mathrm{K}]$;

- $\mathrm{V}_{\mathrm{g}}=$ vazão do combustível $\left[\mathrm{cm}^{3} \cdot \mathrm{min}^{-1}\right]$;

- $\Delta \mathrm{H}_{\mathrm{L}}=$ poder calorífico do combustível [kcal.kg ${ }^{-1}$ ];

TABELA 6 - Especificações dos gases combustíveis utilizados para os ensaios de desempenho do protótipo de queimador de gás

\begin{tabular}{cccc}
\hline Gás & Pureza mínima (\%) & Pressão $\left(\mathbf{K g f . c m}{ }^{-2}\right)$ & $\mathbf{\Delta H}_{\mathbf{L}}\left(\mathbf{K c a l}_{\mathbf{K}} \mathbf{K g}^{-1}\right)$ \\
\hline $\mathrm{CH}_{4}$ & 99,5 & 150 & 6.200 \\
$\mathrm{C}_{4} \mathrm{H}_{10}$ & 99,5 & 2,2 & 11.900 \\
\hline
\end{tabular}




\section{RESULTADOS E DISCUSSÃo}

Neste capítulo são apresentados e discutidos os principais resultados obtidos durante o estudo.

\subsection{Caracterização dos materiais de partida}

\subsection{1 Óxido de ítrio $\left(\mathrm{Y}_{2} \mathrm{O}_{3}\right)$, óxido de disprósio $\left(\mathrm{Dy}_{2} \mathrm{O}_{3}\right)$ e concentrado de terras raras (YTR)}

Os padrões de difração de raios $\mathrm{X}$ dos materiais de partida óxido de ítrio $\left(\mathrm{Y}_{2} \mathrm{O}_{3}\right)$, óxido de disprósio $\left(\mathrm{Dy}_{2} \mathrm{O}_{3}\right)$, carbonato de terras raras $\mathrm{TR}_{2}\left(\mathrm{CO}_{3}\right)_{3} \mathrm{e}$ concentrado de terras raras (YTR) são apresentados na FIG. 39 e FIG. 40. Para a amostra de $\mathrm{Y}_{2} \mathrm{O}_{3}$, verifica-se picos de difração relacionados à ítria de estrutura cristalina cúbica de corpo centrado (P.D.F. 70-603) ${ }^{[225]}$, com pico de difração de alta intensidade a 29 referente ao plano (222). Comparando-se os padrões de difração obtidos para $0 \quad \mathrm{Y}_{2} \mathrm{O}_{3}$ e $\mathrm{Dy}_{2} \mathrm{O}_{3}$, observa-se que ambos são muito semelhantes devido à similaridade dos planos cristalinos das terras raras. $\mathrm{O}$ $\mathrm{Dy}_{2} \mathrm{O}_{3}$ apresenta estrutura cristalina cúbica simples (PDF.79-1722) ${ }^{[226]}$, com um pico de difração de maior intensidade a $2^{\circ}$ eferente ao plano (220).

$\mathrm{O}$ padrão de difração relativo à amostra $\mathrm{TR}_{2}\left(\mathrm{CO}_{3}\right)_{3}$ (FIG. 40) revela os picos característicos e indexados dos carbonatos de $\mathrm{Dy}_{2} \mathrm{O}_{2} \mathrm{CO}_{3}\left(\mathrm{PDF}\right.$. 26-588) ${ }^{[227]}$, $\mathrm{Er}_{2} \mathrm{O}_{2} \mathrm{CO}_{3}$ (PDF. 26-602) $)^{[227]}, \mathrm{Y}(\mathrm{OH}) \mathrm{CO}_{3}$ (PDF. 32-1429) ${ }^{[227]}$ e também oxalato de lutécio, $\mathrm{C}_{6} \mathrm{Lu}_{2} \mathrm{CO}_{12}$ (PDF. 60-652) ${ }^{[228]}$. Para a amostra YTR obtida a partir da calcinação dos pós de $\mathrm{TR}_{2}\left(\mathrm{CO}_{3}\right)_{3}$ a $750^{\circ} \mathrm{C}$ por $3 \mathrm{~h}$, todos os picos de maior intensidade foram identificados e indexados para a ítria de estrutura cúbica de corpo centrado (P.D.F. 70-603) ${ }^{[225]}$, com pico de difração de maior intensidade a 29․ Os picos de difração relacionados aos óxidos de érbio, lutécio e disprósio 
sobrepostos pelos picos da ítria devido à similaridade das distâncias entre os planos de difração destes materiais.

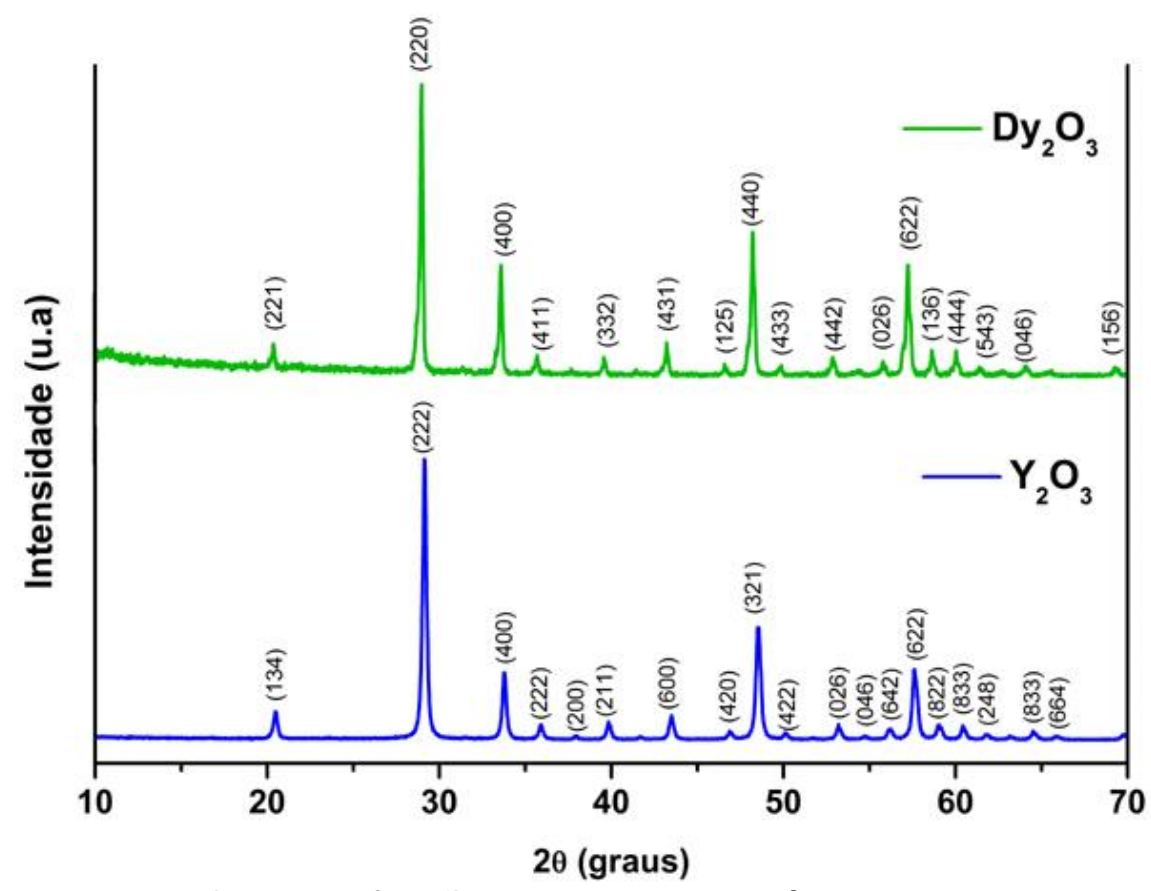

FIGURA 39 - Padrões de difração de raios $\mathrm{X}$ dos óxidos de terras raras $\mathrm{Y}_{2} \mathrm{O}_{3}$ e $\mathrm{Dy}_{2} \mathrm{O}_{3}$.

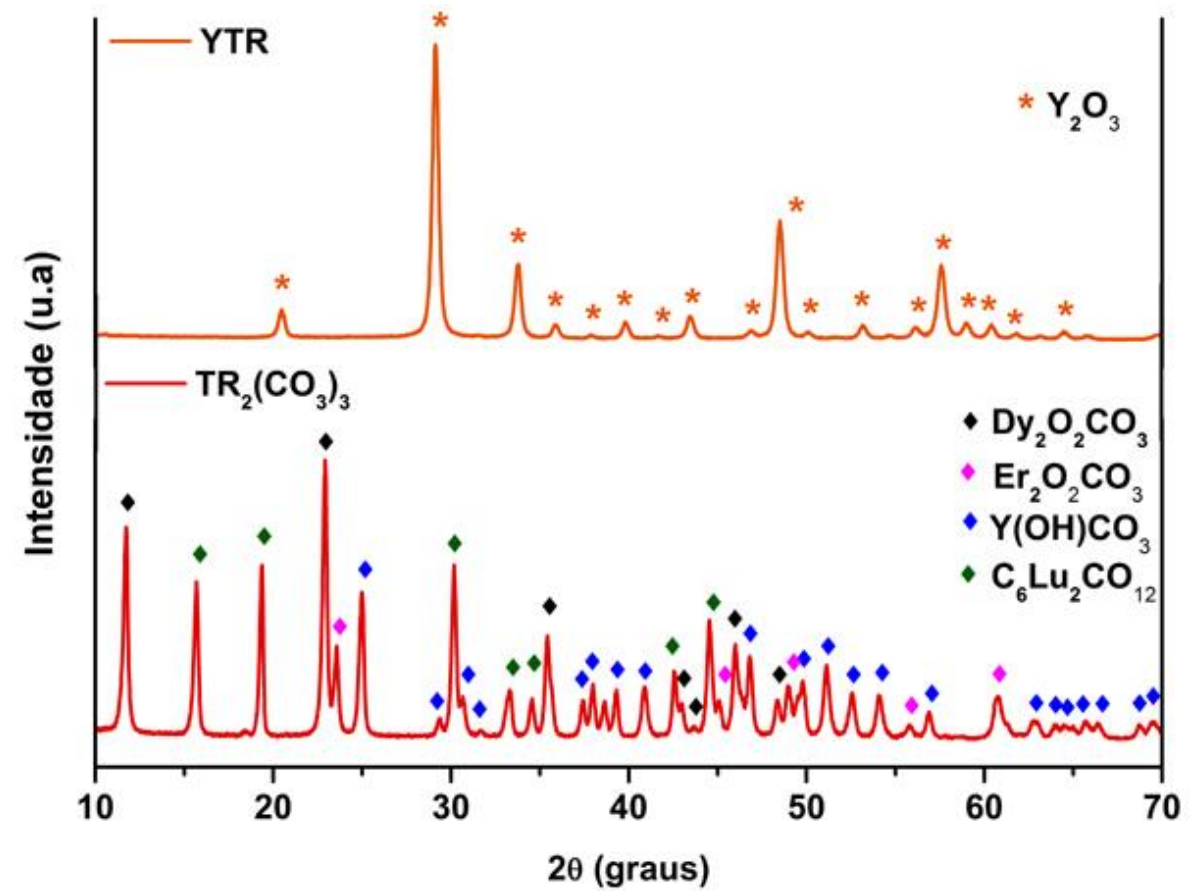

FIGURA 40 - Padrões de difração de raios $X$ do carbonato de terras raras $\mathrm{TR}_{2}\left(\mathrm{CO}_{3}\right)_{3}$ e concentrado de terras raras YTR. 
Na FIG. 41 apresentam-se as micrografias dos pós de $\mathrm{Y}_{2} \mathrm{O}_{3}, \mathrm{Dy}_{2} \mathrm{O}_{3} \mathrm{e}$ YTR obtidas por Microscopia Eletrônica de Varredura (MEV). Pelas micrografias correspondentes às amostras de $\mathrm{Y}_{2} \mathrm{O}_{3}$ (FIG. 41 a) e $\mathrm{Dy}_{2} \mathrm{O}_{3}$ (FIG. 41b), verifica-se que os pós constituem-se de aglomerados em formato de placas com tamanho superior a $2 \mu \mathrm{m}$. Quanto aos pós de YTR (FIG. 41c), nota-se que os aglomerados de partículas mostram-se na forma de flocos aciculares de tamanho superior a $3 \mu \mathrm{m}$.
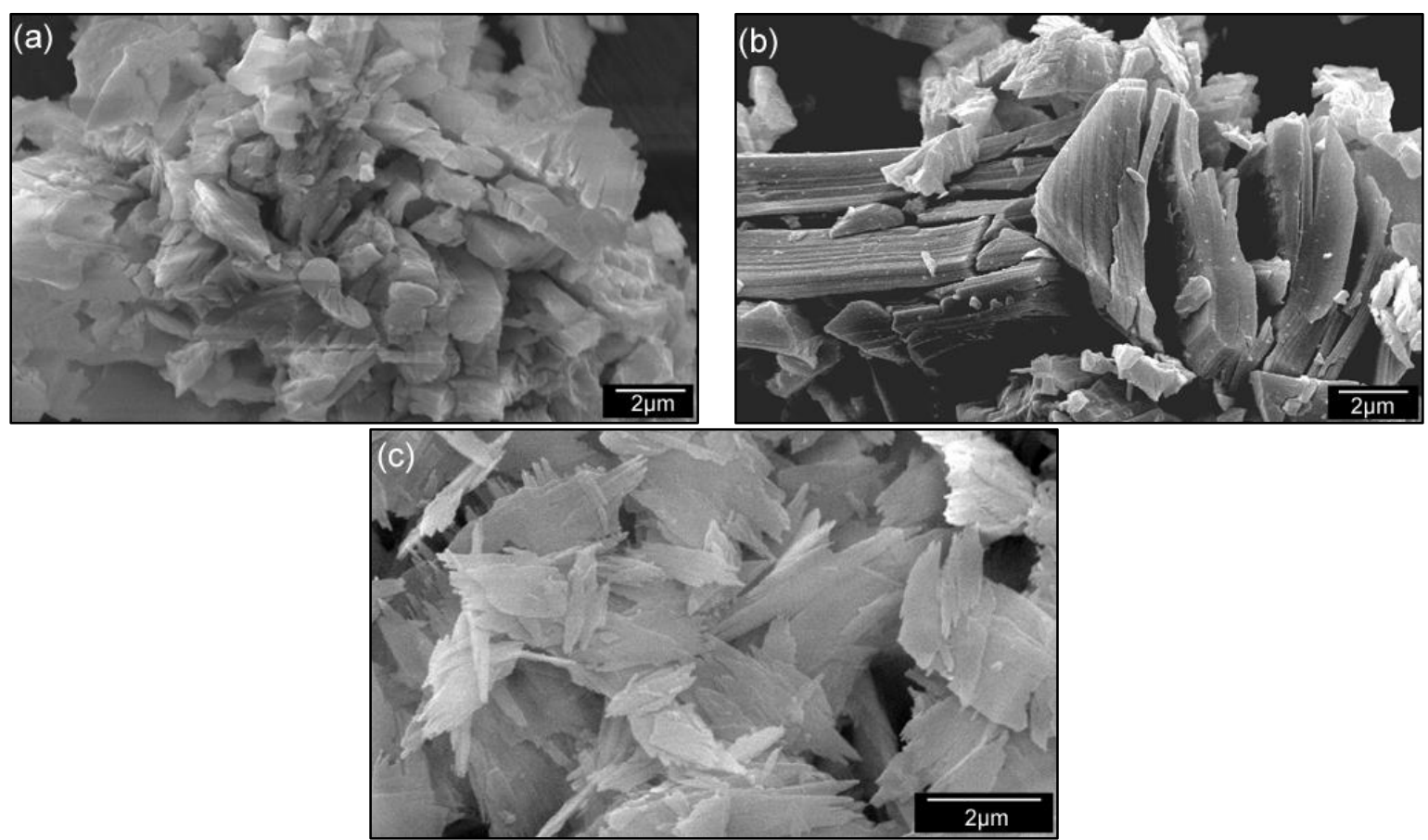

FIGURA 41 - Micrografias dos materiais de partida em pó. Em (a) $\mathrm{Y}_{2} \mathrm{O}_{3}$, (b) $\mathrm{Dy}_{2} \mathrm{O}_{3}$ e (c) YTR obtidas por MEV.

$\mathrm{Na}$ TAB. 7 estão relacionados os resultados de Fluorescência de raios $X$ das amostras $\mathrm{Y}_{2} \mathrm{O}_{3}, \mathrm{Dy}_{2} \mathrm{O}_{3}$ e $\mathrm{YTR}$. $A$ amostra $\mathrm{Y}_{2} \mathrm{O}_{3}$ apresentou 98,7\% $\pm 0,1$ de ítria $\left(\mathrm{Y}_{2} \mathrm{O}_{3}\right)$. A soma das principais impurezas identificadas correspondeu a $1,3 \%$ $\pm 0,1$. Pelo resultado da amostra $\mathrm{Dy}_{2} \mathrm{O}_{3}$, verifica-se que o material apresentou $98,4 \% \pm 0,1$ de óxido de disprósio, onde as demais impurezas corresponderam a $1,6 \% \pm 0,1$. Para o YTR ${ }^{[163]}$, observa-se que a amostra é composta de uma mistura de óxidos de terras raras, onde os majoritários são: $\mathrm{Y}_{2} \mathrm{O}_{3}(56,6 \% \pm 0,1)$ e $\mathrm{Dy}_{2} \mathrm{O}_{3}(19,4 \% \pm 0,5)$. Outros óxidos de menor composição são: $\mathrm{Er}_{2} \mathrm{O}_{3}(6,5 \% \pm$ $0,1), \mathrm{Lu}_{2} \mathrm{O}_{3}(4,1 \% \pm 0,4), \mathrm{Ho}_{2} \mathrm{O}_{3}(3,1 \% \pm 0,1)$ e $\mathrm{Yb}_{2} \mathrm{O}_{3}(2,0 \% \pm 0,2)$. Outros componentes identificados em menores proporções totalizam 8,3\% $\pm 0,1$. 
Devido aos seus constituintes, em particular a considerável concentração de $\mathrm{Y}_{2} \mathrm{O}_{3}(56,6 \% \pm 0,1)$, o YTR mostra-se como potencial insumo para aplicações ópticas. Reporta-se na literatura que a ítria dopada com outros elementos terras raras $\left(\mathrm{Y}_{2} \mathrm{O}_{3}: \mathrm{TR}\right)$ exibe características luminescentes consideráveis. GOLDBURT et al.. ${ }^{[122]}$ mostraram que a eficiência luminosa da ítria dopada com térbio $\left(\mathrm{Y}_{2} \mathrm{O}_{3}: \mathrm{Tb}^{3+}\right)$ é $40 \%$ maior que a do material $\mathrm{LaOBr}: \mathrm{Tb}^{3+}$, apresentando emissão de luz visível no comprimento de onda de 550nm (luz verde). RAUKAS et.al ${ }^{[229]}$ verificaram que a ítria dopada com cério $\left(\mathrm{Y}_{2} \mathrm{O}_{3}: \mathrm{Ce}^{3+}\right)$ apresenta luminescência no comprimento de onda entre 350-550nm (luz branca).

TABELA 7 - Resultados de Fluorescência de raios $X$ das amostras $\mathrm{Y}_{2} \mathrm{O}_{3}, \mathrm{Dy}_{2} \mathrm{O}_{3}$ e YTR

\begin{tabular}{cccccc}
\hline \multicolumn{2}{c}{$\mathrm{Y}_{2} \mathrm{O}_{3}$} & \multicolumn{2}{c}{$\mathrm{Dy}_{2} \mathrm{O}_{3}$} & \multicolumn{2}{c}{ YTR } \\
\hline Substância & \%massa & Substância & \%massa & Substância & $\%$ massa \\
\hline $\mathrm{Y}_{2} \mathrm{O}_{3}$ & $98,7 \pm 0,1$ & $\mathrm{Dy}_{2} \mathrm{O}_{3}$ & $99,4 \pm 0,1$ & $\mathrm{Y}_{2} \mathrm{O}_{3}$ & $56,6 \pm 0,1$ \\
$\mathrm{SO}_{3}$ & $1,2 \pm 0,1$ & $\mathrm{Fe}_{2} \mathrm{O}_{3}$ & $0,6 \pm 0,1$ & $\mathrm{Dy}_{2} \mathrm{O}_{3}$ & $19,4 \pm 0,5$ \\
$\mathrm{Fe}_{2} \mathrm{O}_{3}$ & $0,09 \pm 0,1$ & & & $\mathrm{Er}_{2} \mathrm{O}_{3}$ & $6,5 \pm 0,1$ \\
$\mathrm{CuO}$ & $0,03 \pm 0,01$ & & $\mathrm{Lu}_{2} \mathrm{O}_{3}$ & $4,1 \pm 0,4$ \\
& & & $\mathrm{Ho}_{2} \mathrm{O}_{3}$ & $3,1 \pm 0,1$ \\
& & & & $\mathrm{Yb}_{2} \mathrm{O}_{3}$ & $2,0 \pm 0,2$ \\
& & & $\mathrm{Outros}$ & $8,3 \pm 0,1$ \\
\hline
\end{tabular}

Outros: $\mathrm{Gd}_{2} \mathrm{O}_{3} ; \mathrm{Tm}_{2} \mathrm{O}_{3} ; \mathrm{CeO}_{2} ; \mathrm{Nd}_{2} \mathrm{O}_{3}$ e $\mathrm{ThO}_{2}$

Outros resultados de caracterização das amostras $\mathrm{Y}_{2} \mathrm{O}_{3}, \mathrm{Dy}_{2} \mathrm{O}_{3}$ e YTR estão relacionados na TAB. 8. Os óxidos $\mathrm{Y}_{2} \mathrm{O}_{3}$ e $\mathrm{Dy}_{2} \mathrm{O}_{3}$ apresentaram valores de área de superfície específica (SSA) muito próximos, $6,4 \mathrm{~m}^{2} \cdot \mathrm{g}^{-1}$ e $6,8 \mathrm{~m}^{2} \cdot \mathrm{g}^{-1}$ respectivamente. Para a amostra de YTR, esse valor foi aproximadamente três vezes maior, $20,5 \mathrm{~m}^{2} \cdot \mathrm{g}^{-1}$. Possivelmente, essa diferença está associada a condição de tratamento térmico para obtenção dos pós.

Com relação ao diâmetro médio de partícula $\left(d_{50}\right)$ determinado pela técnica de Espectroscopia de Correlação de Fótons - PCS (TAB. 8), verificou-se que todas as amostras apresentaram valores de diâmetro médio $\left(d_{50}\right)$ em escala nanométrica $\left(d_{50}<1000 \mathrm{~nm}\right)$, onde $\mathrm{Y}_{2} \mathrm{O}_{3} d_{50}=304 \mathrm{~nm}, \mathrm{Dy}_{2} \mathrm{O}_{3} d_{50}=389 \mathrm{~nm}$ e YTR $d_{50}=723 \mathrm{~nm}$. Observa-se também uma diferença entre os valores de $d_{50}$ e $d_{\text {BET }}$ 
para todas as amostras avaliadas. Esta distinção indica que pela técnica de PCS foram determinados os $d_{50}$ de aglomerados de partículas muito menores que aqueles observados por MEV (FIG. 41). Pela determinação do fator de aglomeração das partículas, verifica-se que a amostra de $\mathrm{Y}_{2} \mathrm{O}_{3}$ apresentou 0 menor valor de Fag dentre as três amostras, $F a g=1,61$. Isto indica que $0 d_{50}$ determinado por PCS é próximo da dimensão da partícula unitária (Fag=1). Para a amostra de $\mathrm{Dy}_{2} \mathrm{O}_{3}$, este valor foi um pouco maior, $\mathrm{Fag}=3,45$. A condição de aglomeração de partículas mais significativa foi determinada para a amostra de YTR, com Fag=14,85. Provavelmente, este estado de aglomeração é favorecido pela morfologia acicular das partículas, pelo tratamento térmico e pela $S_{M}$ dos pós.

TABELA 8 - Resultados de caracterização dos pós de $\mathrm{Y}_{2} \mathrm{O}_{3}, \mathrm{Dy}_{2} \mathrm{O}_{3}$ e YTR

\begin{tabular}{lccc}
\hline Características & $\mathbf{Y}_{\mathbf{2}} \mathbf{O}_{3}$ & $\mathbf{D y}_{\mathbf{2}} \mathbf{O}_{3}$ & YTR \\
\hline $\mathrm{S}_{\mathrm{M}}\left(\mathrm{m}^{2} \cdot \mathrm{g}^{-1}\right)$ & 6,4 & 6,8 & 20,5 \\
$\rho\left(\mathrm{g} \cdot \mathrm{cm}^{-3}\right)$ & 4,84 & 7,75 & 6,03 \\
$\rho_{\mathrm{T}}\left(\mathrm{g} \cdot \mathrm{cm}^{-3}\right)$ & 5,01 & 7,81 & - \\
$\mathrm{d}_{\mathrm{BET}}(\mathrm{nm})$ & 190,0 & 113,0 & 48,7 \\
$\mathrm{~d}_{50}(\mathrm{~nm})$ & 304,0 & 389,3 & 723,0 \\
$\mathrm{~F}_{\mathrm{ag}}$ & 1,61 & 3,45 & 14,85 \\
\hline
\end{tabular}

$\mathrm{S}_{\mathrm{M}}$ : área de superfície específica; $\rho$ : densidade picnométrica; $\rho_{\mathrm{T}}$ : densidade teórica; $\mathrm{d}_{\mathrm{BET}}$ : diâmetro médio de partícula teórico; $\mathrm{d}_{50}$ : diâmetro médio de partícula por PCS; Fag: fator de aglomeração; (-) não se considera.

\subsection{Síntese e caracterização do dissilicato de ítrio $\left(\mathrm{Y}_{2} \mathrm{Si}_{2} \mathrm{O}_{7}\right)$}

O Brasil importa grande parte dos compostos de terras raras, como a ítria $\left(\mathrm{Y}_{2} \mathrm{O}_{3}\right)$. $\mathrm{O}$ custo dos produtos à base deste material é alto, o que desestimula economicamente o desenvolvimento de novos componentes nacionais. Portanto, este trabalho tem como objetivo diminuir a concentração de ítrio presente na composição de materiais para queimadores de gás para iluminação, a partir do uso do dissilicato de ítrio $\left(\mathrm{Y}_{2} \mathrm{Si}_{2} \mathrm{O}_{7}\right)$.

$\mathrm{Na}$ FIG. 42 são apresentados os resultados de análise termogravimétrica (ATG) e termo diferencial (ATD) do precursor de dissilicato de ítrio (PDY) tratado até $1400^{\circ} \mathrm{C}$ em atmosfera ambiente. Pela ATG acompanha-se 
a perda de massa do PDY em função da temperatura e do tempo, onde nota-se uma perda de massa significativa de $20 \%$ até a temperatura de $400^{\circ} \mathrm{C}$ em virtude da eliminação de água estrutural do precursor. A partir desta temperatura, a decomposição foi menos acentuada até $1000^{\circ} \mathrm{C}$ devido à eliminação do nitrato. Desta temperatura até a tempetarura limite do ensaio $\left(1400^{\circ} \mathrm{C}\right)$, não se observa perda de massa. A perda total de massa do PDY foi de $25 \%$.

Pela ATD (FIG. 42), pode-se acompanhar os fenômenos de formação do composto desejado. No caso das transformações de fase conhecidas para o $\mathrm{Y}_{2} \mathrm{Si}_{2} \mathrm{O}_{7}$, até o presente momento, as pesquisas realizadas ainda não mostraram um concenso quanto à exatidão destas temperaturas. Têm-se associado as rotas de síntese e composição dos materiais de partida como condicionantes para essas transformações. Pela ATD (FIG. 42), observou-se que as temperaturas de transformação de fase estão próximas às reportadas na literatura ${ }^{[138]}$. Nota-se um pico endotérmico referente à perda de água a $100^{\circ} \mathrm{C}$. Os picos que indicam a mudança da fase e temperatura máxima de cristalização do composto foram identificados como: $\alpha\left(990^{\circ} \mathrm{C}\right) \rightarrow \gamma\left(1044^{\circ} \mathrm{C}\right.$ e $\left.1100^{\circ} \mathrm{C}\right) \rightarrow \delta\left(1200^{\circ} \mathrm{C}\right) \rightarrow \gamma\left(1300^{\circ} \mathrm{C}\right)$.

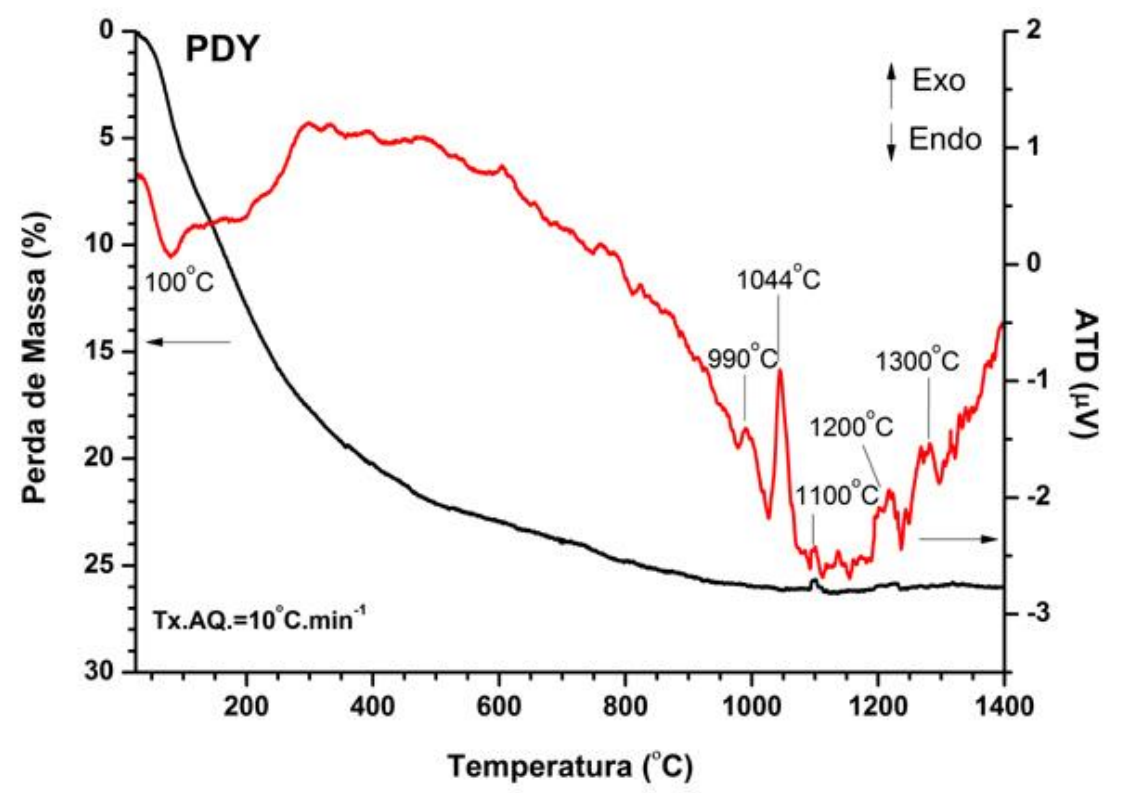

FIGURA 42 - Análise termogravimétrica e termo diferencial do PDY tratado a $10^{\circ} \mathrm{C} \cdot \mathrm{min}^{-1}$ até $1400^{\circ} \mathrm{C}$ em atmosfera ambiente.

A temperatura de formação e estabilidade dos diferentes poliformos do $\mathrm{Y}_{2} \mathrm{Si}_{2} \mathrm{O}_{7}$ varia consideravelmente entre os autores ${ }^{[133,134,138,230-232]}$. KEPÍNSKI et 
al. ${ }^{[233]}$ obtiveram o $\alpha-\mathrm{Y}_{2} \mathrm{Si}_{2} \mathrm{O}_{7}$ e $\mathrm{Y}-\mathrm{Y}_{2} \mathrm{Si}_{2} \mathrm{O}_{7}$ via síntese sol-gel e tratamento térmico respectivamente a $1000^{\circ} \mathrm{C}$ e $1200^{\circ} \mathrm{C}$ em atmosfera ambiente. Por esta mesma rota de síntese, MOYA et al. ${ }^{[135]}$ sintetizaram o $\alpha-\mathrm{Y}_{2} \mathrm{Si}_{2} \mathrm{O}_{7}$ a $1065^{\circ} \mathrm{C}$ por $2 \mathrm{~h}$. SUN, et al. ${ }^{[234]}$ obtiveram o $\mathrm{y}-\mathrm{Y}_{2} \mathrm{Si}_{2} \mathrm{O}_{7}$ por mistura dos óxidos de $\mathrm{SiO}_{2}$ e $\mathrm{Y}_{2} \mathrm{O}_{3}$ com tratamento térmico de $1400^{\circ} \mathrm{C}$ por $4 \mathrm{~h}$ em atmosfera ambiente. DIAZ et al. ${ }^{[138]}$ sintetizaram o $\beta-\mathrm{Y}_{2} \mathrm{Si}_{2} \mathrm{O}_{7}$ via processo hidrotermal e tratamento térmico de $1400^{\circ} \mathrm{C}$ por $2 h$.

Os resultados de difração de raios $\mathrm{X}$ das amostras do precursor tratadas por duas horas nas temperaturas próximas às das tranformações de fase observadas no ensaio de ATD são apresentados na FIG. 43. Observa-se que o precursor tratado a $900^{\circ} \mathrm{C}$ apresenta carater amorfo e um pequeno ordenamento a curto alcance a $30^{\circ}(2 \theta)$. Nesta temperatura possivelmente pode se ter pequenos cristalitos deste material em dimensões tais de dificil indexação pela difração de raios $X$ nas condições analizadas. Para as amostras tratadas a partir de $975^{\circ} \mathrm{C}$, nota-se mais claramente a formação do dissilicato de ítrio cristalino, neste caso indexado como $\alpha-\mathrm{Y}_{2} \mathrm{Si}_{2} \mathrm{O}_{7}$ (PDF. 38233), exibindo também picos indicativos da fase $\mathrm{Y}$ (PDF. 741944), com pico de maior intensidade a $29^{\circ}$. Este resultado indica a complexidade de obter este composto monofásico.

Para as amostras tratadas a $1000^{\circ} \mathrm{C}$ e $1100^{\circ} \mathrm{C}$ (FIG. 43), nota-se o desenvolvimento do $\gamma-\mathrm{Y}_{2} \mathrm{Si}_{2} \mathrm{O}_{7}$ (PDF. 741944), exibindo ainda alguns picos correspondentes da fase a (PDF. 38233). A $1200^{\circ} \mathrm{C}$, verifica-se a formação do $y-Y_{2} \mathrm{Si}_{2} \mathrm{O}_{7}$ (PDF.38440), entretanto, nesta temperatura nota-se também que outras fases também podem coexistir, como $\alpha$ (PDF. 38233), $\beta$ (PDF. 21-1454), $\gamma$ (PDF. 741944) e $\delta$ (PDF. 42168). O precursor tratado na temperatura de $1300^{\circ} \mathrm{C}$, resultou na formação do $\delta-\mathrm{Y}_{2} \mathrm{Si}_{2} \mathrm{O}_{7}$ (PDF.42168), onde nesta condição verifica-se também a presença das fases $\beta$ e y.

Baseado nestes resultados, verifica-se que a formação do $\mathrm{Y}_{2} \mathrm{Si}_{2} \mathrm{O}_{7}$ ocorreu conforme a classificação proposta por ITO et al. ${ }^{[126]}$. A coerência das transfomações de fase indica que realmente a rota escolhida para obtenção do dissilicato de ítrio permite obter um matrial com boa precisão estequimétrica e com fase cristalina bem definida. $O$ acompanhamento da formação destas fases tem como objetivo determinar com precisão a condição de temperatura e tempo 
para obter o $\beta-\mathrm{Y}_{2} \mathrm{Si}_{2} \mathrm{O}_{7}$ que é a fase reportada com melhor desempenho luminescente ${ }^{[138]}$.

Na TAB. 9 são apresentados os resultados de caracterização dos pós $\mathrm{Y}_{2} \mathrm{Si}_{2} \mathrm{O}_{7}$ obtidos por tratamento térmico até $1500^{\circ} \mathrm{C}$. Das cinco fases determinadas, três apresentaram densidade real muito próxima à densidade teórica, sendo o menor valor para a fase a $4,16 \mathrm{~g} . \mathrm{cm}^{-3}(96 \%)$. As fases com predominância $\gamma, \beta$ e $\delta$ apresentaram valores de densidade real idêntica à teórica $4,04 \mathrm{~g} \cdot \mathrm{cm}^{-3}(100 \%)$. O diâmetro médio das partículas $\left(d_{50}\right)$ aumentou em função da temperatura de tratamento térmico, de $65 \mathrm{~nm}$ da fase $\alpha\left(975^{\circ} \mathrm{C}\right)$ para $245,8 \mathrm{~nm}$ da fase $\beta\left(1500^{\circ} \mathrm{C}\right)$. Efeito inverso foi observado para os valores da área de superfície específica, onde o maior valor foi de $128,7 \mathrm{~m}^{2} \cdot \mathrm{g}^{-1}$ para a fase $\alpha$ e o menor de $4,8 \mathrm{~m}^{2} \cdot \mathrm{g}^{-1}$ para aqueles da fase $\beta$. O diâmetro médio teórico determinado para as partículas de $\beta-\mathrm{Y}_{2} \mathrm{Si}_{2} \mathrm{O}_{7}$ é próximo aquele observado na micrografia por MEV (FIG. 44), em torno de 150nm. As partículas de $\alpha-\mathrm{Y}_{2} \mathrm{Si}_{2} \mathrm{O}_{7} \mathrm{e}$ $\mathrm{Y}-\mathrm{Y}_{2} \mathrm{Si}_{2} \mathrm{O}_{7}$ por serem mais reativas, mostraram-se mais aglomeradas com $\mathrm{Fag}=5,9$ e Fag=6,2. Essa variação nos valores tanto de $d_{50}$ como também de área de superfície específica em função da temperatura estão associados às transformações de fase e coalescência das partículas.

TABELA 9 - Resultados de caracterização dos pós de $\mathrm{Y}_{2} \mathrm{Si}_{2} \mathrm{O}_{7}$ tratados termicamente até $1500^{\circ} \mathrm{C}$

\begin{tabular}{|c|c|c|c|c|c|c|}
\hline F. Pred & $\begin{array}{c}\alpha \\
\left(975^{\circ} \mathrm{C}\right)\end{array}$ & $\begin{array}{c}\gamma \\
\left(1000^{\circ} \mathrm{C}\right)\end{array}$ & $\begin{array}{c}\delta \\
\left(1200^{\circ} \mathrm{C}\right)\end{array}$ & $\begin{array}{c}y \\
\left(1300^{\circ} \mathrm{C}\right)\end{array}$ & $\begin{array}{c}\beta \\
\left(1400^{\circ} \mathrm{C}\right)\end{array}$ & $\begin{array}{c}\beta \\
\left(1500^{\circ} \mathrm{C}\right)\end{array}$ \\
\hline $\mathrm{d}_{\mathrm{T}}\left(\mathrm{g} \cdot \mathrm{cm}^{-3}\right)$ & 4,16 & 4,04 & 4,06 & 4,04 & 4,04 & 4,04 \\
\hline$\rho\left(\mathrm{g} . \mathrm{cm}^{-3}\right)$ & 4,30 & 4,04 & 4,11 & 4,04 & 4,03 & 4,03 \\
\hline $\mathrm{d}_{\mathrm{BET}}(\mathrm{nm})$ & 11,0 & 16,0 & 35,0 & 41,0 & 140,2 & 308,1 \\
\hline $\mathrm{d}_{50}(\mathrm{~nm})$ & 65,0 & 97,0 & 122,0 & 166,0 & 185,0 & 245,8 \\
\hline$S_{M}\left(m^{2} \cdot g^{-1}\right)$ & 128,7 & 95,3 & 42,4 & 36,7 & 10,6 & 4,8 \\
\hline $\mathrm{F}_{\mathrm{ag}}$ & 5,9 & 6,2 & 3,5 & 4,1 & 1,3 & 1,2 \\
\hline
\end{tabular}

F. Pred: fase predominante; $d_{\mathrm{T}}$ : densidade teórica $\rho$ : densidade picnométrica; $\mathrm{d}_{50}$ :diâmetro médio de partícula por PCS; $\mathrm{d}_{\mathrm{BET}}$ : diâmetro médio de partícula teórico; $\mathrm{S}_{\mathrm{M}}$ : área de superfície específica; $\mathrm{F}_{\mathrm{ag}}$ : Fator de aglomeração. 


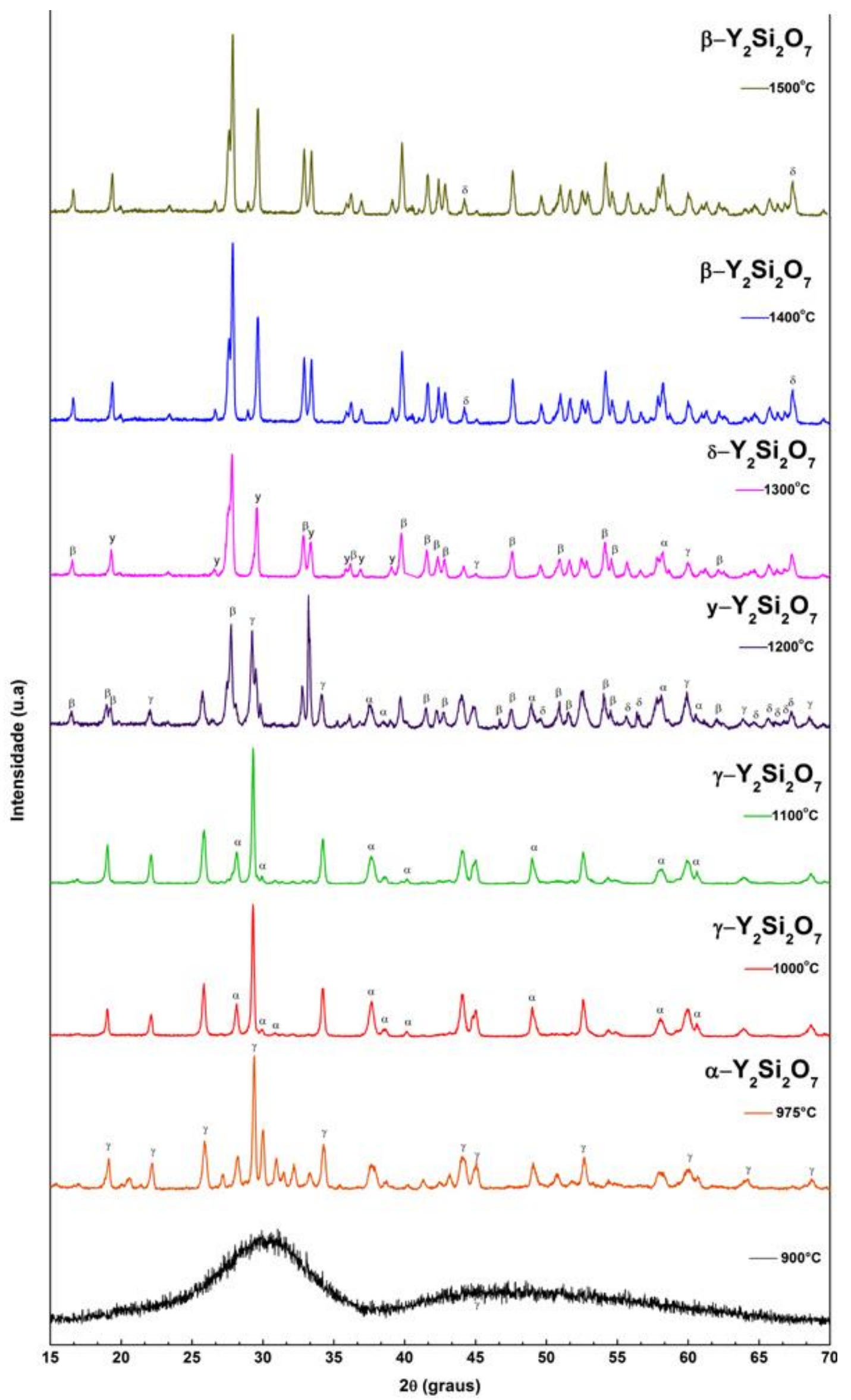

FIGURA 43 - Padrões de difração de raios $X$ das amostras do precursor de $\mathrm{Y}_{2} \mathrm{Si}_{2} \mathrm{O}_{7}$ tratadas até $1500^{\circ} \mathrm{C}$ por $2 \mathrm{~h}$ em atmosfera ambiente. 

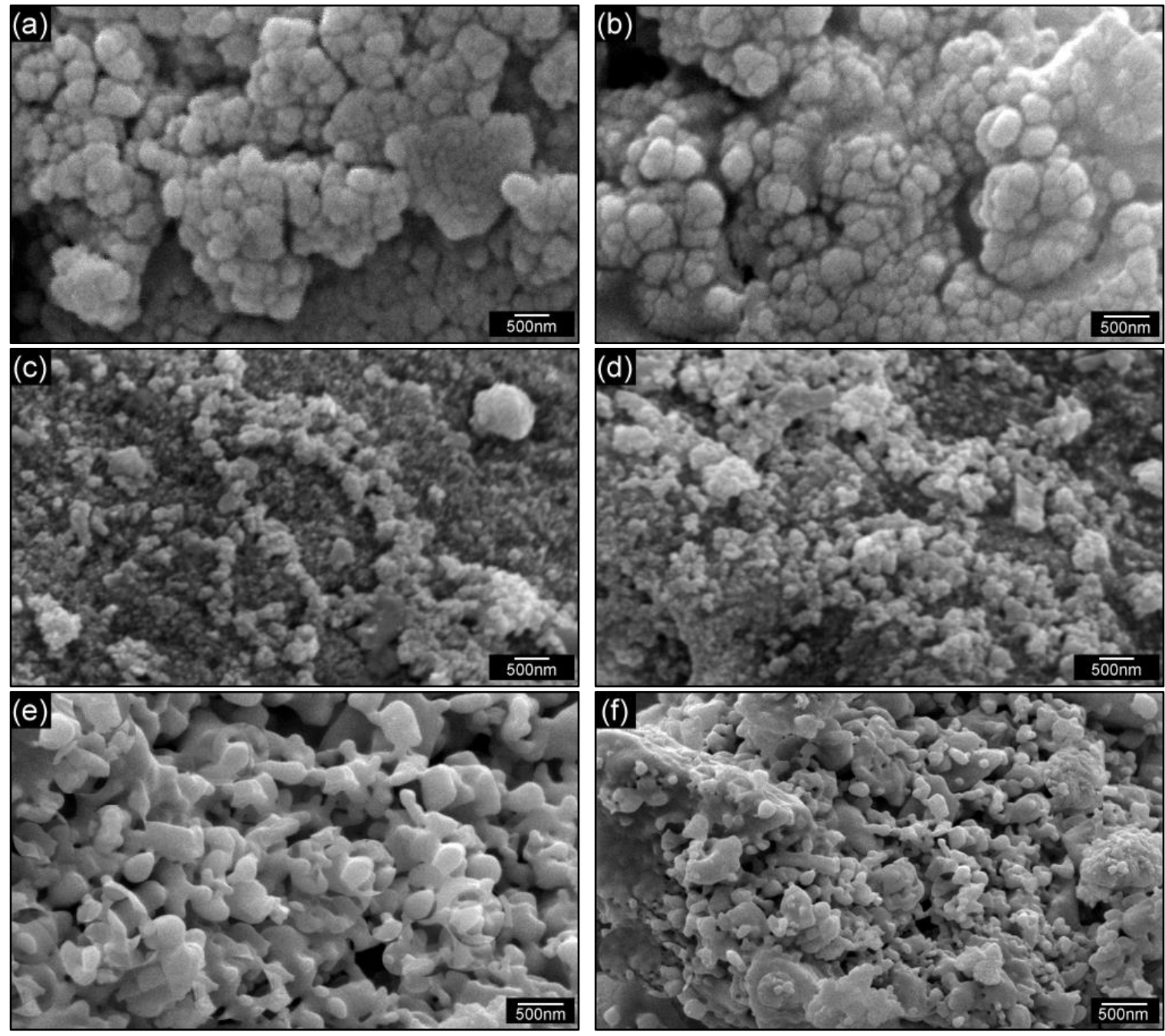

FIGURA 44 - Micrografias obtidas por MEV dos pós de $\mathrm{Y}_{2} \mathrm{Si}_{2} \mathrm{O}_{7}$ tratados por $2 \mathrm{~h}$ em atmosfera ambiente a (a) $975^{\circ} \mathrm{C}$; (b) $1000^{\circ} \mathrm{C}$; (c) $1200^{\circ} \mathrm{C}$; (d) $1300^{\circ} \mathrm{C}$; (e) $1400^{\circ} \mathrm{C}$ e (f) $1500^{\circ} \mathrm{C}$.

\subsubsection{Caracterização do dissilicato de ítrio dopado com disprósio}

Comparando-se os padrões de difração de raios $X$ das amostras $\beta-Y_{2} \mathrm{Si}_{2} \mathrm{O}_{7}$ e $\beta-\mathrm{Y}_{1,95} \mathrm{Dy}_{0,05} \mathrm{Si}_{2} \mathrm{O}_{7}$ obtidas a $1400^{\circ} \mathrm{C}$ por 2 horas (FIG. 45), verifica-se que a presença do $\mathrm{Dy}^{3+}$ na estrutura do dissilicato resultou em alargamento do

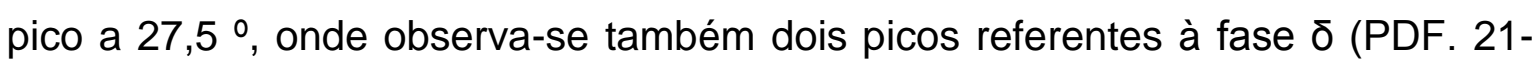
$1460)^{[235]}$ nas distâncias angulares de $28,70^{\circ}$ e $29,37^{\circ}$ respectivamente. 


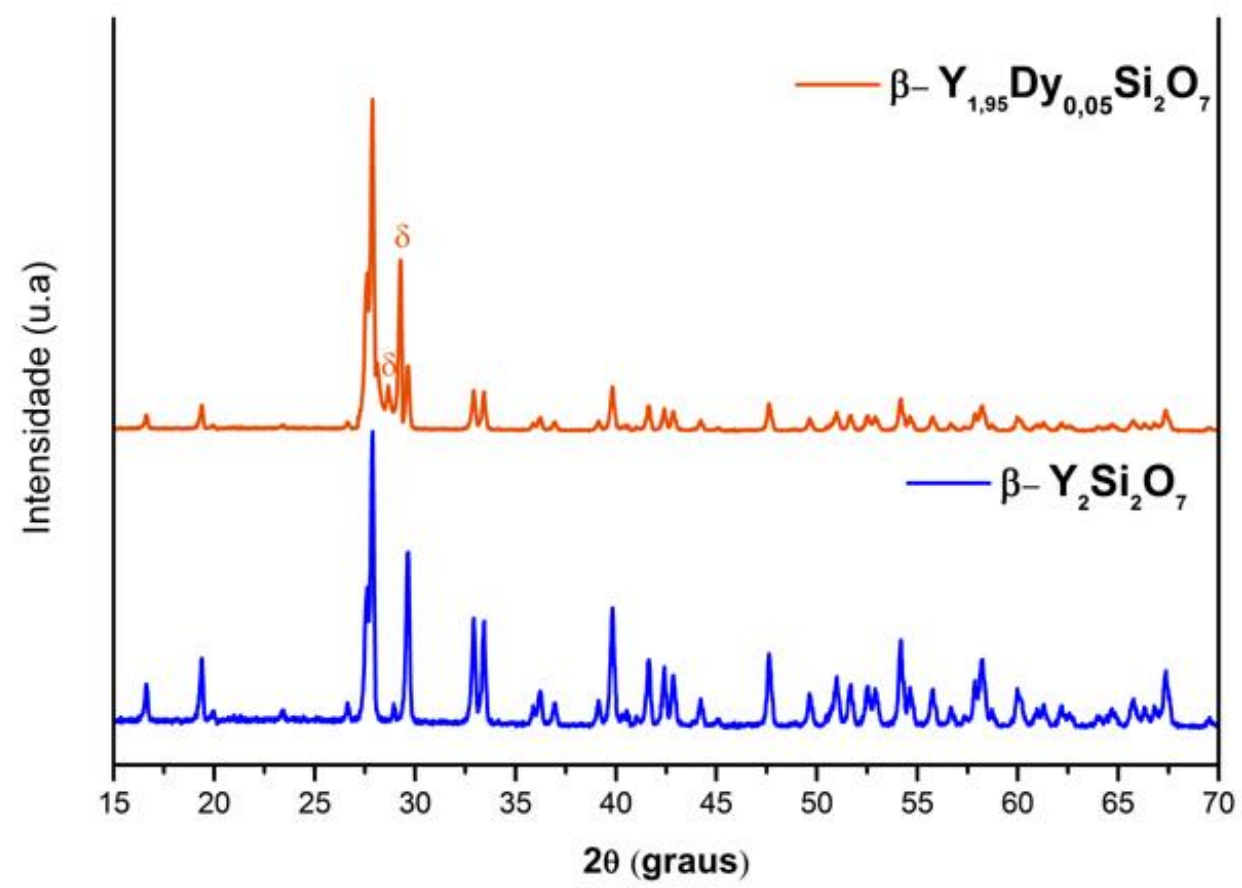

FIGURA 45 - Padrões de difração de raios $X$ das amostras $\beta-Y_{2} \mathrm{Si}_{2} \mathrm{O}_{7}$ e $\beta-Y_{1,95} \mathrm{Dy}_{0,05} \mathrm{Si}_{2} \mathrm{O}_{7}$ obtidas por tratamento térmico a $1400^{\circ} \mathrm{C}$ por $2 \mathrm{~h}$ em atmosfera ambiente.

As curvas de distribuição granulométrica de partículas de $\beta-\mathrm{Y}_{2} \mathrm{Si}_{2} \mathrm{O}_{7} \mathrm{e}$ $\beta-Y_{1,95} \mathrm{Dy}_{0,05} \mathrm{Si}_{2} \mathrm{O}_{7}$ por PCS estão representadas na FIG. 46. Os pós de $\beta$ - $\beta$ $\mathrm{Y}_{1,95} \mathrm{Dy}_{0,05} \mathrm{Si}_{2} \mathrm{O}_{7}$ (curva vermelha) apresentaram $d_{50}=242 \mathrm{~nm}$ e distribuição granulométrica monodispersa, onde a diferença entre os valores de $d_{10}, d_{50}$ e $d_{90}$ foi inferior a $50 \mathrm{~nm}$. A mesma condição foi observada para a amostra $\beta-\mathrm{Y}_{2} \mathrm{Si}_{2} \mathrm{O}_{7}$, sendo $d_{50}=185 \mathrm{~nm}$ e a variação entre as distribuições $d_{10}$, $d_{50 \text { e }} d_{90}$ foi ainda menor, $10 \mathrm{~nm}$.

Pelos resultados apresentados na FIG. 46 verifica-se que o processo hidrotermal utilizado neste trabalho possibilita se obter pós cerâmicos em escala nanométrica e com estreita distribuição de tamanho de partículas. Estudos recentes reportam que 0 tamanho das partículas pode influenciar na luminescência dos materiais à base de terras raras. WANG et al ${ }^{[84]}$ verificaram que a eficiência luminosa do composto $\mathrm{Y}_{2} \mathrm{O}_{3}: \mathrm{Eu}^{3+}$ aumenta em função do tamanho da partícula. Partículas com o diâmetro de 500nm apresentaram emissão de luz $80 \%$ maior se comparadas àquelas de $200 \mathrm{~nm}$. ZHANG et al. ${ }^{[79]}$ reportaram que há um aumento significativo na emissão de luz do composto $\mathrm{Y}_{2} \mathrm{O}_{3}: \mathrm{Eu}^{3+}$ quando constituído de nanopartículas. GOLDBURTA et al. ${ }^{[122]}$ 
observaram que a eficiência luminosa do composto $\mathrm{Y}_{2} \mathrm{O}_{3}: \mathrm{Tb}$ aumentou devido a diminuição do diâmetro de partícula de 100 para $10 \AA$.

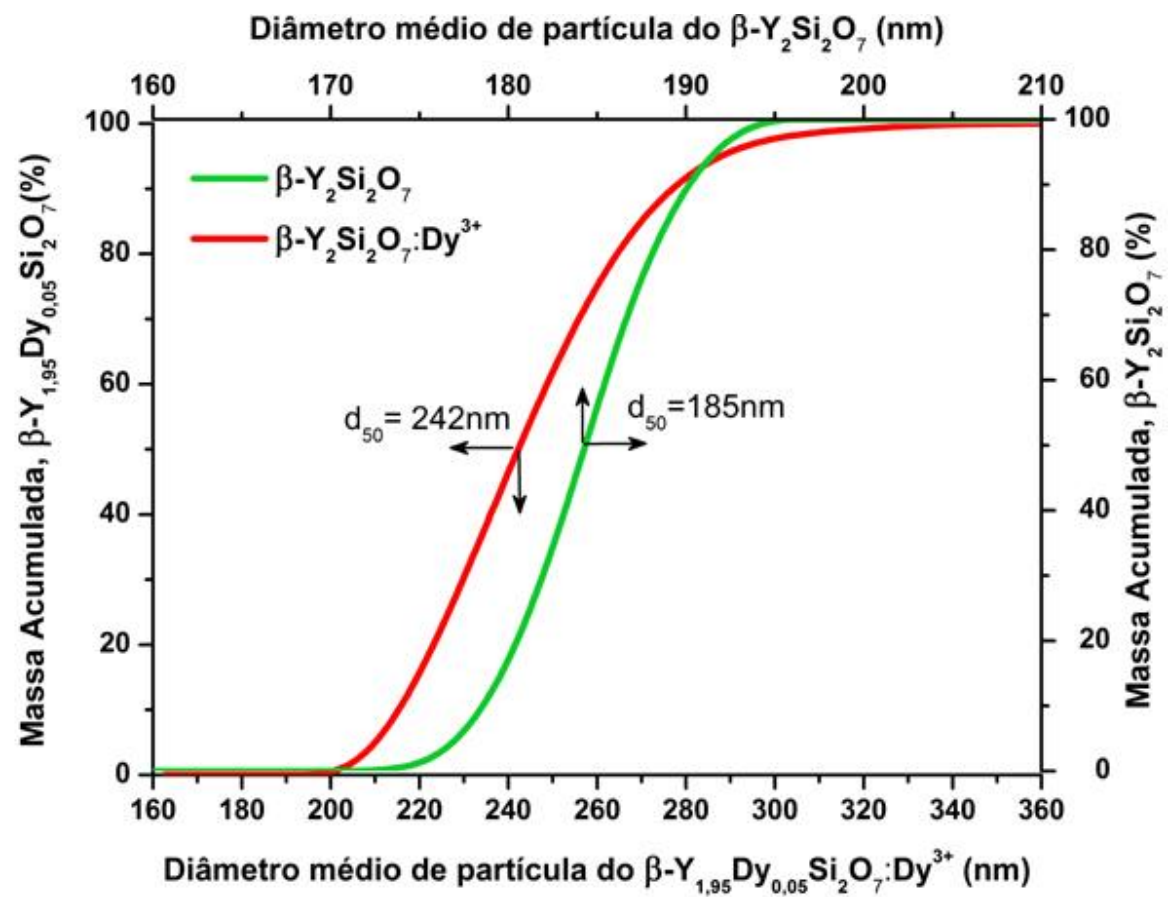

FIGURA 46 - Curvas de distribuição granulométrica de partículas das amostras $\beta-Y_{2} \mathrm{Si}_{2} \mathrm{O}_{7}$ e $\beta-\mathrm{Y}_{1,95} \mathrm{Dy}_{0,05} \mathrm{Si}_{2} \mathrm{O}_{7}$ por PCS, obtidas por tratamento térmico a $1400^{\circ} \mathrm{C}$ por duas horas em atmosfera ambiente.

As micrografias dos pós de $\beta-\mathrm{Y}_{2} \mathrm{Si}_{2} \mathrm{O}_{7}$ e $\beta-\mathrm{Y}_{1,95} \mathrm{Dy}_{0,05} \mathrm{Si}_{2} \mathrm{O}_{7}$ obtidas por MEV são apresentadas na FIG. 47. Para ambas as amostras, observa-se que os pós são constituídos de aglomerados de partículas com tamanho inferior a $1 \mu \mathrm{m}$. Verifica-se também que a amostra $\beta-\mathrm{Y}_{2} \mathrm{Si}_{2} \mathrm{O}_{7}$ é formada por aglomerados de partículas mais coesos e com distribuição de tamanho e forma de partículas mais homogênea que a amostra de $\beta-\mathrm{Y}_{1,95} \mathrm{Dy}_{0,05} \mathrm{Si}_{2} \mathrm{O}_{7}$.
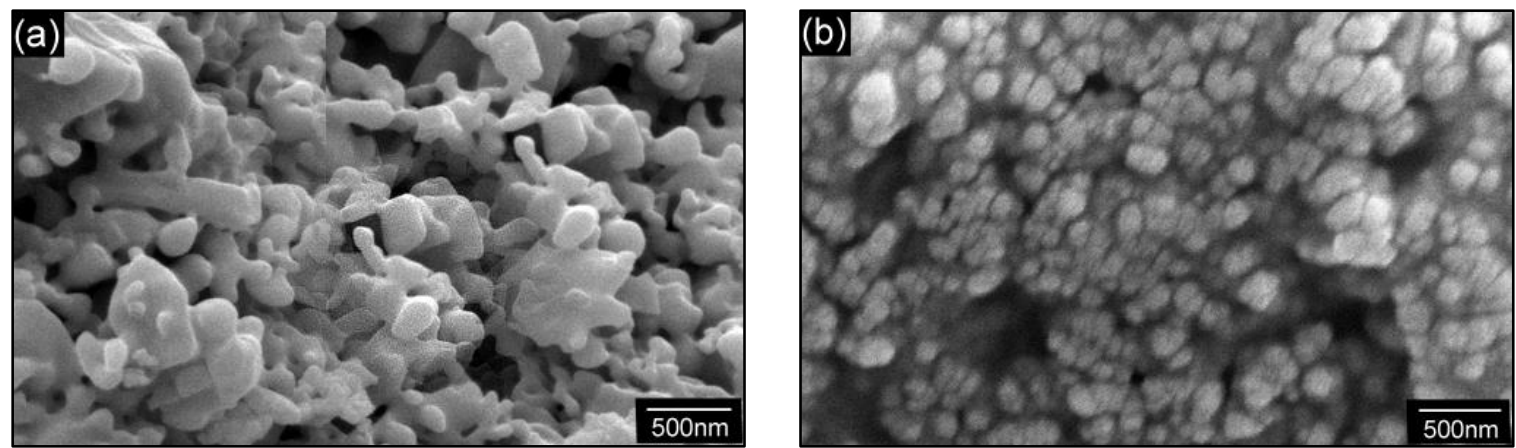

FIGURA 47 - Micrografias dos pós de (a) $\mathrm{Y}_{2} \mathrm{Si}_{2} \mathrm{O}_{7}$ e (b) $\beta-\mathrm{Y}_{1,95} \mathrm{Dy}_{0,05} \mathrm{Si}_{2} \mathrm{O}_{7}$ obtidas por MEV, após tratamento térmico a $1400^{\circ} \mathrm{C}$ por duas horas em atmosfera ambiente. 
Na TAB. 10 mostra-se o comparativo dos resultados de caracterização física dos pós de $\beta-Y_{2} \mathrm{Si}_{2} \mathrm{O}_{7}$ e $\beta-\mathrm{Y}_{1,95} \mathrm{Dy}_{0,05} \mathrm{Si}_{2} \mathrm{O}_{7}$. Os pós de $\beta-Y_{1,95} \mathrm{Dy}_{0,05} \mathrm{Si}_{2} \mathrm{O}_{7}$ apresentaram densidade real de $3,96 \mathrm{~g} . \mathrm{cm}^{-3}$ que corresponde a $98 \%$ da densidade teórica do $\beta-\mathrm{Y}_{2} \mathrm{Si}_{2} \mathrm{O}_{7}\left(4,04 \mathrm{~g} \cdot \mathrm{cm}^{-3}\right)$. Para ambas às amostras, o diâmetro médio de partículas $\left(d_{50}\right)$ determinado por PCS foi inferior a 300nm, para $\beta-Y_{1,95} D y_{0,05} \mathrm{Si}_{2} \mathrm{O}_{7}$ $d_{50}=242 \mathrm{~nm}$ e para $\beta-Y_{2} \mathrm{Si}_{2} \mathrm{O}_{7} d_{50}=185 \mathrm{~nm}$. Pelos resultados de diâmetro médio teórico calculados a partir da equação de BET ( $\left.\mathrm{d}_{\mathrm{BET}}\right)$ para os pós de $\beta-Y_{1,95} \mathrm{Dy}_{0,05} \mathrm{Si}_{2} \mathrm{O}_{7}$ e $\quad \beta-\mathrm{Y}_{2} \mathrm{Si}_{2} \mathrm{O}_{7}$, nota-se que os valores são coerentes aos observados nas micrografias por MEV (FIG. 47), em torno de 150nm. Apesar desta pequena variação nos valores de $d_{50}$, verifica-se que 0 fator de aglomeração (Fag) para ambas as amostras mostra-se próximo a 1, ou seja, os valores de $\mathrm{d}_{50}$ determinados por PCS são muito semelhantes aqueles da partícula unitária.

TABELA 10 - Resultados de caracterização física dos pós de $\beta-\mathrm{Y}_{2} \mathrm{Si}_{2} \mathrm{O}_{7}$ e $\beta-Y_{1,95} \mathrm{Dy}_{0,05} \mathrm{Si}_{2} \mathrm{O}_{7}$

\begin{tabular}{|c|c|c|}
\hline Características & $\beta-Y_{2} \mathrm{Si}_{2} \mathrm{O}_{7}$ & $\beta-Y_{1,95} \mathrm{Dy}_{0,05} \mathrm{Si}_{2} \mathrm{O}_{7}$ \\
\hline $\mathrm{d}_{\mathrm{T}}\left(\mathrm{g} \cdot \mathrm{cm}^{-3}\right)$ & 4,04 & - \\
\hline$\rho\left(\mathrm{g} \cdot \mathrm{cm}^{-3}\right)$ & 4,03 & 3,96 \\
\hline $\mathrm{d}_{\mathrm{BET}}(\mathrm{nm})$ & 140,0 & 161,8 \\
\hline $\mathrm{d}_{50}(\mathrm{~nm})$ & 185,0 & 242,0 \\
\hline$S_{M}\left(m^{2} \cdot g^{-1}\right)$ & 10,6 & 9,2 \\
\hline $\mathrm{F}_{\mathrm{ag}}$ & 1,3 & 1,50 \\
\hline
\end{tabular}

Obteve-se pelo processo hidrotermal e tratamento térmico a $1400 \mathrm{C}$ por 2 horas $2,3 \mathrm{~kg}$ de pós de dissilicato de ítrio em escala nanométrica e com distribuição homogênea de tamanho e forma de partículas. O controle destas características é importante para as etapas seguintes do processamento cerâmico. Pós com características controladas contribuem para uma melhor condição empacotamento durante a etapa de conformação. Consequentemente, podem contribuir positivamente nas propriedades finais da peça conformada, 
como maior controle dimensional e microestrutura homogênea com menor concentração de defeitos.

\subsection{Estabilidade das partículas em meio aquoso - potencial Zeta (ろ)}

As curvas de potencial zeta das suspensões de $\beta-\mathrm{Y}_{2} \mathrm{Si}_{2} \mathrm{O}_{7}$, $\beta-Y_{1,95} D_{0} y_{0,05} \mathrm{Si}_{2} \mathrm{O}_{7}$ e $\mathrm{Y}_{2} \mathrm{O}_{3}$ em função do $\mathrm{pH}$ estão representadas na FIG. 48. Sem adição de dispersante o $\beta-\mathrm{Y}_{2} \mathrm{Si}_{2} \mathrm{O}_{7}$ apresenta ponto isoelétrico (PIE) em $\mathrm{pH}=7,8$ valor intermediário aos compostos de $\mathrm{Y}_{2} \mathrm{O}_{3}$ e $\mathrm{SiO}_{2}, \mathrm{pH}_{\mathrm{PIE}}=8-9$ e $\mathrm{pH}_{\mathrm{PIE}}=2-3$ respectivamente ${ }^{[160]}$. Na condição de $\zeta=0 \mathrm{mV}$ ocorre o predomínio das forças de atração entre as partículas. Portanto, a estabiliade das partículas em suspensão é favorecida em valores de $\mathrm{pH}$ distantes do PIE. Neste sentido, condições de estabilidade foram estabelecidas em $\mathrm{pH}=5(|\zeta|=32 \mathrm{mV}), \mathrm{pH}=6(|\zeta|=37 \mathrm{mV})$ e a partir do $\mathrm{pH}=8,5$. $\bigcirc \quad \beta-\mathrm{Y}_{2} \mathrm{Si}_{2} \mathrm{O}_{7}$ mostrou-se mais estável em $\mathrm{pH}$ alcalino, onde a promoção da dupla camada elétrica foi mais significativa em $\mathrm{pH}=11(|\zeta|=58 \mathrm{mV})$.

$\mathrm{O}$ comportamento do $\beta-\mathrm{Y}_{1,95} \mathrm{Dy}_{0,05} \mathrm{Si}_{2} \mathrm{O}_{7}$ em meio aquoso (FIG. 48) foi análogo ao $\beta-Y_{2} \mathrm{Si}_{2} \mathrm{O}_{7}$. Sem adição de dispersante $\beta-Y_{1,95} \mathrm{Dy}_{0,05} \mathrm{Si}_{2} \mathrm{O}_{7}$ apresenta ponto isoelétrico (PIE) em $\mathrm{pH}=8,3$ - valor muito próximo ao do composto $\mathrm{Y}_{2} \mathrm{O}_{3}$, $\mathrm{pH}_{\mathrm{PIE}}=8,5^{[139]}$. Comparando-se o comportamento das partículas do dissilicato de ítrio dopado em meio aquoso com aqueles das amostras $\beta-\mathrm{Y}_{2} \mathrm{Si}_{2} \mathrm{O}_{7}$ e $\mathrm{Y}_{2} \mathrm{O}_{3}$, notase que as partículas de $\beta-Y_{1,95} \mathrm{Dy}_{0,05} \mathrm{Si}_{2} \mathrm{O}_{7}$ apresentaram um estado de supefície mais favorável ao desenvolvimento da dupla camada elétrica, resultando em valores maiores de potencial zeta, $|\zeta|=50 \mathrm{mV}$. Neste caso, as condições de estabilidade foram estabelecidas em $\mathrm{pH}<7,5$ e a partir do $\mathrm{pH}=8,7$. Assim como o $\beta-\mathrm{Y}_{2} \mathrm{Si}_{2} \mathrm{O}_{7}$, o $\beta-\mathrm{Y}_{1,95} \mathrm{Dy}_{0,05} \mathrm{Si}_{2} \mathrm{O}_{7}$ mostrou-se mais estável em $\mathrm{pH}$ alcalino, onde a promoção da dupla camada elétrica foi mais significativa em $\mathrm{pH}=11(|\zeta|=55 \mathrm{mV})$.

Conforme reportado em estudo anterior ${ }^{[139]}, \mathrm{o}_{2} \mathrm{O}_{3}$ (FIG. 48) apresenta ponto isoelétrico (PIE) a $\mathrm{pH}=8,5$ e condições de estabilidade a $\mathrm{pH}=5, \mathrm{pH}=6$ e a partir do $\mathrm{pH}=9,6$. Neste caso, a promoção do mecanismo de repulsão eletrostático a partir da dupla camada elétrica foi mais favorecido a $\mathrm{pH}=10,5(|\zeta|=50 \mathrm{mV})$. 


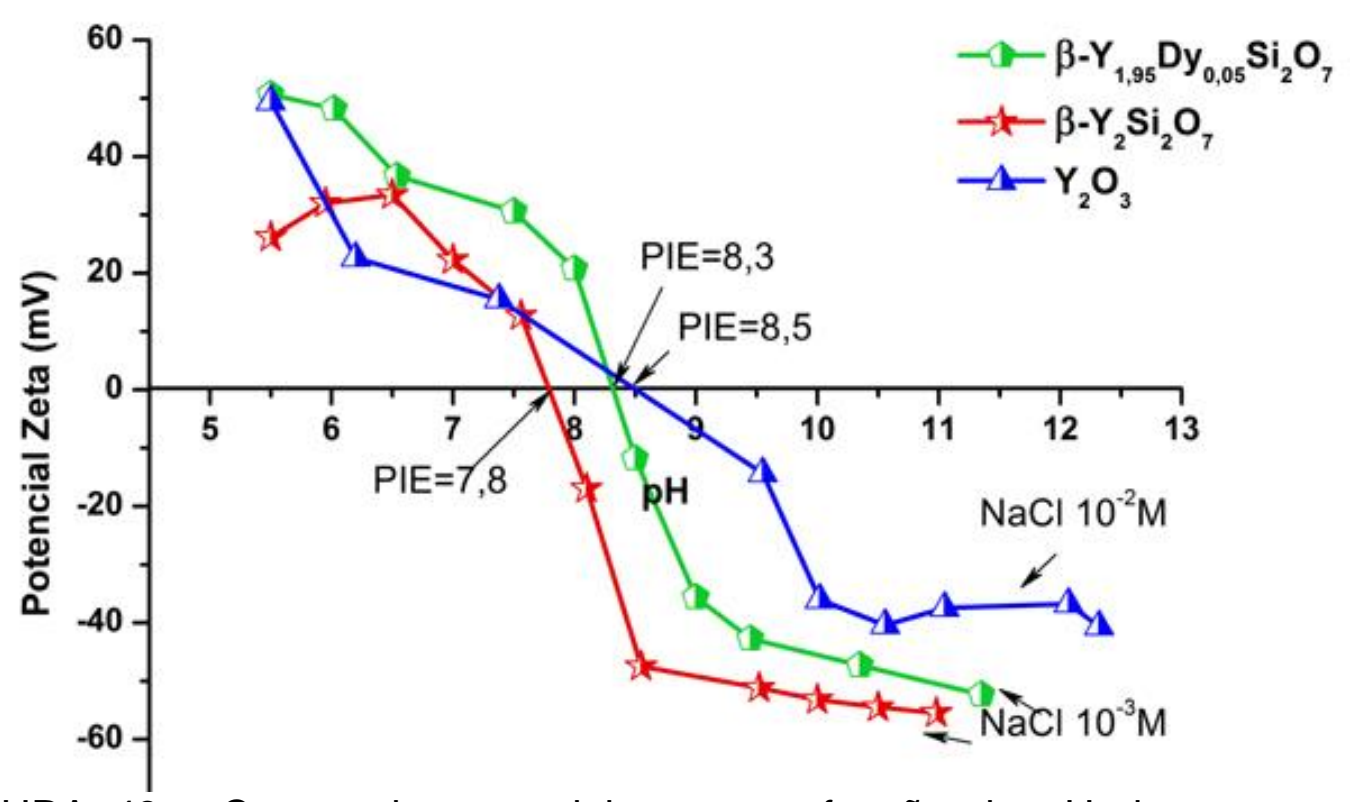

FIGURA 48 - Curvas de potencial zeta em função do $\mathrm{pH}$ das suspensões cerâmicas de $\beta-\mathrm{Y}_{2} \mathrm{Si}_{2} \mathrm{O}_{7} \quad(\mathrm{PIE}=7,8), \quad \beta-\mathrm{Y}_{1,95} \mathrm{Dy}_{0,05} \mathrm{Si}_{2} \mathrm{O}_{7} \quad(\mathrm{PIE}=8,3)$ e $\quad \mathrm{Y}_{2} \mathrm{O}_{3}$ $(\mathrm{PIE}=8,5)$.

O uso do dispersante poliacrilato de amônio (PAA) promove a estabilidade das partículas pelo mecanismo eletroestérico. Neste caso, o compotamento das partículas em suspensão é determinado pela interface líquido/dispersante/partícula. Consequentemente, os valores do PIE e do $\zeta$ são resultantes dessa interação. O PAA é composto pelo grupo carboxílico $(\mathrm{COOH})$, onde o mecanismo de dissociação em meio aquoso está indicado na equação 15. A fração dos grupos ( $\mathrm{COO}^{-}$) que disassociam e aqueles que não dissassociam $(\mathrm{COOH})$ é dependente do $\mathrm{pH}$. Quando o pH é ajustado da condição neutra para a alkalina a quantidade de grupos $\mathrm{COOH}$ disassociados aumenta, assim como a carga elétrica do polímero. Consequentemente, mais moléculas de dispersante serão adsorvidas à superfície da partícula e sua morfologia será mais estendida. Portanto, a estabilização das partículas a partir deste polieletrólito ocorre pela carga elétrica formada na superfície do polímero e da barreria física das longas cadeias poliméricas adsorvidas à superfície da partícula.

$$
\mathrm{A}-\mathrm{COOH}+\mathrm{H}_{2} \mathrm{O} \leftrightarrow \mathrm{A}-\mathrm{COO}^{-}+\mathrm{H}_{3} \mathrm{O}^{+}
$$

Conforme indicado na FIG. 49, a estabilização eletroestérica a partir de $0,5 \%$ em massa de PAA praticamente não alterou as condições de estabilidade das partículas de $\beta-\mathrm{Y}_{2} \mathrm{Si}_{2} \mathrm{O}_{7}$ quando comparado ao mecanismo eletrostático. 
Neste caso, o PIE manteve-se praticamente inalterado e os valores de potencial zeta determinados a $\mathrm{pH}$ ácido foram inferiores a $25 \mathrm{mV}$. Em $\mathrm{pH}$ alcalino, a condição de estabilidade foi estabelecida a partir do $\mathrm{pH}=9,5$, sendo mais significativa em $\mathrm{pH}=11$. A partir de $1 \%$ em massa de $\mathrm{PAA}$, o efeito do mecanismo eletroestérico na estabilidade das partículas foi mais expressivo. Como resultado, o PIE foi deslocado do $\mathrm{pH}=7,8$ para $\mathrm{pH}=6,5$ e $\mathrm{pH}=6,3$. Para a suspensão preparada com $1 \%$ em massa de PAA a condição de estabilidade foi estabelecida a partir do $\mathrm{pH}=8(|\zeta|=35 \mathrm{mV})$. Para suspensões preparadas com 2 e $3 \%$ em massa de PAA esta condição foi obtida a partir do $\mathrm{pH}=7$. Comparando-se os resultados encontrados para todas as situações avaliadas, observa-se que a melhor condição de estabiliade das suspensões à base de $\beta-\mathrm{Y}_{2} \mathrm{Si}_{2} \mathrm{O}_{7}$ foi estabelecida com $2 \%$ em massa de PAA e $\mathrm{pH}=10(|\zeta|=75 \mathrm{mV})$.

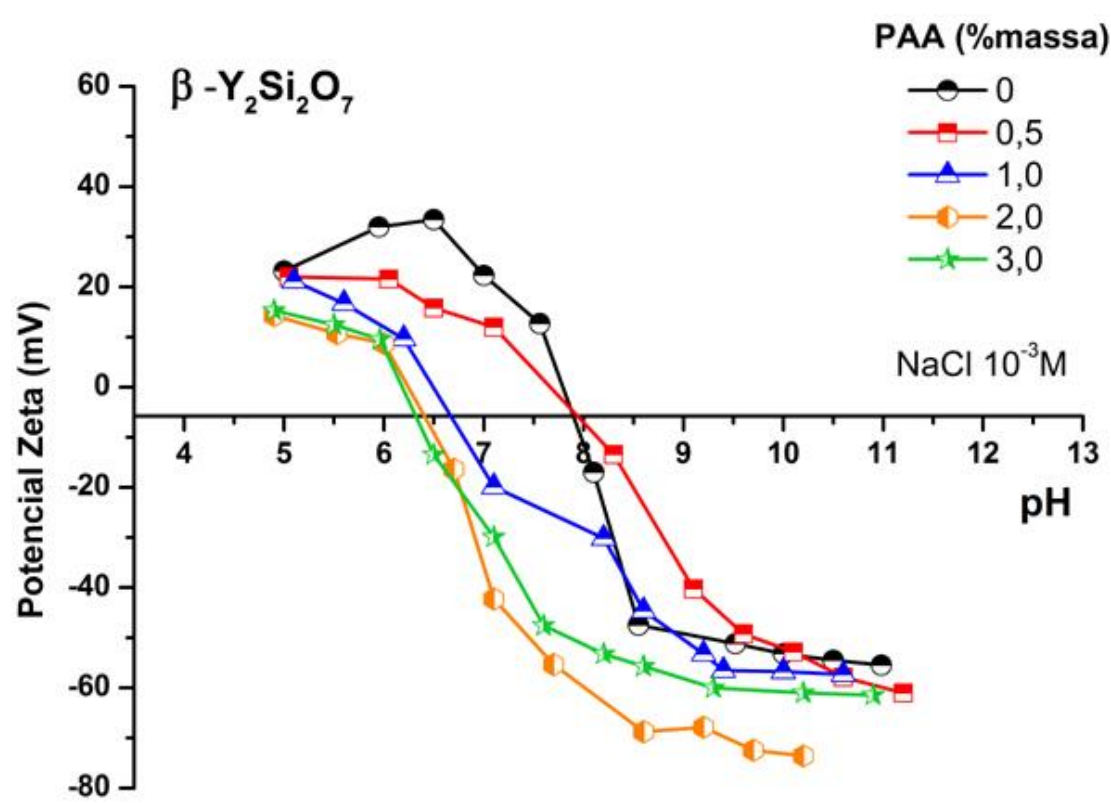

FIGURA 49 - Variação do potencial zeta do $\beta-\mathrm{Y}_{2} \mathrm{Si}_{2} \mathrm{O}_{7}$ em função do $\mathrm{pH}$ e da concentração em massa de dispersante PAA.

Na FIG. 50 estão representadas as curvas de potencial zeta das partículas de $\beta-Y_{1,95} D_{0,05} \mathrm{Si}_{2} \mathrm{O}_{7}$ em função do $\mathrm{pH}$ e da concentração de PAA. Pelos resultados, verifica-se que a amostra $\beta-Y_{1,95} D_{0} y_{0,05} \mathrm{Si}_{2} \mathrm{O}_{7}$ apresentou aspecto de supefície mais favorável para o desenvolvimento dos mecanismos de repulsão eletrostático (sem PAA) e eletroestérico (com PAA). Com 0,5\% em massa de $\mathrm{PAA}$, observa-se que o PIE apresentou pequeno deslocamento de $\mathrm{pH} \mathrm{PIE}_{\mathrm{P}}=8,3$ para $\mathrm{pH}_{\mathrm{PIE}=8,1}$ e as condições de estabilidade foram estabelecidas a $\mathrm{pH}<7,5$ 
$(|\zeta|=30 \mathrm{mV})$ e $\mathrm{pH}>8,5(|\zeta|=25 \mathrm{mV})$, sendo mais favorecida a $\mathrm{pH}=10 \mathrm{com}|\zeta|=58 \mathrm{mV}$. A partir de 1\%massa de PAA, nota-se o deslocamento mais efetivo do PIE, onde o valor máximo foi obtido com $2 \%$ massa de PAA, $\mathrm{pH}_{\mathrm{PIE}}=6,9$. Nesta circusntância, condições de estabilidade foram estabelecidas a partir do $\mathrm{pH}=8(|\zeta|=30 \mathrm{mV})$, sendo mais efetiva a $\mathrm{pH}=10(|\zeta|=60 \mathrm{mV})$. Comportamento semelhante foi observado em estudos anteriores para $\circ \mathrm{Y}_{2} \mathrm{O}_{3}{ }^{[139,236]}$. Neste caso, as partículas de $\mathrm{Y}_{2} \mathrm{O}_{3}$ mostraram-se mais estáveis a $\mathrm{pH}=10$ e com adição de $1 \%$ massa de PAA, com $|\zeta|=56 \mathrm{mV}$.

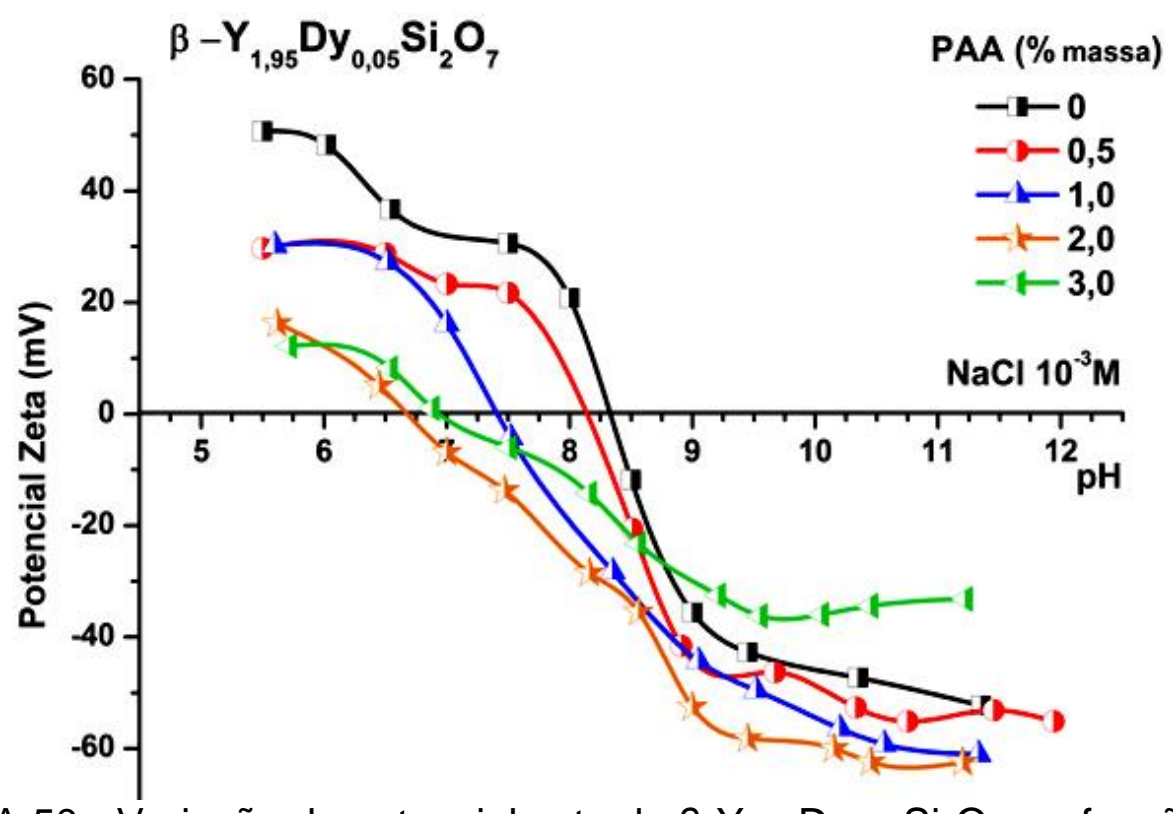

FIGURA 50 - Variação do potencial zeta do $\beta-Y_{1,95} \mathrm{Dy}_{0,05} \mathrm{Si}_{2} \mathrm{O}_{7}$ em função do $\mathrm{pH}$ e da concentração em massa de dispersante PAA.

\subsection{Reologia das suspensões cerâmicas}

\subsubsection{Estabilidade das suspensões pelo ajuste de pH}

Suspensões estáveis são preparadas a valores de $\mathrm{pH}$ distantes do PIE, onde pode-se estabelecer elevado valor de potencial zeta $(|\zeta|>20 \mathrm{mV})$ e geralmente baixa viscosidade. Na FIG. 51 é apresentada a correlação entre pH e viscosidade aparente $(\eta)$ das suspensões aquosas das amostras $\beta-\mathrm{Y}_{2} \mathrm{Si}_{2} \mathrm{O}_{7}, \beta$ - $\beta$ $\mathrm{Y}_{1,95} \mathrm{Dy}_{0,05} \mathrm{Si}_{2} \mathrm{O}_{7}, \mathrm{Y}_{2} \mathrm{O}_{3}$ e YTR com $5 \%$ vol de sólidos. Para todas as suspensões preparadas em $\mathrm{pH}$ abaixo do PIE, foram observados os elevados valores de 
viscosidade à taxa de cisalhamento de $500 \mathrm{~s}^{-1}$. No $\mathrm{PIE}$, onde o $\zeta=0$ e não há formação da dupla camada elétrica, foram determinados os maiores valores de $\eta$, sendo para $\beta-\mathrm{Y}_{2} \mathrm{Si}_{2} \mathrm{O}_{7}$ ( $(\eta=3,8 \mathrm{mPa} . \mathrm{s}), \quad \beta-\mathrm{Y}_{1,95} \mathrm{Dy}_{0,05} \mathrm{Si}_{2} \mathrm{O}_{7} \quad(\eta=3,3 \mathrm{mPa} . \mathrm{s}), \quad \mathrm{Y}_{2} \mathrm{O}_{3}$ $(\eta=25 \mathrm{mPa} . \mathrm{s})$ e YTR (80mPa.s). Para todas as amostras, a partir do $\mathrm{pH}=9$, verifica-se diminuição da viscosidade em função da promoção do mecanismo de estabilização das partículas. Conforme mostrado anteriormente na FIG. 48, as amostras de $\beta-\mathrm{Y}_{2} \mathrm{Si}_{2} \mathrm{O}_{7}, \beta-\mathrm{Y}_{1,95} \mathrm{Dy}_{0,05} \mathrm{Si}_{2} \mathrm{O}_{7}$ e $\mathrm{Y}_{2} \mathrm{O}_{3}$ apresentaram elevados valores de potencial zeta a $\mathrm{pH}=10$, como $|\zeta|=50 \mathrm{mV}, \quad|\zeta|=50 \mathrm{mV}$ e $|\zeta|=55 \mathrm{mV}$ respectivamente. Nesta condição, os menores valores de $\eta$ à taxa de cisalhamento de $500 s^{-1}$ foram determinados para $\beta-Y_{2} \mathrm{Si}_{2} \mathrm{O}_{7}$ ( $\eta=2 \mathrm{mPa} . \mathrm{s}$ ), $\beta-\beta$ $\mathrm{Y}_{1,95} \mathrm{Dy}_{0,05} \mathrm{Si}_{2} \mathrm{O}_{7}$ ( $(n=1,7 \mathrm{mPa} . \mathrm{s}), \mathrm{Y}_{2} \mathrm{O}_{3}$ ( $(n=8 \mathrm{mPa} . \mathrm{s})$ e YTR (25mPa.s). Portanto, verifica-se que a melhor condição para estabilização destas suspensões foi estabelecida em $\mathrm{pH}=10$.

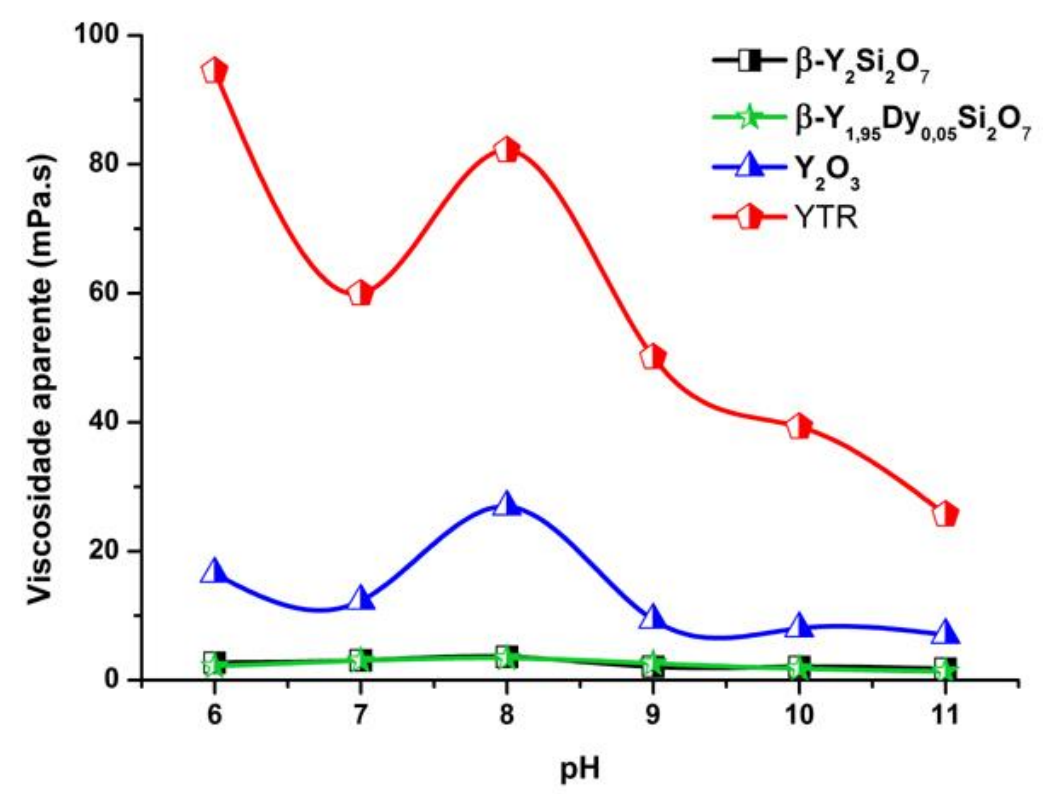

FIGURA 51 - Correlação entre $\mathrm{pH}$ e viscosidade aparente a $500 \mathrm{~s}^{-1}$ das suspensões aquosas de $\beta-\mathrm{Y}_{2} \mathrm{Si}_{2} \mathrm{O}_{7}, \beta-\mathrm{Y}_{1,95} \mathrm{Dy}_{0,05} \mathrm{Si}_{2} \mathrm{O}_{7}, \mathrm{Y}_{2} \mathrm{O}_{3}$ e YTR.

\subsubsection{Curvas de defloculação para ajuste de dispersante}

As curvas de variação de viscosidade por taxa de cisalhamento controlado até $1000 \mathrm{~s}^{-1}$ das suspensões aquosoas de $\beta-\mathrm{Y}_{2} \mathrm{Si}_{2} \mathrm{O}_{7}$ estão indicadas 
na FIG. 52. Nesta avaliação, as suspensões com $5 \%$ vol de sólidos foram preparadas em $\mathrm{pH}=10$ e com até $3 \%$ massa de PAA. Conforme indicado anteriormente na FIG. 49, este valor de pH proporciona melhor condição de dissociação dos grupos $\mathrm{COO}^{-}$constituintes do PAA. Suspensões com até $1 \% \mathrm{em}$ massa de PAA apresentaram dois tipos de comportamento de fluxo. Comportamento reológico pseudoplástico até a taxa de cisalhamente de $300 \mathrm{~s}^{-1}$, caracterizado pela diminuição da viscosidade aparente em função do aumento da taxa de cisalhamanento aplicada. E a partir desta taxa, as suspensões mostraram tendência à dilatantância, onde a viscosidade aumentou continuadamente até a taxa de cisalhamento limite de $1000 \mathrm{~s}^{-1}$. Suspensões dilatantes não são adequadas para grande parte dos processos de materiais cerâmicos, em particular ao processo de réplica. Para este processo de conformação, a suspensão deve apresentar viscosidade mínima para penetrar nos poros da matriz de réplica e recobrir uniformemente sua superfície.

A dispersão das partículas pelo mecanismo eletroestérico foi mais efetivo para as concentrações de 2 e $3 \%$ em massa de PAA (FIG. 52). Suspensões preparadas com $2 \%$ em massa de PAA apresentaram comportamente de fluxo linear, correspondendo ao modelo Newtoniano, onde a viscosidade é constante independente da taxa de cisalhamento aplicada ( $\eta<2,5 \mathrm{mPa} . \mathrm{s})$. Comportamento semelhante foi observado para as suspensões preparadas com $3 \%$ em massa de PAA. Portanto, este resultado é um indicativo do limite de dosagem de dispersante na suspensão. Baseado nestes resultados, as condições de estabilidade das partículas de $\beta-\mathrm{Y}_{2} \mathrm{Si}_{2} \mathrm{O}_{7}$ em meio aquoso são $2 \%$ em massa de dispersante e $\mathrm{pH}=10$, conforme previamente determinado pelas curvas de potencial zeta (FIG. 49). 


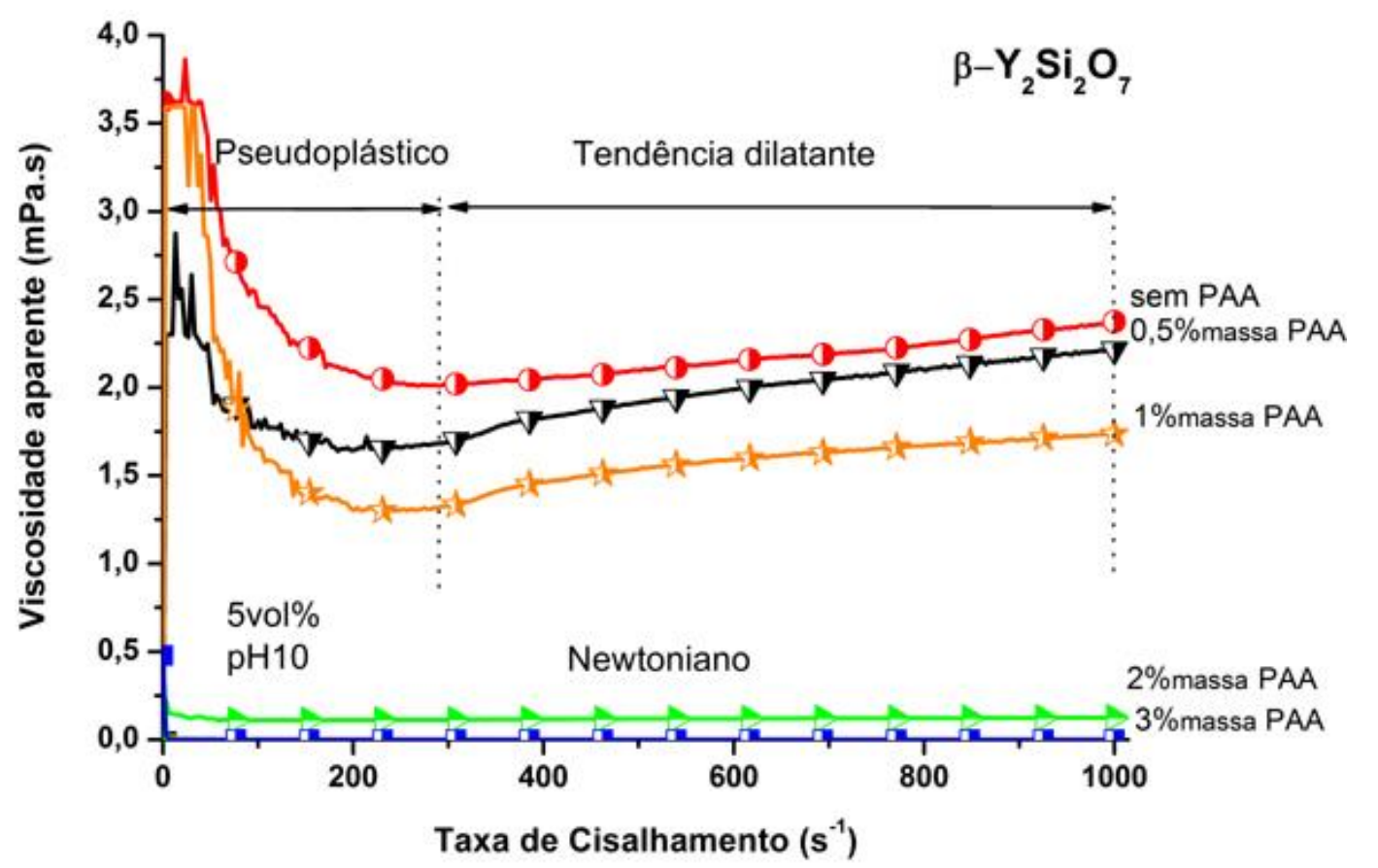

FIGURA 52 - Variação da viscosidade aparente em função da taxa de cisalhamento controlado até $1000 \mathrm{~s}^{-1}$ das suspensões aquosas de $\beta-\mathrm{Y}_{2} \mathrm{Si}_{2} \mathrm{O}_{7}$ preparadas com até $3 \%$ em massa de PAA.

$\mathrm{Na}$ FIG. 53 comparam-se as curvas de viscosidade aparente em função da taxa cisalhamento controlado até $1000 \mathrm{~s}^{-1}$ das suspensões aquosas de $\beta-\mathrm{Y}_{2} \mathrm{Si}_{2} \mathrm{O}_{7}, \beta-\mathrm{Y}_{1,95} \mathrm{Dy}_{0,05} \mathrm{Si}_{2} \mathrm{O}_{7}, \mathrm{Y}_{2} \mathrm{O}_{3}$ e YTR com $5 \%$ vol de sólidos preparadas nas melhores condições de estabilidade. Para todas as amostras, verifica-se que até a taxa de cisalhamento de $200 \mathrm{~s}^{-1}$, as suspensões apresentaram uma pequena variação na viscosidade. Esse comportamento possivelmente está associado à transição do estado de repouso para o dinâmico, onde geralmente ocorrem eventos de quebra de aglomerados, orientação das partículas, dispersão, ou seja, eventos de redistribuição das partículas em suspensão. A partir de $200 \mathrm{~s}^{-1}$ até 0 limite do ensaio, observa-se que o comportamento de fluxo é linear, correspondente ao modelo Newtoniano. Pelos resultados, verifica-se que todas as suspensões apresentaram baixa viscosidade $(\eta<2,5 \mathrm{mPa} . \mathrm{s})$, onde a suspensão de $\mathrm{Y}_{2} \mathrm{O}_{3}$ mostrou-se a mais fluída com $(n<0,05 \mathrm{mPa} . \mathrm{s})$. Nesta condição de estabilidade, pode-se preparar suspensões mais concentradas para os distintos processos de conformação a partir de suspensões cerâmicas. 


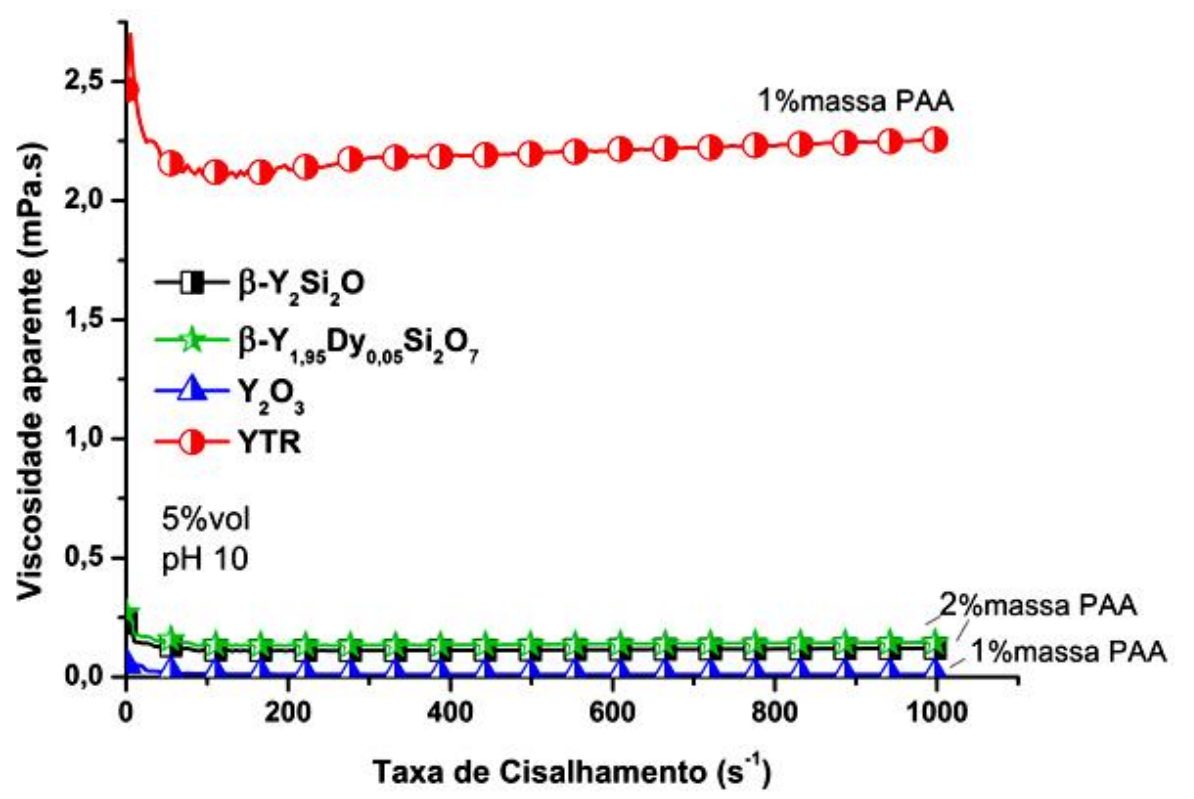

FIGURA 53 - Curvas de viscosidade aparente em função da taxa de cisalhamento controlado até $1000 \mathrm{~s}^{-1}$ das suspensões aquosas de $\beta-\mathrm{Y}_{2} \mathrm{Si}_{2} \mathrm{O}_{7}, \beta$ $\mathrm{Y}_{1,95} \mathrm{Dy}_{0,05} \mathrm{Si}_{2} \mathrm{O}_{7}, \quad \mathrm{Y}_{2} \mathrm{O}_{3}$ e YTR preparadas nas melhores condições de estabilidade.

\subsubsection{Influência da concentração de sólidos no comportamento de fluxo das suspensões}

A influência da concentração de sólidos no comportamento reológico foi avaliada a partir das curvas de fluxo das suspensões de $\beta-\mathrm{Y}_{2} \mathrm{Si}_{2} \mathrm{O}_{7}$ com até $25 \%$ vol de sólidos, preparadas na melhor condição de estabilidade, $\mathrm{pH}=10$ e $2 \%$ massa de PAA (FIG. 54). Suspensões com até 15\%vol de sólidos apresentaram comportamento de fluxo linear, semelhante ao modelo Newtoniano. Para concentrações de sólidos mais elevadas a constante de proporcionalidade ( $)$ entre tensão e taxa de cisalhamento não é mais válida. Suspensões com $20 \%$ vol e $25 \%$ vol de sólidos mostraram comportamento de fluxo dilatante, seguindo o modelo Oswald de Waele ${ }^{[160]}$.

Quando uma suspensão dilatante é submetida a uma tensão externa, as partículas dispersas são deslocadas das suas posições iniciais no sentido de constituir uma nova disposição. Durante esta etapa de rearrajno do sistema particulado pode ocorrer à aproximação partículas altamente estabilizadas, resultando em uma forte repulsão entre elas. Como consequência, a viscosidade 
da suspensão aumenta. Portanto, suspensões com comportamento dilatante não são indicadas para a maioria dos processos de materiais cerâmicos, como jateamento, injeção, extrusão, colagem e impregnação.

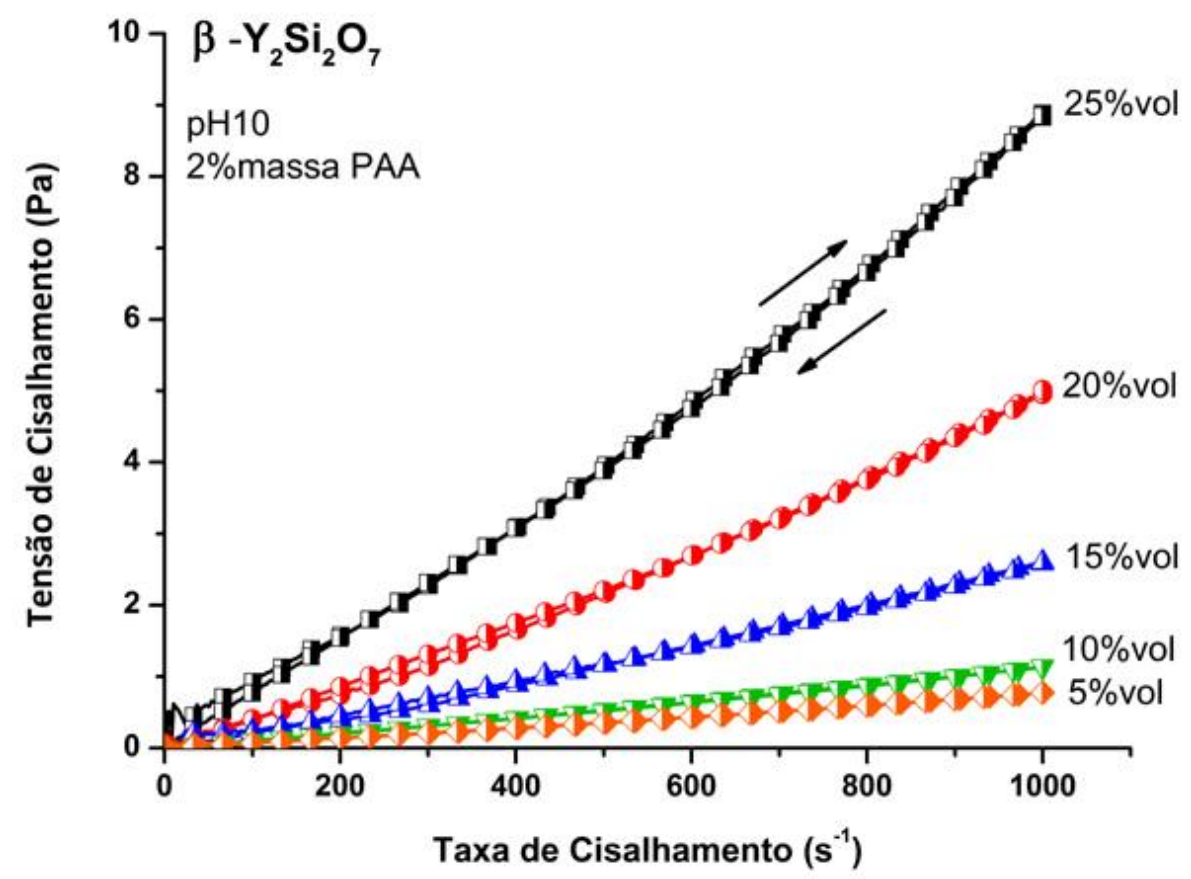

FIGURA 54 - Curvas de fluxo das suspensões de $\beta-Y_{2} \mathrm{Si}_{2} \mathrm{O}_{7}$ com até $25 \%$ vol de sólidos em modo de taxa de cisalhamento controlado até $1000 \mathrm{~s}^{-1}$.

Na FIG. 55 são comparadas as curvas de fluxo em modo de taxa de cisalhamento controlado até $1000 \mathrm{~s}^{-1}$ das suspensões aquosas de $\beta-\mathrm{Y}_{2} \mathrm{Si}_{2} \mathrm{O}_{7}$, $\beta-\mathrm{Y}_{1,95} \mathrm{Dy}_{0,05} \mathrm{Si}_{2} \mathrm{O}_{7}, \mathrm{Y}_{2} \mathrm{O}_{3}$ e YTR preparadas com $25 \%$ vol de sólidos. Pelos resultados, nota-se que a suspensão de $\beta-Y_{1,95} \mathrm{Dy}_{0,05} \mathrm{Si}_{2} \mathrm{O}_{7}$ apresentou comportamento reológico dilatante (modelo de Oswald de Waele) ${ }^{[160]}$, sendo mais evidente que o exibido pela suspensão de $\beta-\mathrm{Y}_{2} \mathrm{Si}_{2} \mathrm{O}_{7}$, com tensão de cisalhamento de $13 \mathrm{~Pa}$ à $1000 \mathrm{~s}^{-1}$. Nesta circusntância, a dilatância está associada a forte repulsão entre as partículas de $\beta-\mathrm{Y}_{2} \mathrm{Si}_{2} \mathrm{O}_{7}$ altamente estabilizadas, como indicado nas curvas de potencial zeta da FIG. 50.

As suspensões de $\mathrm{Y}_{2} \mathrm{O}_{3}$ e YTR (FIG. 55) exibiram comportamento reológico pseudoplástico, correspondendo ao modelo de Casson Yassuda. Em estudos anteriores ${ }^{[139,146,163,236,237]}$, foi mostrado que suspensões aquosas de $\mathrm{Y}_{2} \mathrm{O}_{3}$ preparadas com mais de $25 \% \mathrm{vol}$ de sólidos apresentaram comportamento dilatante. JIN et al. ${ }^{[147]}$ reportaram que suspensões aquosas de ítria preparadas 
com $30 \%$ vol de sólidos a $\mathrm{pH}=10$ e $0,75 \%$ massa de polimetacrilato de amônio (PMA, Dolapix CE 64) exibiram comportamento de fluxo linear, com pequena variação na viscosidade de $0,06 \mathrm{~Pa}$.s para $0,04 \mathrm{~Pa}$.s à taxa de cisalhamento de $0-500 \mathrm{~s}^{-1}$.

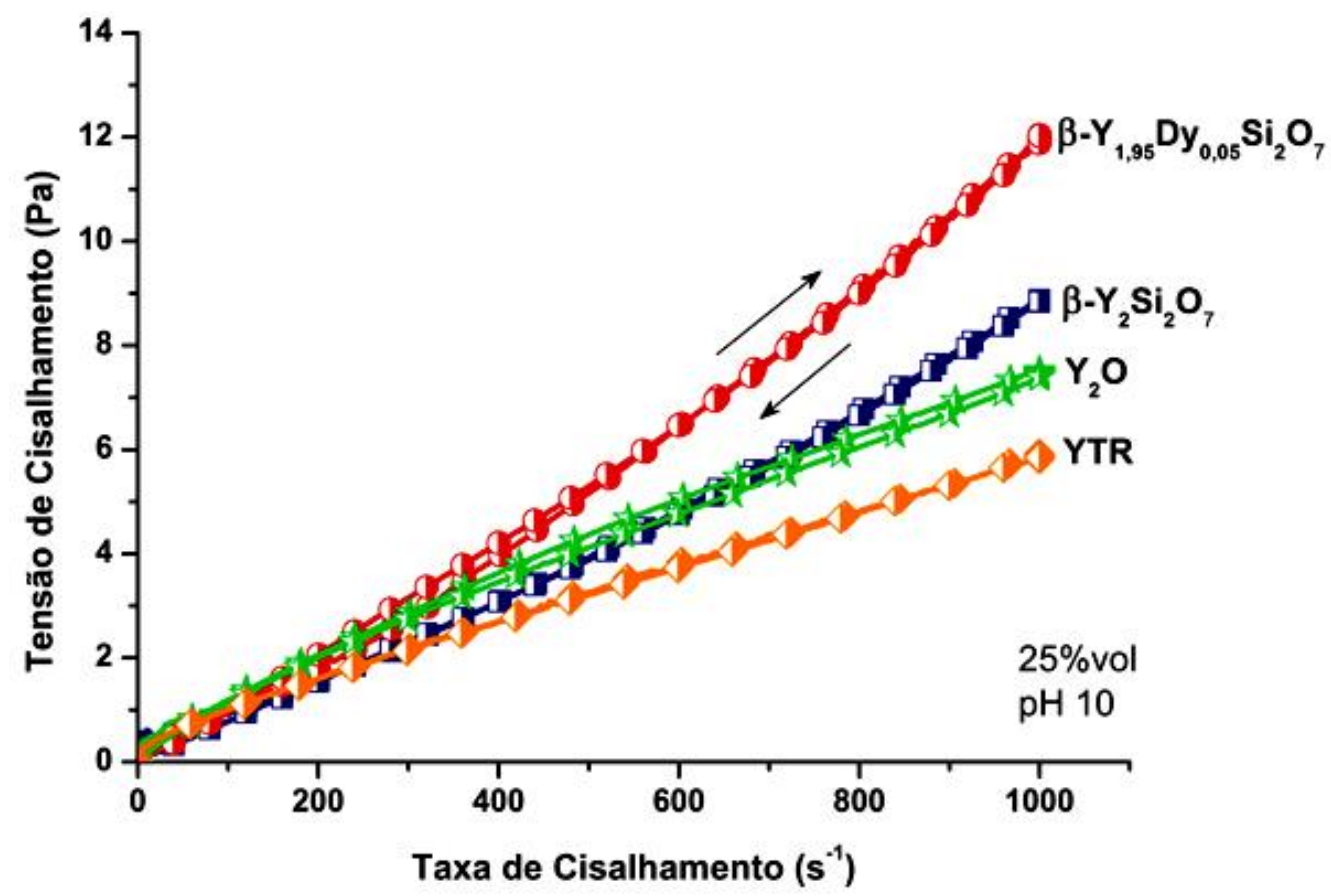

FIGURA 55 - Curvas de fluxo das suspensões aquosas de $\beta-Y_{2} \mathrm{Si}_{2} \mathrm{O}_{7}$, $\beta-Y_{1,95} D_{0,05} S i_{2} O_{7}, Y_{2} O_{3}$ e YTR com $25 \%$ vol de sólidos em modo de taxa de cisalhamento controlado até $1000 \mathrm{~s}^{-1}$.

Considerando-se que suspensões dilatantes não são indicadas para o processo de réplica, utiliza-se o ligante, um aditivo para favorecer a pseudoplasticidade as suspensões, como também para contribuir para a resistência mecânica à verde das amostras impregnadas. A quantidade deste aditivo é um parâmetro importante para o preparo de suspensões adequadas ao processo réplica, favorecendo uma impregnação homogênea da camada de suspensão na matriz de réplica e preservando a morfologia original da mesma.

\subsubsection{Determinação da concentração do ligante CMC}

$O$ efeito do ligante carboximetilcelulose (CMC) no comportamento reológico das suspensões aquosas à base de $\beta-Y_{2} \mathrm{Si}_{2} \mathrm{O}_{7}$ com $25 \%$ vol de sólidos 
está indicado na FIG. 56. Obseva-se que a quantidade de CMC é um parâmetro determinante para o controle da estabilidade das partículas. Suspensões preparadas com até $0,2 \%$ em massa de CMC apresentaram comportamento de fluxo linear, correspondendo aos modelos de Carreau Yasuda e Casson Linear ${ }^{[160]}$ para as suspensões sem CMC e com $0,2 \%$ em massa deste ligante respectivamente. Pelas curvas de viscosidade (FIG. 57), nota-se que para todo intervalo de taxa de cisalhamento avaliado, a viscosidade das suspensões com até $0,2 \%$ em massa de CMC permaneceu praticamente constante, $14 \mathrm{mPa}$.s e $61 \mathrm{mPa}$.s, respectivamente para a suspensão sem ligante e com $0,2 \%$ em massa de CMC. Pelos resultados de impregnação a partir destas suspensões, verifica-se que suspensões muito fluídas e com viscosidade praticamente constante independente da taxa de cisalhamento aplicada não são adequadas para o processo de réplica.

A partir de 0,4\%massa de CMC, nota-se uma mudança no comportamente de fluxo suspensões (FIG. 56). Para as condições de 0,4 e 0,6\% em massa de CMC há uma pequena área entre as cuvas de subida e descida. Este comportamento, conhecido como tixotropia está relacionado com a variação da viscosidade aparente em função do tempo a uma taxa de cisalhamento constante. A viscosidade diminui devido à quebra de aglomerados de partículas formados pelas longas cadeias do CMC.

Nota-se também pelas curvas de viscosidade (FIG. 57) que a resitência ao fluxo das suspensões de $0,4-0,6 \%$ massa de CMC diminui em função do aumento da taxa de cisalhamento, característico das suspensões pseudoplásticas, correspodendo ao modelo de $\operatorname{Cross}^{[238]}{ }^{\text {. Neste caso, a condição }}$ de proporcionalidade entre tensão e taxa de cisalhamento não é mais satisfeita (fluidos Newtonianos). A suspensão apresenta menor viscosidade quando submetida ao cisalhamento e maior viscosidade quando em repouso. Este comportamento é importante para aplicações como pinturas, bombeamento, jateamento e impregnação.

Suspensões de $\beta-Y_{2} \mathrm{Si}_{2} \mathrm{O}_{7}$ preparadas com 0,4 e $0,6 \%$ massa de $\mathrm{CMC}$ apresentaram viscosidade míninma (à $1000 \mathrm{~s}^{-1}$ ) de $370 \mathrm{mPa}$.s e $550 \mathrm{mPa} . \mathrm{s}$ respectivamente (FIG. 57). Pelos ensaios de impregnação a partir destas suspensões, observa-se que suspensões preparadas com $0,4 \%$ massa de CMC impregnaram uniformemente na matriz de réplica, preservando também a 
morfologia e cavidades orignais deste substrato. Suspensões com $0,6 \%$ massa de CMC por apresentarem a maior viscosidade entre todas as avaliadas, não impregnaram adequadamente as fibras vegetais da matriz. Nesta condição, as réplicas exibiram grande parte da sua estrutura recoberta por uma espessa camada de suspensão, onde as cavidades do substrato permaneceram fechadas.

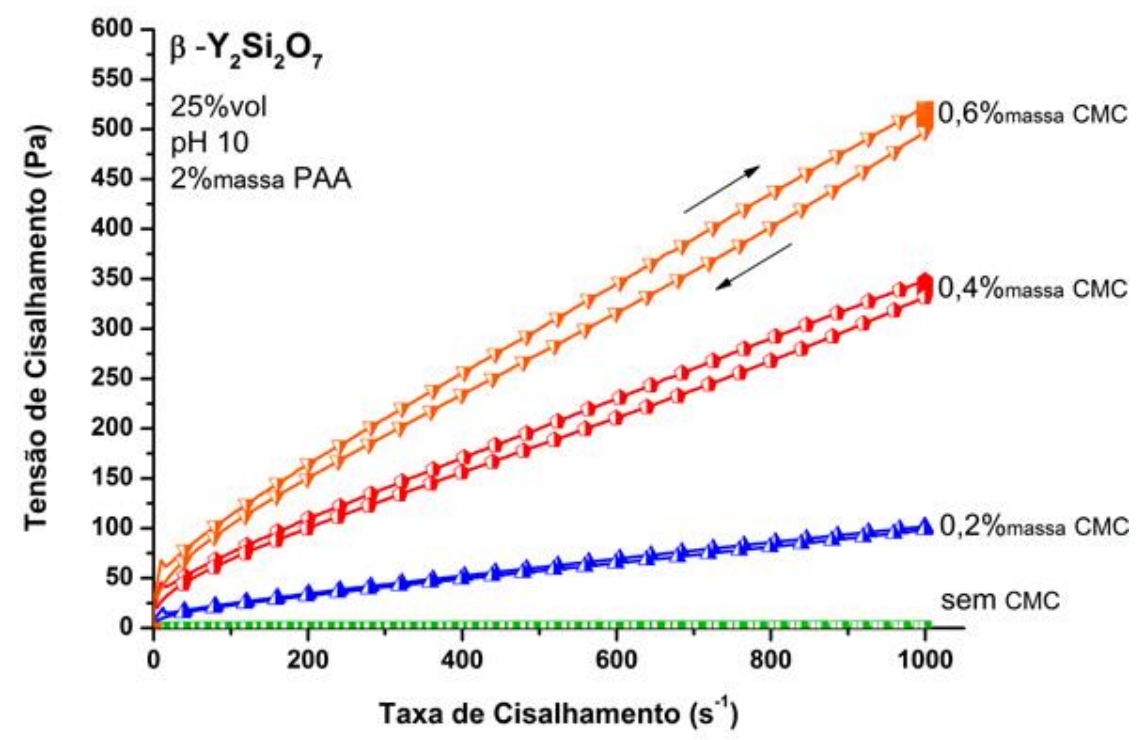

FIGURA 56 - Curvas de fluxo das suspensões de $\beta-\mathrm{Y}_{2} \mathrm{Si}_{2} \mathrm{O}_{7}$ com $25 \%$ vol de sólidos e até $0,6 \%$ em massa de CMC.

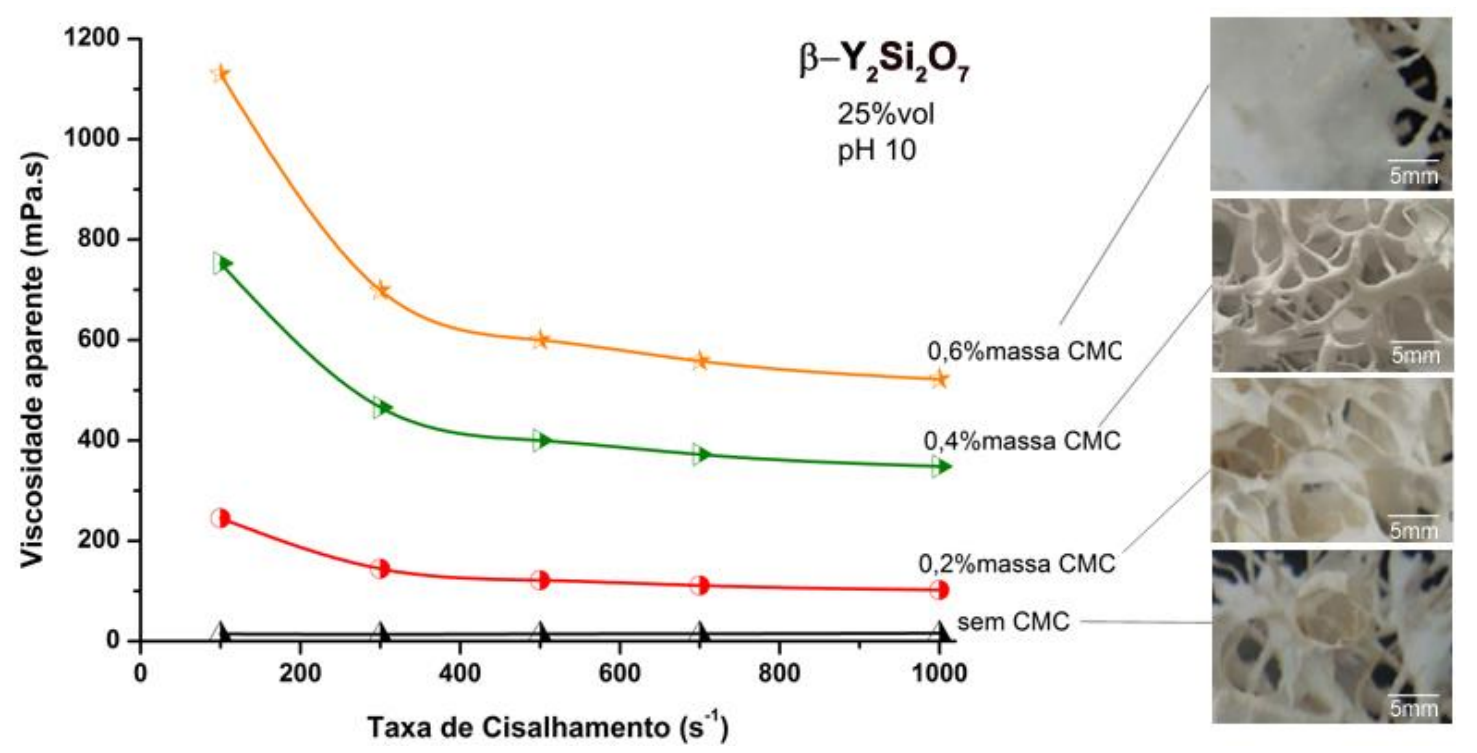

FIGURA 57 - Curvas de viscosidade aparente das suspensões de $\beta-\mathrm{Y}_{2} \mathrm{Si}_{2} \mathrm{O}_{7}$ preparadas com $25 \%$ vol de sólidos e com até $0,6 \%$ massa de CMC. 
Baseado nestes resultados, verifica-se que o uso de 0,4\%massa de $\mathrm{CMC}$ favorece o comportamento reológico pseudoplástico das suspensões à base de $\beta-\mathrm{Y}_{2} \mathrm{Si}_{2} \mathrm{O}_{7}$ com $25 \%$ vol de sólidos e viscosidade aparente compatível ao processo de réplica. Consequentemente, as amostras de LCy impregnadas apresentam uma camada uniforme de suspensão, onde a morfologia e cavidades originais do substrato são preservados. Portanto, as suspensões de $\beta$ $\mathrm{Y}_{1,95} \mathrm{Dy}_{0,05} \mathrm{Si}_{2} \mathrm{O}_{7}, \mathrm{Y}_{2} \mathrm{O}_{3}$ e YTR com $25 \%$ vol de sólidos foram preparadas nesta condição.

Na FIG. 58 são comparadas as curvas de fluxo no modo de taxa de cisalhamento controlado das suspensões aquosas à base de $\beta-Y_{2} \mathrm{Si}_{2} \mathrm{O}_{7}, \beta$ $\mathrm{Y}_{1,95} \mathrm{Dy}_{0,05} \mathrm{Si}_{2} \mathrm{O}_{7}, \mathrm{Y}_{2} \mathrm{O}_{3}$ e YTR com $25 \%$ vol de sólidos e as imagens das amostras de LCy impregmadas à partir destas suspensões. Pelos resultados das curvas de fluxo, verifica-se que as suspensões à base de $\beta-\mathrm{Y}_{2} \mathrm{Si}_{2} \mathrm{O}_{7}$ e $\beta-\mathrm{Y}_{1,95} D \mathrm{Dy}_{0,05} \mathrm{Si}_{2} \mathrm{O}_{7}$ (FIG. 58a) exibiram comportamento reológico pseudoplástico correspondente ao modelo de Casson Linear, com viscosidade aparente à $1000 \mathrm{~s}^{-1}$ de $400 \mathrm{mPa}$.s e $700 \mathrm{mPa}$.s respectivamente. Nesta circustância, observa-se também que ambas as suspensões mostraram comportamento tixotrópico devido aos eventos de cisalhamento que as suspensões foram submetidas, como a quebra de aglomerados de partículas constituídos pelas longas cadadeias de CMC. Consequentemente, os valores de tixotropia determinados para as suspensões $\beta$ $\mathrm{Y}_{2} \mathrm{Si}_{2} \mathrm{O}_{7}$ e $\beta-\mathrm{Y}_{1,95} \mathrm{Dy}_{0,05} \mathrm{Si}_{2} \mathrm{O}_{7}$ foram $3,263.10^{5} \mathrm{~Pa}^{-1}{ }^{-1}$ e $3,142 \mathrm{~Pa} . \mathrm{s}^{-1}$.

As supensões à base de $\mathrm{Y}_{2} \mathrm{O}_{3}$ e YTR (FIG. 58b) exibiram comportamentos reológicos pseudoplásticos, correspondentes respectivamente aos modelos de Cross e Casson Linear, com viscosidade aparente inferior a $300 \mathrm{mPa}$.s para todo o intervalo de taxa de cisalhamento avaliado. Neste caso, as suspensões apresentaram comportamento tixotrópico mais evidente, $\mathrm{Y}_{2} \mathrm{O}_{3}$ $\left(4,485.10^{6} \mathrm{~Pa} . \mathrm{s}^{-1}\right)$ e YTR $\left(4,394.10^{6} \mathrm{~Pa} . \mathrm{s}^{-1}\right)$ em virtude do tamanho e morfologia das partículas que favorecem a formação de aglomerados maiores.

Para todos os ensaios de impregnação a partir das suspensões à base de $\mathrm{Y}_{2} \mathrm{O}_{3}$ e YTR, observa-se que as amostras impregnadas exibiram uma camada uniforme de suspensão aderida, onde seus aspectos originais como morfologia e reticulados foram preservados. Portanto, o parâmetro de 0,4\%massa de CMC mostrou-se compatível ao processo de réplica para todas as suspensões avaliadas neste estudo. 


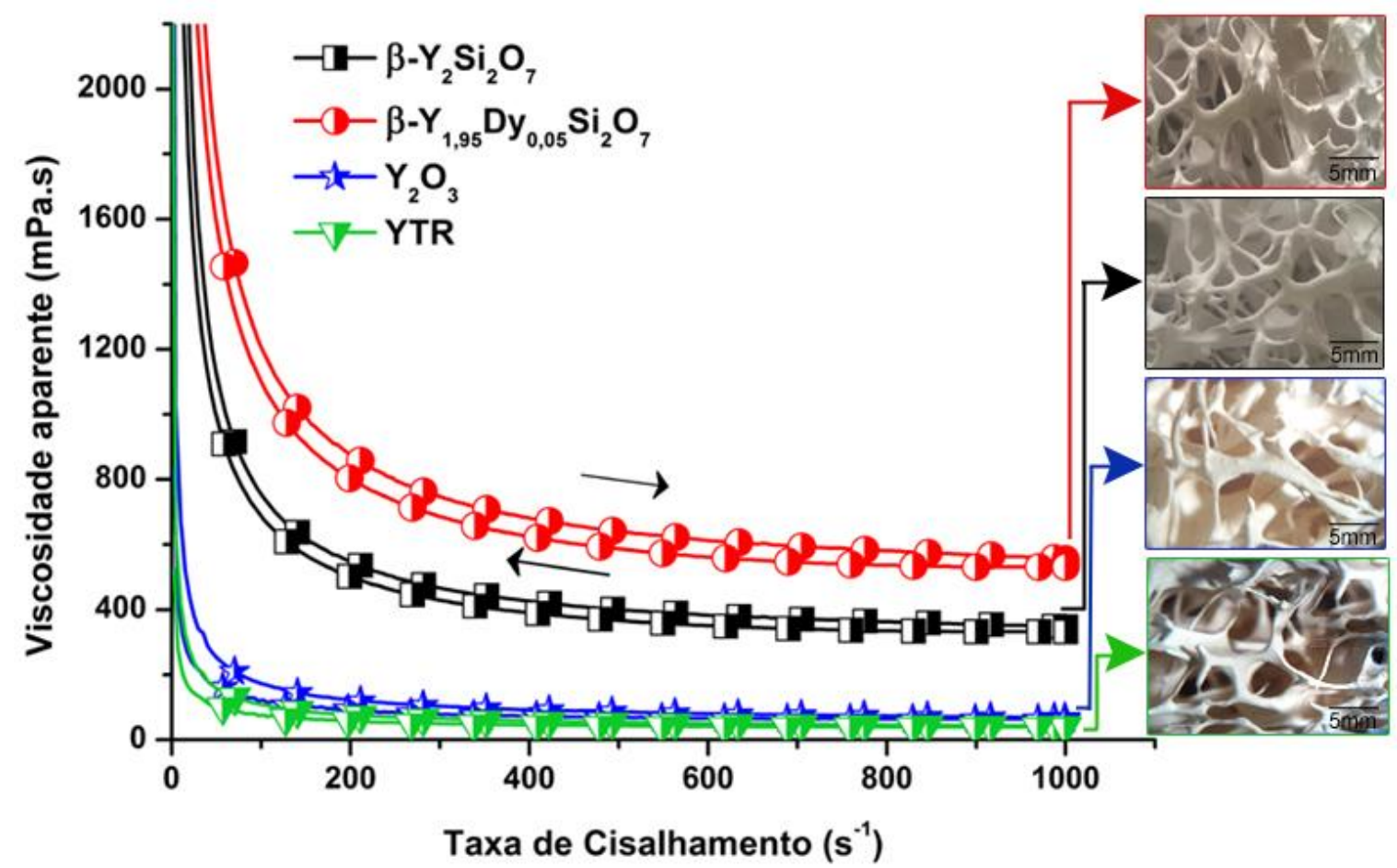

FIGURA 58 - Curvas de viscosidade aparente das suspensões aquosas de $\beta-Y_{1,95} \mathrm{Dy}_{0,05} \mathrm{Si}_{2} \mathrm{O}_{7}$ preparadas com $25 \%$ vol de sólidos e $0,4 \%$ em massa de CMC.

$\mathrm{Na}$ TAB. 11 estão relacionados os parâmetros de processamento determinados para as suspensões aquosas de $\beta-Y_{2} \mathrm{Si}_{2} \mathrm{O}_{7}, \quad \beta-Y_{1,95} \mathrm{Dy}_{0,05} \mathrm{Si}_{2} \mathrm{O}_{7}$, $\mathrm{Y}_{2} \mathrm{O}_{3}$ e YTR com $25 \%$ vol. de sólidos e $0,4 \%$ massa de $\mathrm{CMC}$ selecionadas para os ensaios de impregnação das fibras vegetais LCy. Comparando-se os resultados obtidos nos ensaios de impregnação com estudos anteriores ${ }^{[139,146,163,236,237]}$, observa-se que os parâmetros de processamento podem não ser válidos para diferentes tipos de matrizes de réplica. SANTOS, et al. ${ }^{[139]}$ produziram telas de ítria a partir de suspensões com $30 \%$ vol de sólidos e $0,2 \%$ massa de CMC, utilizando-se uma tela mista de nylon-algodão como matriz. Segundo o estudo, o uso de CMC em concentração superior a $0,2 \%$ massa resulta no aumento significativo da viscosidade das suspensões e impossibilida a impregnação uniforme das mesmas nas réplicas de nylon-algodão. Outro aspecto importante desse processo consiste na condição de superfície do substrato. Neste estudo foi selecionada como matriz de réplica à esponja vegetal da espécie Luffa Cyllindrica (LCy). Em geral, as fibras vegetais apresentam em sua superfície substâncias que inibem a impregnação de outros materiais. Portanto, é importante condicionar a 
superfície das fibras para proporcionar uma adesão eficiente da suspensão cerâmica.

TABELA 11 - Parâmetros de processamento determinados para as suspensões selecionadas para os ensaios de impregnação das fibras vegetais LCy.

\begin{tabular}{|c|c|c|c|c|c|}
\hline Susp. & $\begin{array}{c}\boldsymbol{\eta} \\
(\mathrm{mPa} . \mathrm{s})\end{array}$ & $\begin{array}{c}\text { Tixotropia } \\
\left(\mathrm{Pa}_{\mathrm{s}} \mathrm{s}^{-1}\right)\end{array}$ & M.Reológico & \multicolumn{2}{|c|}{ Parâmetro } \\
\hline$\beta-Y_{2} \mathrm{Si}_{2} \mathrm{O}_{7}$ & 480 & $3,263.10^{5}$ & $\begin{array}{l}\text { Casson } \\
\text { Linear }\end{array}$ & $\begin{array}{c}\mathrm{T}_{0}(\mathrm{~Pa}) \\
\eta_{\mathrm{p}}(\mathrm{mPa} . \mathrm{s})\end{array}$ & $\begin{array}{c}0,4189 \\
11,86\end{array}$ \\
\hline \multirow[t]{2}{*}{$\beta-Y_{1,95} D_{0,05} \mathrm{Si}_{2} \mathrm{O}_{7}$} & 473 & $3,142 \cdot 10^{5}$ & $\begin{array}{l}\text { Casson } \\
\text { Linear }\end{array}$ & $\begin{array}{c}\mathrm{T}_{0}(\mathrm{~Pa}) \\
\eta_{\mathrm{p}}(\mathrm{mPa} . \mathrm{s})\end{array}$ & $\begin{array}{c}0,5673 \\
12,37\end{array}$ \\
\hline & & & & $\begin{array}{c}\eta_{0} \\
\text { (mPa.s) }\end{array}$ & 5,848 \\
\hline \multirow{4}{*}{$\mathrm{Y}_{2} \mathrm{O}_{3}$} & 243 & $4,394.10^{6}$ & Cross & $\eta_{\infty}(\mathrm{mPa} . \mathrm{s})$ & 44,85 \\
\hline & & & & $\dot{\gamma}\left(\mathrm{s}^{-1}\right)$ & $2,569.10^{4}$ \\
\hline & & & & $\mathrm{n}$ & 1,707 \\
\hline & & & & $\begin{array}{c}\eta_{0} \\
(\mathrm{mPa} . \mathrm{s})\end{array}$ & 14,27 \\
\hline \multirow[t]{3}{*}{ YTR } & 245 & $4,485.10^{6}$ & Cross & $\eta_{\infty}(\mathrm{mPa} . \mathrm{s})$ & 23,11 \\
\hline & & & & $\dot{\gamma}\left(\mathrm{s}^{-1}\right)$ & $2,397.10^{4}$ \\
\hline & & & & $\mathrm{n}$ & 0,2347 \\
\hline
\end{tabular}

Susp: Suspensão; $\eta$ : viscosidade aparente à $10 \mathrm{~s}^{-1} ; \mathrm{T}_{0}$ : Tensão inicial; $\eta_{\mathrm{p}}$ viscosidade plástica de Casson ; $\eta_{\infty}$ : viscosidade à taxa de deformação infinita; $\dot{\gamma}$ : taxa de cisalhamento; $\mathrm{n}$ : índice da lei de potência.

\subsection{Condicionamento da superfície das fibras vegetais para impregnação}

Na FIG. 59A é apresentada a morfologia das fibras da LCy antes e após o tratamento alcalino. A bucha vegetal de densidade $1,55 \mathrm{~g} \cdot \mathrm{cm}^{-3}$ é constituída de fibras com diâmetro médio de $\varnothing_{\mathrm{m}}=60 \mu \mathrm{m}$ e área de superfície 
específica de $22,50 \mathrm{~m}^{2} \cdot \mathrm{g}^{-1}$, dispostas num arranjo matricial e multidirecional (FIG. 59B). As fibras são compostas por fibrilos, os quais são unidos por uma resina natural do tecido vegetal.
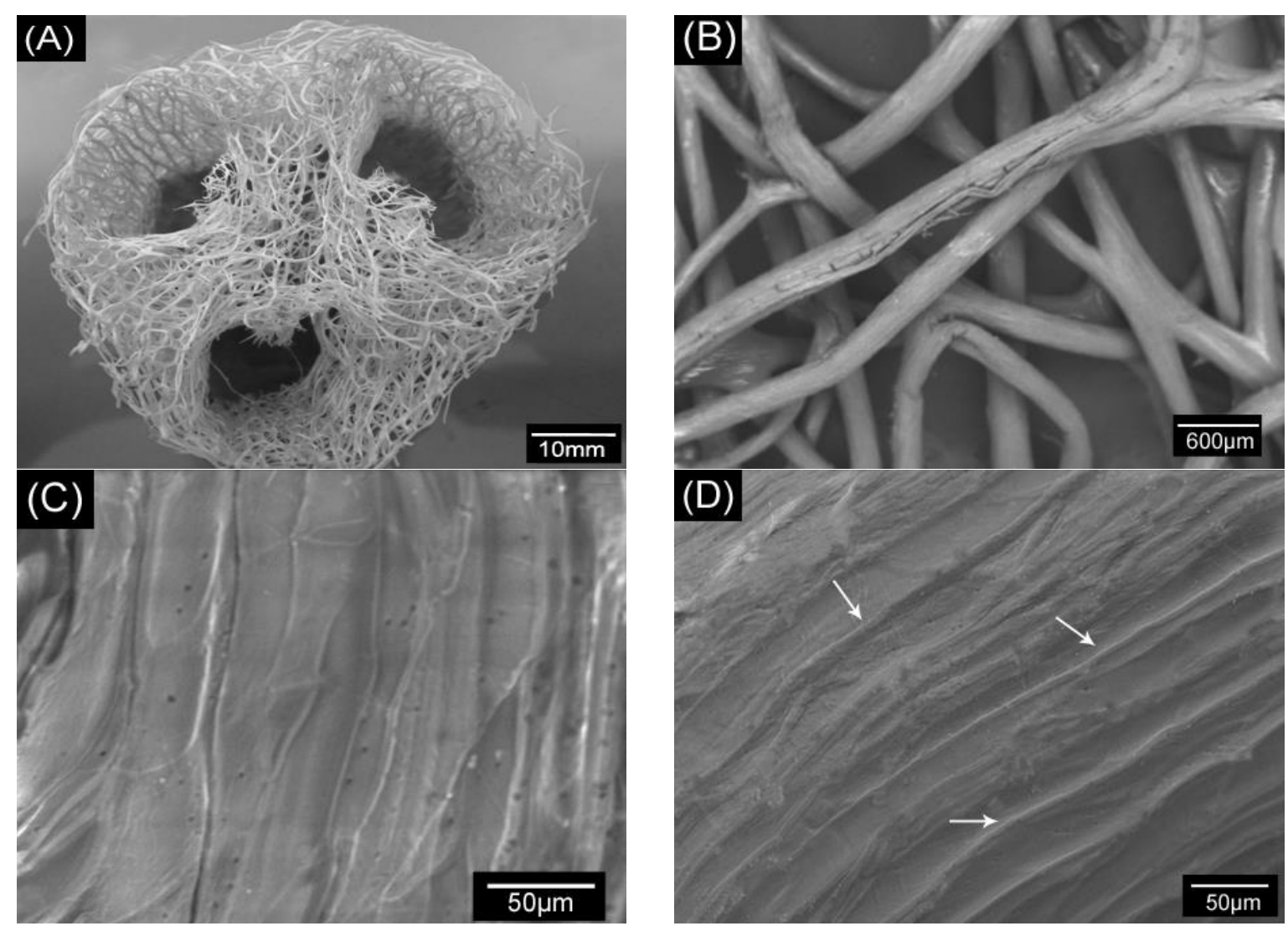

FIGURA 59 - Esponja vegetal Luffa Cylindrica (LCy). Em (A) perspectiva macroscópica da esponja; (B) micrografia das fibras da LCy dispostas em arranjo matricial e aleatório; micrografias das superfícies das fibras (C) como recebido e (D) após o tratamento com $2 \%$ massa de $\mathrm{NaOH}$, onde as ranhuras e micro canais estão indicados pelas setas.

Com o tratamento à base de $2 \%$ massa de $\mathrm{NaOH}$ a $60^{\circ} \mathrm{C}$ por $2 \mathrm{~h}$, notase que as substâncias como celulose e lignina foram removidas da superfície das fibras, conforme indicado respectivamente nas FIG. 59C e FIG. 59D. Como resultado, as fibras apresentaram ranhuras e microcanais (indicados pelas setas) na superfície devido à remoção da lignina e hemicelulose ${ }^{[224]}$. No trabalho de TANOBE et al. ${ }^{[224]}$ foi obtido resultado semelhante utilizando-se a solução com $2 \%$ massa de $\mathrm{NaOH}$, contudo a uma temperatura de $100^{\circ} \mathrm{C}$ por $1,5 \mathrm{~h}$. Possivelmente esta diferença nos parâmetros utilizados está associada a fatores como espécie da bucha vegetal, variedade, tipo de solo, condições climáticas e idade da planta. Portanto, o tratamento alcalino a $60^{\circ} \mathrm{C}$ por $2 \mathrm{~h}$ foi eficiente para 
limpar a superfície das fibras e pode favorecer uma impregnação mais eficiente da suspensão cerâmica na superfície das fibras da LCy.

\subsection{Impregnação das fibras vegetais}

Os resultados de impregnação das fibras de LCy não tratadas e condicionadas via o tratamento alcalino estão indicados na FIG. 60. Conforme apresentado na FIG. 60A, as fibras não tratadas apresentaram-se pouco impregnadas. As substâncias como lignina e celulose presentes na superfície das fibras dificultaram a impregnação da suspensão cerâmica. Nesta condição, o ganho de massa da amostra foi de $7 \%$.

Para as amostras de LCy tratadas com $2 \%$ massa de $\mathrm{NaOH}$ (FIG. 60B), nota-se uma camada espessa de dissilicato de ítrio impregnado na superfície das fibras. Neste caso, o ganho de massa da amostra foi mais significativo, $750 \%$. Baseado nestes resultados, o tratamento com $2 \%$ massa de $\mathrm{NaOH}$ a $60^{\circ} \mathrm{C}$ por duas horas foi eficiente para limpar a superfície das fibras de LCy. O condicionamento das amostras de LCy a partir da remoção de substâncias solúveis em $\mathrm{NaOH}$ favorece $\mathrm{o}$ aparecimento de ranhuras e microcanais na superfície das fibras, os quais proporcionam melhor impregnação da suspensão cerâmica.
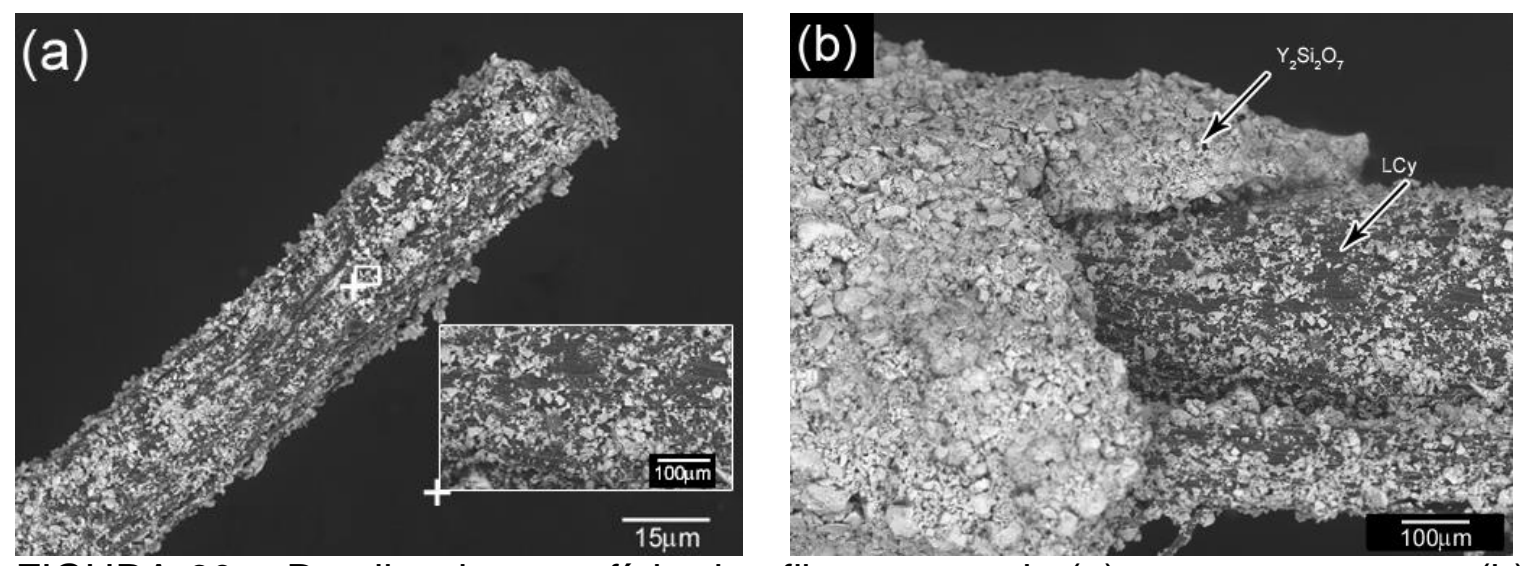

FIGURA 60 - Detalhe da superfície das fibras vegetais (a) sem tratamento e (b) com tratamento alcalino, ilustrando a adesão da suspensão na superfície das mesmas. 


\subsection{Tratamento térmico das amostras impregnadas}

Os resultados das análises termogravimétrica (ATG) e termodiferencial (ATD) da esponja vegetal LCy avaliada até $800^{\circ} \mathrm{C}$ em atmosfera ambiente são apresentados na FIG. 61. Pela ATG (curva em vermelho), verifica-se que a degradação da amostra de LCy é maior na faixa de temperatura entre $250^{\circ} \mathrm{C}$ e $450^{\circ} \mathrm{C}$, correspondendo à $76 \%$ de perda de massa. A degradação da amostra continua até $500^{\circ} \mathrm{C}$. A partir desta temperatura, nota-se que a curva ATG permanece constante até a temperatura limite do ensaio. Portanto, verifica-se que a amostra de LCy foi totalmente degradada a $500^{\circ} \mathrm{C}$. Segundo a literatura ${ }^{[222,223,}$ ${ }^{239,240]}$, as fibras vegetais degradam-se na faixa de temperatura entre $500-850^{\circ} \mathrm{C}$ em atmosfera ambiente, onde o percentual de cinzas corresponde a menos de $0,5 \%$ da massa inicial da amostra.

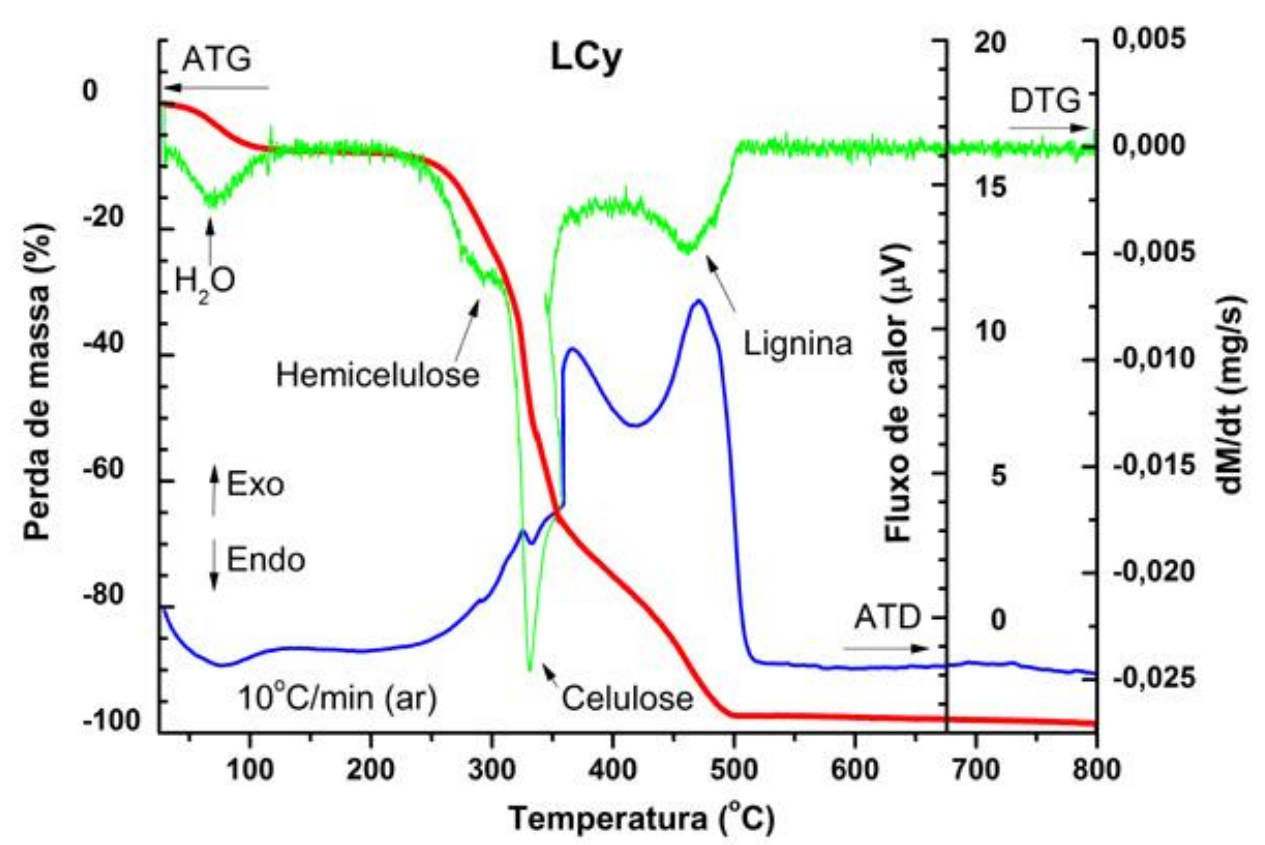

FIGURA 61 - Análises térmicas das fibras da LCy à taxa de aquecimento de $10^{\circ} \mathrm{C} \cdot \mathrm{min}^{-1}$ até $800^{\circ} \mathrm{C}$ em atmosfera ambiente.

Pela ATD (FIG. 61, curva azul), observam-se picos característicos correspondentes à decomposição das principais substâncias constituintes da LCy (FIG. 61, curva azul) e DTG (FIG. 61, curva verde). Com o aumento da temperatura a $100^{\circ} \mathrm{C}$ nota-se o pico endotérmico correspondente à eliminação de água. Os picos que identificam a degradação das principais substâncias que 
constituem as fibras são observados respectivamente nas temperaturas de: $280^{\circ} \mathrm{C}$ hemicelulose $\left(100-280^{\circ} \mathrm{C}\right), 330^{\circ} \mathrm{C}$ celulose $\left(280-350^{\circ} \mathrm{C}\right)$ e $490^{\circ} \mathrm{C}$ lignina $\left(350-500^{\circ} \mathrm{C}\right)^{[223,241]}$.

Na FIG. 62 mostram-se o os padrões de difração de raios $X$ da amostra LCy in natura (FIG. 62a) e das cinzas da LCy resultantes da calcinação a $800^{\circ} \mathrm{C}$ por $1 \mathrm{~h}$ em atmosfera ambiente (FIG. 62b). De acordo com os resultados, verifica-se que as fibras da LCy (FIG. 62a) apresentam um pico indicativo de ordenamento de curto alcance em torno de $23^{\circ}$, possivelmente relacionado ao seu principal constituinte, a celulose ${ }^{[222]}$. De modo geral, as cinzas resultantes da calcinação das fibras vegetais são constituídas de substâncias inorgânicas presentes no tecido da planta e provenientes do solo, como $\mathrm{Na}, \mathrm{Mg}, \mathrm{K}, \mathrm{P}, \mathrm{Ca}, \mathrm{Cl}$, $\mathrm{SiO}_{2}$ e silicatos ${ }^{[222,}{ }^{223]}$. Pelo padrão de difração de raios $X$ (FIG. 62b) são observados picos relacionados majoritariamente aos compostos de $\mathrm{CaSi}_{2} \mathrm{O}_{5}\left(30^{\circ}\right.$, $33^{\circ}, 36-60^{\circ}$; PDF.51-92) e $\mathrm{SiO}_{2}$ (21-29 , PDF. 14-260). Além disso, verificam-se também dois picos referentes ao $\mathrm{P}_{2} \mathrm{O}_{5}\left(34^{\circ}\right.$ e $35^{\circ}$; PDF 83-602).

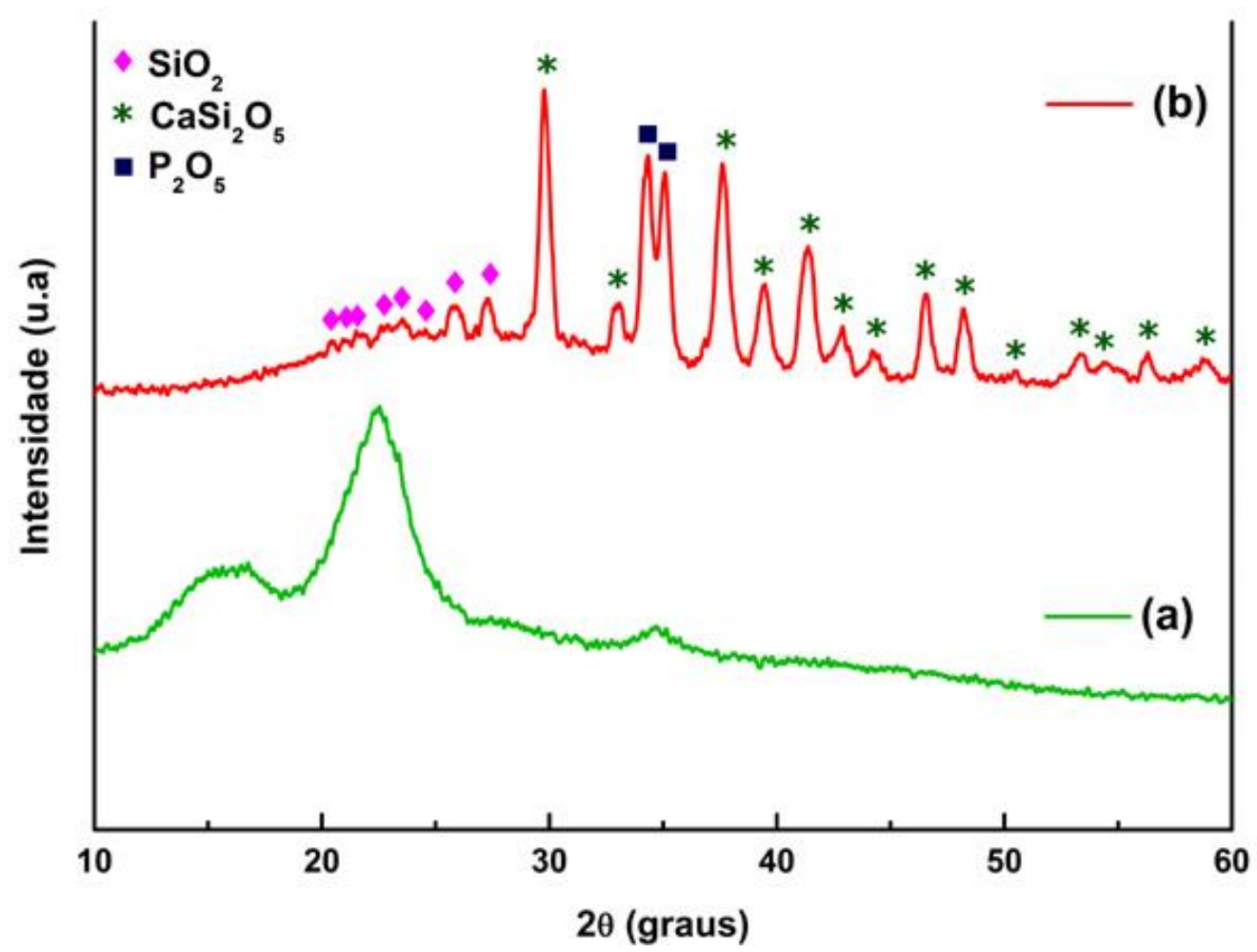

FIGURA 62 - Padrões de difração de raios X das fibras vegetais LCy. Em (a) LCy in natura e (b) cinzas da LCy resultantes da calcinação com taxa de aquecimento de $10^{\circ} \mathrm{C} / \mathrm{min}$ até $800^{\circ} \mathrm{C} / 1 \mathrm{~h}$ em atmosfera ambiente. 
Baseado nos resultados da ATG e ATD das fibras de LCy foram propostas e avaliadas diversas condições de tratamento térmico para as amostras impregnadas, onde algumas dessas condições estão relacionadas na TAB. 12. De acordo com os resultados, verifica-se que a taxa de aquecimento é um fator determinante na etapa de pré-queima. As condições de pré-queima de 1-4 com taxas de aquecimento superiores a $1^{\circ} \mathrm{C} \cdot \mathrm{min}^{-1}$, em diferentes temperaturas $\mathrm{e}$ patamares, mostraram-se inadequadas para decompor a matriz vegetal de LCy e promover o início da consolidação da fase cerâmica, resultando portanto na fragmentação das amostras. A condição de taxa de aquecimento de $1^{\circ} \mathrm{C} \cdot \mathrm{min}^{-1}$ nas temperaturas de $150 / 250 / 1000^{\circ} \mathrm{C}$ com os respectivos patamares de $8 / 8 / 2 \mathrm{~h}$ proporcionou amostras pré-queimadas íntegras. Portanto, dentre as condições avaliadas, a condição de número 5 mostrou-se mais adequada.

Quanto à etapa de sinterização, as amostras tratadas a $1500^{\circ} \mathrm{C}$ por até $5 \mathrm{~h}$ mostraram-se frágeis. A condição de tratamento térmico por $7 \mathrm{~h}$ resultou em amostras com resistência mecânica ao manejo e microestrutura porosa. Portanto, baseado em todos os resultados apresentados, a condição de tratamento térmico determinada para as amostras de LCy impregnadas neste estudo consiste na condição de pré-queima 5 e condição de sinterização 4.

TABELA 12 - Condições de tratamento térmico propostas para as amostras de LCy impregnadas

\begin{tabular}{|c|c|c|c|c|c|}
\hline \multirow{6}{*}{ 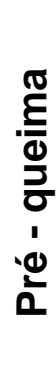 } & Condição & $\mathrm{Tx} . \mathrm{AQ}\left({ }^{\circ} \mathrm{C} / \mathrm{min}\right)$ & $\mathrm{T}\left({ }^{\circ} \mathrm{C}\right)$ & PT (h) & Resultado \\
\hline & 1 & 3 & $150 / 350 / 1000$ & $4 / 4 / 2$ & Fragmentou \\
\hline & 2 & 2 & $150 / 350 / 1000$ & $12 / 4 / 4$ & Fragmentou \\
\hline & 3 & 2 & $150 / 250 / 1000$ & $4 / 12 / 4$ & Fragmentou \\
\hline & 4 & 2 & $150 / 250 / 1000$ & $4 / 4 / 2$ & Fragmentou \\
\hline & 5 & 1 & $150 / 250 / 1000$ & $8 / 8 / 2$ & İntegra \\
\hline \multirow{4}{*}{$\stackrel{\vec{E}}{\text { के }}$} & 1 & 2 & 1500 & 1 & Muito frágil \\
\hline & 2 & 2 & 1500 & 3 & Frágil \\
\hline & 3 & 2 & 1500 & 5 & Frágil \\
\hline & 4 & 2 & 1500 & 7 & Resistente \\
\hline
\end{tabular}

Tx.AQ: Taxa de aquecimento; T: Temperatura; PT: Patamar.

Sint: Sinterização. 


\subsection{Caracterização microestrutural dos protótipos}

Com o propósito de confeccionar componentes para iluminação, a matriz vegetal LCy foi modelada na forma de bulbo de lâmpada (FIG. 63 a FIG. 66). Todas as amostras impregnadas com as suspensões cerâmicas apresentaram uma mudança relativa às suas formas originais devido à compressão das mesmas para a retirada do excesso de suspensão durante o processo de conformação.

Na FIG. 63a é mostrado o protótipo de queimador de gás à base de $\beta-Y_{2} \mathrm{Si}_{2} \mathrm{O}_{7}$ sinterizado a $1500^{\circ} \mathrm{C}$ por $7 \mathrm{~h}$. Nesta condição, o componente final apresentou perda de massa de $5 \%$ com relação a amostra a verde, densidade picnométrica de $3,21 \mathrm{~g} \cdot \mathrm{cm}^{-3}\left(80 \% \rho_{\mathrm{T}}\right)$, morfologia reticulada e sem trincas aparentes. Pela FIG. 63b, observa-se que as fibras foram impregnadas uniformemente, onde a disposição aleatória das mesmas foi mantida. As micrografias de superfície (FIG. 64 63c e FIG. 63d) e da região interna da fibra (FIG. 63e e FIG. 63f) das fibras revelam microestruturas porosas e homogêneas.

$O$ protótipo à base de $\beta-Y_{1,95} \mathrm{Dy}_{0,05} \mathrm{Si}_{2} \mathrm{O}_{7}$ (FIG. 64a) foi obtido nas mesmas condições estabelecidas para $\circ \quad \beta-Y_{2} \mathrm{Si}_{2} \mathrm{O}_{7}$. O componente final apresentou perda de massa de $6 \%$ com relação a amostra a verde, densidade picnométrica de $3,23 \mathrm{~g} \cdot \mathrm{cm}^{-3}\left(80 \% \rho_{\mathrm{T}}\right)$, morfologia reticulada e sem trincas aparentes. Pela FIG. 63 64b, observa-se que as fibras foram impregnadas uniformemente. Observa-se pelas micrografias de superfície (FIG. 64c FIG. 64d) a formação de poros esféricos de diâmetro superior a $10 \mu \mathrm{m}$ distribuídos por toda a fibra. As micrografias da região interna das fibras (FIG. 64e e FIG. 64f) revelam microestruturas porosas com grãos de tamanho superior a $1 \mu \mathrm{m}$ e morfologia heterogênea.

No geral, para os protótipos à base de dissilicato de ítrio, verifica-se que a microestrutura porosa é resultado da eliminação da fibra durante o tratamento térmico, como também da impregnação da suspensão constituída de particulas floculadas pela adição de CMC. Quando o ligante dissolve em água, suas macromoléculas podem ser simultaneamente adsosrvidas em duas ou mais partículas, promovendo a floculação das mesmas pelo mecanismo de ponte. 
Como consequência, a sinterização de componentes constituídos de aglomerados de partículas geralmente resulta em peças com microestrutura porosa ${ }^{[142]}$.

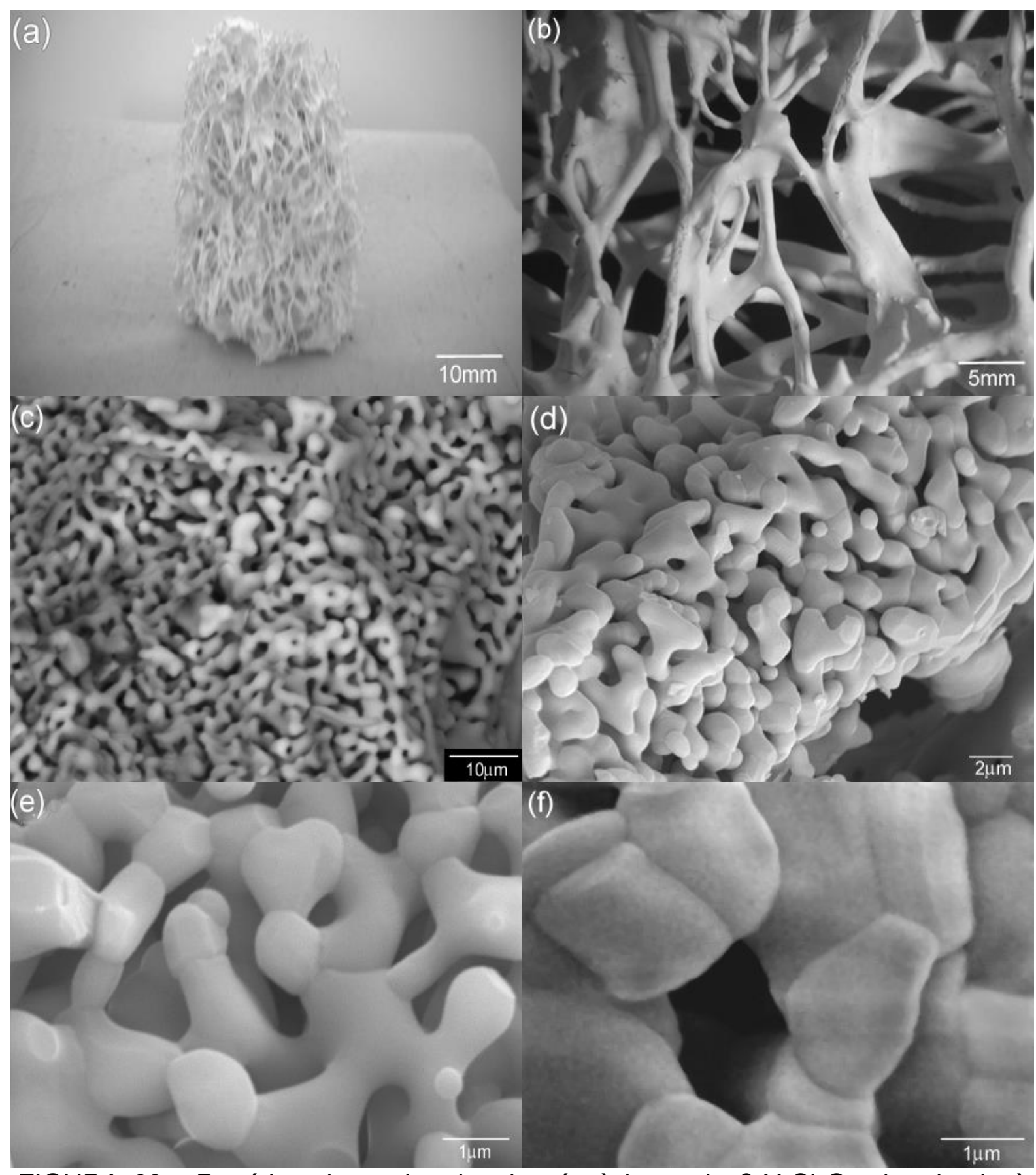

FIGURA 63 - Protótipo de queimador de gás à base de $\beta-\mathrm{Y}_{2} \mathrm{Si}_{2} \mathrm{O}_{7}$ sinterizado à $1500^{\circ} \mathrm{C}$ por $7 \mathrm{~h}$ em atmosfera ambiente. Em (a) protótipo em forma de bulbo à partir da réplica LCy; (b) disposição aleatória das fibras constituintes do bulbo; (c) microestrutura porosa do bulbo; (d) superfície da fibra e (e) superfície interna da fibra de estrutura reticulada com poros de tamanho inferior a $2 \mu \mathrm{m}$; (f) superfície interna da fibra constituída de grãos de tamanho e formato heterogêneos. 


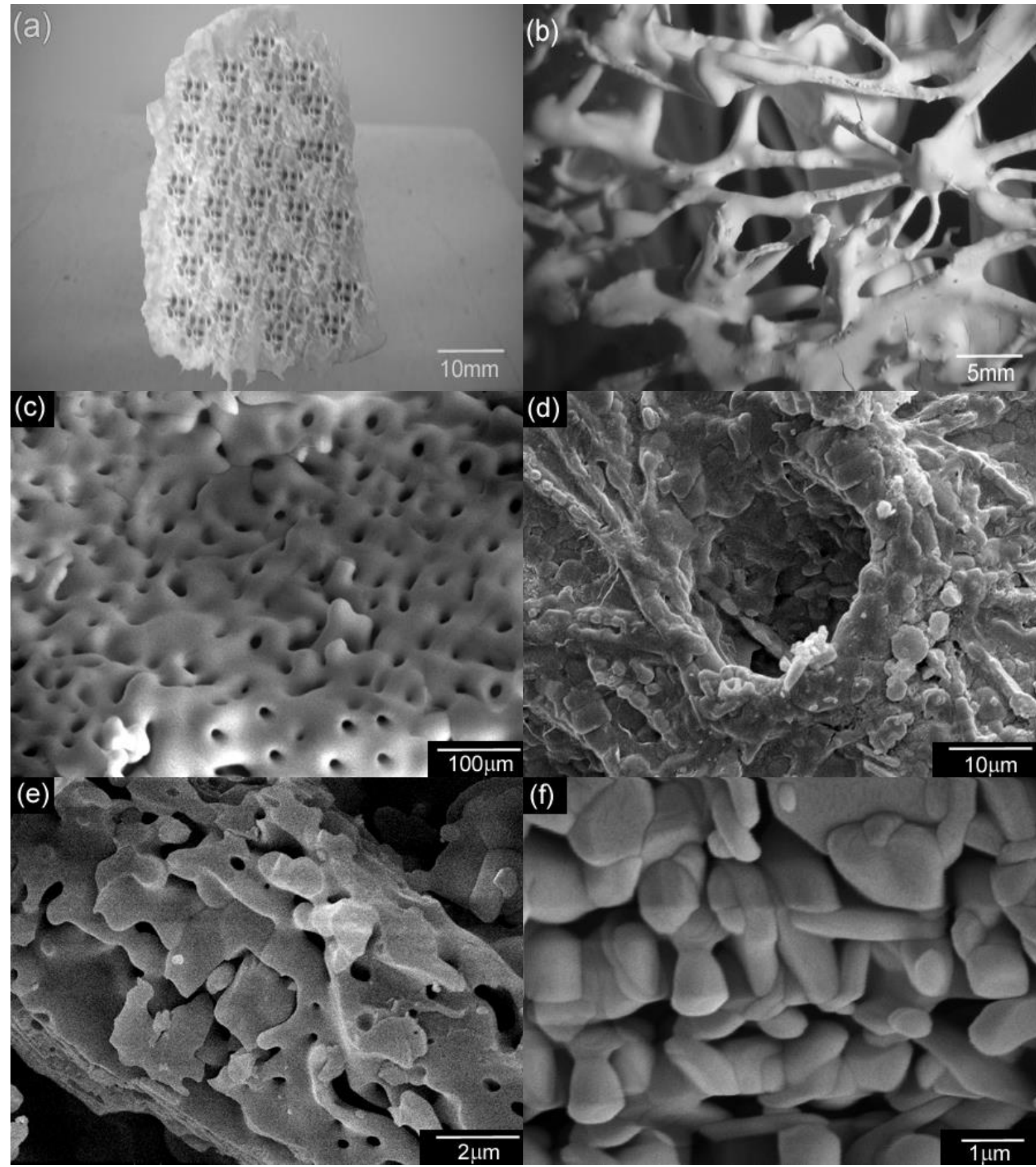

FIGURA 64 - Protótipo de queimador de gás à base de $\beta-Y_{1,95} \mathrm{Dy}_{0,05} \mathrm{Si}_{2} \mathrm{O}_{7}$ sinterizado a $1500^{\circ} \mathrm{C}$ por $7 \mathrm{~h}$ em atmosfera ambiente. Em (a) protótipo em forma de bulbo; (b) fibras; (c) microestrutura porosa do bulbo; (d) detalhe do poro presente na superfície da fibra e (e) superfície porosa da fibra; (f) superfície interna da fibra. 
O protótipo de $\mathrm{Y}_{2} \mathrm{O}_{3}$ sinterizado a $1600^{\circ} \mathrm{C}$ por 2h (FIG. 65a) apresentou perda de massa de $6 \%$ em relação a amostra a verde e densidade picnométrica de $4,55 \mathrm{~g}_{\mathrm{cm}} \mathrm{cm}^{-3}\left(90 \% \rho_{\mathrm{T}}\right)$, morfologia reticulada (FIG. 65b) e sem trincas aparentes (FIG. 65c). Pela micrografia da FIG. 65d, verifica-se que a superfície das fibras apresenta microsestrutura relativamente porosa, com distribuição heterogênea de tamanho e forma de grãos e poros. Em estudo anterior ${ }^{[139]}$ também foi observada esta condição para a microestrutura das telas de ítria sinterizadas a $1600^{\circ} \mathrm{C}$ por $1 \mathrm{~h}$ em atmosfera ambiente.

Observa-se na região interna da fibra de $\mathrm{Y}_{2} \mathrm{O}_{3}$ (FIG. 65e) uma

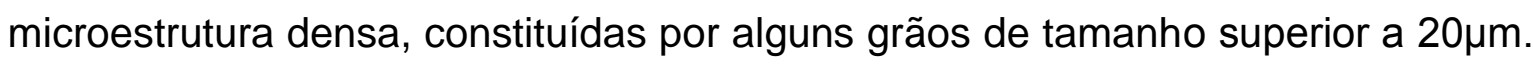
Pela micrografia de fratura (FIG. 65f), nota-se que as fibras apresentaram fratura intergranular, revelando a morfologia tridimensional dos grãos de tamanho e forma distintos.

O queimador de YTR (FIG. 66a) obtido nas mesmas condições estabelecidas para $\circ \mathrm{Y}_{2} \mathrm{O}_{3}$, apresentou perda de massa de $7 \%$, densidade picnométrica de $6,03 \mathrm{~g} . \mathrm{cm}^{-3}\left(100 \% \rho_{\mathrm{T}}\right)$ e morfologia reticulada análoga a matriz vegetal (FIG. 66b). Pelas micrografias de superfície das fibras (FIG. 66c e FIG. 66d), observa-se que as fibras apresentam microsestrutura densa, com distribuição heterogênea de tamanho e forma de grãos. Em estudo anterior também foi observada esta condição para a microestrutura de telas de YTR sinterizadas à $1600^{\circ} \mathrm{C}$ por $1 \mathrm{~h}^{[141]}$. A partir da micrografia de fratura das fibras de YTR (FIG. 66e, FIG. 66f), observa-se que as fibras apresentaram modo de fratura transgranular.

Baseado nos resultados apresentados, demostra-se que é possível obter bulbos cerâmicos porosos para a aplicação em queimadores de gás pelo processo de conformação por réplica, utilizando-se a esponja vegetal Luffa Cylindrica como matriz após condicionamento das fibras pelo tratamento alcalino, as suspensões aquosas otimizadas e o tratamento térmico das amostras impregnadas nas melhores condições estabelecidas. 


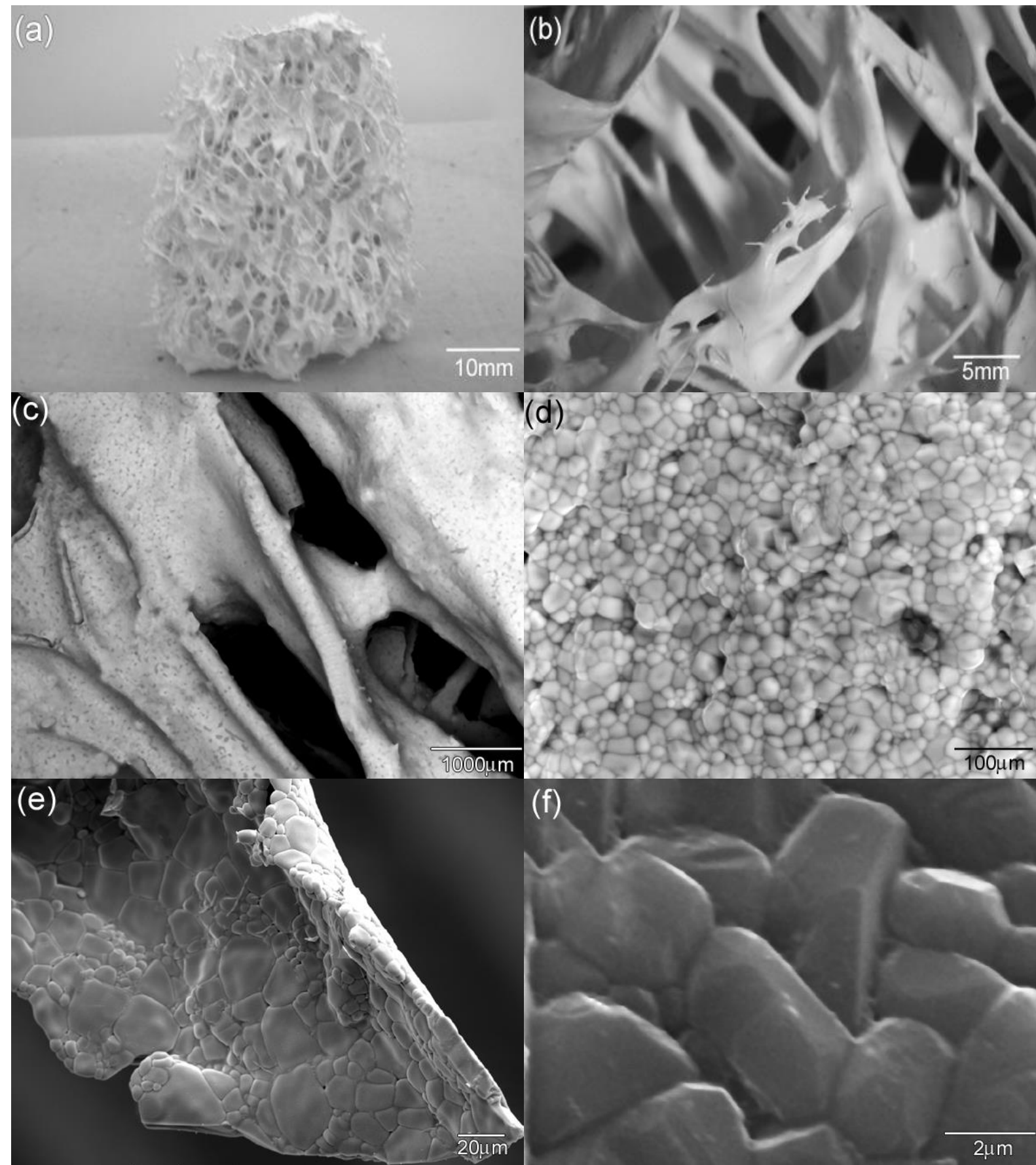

FIGURA 65 - Protótipo de queimador de gás à base de $\mathrm{Y}_{2} \mathrm{O}_{3}$ sinterizado a $1600^{\circ} \mathrm{C}$ por $2 \mathrm{~h}$ em atmosfera ambiente. Em (a) protótipo em forma de bulbo à partir da réplica LCy; (b) disposição aleatória das fibras constituintes do bulbo; (c) micrografia da estrutura reticulada do bulbo; (d) microestrutura porosa da superfície da fibra (e) camada interna da fibra constituída de grãos de tamanho e formato heterogêneos; (f) superfície interna da fibra em fratura de modo intergranular. 


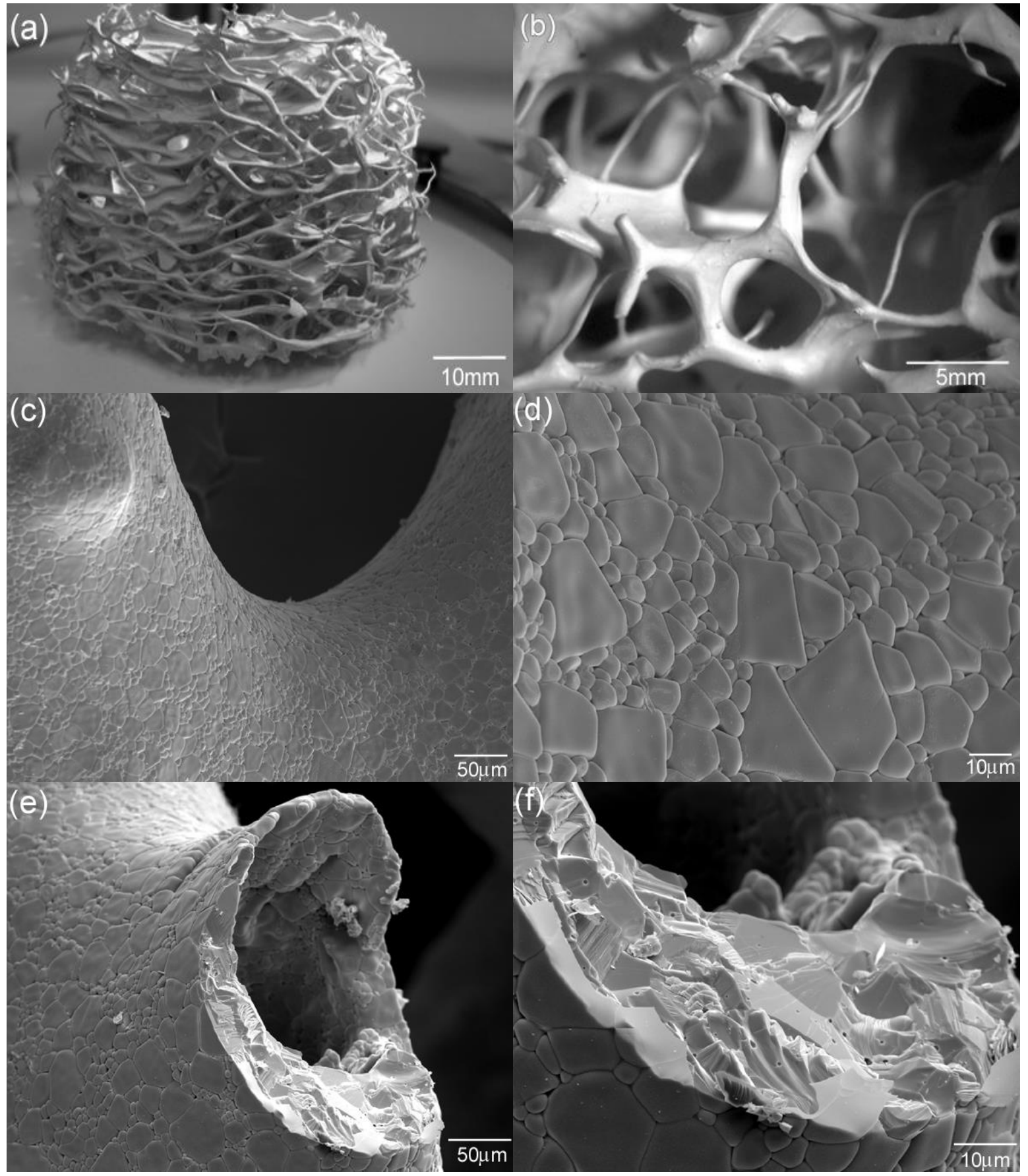

FIGURA 66 - Protótipo de queimador de gás à base de YTR sinterizado a $1600^{\circ} \mathrm{C}$ por $2 \mathrm{~h}$ em atmosfera ambiente. Em (a) protótipo em forma de bulbo à partir da réplica LCy; (b) disposição aleatória das fibras constituintes do bulbo; (c) microestrutura porosa do bulbo; (d) superfície da fibra e (e) superfície de fratura da fibra de estrutura reticulada com poros de tamanho inferior a $2 \mu \mathrm{m}$; (f) superfície interna da fibra em fratura de modo transgranular. 


\subsection{Luminescência estimulada pela temperatura}

Na FIG. 67 é apresentado o espectro de emissão de luz estimulada pela temperatura do $\beta-\mathrm{Y}_{2} \mathrm{Si}_{2} \mathrm{O}_{7}$. Conforme indicado na FIG. $67 \mathrm{a}$, o $\beta-\mathrm{Y}_{2} \mathrm{Si}_{2} \mathrm{O}_{7}$ não mostra nenhum pico de emissão no espectro visível $(\lambda=350-750 \mathrm{~nm})$. A emissividade do material ocorreu na faixa do infravermelho $(\lambda=750-4300 \mathrm{~nm}) \mathrm{com}$ $\lambda=1000 \mathrm{~nm}$ na temperatura de $400^{\circ} \mathrm{C}$, comportamento análogo aos emissores de corpo negro (FIG. 67b). Nesta condição, quando um sólido é aquecido, a partir de $200^{\circ} \mathrm{C}$ começa a emitir radiação na forma de um espectro contínuo, cuja intensidade aumenta em função do aumento da temperatura. Grande parte desta radiação é invisível a olho nú (ultravioleta e infravermelho) e apenas uma pequena fração ocorre na faixa do espectro do visível ${ }^{[103]}$.

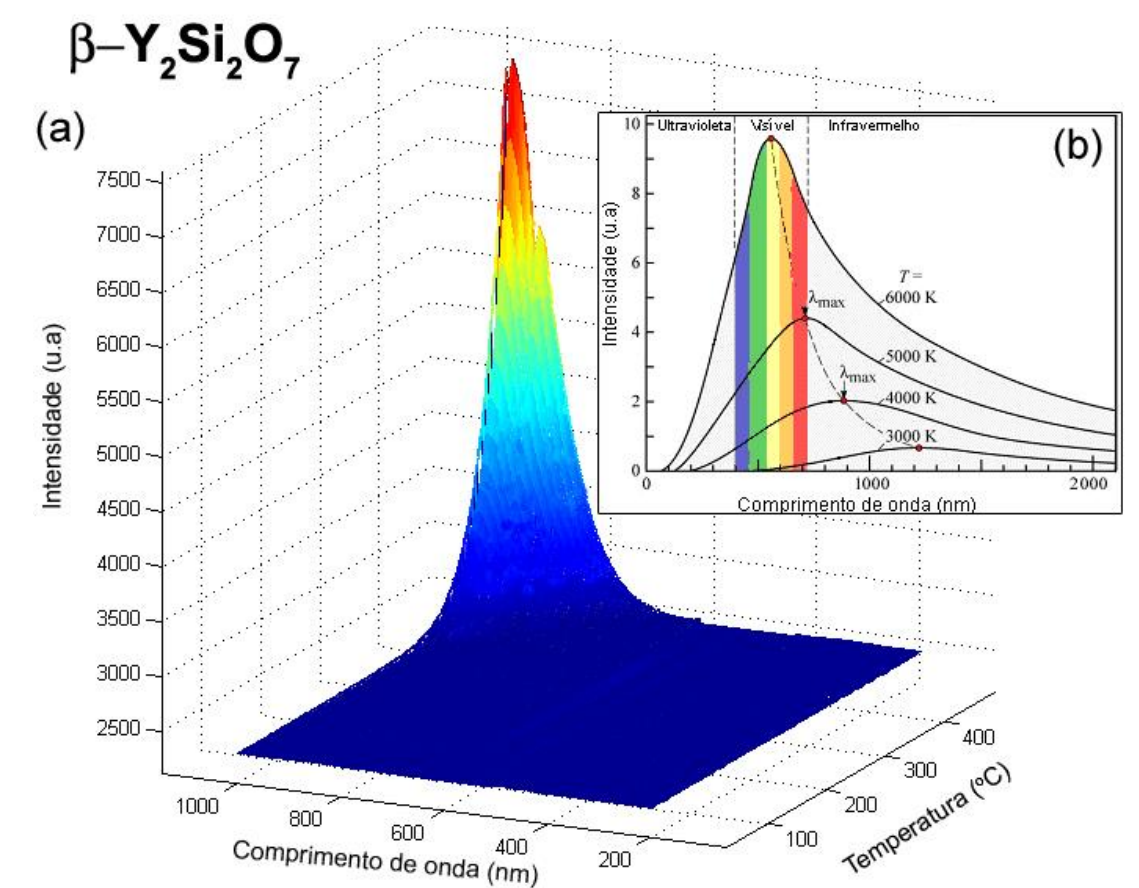

FIGURA 67 - Termoluminescência da amostra $\beta-\mathrm{Y}_{2} \mathrm{Si}_{2} \mathrm{O}_{7}$. Em (a) espectro de emissão de luz à taxa de $10^{\circ} \mathrm{C} . \mathrm{s}^{-1}$ até $400^{\circ} \mathrm{C}$ em atmosfera ambiente, com emissão de luz análoga ao corpo negro; (b) espectro padrão de emissão do corpo negro.

Conforme mostrado na FIG. 68, observa-se que o $\beta-Y_{1,95} \mathrm{Dy}_{0,05} \mathrm{Si}_{2} \mathrm{O}_{7}$ apresentou emissão no espectro visível, com intensidade máxima em $\lambda=580 \mathrm{~nm}$ 
(correspondente ao amarelo) na temperatura de $180^{\circ} \mathrm{C}$. Segundo a Comissão Internacional de lluminação ("Commission International de l'Eclairage", CIE), a luz amarela é muito indicada para iluminação de ambientes internos, onde se pretende criar uma condição de conforto e aconchego ${ }^{[207]}$.

A emissão de luz visível nesta temperatura é inédita na literatura. QIU et al. ${ }^{[242]}$ desenvolveram um protótipo de queimador de gás à base de $\mathrm{Yb}_{2} \mathrm{O}_{3}: \mathrm{CeO}_{2}$, cuja emissão de luz branca foi determinada na temperatura de $550^{\circ} \mathrm{C}$. VAKHIDOV et al. ${ }^{[243]}$ obtiveram $\beta-Y_{1,95} \mathrm{Dy}_{0,05} \mathrm{Si}_{2} \mathrm{O}_{7}$ com emissão de luz a $\lambda=540 \mathrm{~nm}$. GONZALÉZ-ORTEGA et al. ${ }^{[244]}$ determinaram três emissões intensas correspondentes ao branco, vermelho e verde respectivamete para os compostos $\mathrm{Y}_{2} \mathrm{Si}_{2} \mathrm{O}_{7}: \mathrm{Ce}^{3+}: \mathrm{Tb}^{3+}, \mathrm{Y}_{2} \mathrm{Si}_{2} \mathrm{O}_{7}: \mathrm{Eu}^{3+}$ e $\mathrm{Y}_{2} \mathrm{Si}_{2} \mathrm{O}_{7}: \mathrm{Tb}^{3+}$ quando estimulados por radiação ultravileta.

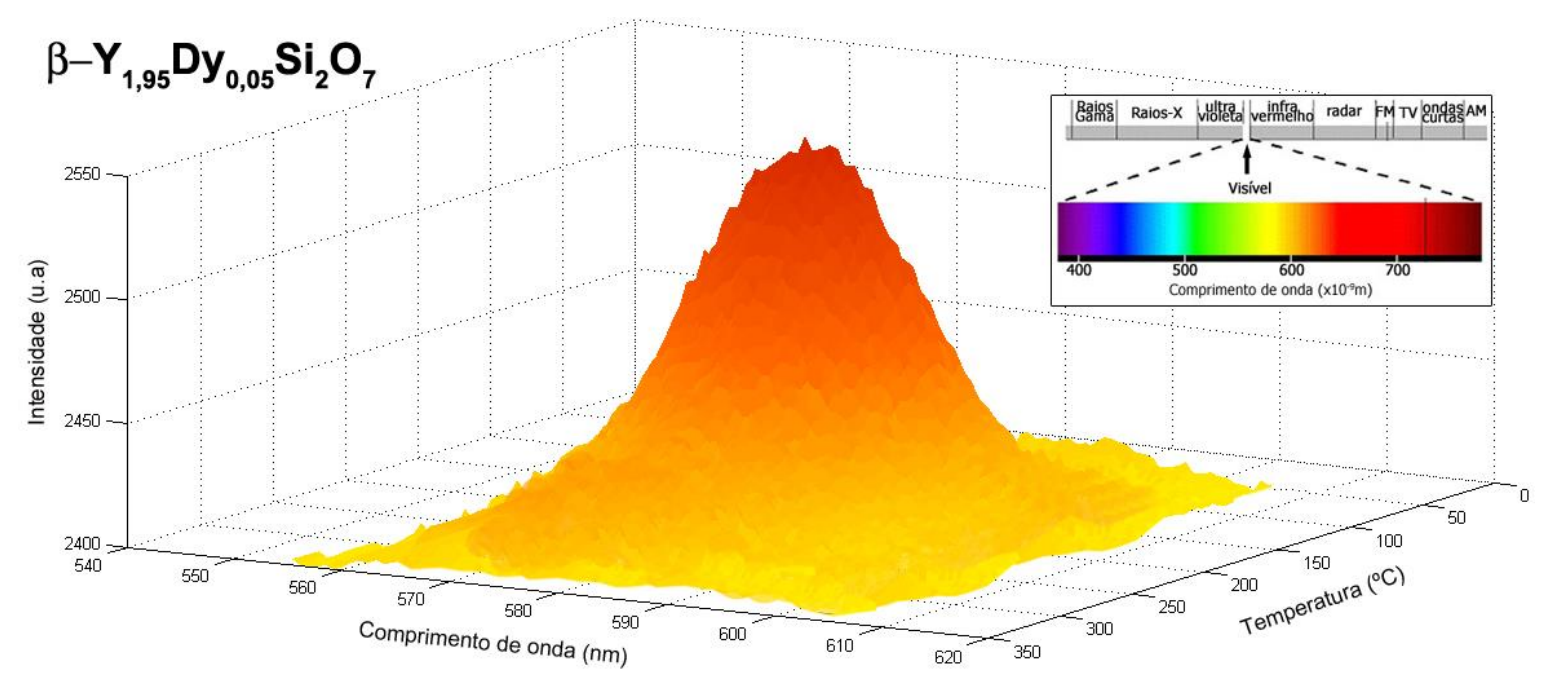

FIGURA 68 - Termoluminescência da amostra $\beta-Y_{1,95} \mathrm{Dy}_{0,05} \mathrm{Si}_{2} \mathrm{O}_{7}$ à taxa de $10^{\circ} \mathrm{C} / \mathrm{s}$ até $350^{\circ} \mathrm{C}$ em atmosfera ambiente, com emissão no comprimento de onda visível $(\lambda=580 \mathrm{~nm})$, correspondente à cor amarela.

Na FIG. 69 é apresentado o espectro de emissão de luz estimulada pela temperatura do $\mathrm{Y}_{2} \mathrm{O}_{3}$ quando aquecido à taxa de $10^{\circ} \mathrm{C} . \mathrm{s}^{-1}$ até $350^{\circ} \mathrm{C}$ em atmosfera ambiente. A partir deste resultado, verifica-se que $\circ \mathrm{Y}_{2} \mathrm{O}_{3}$ apresenta emissão no espectro visível ( $\lambda=350-750 \mathrm{~nm})$. A liberação dos elétrons aprisionados ocorre a partir de $100^{\circ} \mathrm{C}$, exibindo emissividade máxima na temperatura de $150^{\circ} \mathrm{C}$, com comprimento de onda $(\lambda)$ da ordem de $550 \mathrm{~nm}$ correspondente à cor verde $^{[139]}$. A partir desta temperatura, observa-se que a intensidade de luz emitida 
diminui. Nesta circunstância, a combinação de elétrons e lacunas na estrutura do material diminui até a condição de equilíbrio (estado fundamental dos elétrons), onde não se observa emissão de luz visível ${ }^{[102]}$.

A luminescência da amostra $\mathrm{Y}_{2} \mathrm{O}_{3}$ possivelmente está associada à presença de impurezas, defeitos cristalinos, ou de superfície. Esses fatores podem produzir vacâncias transportadoras de carga, ou outros centros de luminescência. Grande parte dos trabalhos referentes à luminescência dos materiais à base de óxido de ítrio não apresentam esta particularidade. KAUKAS et al. ${ }^{[229]}$ reportaram que partículas nanométrias de óxido de ítrio exibiram emissão de luz no comprimento de onda de 330nm (luz branca), semelhamente ao material $\mathrm{Y}_{2} \mathrm{O}_{3}: \mathrm{Ce}^{3+}$. Schmidt et al. ${ }^{[245]}$ também observaram emissão de luz branca para nanopartículas de $\mathrm{LaPO}_{4}: \mathrm{Pr}$.

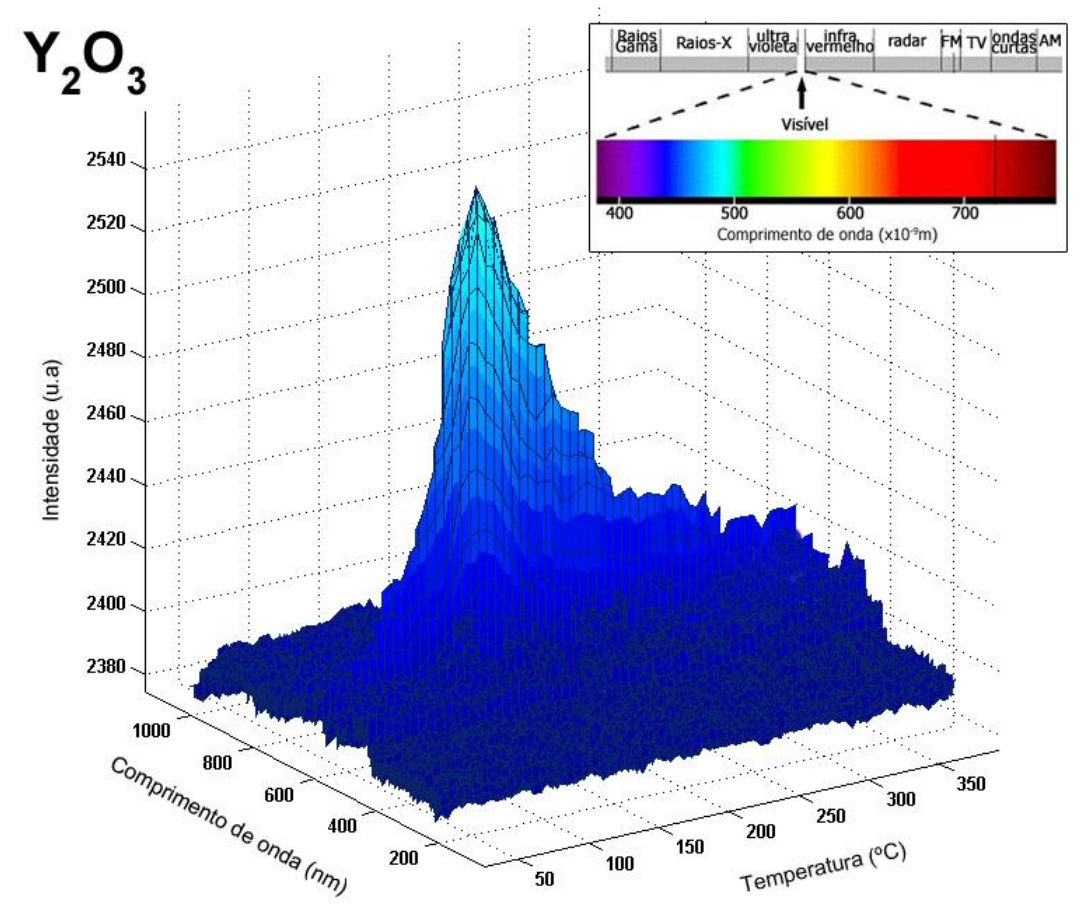

FIGURA 69 - Termoluminescência da amostra $\mathrm{Y}_{2} \mathrm{O}_{3}$ à taxa de $10^{\circ} \mathrm{C} . \mathrm{s}^{-1}$ até $350^{\circ} \mathrm{C}$ em atmosfera ambiente, com emissão no comprimento de onda visível $(\lambda=550 \mathrm{~nm})$, correspondente à cor verde.

Pelo espectro de emissão de luz estimulada pela temperatura do YTR (FIG. 70a), verifica-se que a amostra de YTR não exibe nenhum pico de emissão no espectro visível $(\lambda=350-750 \mathrm{~nm})$. A emissividade do material ocorre na faixa do 
infravermelho com $\lambda=1000 \mathrm{~nm}$ na temperatura de $400^{\circ} \mathrm{C}$, comportamento análogo à amostra $\beta-\mathrm{Y}_{2} \mathrm{Si}_{2} \mathrm{O}_{7}$ e aos emissores de corpo negro (FIG. 70b). A amostra YTR é composta por uma variedade de óxidos de terras raras, onde os de maior concentração são $\mathrm{Y}_{2} \mathrm{O}_{3}$ (56,6\%massa), $\mathrm{Dy}_{2} \mathrm{O}_{3}$ (19,4\%massa), $\mathrm{Er}_{2} \mathrm{O}_{3}$ (6,5\%massa) e $\mathrm{Lu}_{2} \mathrm{O}_{3}$ (4,0\%massa). Possivelmente a interferência de um íon terra rara na emissão de outro pode prejudicar a emissividade total da amostra, resultando na emissão de luz na faixa do ultravioleta e infravermelho.

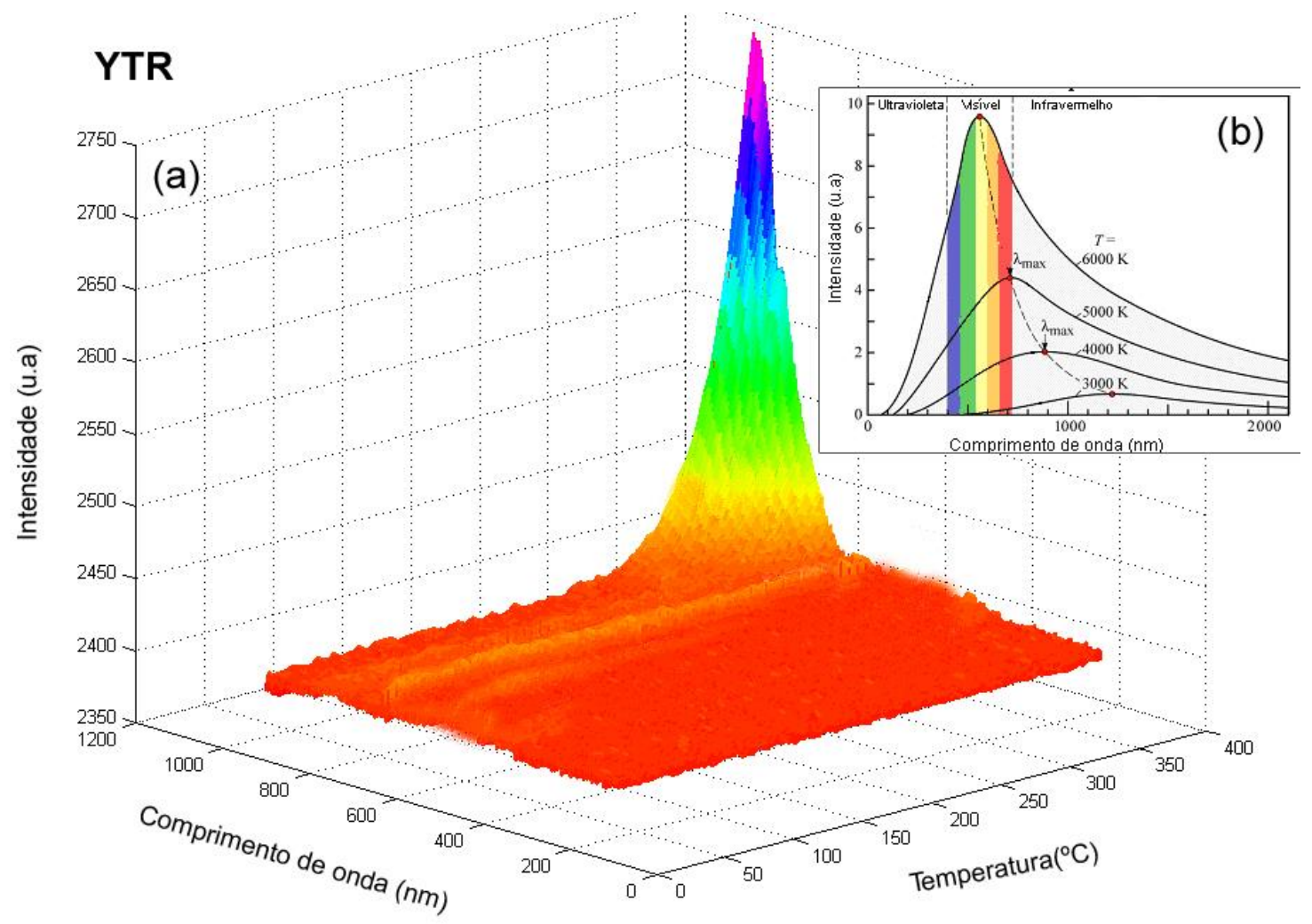

FIGURA 70 - Termoluminescência da amostra YTR. Em (a) espectro de emissão de luz à taxa de $10^{\circ} \mathrm{C} . \mathrm{s}^{-1}$ até $400^{\circ} \mathrm{C}$ em atmosfera ambiente, com emissão de luz análoga ao corpo negro; (b) espectro padrão de emissão do corpo negro.

Pelos resultados mostrados para os materiais estudados, pode-se comprovar a hipótese da capacidade de luminescência estimulada pela temperatura para o dissilicato de ítrio. A luminescência na faixa do visível foi observada para o $\beta-Y_{1,95} \mathrm{Dy}_{0,05} \mathrm{Si}_{2} \mathrm{O}_{7}(\lambda=580 \mathrm{~nm})$, sendo a cor amarelo considerada 
a mais adequada para iluminação de ambientes internos destinados ao repouso ou lazer ${ }^{[246]}$.

\subsection{Eficiência radiante (Nrad)}

A eficiência radiante (Nrad) é um dos parâmetros de desempenho mais importante do queimador de gás, pois indica a capacidade da estrutura reticulada do queimador em converter a energia fornecida pelo combustível em calor. $\mathrm{Na}$ FIG. 71 é mostrado uma estimativa da Nrad determinada a partir da equação 14 para o protótipo de $\beta-Y_{1,95} D y_{0,05} \mathrm{Si}_{2} \mathrm{O}_{7}$ em função da temperatura medida na superfície do queimador e do tipo de gás combustível utilizado. Para os dois tipos de gases combustíveis $\left(\mathrm{CH}_{4}\right.$ e $\left.\mathrm{C}_{4} \mathrm{H}_{10}\right)$, observa-se que a eficiência radiante do queimador aumentou em função da temperatura. Nas condições estabelecidas para 0 ensaio, 0 melhor desempenho foi observado para 0 gás $\mathrm{CH}_{4}$ a temperatura de $600^{\circ} \mathrm{C}(\mathrm{Nrad}=13 \%)$, o mesmo resultado foi obtido no estudo de QIU et al. ${ }^{[242]}$ utilizando um queimador de gás à base de $\mathrm{Yb}_{2} \mathrm{O}_{3}: \mathrm{CeO}_{2}$. Por apresentar maior poder calorífico (11.900 $\left.\mathrm{kcal} . \mathrm{kg}^{-1}\right)$, verifica-se que o gás $\mathrm{C}_{4} \mathrm{H}_{10}$ favoreceu maior temperatura de combustão $\left(675^{\circ} \mathrm{C}\right)$ e uma tendência de aumento da Nrd.

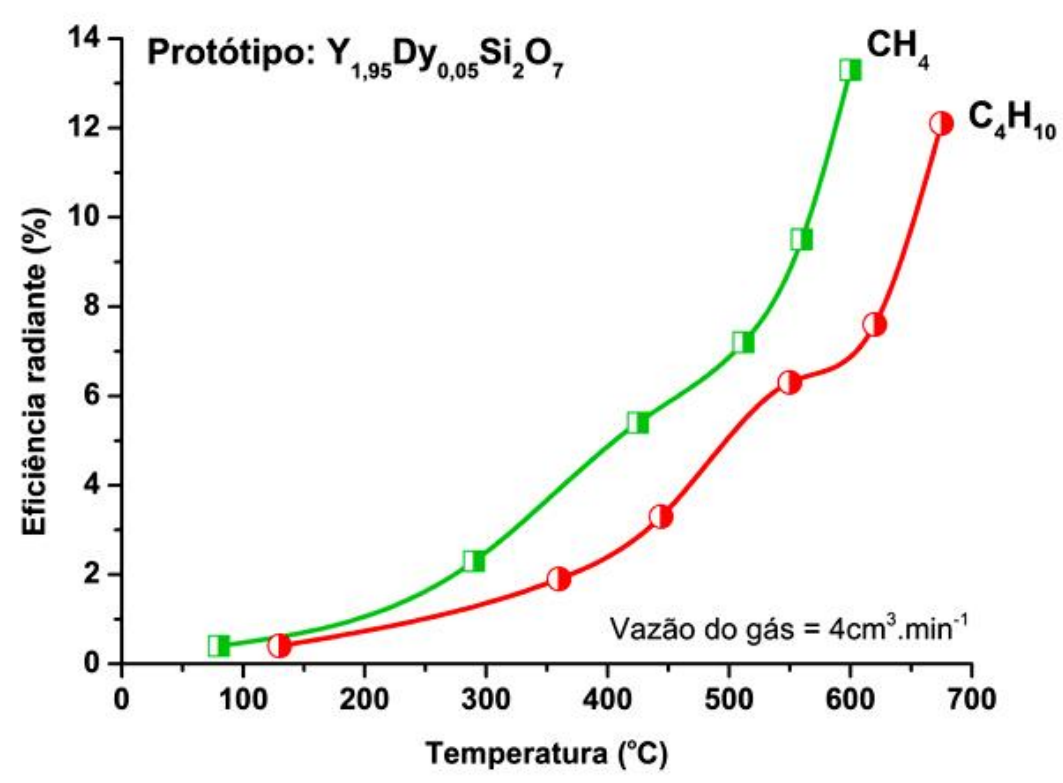

FIGURA 71 - Eficiência radiante do queimador de gás à base de $\beta$ $\mathrm{Y}_{1,95} \mathrm{Dy}_{0,05} \mathrm{Si}_{2} \mathrm{O}_{7}$ em função da temperatura e do tipo de gás combustível utilizado. 
Comprovou-se por este estudo a característica termoluminescente do $\beta-Y_{1,95} \mathrm{Dy}_{0,05} \mathrm{Si}_{2} \mathrm{O}_{7}$ no espectro visível $(\lambda=580 \mathrm{~nm}$ ), conforme ilustrado na FIG. 72 , resultado inédito na literatura. Mostrou-se ainda que o $\beta-Y_{1,95} \mathrm{Dy}_{0,05} \mathrm{Si}_{2} \mathrm{O}_{7}$ apresentou eficiência radiante igual ao $\mathrm{Yb}_{2} \mathrm{O}_{3}: \mathrm{CeO}_{2}$. Verificou-se que o uso do dissilicato de ítrio $\left(\mathrm{Y}_{2} \mathrm{Si}_{2} \mathrm{O}_{7}\right)$ como matriz para obtenção de materiais luminescentes favorece uma redução de ítrio de $35 \%$ em relação ao óxido $\left(\mathrm{Y}_{2} \mathrm{O}_{3}\right)$. Portanto, o dissilicato de ítrio dopado com disprósio $\left(\beta-\mathrm{Y}_{1,95} \mathrm{Dy}_{0,05} \mathrm{Si}_{2} \mathrm{O}_{7}\right)$ é um material promissor para substituir os óxidos de terras raras na composição de lâmpadas de queimadores de gás.

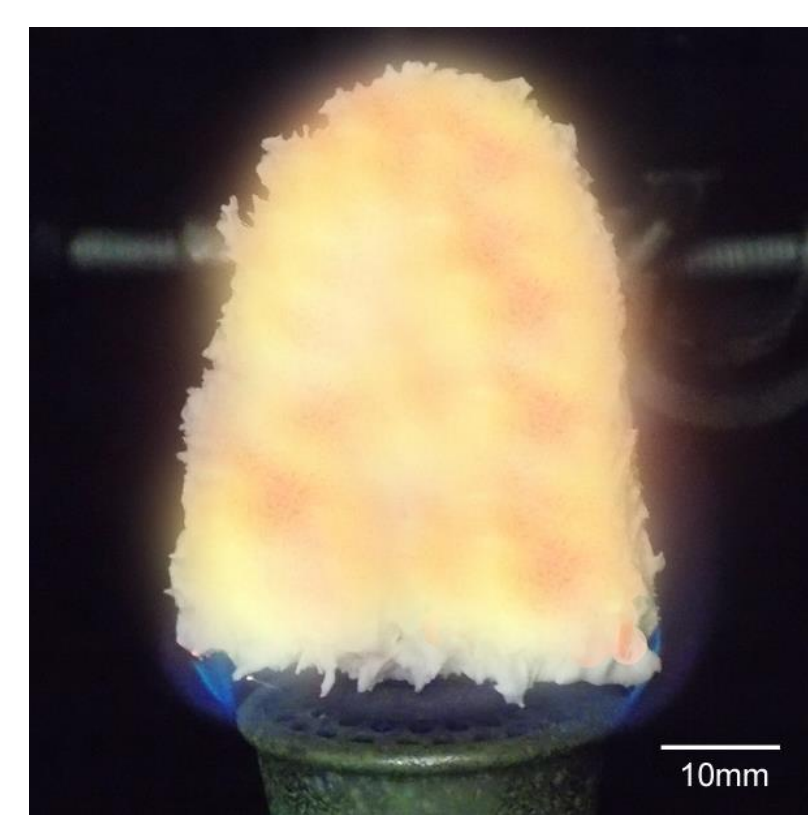

FIGURA 72 - Protótipo de lâmpada de queimador de gás à base de $\beta-Y_{1,95} \mathrm{Dy}_{0,05} \mathrm{Si}_{2} \mathrm{O}_{7}$ durante ensaio de queima de gás metano a temperatura de $600^{\circ} \mathrm{C}$. 


\section{CONCLUSÃo}

Desenvolveu-se um protótipo de lâmpada de queimador de gás com emissividade espectral no visível $(\lambda=580 \mathrm{~nm})$ e eficiência radiante de $13 \%$, por processamento coloidal do beta dissilicato de ítrio dopado com disprósio $\left(\beta-Y_{1,95} \mathrm{Dy}_{0,05} \mathrm{Si}_{2} \mathrm{O}_{7}\right)$, utilizando-se o processo de conformação por réplica a partir da esponja vegetal Lufa Cylindrica.

Definiram-se as condições de síntese via processamento hidrotermal e tratamento térmico do precursor estabelecidas para a obtenção do $\beta-Y_{1,95} \mathrm{Dy}_{0,05} \mathrm{Si}_{2} \mathrm{O}_{7}$ como: tempo de processamento da suspensão do precursor de $6 \mathrm{~h}$, a temperatura de $60^{\circ} \mathrm{C}, \mathrm{pH}=10$, tratamento térmico do precursor a $1400^{\circ} \mathrm{C}$ por 2 horas em atmosfera ambiente.

Determinaram-se os parâmetros de processo para obtenção do protótipo de lâmpada de queimador de gás como: suspensões aquosas com $25 \%$ vol de $\beta-Y_{1,95} \mathrm{Dy}_{0,05} \mathrm{Si}_{2} \mathrm{O}_{7}, \mathrm{pH}=10,2 \%$ massa de dispersante e $0,4 \%$ massa de ligante; fibras da esponja Lufa Cylindrica condicionadas com $2 \%$ massa de $\mathrm{NaOH}$, na temperatura de $60^{\circ} \mathrm{C}$, por 2 horas; conformação por réplica, secagem ambiente das amostras impregnadas por 24 horas e tratamento térmico nas condições de taxa de aquecimento - temperatura - patamar de: $1^{\circ} \mathrm{C} / \mathrm{min}$ $150 / 250 / 1000^{\circ} \mathrm{C}-8 / 8 / 2 \mathrm{~h}$ (calcinação) e $2^{\circ} \mathrm{C} \cdot \mathrm{min}^{-1}$ até $1500^{\circ} \mathrm{C}$ por $7 \mathrm{~h}$ em atmosfera ambiente.

Comprovou-se a hipótese de se substituir a ítria $\left(\mathrm{Y}_{2} \mathrm{O}_{3}\right)$ normalmente utilizada como matriz na composição de materiais luminescentes pelo $\beta-\mathrm{Y}_{1,95} \mathrm{Dy}_{0,05} \mathrm{Si}_{2} \mathrm{O}_{7}$, com uma redução $35 \%$ de ítrio em relação a $\mathrm{Y}_{2} \mathrm{O}_{3}$ e obteve-se uma lâmpada de queimador de gás com eficiência radiante considerável, emissividade espectral visível e adequada para iluminação de ambientes internos em conformidade com as normas internacionais. 


\section{REFERÊNCIAS BIBLIOGRÁFICAS}

[1] NYE JR., S. J., Soft Power - The means to success in World Politics: Perseus Books, 2005.

[2] INTERnAtional enERGY AGENCY, I. E. A., "Energy Poverty. How to make modern energy access universal?," International Energy Agency (I.E.A), New York2010.

[3] INTERNATIONAL ENERGY AGENCY, I. E. A., "Cities, Towns and Renewable Energy," International Energy Agency (I.E.A)2009.

[4] WOOD, S.,HARRIS, A. T., Porous burners for lean-burn applications, Prog Energ Combust. vol. 34, 5, pp. 667-684, 2008.

[5] CURADO, F. F., "Multinacionais na nova ordem global.," in O Estado de São Paulo, ed. São Paulo: O Estado de São Paulo, 2013, p. B2.

[6] SCHWAB, K., "The Global Competitiveness Report 2010-2011," in The Global Competitiveness Report, ed: World Economic Forum, 2010.

[7] 15/12/2010). Mineral Summary: Mineral production database. Available: www.dnpm.gov.br/enportal/mostra_arquivo.asp?IDBancoArquivoArquivo=1 653

[8] CORDIER, D. J., "Mineral Commodity Summaries 2011," SURVEY, Ed., ed. Virginia: United States Department of Interior, 2011, p. 198.

[9] INTERNATIONAL ENERGY AGENCY, I. E. A., "Key World Statistics," International Energy Agency, I. E. A, Paris2013.

[10] KI-MOON, B., "Energy for a Sustainable Future," United Nations04/28/2010 2010.

[11] PIEROZAN, J. H. (2011,08/01/11). A Lei do Caminhão de Lixo. Available: http://pviverpelafe.blogspot.com.br/2011/01/lei-do-caminhao-de-lixo.html

[12] MARANHÃO, L. (2011,08/01/2011). Porcos. Available: http://novotempo.com/noticias/2011/03/03/porcos-aves-e-vacas-sao-osanimais-que-mais-sofrem/ 
[13] AMARAL, L. (2011,08/01/2011). Esgoto. Available: http://bocadesirilais.blogspot.com.br/2012/05/jornalismo-de-esgoto-da-veja-fede-mais.html

[14] WALSH, J. L., ROSS, C. C., SMITH, M. S.,HARPER, S. R., Utilization of Biogas, Biomass. vol. 20, 3-4, pp. 277-290, 1989.

[15] BRUNI, E., JENSEN, A. P.,ANGELIDAKI, I., Comparative study of mechanical, hydrothermal, chemical and enzymatic treatments of digested biofibers to improve biogas production, Bioresource Technology. vol. 101, 22, pp. 8713-8717, 2010.

[16] BRUNO, J. C., ORTEGA-LÓPEZ, V.,CORONAS, A., Integration of absorption cooling systems into micro gas turbine trigeneration systems using biogas: Case study of a sewage treatment plant, Applied Energy. vol. 86, 6, pp. 837-847, 2009.

[17] EL-MASHAD, H. M.,ZHANG, R., Biogas production from co-digestion of dairy manure and food waste, Bioresource Technology. vol. 101, 11, pp. 4021-4028, 2010.

[18] HILKIAH IGONI, A., AYOTAMUNO, M. J., EZE, C. L., OGAJI, S. O. T.,PROBERT, S. D., Designs of anaerobic digesters for producing biogas from municipal solid-waste, Applied Energy. vol. 85, 6, pp. 430-438, 2008.

[19] HARASIMOWICZ, M., ORLUK, P., ZAKRZEWSKA-TRZNADEL, G.,CHMIELEWSKI, A. G., Application of polyimide membranes for biogas purification and enrichment, Journal of Hazardous Materials. vol. 144, 3, pp. 698-702, 2007.

[20] LAU, C. S., TSOLAKIS, A.,WYSZYNSKI, M. L., Biogas upgrade to syn-gas (H2-CO) via dry and oxidative reforming, International Journal of Hydrogen Energy. vol. 36, 1, pp. 397-404, 2011.

[21] MAKARUK, A., MILTNER, M.,HARASEK, M., Membrane biogas upgrading processes for the production of natural gas substitute, Separation and Purification Technology. vol. 74, 1, pp. 83-92, 2010.

[22] PÖSCHL, M., WARD, S.,OWENDE, P., Evaluation of energy efficiency of various biogas production and utilization pathways, Applied Energy. vol. 87, 11, pp. 3305-3321, 2010.

[23] COELHO, S. T. (2010, Waste rote. Brazilian Bio-Energy Magazine (16773926), 55. Available: http://cenbio.iee.usp.br/download/revista/RBB9.pdf 
[24] MINISTÉRIO DE MINAS E ENERGIA, M. M. E., "PROINFA: Brazilian program to universalize the access of energy by stimulating the use of renewables sources from modern biomass," (M.E.M), Ed., ed. Brazil, 2004.

[25] DONDERO, L.,GOLDEMBERG, J., Environmental implications of converting light gas vehicles: the Brazilian experience, Energ Policy. vol. 33, 13, pp. 1703-1708, 2005.

[26] GOLDEMBERG, J.,COELHO, S. T., Renewable energy - traditional biomass vs. modern biomass, Energ Policy. vol. 32, 6, pp. 711-714, 2004.

[27] LETCHER, T. M., Future Energy: Elsevier, 2008.

[28] AGENCY, I. E. A., "Renewables Global Status Report," International Energy Agency, New York2010.

[29] "Resolução Normativa Aneel " in 390/2009, ed. Brazil, 2009.

[30] SILVA, S. A., BRUNELLI, D. D., MELO, F. C. L.,THIM, G. P., Preparation of a reticulated ceramic using vegetal sponge as templating, Ceram Int. vol. 35, 4, pp. 1575-1579, 2009.

[31] A, L. S. (05/01/21011). Luffa-b-font-font-b-cylindrica-a.jpg. Available: http://i00.i.aliimg.com/wsphoto/v1/932729228_1/33-Long-Suakwa-

Vegetablesponge-Towelgourd-Seeds-Loofah-font-b- Luffa-b-font-font-bcylindrica-b.jpg

[32] B, L. S. (05/01/2013). Luffa Cylindrica - B. Available: http://i00.i.aliimg.com/wsphoto/v1/932729228_1/33-Long-Suakwa-

Vegetablesponge-Towelgourd-Seeds-Loofah-font-b- Luffa-b-font-font-bcylindrica-b.jpg

[33] LUFFA, S. (2011). Luffa Cylindrica C. Available: http://4.bp.blogspot.com/_wQZ-

DdUCnaM/TPLLPirQ0rl/AAAAAAAAAjc/oQcbC2iBR_c/s400/Bucha+4.jpg

[34] LUFFA, S. (05 01 2011). Luffa Cylindrica D. Available: http://adeniumdoma.ru/shop/1679/desc/luffa-cylindrica

[35] BOYNARD, C. A., MONTEIRO, S. N.,D'AlMEIDA, J. R. M., Aspects of alkali treatment of sponge gourd (Luffa cylindrica) fibers on the flexural properties of polyester matrix composites, J Appl Polym Sci. vol. 87, 12, pp. 1927-1932, 2003.

[36] MEDINA, J. C., Plantas fibrosas da flora mundial. Campinas: Instituto Agronômico de Campinas, 1959. 
[37] GIANPIETRO V, A. S., VANNINI L. MULTI-USE CROPS, "Programme by DG XII of the European Commission," AGRONOMY, Ed., ed, 2000, pp. 8283.

[38] OGBONNA, J. C., TOMIYAMA, S., TANAKA, H., Development of a method for immobilization of non-flocculating cells in loofa (Luffa cylindrica) sponge, Process Biochem. vol. 31, 8, pp. 737-744, 1996.

[39] TANOBE, V. O. A., SYDENSTRICKER, T. H. D., MUNARO, M.,AMICO, S. C., A comprehensive characterization of chemically treated Brazilian sponge-gourds (Luffa cylindrica) (vol 24, pg 474, 2005), Polym Test. vol. 29, 2, pp. 288-289, 2010.

[40] SHEN, J. H., XIE, Y. M., HUANG, X. D., ZHOU, S. W.,RUAN, D., Behaviour of luffa sponge material under dynamic loading, Int. J. Impact Eng., vol. 57, pp. 17-26, 2013.

[41] DEMIR, H., TOP, A., BALKOSE, D.,ULKU, S., Dye adsorption behavior of Luffa cylindrica fibers, Journal of Hazardous Materials. vol. 153, 1-2, pp. 389-394, 2008.

[42] KOTANI, Y., BEHBAHANI, H. F.,TAKENO, T., An excess enthalpy flame combustor for extended flow ranges, Symposium (International) on Combustion. vol. 20, 1, pp. 2025-2033, 1985.

[43] KOTANI, Y.,TAKENO, T., An experimental study on stability and combustion characteristics of an excess enthalpy flame, Symposium (International) on Combustion. vol. 19, 1, pp. 1503-1509, 1982.

[44] VAFAI, K., Handbook of porous media, 2 ed.: Taylor \& Francis, 2005.

[45] XU, K., LIU, M.,ZHAO, P., Stability of lean combustion in mini-scale porous media combustor with heat recuperation, Chemical Engineering and Processing: Process Intensification. vol. 50, 7, pp. 608-613, 2011.

[46] BARRA, A. J.,ELLZEY, J. L., Heat recirculation and heat transfer in porous burners, Combustion and Flame. vol. 137, 1-2, pp. 230-241, 2004.

[47] MUjeEBU, M. A., ABDULlAH, M. Z., BAKAR, M. Z. A., MOHAMAD, A. A.,ABDULLAH, M. K., Applications of porous media combustion technology - A review, Applied Energy. vol. 86, 9, pp. 1365-1375, 2009.

[48] PAUL, G. A., "Process Heat and Drying Technology," in GoGas, GMBH\&CO.KG, Ed., ed. Alemanha: GoGas, 2010.

[49] AMERICA, G., GasLight America Porous Burner, 2010. 
[50] GREATROOM, T. O., The Outdoor GreatRoom Lamps and Burners, 2010.

[51] HEATER, M. (2010). Mr. Heater Porous Burner. Available: http://www.gaslights.com/Merchant2/merchant.mvc?Screen=PROD\&Store_Code=gaslights\&Product_Code=F220370\&Category_Code=IGL

[52] LIGHTING, G. S., Gallery Series Lighting Porous Burners, 2010.

[53] ROLES, J. L.,GUIOCHON, G., Characterization of Aluminum-Oxides Used in Ceramic Processing by Inverse Chromatography, Abstr Pap Am Chem S. vol. 201, pp. 203-ANYL, 1991.

[54] ANJARD, R. P., Microelectronics and Reliabilitys New Tool - Unix Today, Microelectron Reliab. vol. 31, 6, pp. 1127-1131, 1991.

[55] BERUTO, D., BOTTER, R., GIORDANI, M., MARTINI, L., OTTOBONI, V., RICCA, A. M., RIPAMONTI, G.,ZANNELLA, S., Ceramic Processing for Yba2cu3o7-X Powders - Effect of Silver-Oxides on Solid-State Reactivity, High-Temperature Superconductors : Materials Aspects, Vols 1 and 2. pp. 351-356, 1991.

[56] PELleRIN, N., StaleY, J. T., REN, T., GRAFF, G. L., TREADWELL, D. R.,AKSAY, I. A., Acidic Biopolymers as Dispersants for Ceramic Processing, Materials Synthesis Based on Biological Processes. vol. 218, pp. 123-128, 1991.

[57] WAKAI, F., Superplasticity of Ceramics, Ceram Int. vol. 17, 3, pp. 153-163, 1991.

[58] BISWAS, D. R., Development of Novel Ceramic Processing, J Mater Sci. vol. 24, 10, pp. 3791-3798, 1989.

[59] YAN, M. F., LING, H. C., OBRYAN, H. M., GALLAGHER, P. K.,RHODES, W. W., Ceramic Processing of Yba2cu3ox Based High-Tc Superconductors, leee T Compon Hybr. vol. 11, 4, pp. 401-406, 1988.

[60] SCHORR, J. R., Overview of New Technology Which Can Improve Energy Use in Ceramic Processing, Am Ceram Soc Bull. vol. 59, 3, pp. 325-325, 1980.

[61] PASK, J. A., Ceramic Processing - Ceramic Science, Am Ceram Soc Bull. vol. 58, 12, pp. 1163-\&, 1979.

[62] STUIJTS, A. L., Science of Ceramic Processing, Am Ceram Soc Bull. vol. 56, 3, pp. 295-296, 1977. 
[63] PRIGGE, R. E., Production and Selection of Refractories for Ceramic Processing, Am Ceram Soc Bull. vol. 50, 9, pp. 803-\&, 1971.

[64] HARKORT, P. D., Trends of Ceramic Processing in Europe, Am Ceram Soc Bull. vol. 48, 9, pp. 901-\&, 1969.

[65] ERKALFA, H., YUKSEL, B.,OZKAN, T. O., The effect of B2O3 addition on the sintering of Sb2O3 doped BaTiO3, Key Eng Mater. vol. 264-268, pp. 1333-1336, 2004.

[66] PINCUS, A. G.,ONODA, G. Y., Research on Binders for Ceramic Processing, Am Ceram Soc Bull. vol. 48, 8, pp. 817-\&, 1969.

[67] VICKER, R. C., International series of monographs on inorganic chemistry: The chemistry of yttrium and scandium vol. 2: Pergamon Press, 1960.

[68] ABRÃO, A., Química e tecnologia das terras raras. Rio de Janeiro: CETEM/CNPq, 1994.

[69] LEE, J. D., Química inorgânica não tão concisa. São Paulo: Edgar Blucher, 1999.

[70] HUtTON, A. T., HARTSHORN, R. M., CONNELLY, N. G.,DAMHUS, T., Nomenclature of inorganic chemistry: RSC Publishing, 2005.

[71] TAYLOR, S. R., Abundance of Chemical Elements in the Continental Crust - a New Table, Geochim Cosmochim Ac. vol. 28, Aug, pp. 1273-1285, 1964.

[72] ZHANHENG, C., Global rare earth resources and scenarios of future rare earth industry, J Rare Earth. vol. 29, 1, pp. 1-6, 2011.

[73] JOSEPH, G., "2011 Minerals Yearbook," SURVEY, Ed., ed, 2011, p. 13.

[74] "COMMONWEALTH OF INDEPENDENT STATES (CIS)," REGIMES, Ed., ed, 2007.

[75] SANTOS, S. C., YAMAGATA, C.,MELLO CASTANHO, S., Lighting by biogas burners: perspectives on development in Brazil Journal of Materials Sciences and Applications. 2014.

[76] BRITO, H. F., HÖLSÄ, J., JUNGNER, H., LAAMANEN, T., LASTUSAARI, M., MALKAMÄKI, M.,RODRIGUES, L. C. V., Persistent luminescence fading in Sr2MgSi2O7:Eu2+,R3+ materials: a thermoluminescence study, Opt. Mater. Express. vol. 2, 3, pp. 287-293, 2012. 
[77] SANTOS, D. R. S., SANTOS, C. N., DE CAMARGO, A. S. S., SILVA, W. F., SANTOS, W. Q., VeRMELHO, M. V. D., ASTRATH, N. G. C., MALACARNE, L. C., LI, M. S., HERNANDES, A. C., IBANEZ, A.,JACINTO, C., Thermo-optical characteristics and concentration quenching effects in $\mathrm{Nd}[\sup 3+$ ]doped yttrium calcium borate glasses, The Journal of Chemical Physics. vol. 134, 12, pp. 124503-7, 2011.

[78] MORAeS, A. P. A., SOUZA, A. G., FREIRE, P. T. C., MENDES, J., M'PEKO, J. C., HERNANDES, A. C., ANTONELLI, E., BLAIR, M. W., MUENCHAUSEN, R. E., JACOBSOHN, L. G.,PARAGUASSU, W., Structural and optical properties of rare earth-doped $(\mathrm{Ba}(0.77) \mathrm{Ca}(0.23))(1$ x)(Sm, Nd, Pr, Yb)(x)TiO(3), J Appl Phys. vol. 109, 12, 2011.

[79] ZHANG, H., CEN, Y., CHEN, L. F., ZHU, H. Y., QIAN, L. J.,FAN, D. Y., Fullangle collimations of two-dimensional photonic crystals with ultrahigh-index background materials, J Opt-Uk. vol. 12, 4, pp. -, 2010.

[80] WANG, T. S., LIU, H., ZHANG, H., ZHANG, H. X., SUN, Q. A.,LU, Z. W., Evaluation of the imaging performance of hybrid refractive-diffractive systems using the modified phase function model, $\boldsymbol{J}$ Opt-Uk. vol. 12, 4, pp. $-, 2010$.

[81] SHAN, Z. F., CHEN, D. Q., YU, Y. L., HUANG, P., LIN, H.,WANG, Y. S., Luminescence in rare earth-doped transparent glass ceramics containing GdF3 nanocrystals for lighting applications, J Mater Sci. vol. 45, 10, pp. 2775-2779, 2010.

[82] ZORENKO, Y., MARES, J. A., KUCERKOVA, R., GORBENKO, V., SAVCHYN, V., VOZNYAK, T., NIKL, M., BEITLEROVA, A.,JUREK, K., Optical, luminescence and scintillation characteristics of Bi-doped LuAG and YAG single crystalline films, J Phys D Appl Phys. vol. 42, 7, pp. -, 2009.

[83] WEl, G. C., Transparent ceramics for lighting, J Eur Ceram Soc. vol. 29, 2, pp. 237-244, 2009.

[84] WANG, W. N., WIDIYASTUTI, W., OGI, T., LENGGORO, I. W.,OKUYAMA, K., Correlations between crystallite/particle size and photoluminescence properties of submicrometer phosphors, Chem Mater. vol. 19, 7, pp. 17231730, 2007. 
[85] ELSEVIER. Scopus: abstract and citation database of peer-reviewed literature Disponível em: http://www.scopus.com/results/results.url?sort=plf$\mathrm{f} \& \mathrm{src}=\mathrm{s} \& \mathrm{st} 1=\mathrm{rare}+\mathrm{earths} \& \mathrm{st} 2=$ lanthanides $\& \mathrm{nlo}=\& \mathrm{nlr}=\& \mathrm{nls}=\& \mathrm{sid}=268 \mathrm{D} 6067$ 6EBE2D4609CC666927C9667C.I0QkgbljGqqLQ4Nw7dqZ4A\%3a130\&sot= b\&sdt=cl\&cluster=scoaffilctry\%2c\%22Brazil\%22\%2ct\%2c\%22Brazil\%22\%2 ct\&sl=136\&s=\%28TITLE-ABS-KEY\%28rare+earths\%29+OR+TITLE-ABSKEY\%28lanthanides\%29+OR+TITLE-ABS-

KEY\%28luminescence\%29+OR+TITLE-ABS-

KEY\%28phosphors\%29\%29+AND+PUBYEAR+\%3e+1999\&origin=resultsli st\&zone=leftSideBar\&txGid=268D60676EBE2D4609CC666927C9667C. .10 QkgbljGqqLQ4Nw7dqZ4A\%3a13.

[86] MOELLER, T., The Chemistry of the lanthanides: Pergamon Press, 1975.

[87] ABRÃO, A., Química e Tecnologia das Terras Raras. Brasil: CETEM/CNPq, 1994.

[88] WILBURN, D. R., "Byproduct Metals and Rare-Earth Elements Used In the Production of Light-Emitting Diodes-Overview of Principal Sources of Supply and Material Requirements for Selected Markets. Overview of Principal Sources of Supply and Material Requirements for Selected Markets," SURVEY, Ed., ed. Virginia: U.S. Geological Survey, 2012, p. 24.

[89] MARTINS, T. S.,ISOLANI, P. C., Rare earths: Industrial and biological applications., Química Nova. vol. 28, 1, pp. 111-117, 2005.

[90] MAESTRO, P.,HUGUENIN, D., Industrial Applications of Rare-Earths Which Way for the End of the Century, J Alloy Compd. vol. 225, 1-2, pp. 520-528, 1995.

[91] REISFELD, R., Industrial Applications of Rare-Earths in Fiber Optics, Luminescent Solar Concentrators and Lasers, Inorg Chim Acta. vol. 140, 1-2, pp. 345-350, 1987.

[92] BUNZLI, J. C., Some Industrial and Scientific Applications of Rare-Earths, Chimia. vol. 37, 1, pp. 13-14, 1983.

[93] U.S. GEOLOGICAL SURVEY, U. S. G. S., "Mineral commodity summaries 2014," ed. Virginia, 2014, p. 196. 
[94] WU, Z. K., LI, N., JIAN, C., ZHAO, W. Q.,YAN, J. Z., Low temperature degradation of Al2O3-doped 3Y-TZP sintered at various temperatures, Ceram Int. vol. 39, 6, pp. 7199-7204, 2013.

[95] ZHANG, R. H., ZHANG, X. T.,HU, S. M., Nanocrystalline ZrO2 thin films as electrode materials using in high temperature-pressure chemical sensors, Mater Lett. vol. 60, 25-26, pp. 3170-3174, 2006.

[96] ARMANI, C. J., RUGGLES-WRENN, M. B., HAY, R. S., FAIR, G. E.,KELLER, K. A., Creep of polycrystalline yttrium aluminum garnet (YAG) at elevated temperature in air and in steam, Mat Sci Eng a-Struct. vol. 589, pp. 125-131, 2014.

[97] PENG, Q. M., ZHAO, S. S., LI, H., MA, N., LI, X. J.,TIAN, Y. J., High Pressure Solidification: An Effective Approach to Improve the Corrosion Properties of Mg-Y Based Implants, Int J Electrochem Sc. vol. 7, 6, pp. 5581-5595, 2012.

[98] LEE, K., YI, J. E., KIM, B., KO, J., JEONG, S., NOH, M.,LEE, S. S., Microenergy storage system using permanent magnet and high-temperature superconductor, Sensor Actuat a-Phys. vol. 143, 1, pp. 106-112, 2008.

[99] ZHOU, R., TANG, P. H., CHEN, Y., CHEN, S. Q., ZHAO, C. J., ZHANG, H.,WEN, S. C., Large-energy, narrow-bandwidth laser pulse at $1645 \mathrm{~nm}$ in a diode-pumped Er:YAG solid-state laser passively Q-switched by a monolayer graphene saturable absorber, Appl Optics. vol. 53, 2, pp. 254258, 2014.

[100] NARISADA, K. K., S., Phosphor Handbook. New York: CRC, 1999.

[101] CALLISTER JR., W. D., Ciência e Engenharia de Materiais: uma introdução. Rio de Janeiro: LTC, 2002.

[102] BOS, A. J. J., Theory of thermoluminescence, Radiat Meas. vol. 41, Supplement 1, 0, pp. S45-S56, 2006.

[103] VIJ, D. R., Luminescence of solids. New York: Plenum Press, 1998.

[104] HOOGENBOOM, J. E., DEVRIES, W., DIELHOF, J. B.,BOS, A. J. J., Computerized Analysis of Glow Curves from Thermally Activated Processes, J Appl Phys. vol. 64, 6, pp. 3193-3200, 1988.

[105] RANDALL, J. T.,WILKINS, M. H. F., Phosphorescence and Electron Traps .2. The Interpretation of Long-Period Phosphorescence, Proc R Soc Lon Ser-A. vol. 184, 999, pp. 390-407, 1945. 
[106] RANDALL, J. T.,WILKINS, M. H. F., Phosphorescence and Electron Traps .1. The Study of Trap Distributions, Proc R Soc Lon Ser-A. vol. 184, 999, pp. 366-389, 1945.

[107] DEKKER, H., Some Aspects of a Caf-2 - Mn Thermoluminescent Dosimeter, Health Phys. vol. 30, 5, pp. 399-401, 1976.

[108] BINDER, W.,CAMERON, J. R., Dosimetric Properties of Caf2 - Dy, Health Phys. vol. 17, 4, pp. 613-+, 1969.

[109] YAMASHIT.T, NADA, N., ONISHI, H.,KITAMURA, S., Calcium Sulfate Activated by Thulium or Dysprosium for Thermoluminescence Dosimetry, Health Phys. vol. 21, 2, pp. 295-+, 1971.

[110] WANG, T. K., HSU, P. C.,WENG, P. S., Feasibility Study of Using Caso4Dy Phosphor for Simultaneous Estimation of Exposure and Time Elapsed Postexposure, Radiat Prot Dosim. vol. 18, 3, pp. 157-161, 1987.

[111] BURGKHARDT, B., PIESCH, E.,SINGH, D., High-Dose Characteristic of Lif and Li2b4o7 Thermoluminescent Dosimeters, Nucl Instrum Methods. vol. 148, 3, pp. 613-617, 1978.

[112] YAMASHIT.T, YASUNO, Y.,IKEDO, M., Beryllium-Oxide Doped with Lithium or Sodium for Thermoluminescence Dosimetry, Health Phys. vol. 27, 2, pp. 201-206, 1974.

[113] LAKSHMANAN, A. R.,VOHRA, K. G., Gamma-Radiation Induced Sensitization and Photo-Transfer in Mg2sio4-Tb Tld Phosphor, Nucl Instrum Methods. vol. 159, 2-3, pp. 585-592, 1979.

[114] MEHTA, S. K.,SENGUPTA, S., Photostimulated Thermoluminescence of Al2o3 ( $\mathrm{Si}, \mathrm{Ti}$ ) and Its Application to Ultraviolet-Radiation Dosimetry, Phys Med Biol. vol. 23, 3, pp. 471-480, 1978.

[115] XU, Y. N., GU, Z. Q.,CHING, W. Y., Electronic, structural, and optical properties of crystalline yttria, Phys Rev B. vol. 56, 23, pp. 14993-15000, 1997.

[116] PATON, M. G.,MASLEN, E. N., A Refinement of Crystal Structure of Yttria, Acta Crystallogr. vol. 19, pp. 307-\&, 1965.

[117] HOEKSTRA, H. R.,GINGERICH, K. A., High-Pressure B-Type Polymorphs of Some Rare-Earth Sesquioxides, Science. vol. 146, 364, pp. 1163-\&, 1964. 
[118] GOURLAOUEN, V., SCHNEDECKER, G., LEJUS, A. M., BONCOEUR, M.,COLLONGUES, R., Metastable Phases in Yttrium-Oxide Plasma Spray Deposits and Their Effect on Coating Properties, Mater Res Bull. vol. 28, 5 , pp. 415-425, 1993.

[119] NAVROTSKY, A., BENOIST, L.,LEFEBVRE, H., Direct calorimetric measurement of enthalpies of phase transitions at 2000 degrees-2400 degrees C in yttria and zirconia, J Am Ceram Soc. vol. 88, 10, pp. 29422944, 2005.

[120] QIN, X., JU, Y. G., BERNHARD, S.,YAO, N., Flame synthesis of Y2O3 : Eu nanophosphors using ethanol as precursor solvents, $\boldsymbol{J}$ Mater Res. vol. 20, 11, pp. 2960-2968, 2005.

[121] BRITO, H. F., "Materiais luminescentes à base de terras raras.," presented at the Curso de Nanomateriais e Nanotecnologia, Proceedings. São Paulo, 2008

[122] GOLDBURT, E. T., KULKARNI, B., BHARGAVA, R. N., TAYLOR, J.,LIBERA, M., Size dependent efficiency in Tb doped Y2O3 nanocrystalline phosphor, J Lumin. vol. 72-74, 0, pp. 190-192, 1997.

[123] CASTANHO, S. M., FIERRO, J. L. G.,MORENO, R., Surface oxidation of Si3N4 green compacts: Effect of sintering aids, $\boldsymbol{J}$ Eur Ceram Soc. vol. 17, 2-3, pp. 383-391, 1997.

[124] LEE, K. N., FOX, D. S.,BANSAL, N. P., Rare earth silicate environmental barrier coatings for $\mathrm{SiC} / \mathrm{SiC}$ composites and Si3N4 ceramics, J Eur Ceram Soc. vol. 25, 10, pp. 1705-1715, 2005.

[125] BATALIEV.NG,PYATENKO, Y. A., Artificial Yttrialite (Y-Phase) Representative of a New Structure Type in Rare-Earth Diorthosilicate Series, Sov Phys Crystallogr. vol. 16, 5, pp. 786-\&, 1972.

[126] ITO, J. J., H., Synthesis and study of yttrialite, Am Mineral. vol. 53, pp. 1112, 1968.

[127] FELSCHE, J.,HIRSIGER, W., The polymorphs of the rare-earth pyrosilicates R.E.2Si2O7, [R.E.: La, Ce, Pr, Nd, Sm], Journal of the Less Common Metals. vol. 18, 2, pp. 131-137, 1969.

[128] FELSCHE, J., Polymorphism and crystal data of the rare-earth disilicates of type R.E.2Si2O7, Journal of the Less Common Metals. vol. 21, 1, pp. 114, 1970. 
[129] BONDAR, I. A.,TOROPOV, N. A., Preparation and Properties of Rare-Earth Silicates and Aluminates, Mater Res Bull. vol. 2, 4, pp. 479-\&, 1967.

[130] DILEK, T., KOPARAN, E. T., BASOGLU, M.,YANMAZ, E., The Magnetic and Structural Properties of SiC-Doped MgB(2) Bulks Prepared by the Standard Ceramic Processing, J Supercond Nov Magn. vol. 24, 1-2, pp. 495-497, 2011.

[131] LIDDELL, K. T., D. P. , X-ray diffraction data for yttrium silicates, British Ceramic Transactions and Journal vol. 85, pp. 17-22, 1986.

[132] TRUSTY, P. A., CHAN, K. C.,PONTON, C. B., Synthesis of sinteractive single-phase microstructure yttrium disilicate precursor powder using hydrothermal processing, J Mater Res. vol. 13, 11, pp. 3135-3143, 1998.

[133] BECERRO, A. I., NARANJO, M., PERDIGON, A. C.,TRILLO, J. M., Hydrothermal chemistry of silicates: Low-temperature synthesis of y-yttrium disilicate, J Am Ceram Soc. vol. 86, 9, pp. 1592-1594, 2003.

[134] DIAZ, M., GARCIA-CANO, I., MELLO-CASTANHO, S., MOYA, J. S.,RODRIGUEZ, M. A., Synthesis of nanocrystalline yttrium disilicate powder by a sol-gel method, Journal of Non-Crystalline Solids. vol. 289, 1-3, pp. 151-154, 2001.

[135] MOYA, J. S., DIAZ, M., SERNA, C. J.,MELLO-CASTANHO, S., Formation of nanocrystalline yttrium disilicate powder by an oxalate gel method, $\boldsymbol{J}$ Eur Ceram Soc. vol. 18, 9, pp. 1381-1384, 1998.

[136] LEVIN, E. M., ROBBINS, C.R. MURDIE, H.F., Phases diagrams for Ceramists. Metal oxide systems: The American Ceramic Society, 1969.

[137] KIM, J. M., LEE, H. J., KIM, K. P.,YOO, J. S., Optical Characteristics of Polymorphic $\mathrm{Y}(2-\mathrm{x}) \mathrm{Si}(2) \mathrm{O}(7): \mathrm{Eu}(\mathrm{x})(3+)$ Crystal for Lamp Application, $\boldsymbol{J}$ Electrochem Soc. vol. 155, 12, pp. E189-E192, 2008.

[138] DIAZ, M., PEChARROMAN, C., DEL MONTE, F., SANZ, J., IGLESIAS, J. E., MOYA, J. S., YAMAGATA, C.,MELLO-CASTANHO, S., Synthesis, thermal evolution, and luminescence properties of yttrium disilicate host matrix, Chem Mater. vol. 17, 7, pp. 1774-1782, 2005.

[139] SANTOS, S. C., ACCHAR, W., YAMAGATA, C.,MELLO-CASTANHO, S., Yttria nettings by colloidal processing, $\boldsymbol{J}$ Eur Ceram Soc. vol. 34, 10, pp. 2509-2517, 2014. 
[140] SANTOS, S. C., YAMAGATA, C., SILVA, A. C., SETZ, L. F. G.,MELLOCASTANHO, S. R. H., Yttrium Disilicate Micro-Cellular Architecture from Biotemplating of Luffa Cylindrica, Journal of Ceramic Science and Technology. 2014.

[141] SANTOS, S. C., YAMAGATA, C.,MELLO-CASTANHO, S. R. H., Perspectives on the development of porous burners in Brazil, Journal of Materials Sciences and Applications. 2014.

[142] LEWIS, J. A., Colloidal processing of ceramics, J Am Ceram Soc. vol. 83, 10, pp. 2341-2359, 2000.

[143] LI, X.,LI, Q., YAG ceramic processed by slip casting via aqueous slurries, Ceram Int. vol. 34, 2, pp. 397-401, 2008.

[144] SANTOS, S. C., SETZ, L. F. G., YAMAGATA, C.,MELLO-CASTANHO, S. R. H., Rheological study of yttrium oxide aqueous suspensions, Materials Science Forum vol. 660 - 661

pp. 712-717, 2010.

[145] SONODA, K., HIGASHI, K., ONO, H., SAMESHIMA, S.,HIRATA, Y., Surface properties and aqueous processing of rare earth-doped ceria powders by coprecipitation method, Novel Synthesis and Processing of Ceramics. vol. 159-1, pp. 169-174, 1999.

[146] SANTOS, S. C., SILVA, A. C.,MELLO-CASTANHO, S. R. H., Morphology evolution of yttria porous ceramics during replica processing, Materials Science Forum. 2011.

[147] JIN, L. L., MAO, X. J., WANG, S. W.,DONG, M. J., Optimization of the rheological properties of yttria suspensions, Ceram Int. vol. 35, 2, pp. 925927, 2009.

[148] APPIAGYEI, K. A., MESSING, G. L.,DUMM, J. Q., Aqueous slip casting of transparent yttrium aluminum garnet (YAG) ceramics, Ceram Int. vol. 34, 5, pp. 1309-1313, 2008.

[149] TAKAI, C., TSUKAMOTO, M., FUJI, M.,TAKAHASHI, M., Control of high solid content yttria slurry with low viscosity for gelcasting, $J$ Alloy Compd. vol. 408, pp. 533-537, 2006. 
[150] APARICIO, M., MORENO, R.,DURAN, A., Colloidal stability and sintering of yttria-silica and yttria-silica-alumina aqueous suspensions, $J$ Eur Ceram Soc. vol. 19, 9, pp. 1717-1724, 1999.

[151] SANTOS, S. C., ACCHAR, W., SILVA, A. C., YAMAGATA, C.,MELLOCASTANHO, S. R. H., "Yttrium disilicate stability in aqueous medium," presented at the 57. Congresso Brasileiro de Cerâmica e 5० Congresso Ibero Americano de Cerâmica, 19-22 de maio, 2013. Proceedings. Hotel Praiamar , Natal, Rio Grande do Norte, RN, Brasil. , 2013

[152] JAYCOCK, M. J.,PARFITT, G. D., Chemistry of Interfaces. U.K: Ellis Horwood, 1981.

[153] PARFITT, G. D.,SING, K. S. W., Characterization of Powders Surfaces. New York: Academic Press, 1976.

[154] VOLD, R. D.,VOLD, M. J., Colloid and Interface Chemistry. New York: Addison-Wesly, 1983.

[155] REED, J., Principles of Ceramics Processing, 2 ed. vol. 1. New York: John Wiley \& Sons, 1995.

[156] GRAHAME, D. C., The Electrical Double Layer and the Theory of Electrocapillarity, Chem Rev. vol. 41, 3, pp. 441-501, 1947.

[157] DERJAGUIN, B. V., CHURAEV, N. V.,MULLER, V. M., "The DerjaguinLandau-Verwey-Overbeek (DLVO) Theory of Stability of Lyophobic Colloids," in Surface Forces, ed: Springer US, 1987, pp. 293-310.

[158] SHAW, D. J., Introduction to Colloid and Surface Chemistry, 4 ed. Oxford: Butterworth Heinemann, 1989.

[159] HUNTER, R. J., Foundations of colloidal science. Oxford: Oxford Science, 1986.

[160] MORENO, R., Reología de suspensiones cerámicas. Madrid: Consejo Superior de Investigaciones Científicas, 2005.

[161] LOEB, A. L., OVERBEEK, J. T. G.,WIERSEMA, P. H., The Electrical Double Layer Around a Spherical Particle. Massachusetts M.I.T Press, 1961.

[162] HUNTER, R. J., Zeta potential in colloid science. Londres: Academic Press, 1981. 
[163] SANTOS, S. C., "Processamento coloidal de componentes cerâmicos para queimadores de gás," Dissertação de Mestrado. 2010. Instituto de Pesquisas Energéticas e Nucleares (IPEN), Universidade de São Paulo (USP), São Paulo.

[164] Pettersson, A., MARINO, G., PURSIHEIMO, A.,ROSENHOLM, J. B., Electrosteric stabilization of $\mathrm{Al} 2 \mathrm{O} 3, \mathrm{ZrO} 2$, and $3 \mathrm{Y}$-ZrO2 suspensions: Effect of dissociation and type of polyelectrolyte, Journal of Colloid and Interface Science. vol. 228, 1, pp. 73-81, 2000.

[165] OOSAWA, F.,ASAKURA, S., Surface Tension of High-Polymer Solutions, $\boldsymbol{J}$ Chem Phys. vol. 22, 7, pp. 1255-1255, 1954.

[166] VINCENT, B., LUCKHAM, P. F.,WAITE, F. A., Effect of Free Polymer on the Stability of Sterically Stabilized Dispersions, Journal of Colloid and Interface Science. vol. 73, 2, pp. 508-521, 1980.

[167] IUPAC, Manual of symbols and terminology for physicochemical quantities and units vol. 2. Oxford: Blackwell Scientific Publications, 1979.

[168] SIGMUND, W. M., BELL, N. S.,BERGSTROM, L., Novel powderprocessing methods for advanced ceramics, J Am Ceram Soc. vol. 83, 7, pp. 1557-1574, 2000.

[169] SCHRAMM, G., A practical approach to rheology and rheometry. Alemanha: Gebrueder HAAKE GmbH, 1994.

[170] STUDART, A. R., GONZENBACH, U. T., TERVOORT, E.,GAUCKLER, L. J., Processing routes to macroporous ceramics: A review, J Am Ceram Soc. vol. 89, 6, pp. 1771-1789, 2006.

[171] SAgGIOWOYANSKY, J., SCOTT, C. E.,MINNEAR, W. P., Processing of Porous Ceramics, Am Ceram Soc Bull. vol. 71, 11, pp. 1674-1682, 1992.

[172] (United States of America) SCHWARTZWALDER, K.,SOMERS, A. V., "Method of Making Porous Ceramic," 1963.

[173] MONTANARO, L., JORAND, Y., FANTOZZI, G.,NEGRO, A., Ceramic foams by powder processing, J Eur Ceram Soc. vol. 18, 9, pp. 1339-1350, 1998.

[174] LUYTEN, J., MULLENS, S., COOYMANS, J., DE WILDE, A. M., THIJS, I.,KEMPS, R., Different methods to synthesize ceramic foams, J Eur Ceram Soc. vol. 29, 5, pp. 829-832, 2009. 
[175] LUYTEN, J., THIJS, I., VANDERMEULEN, W., MULLENS, S., WALLAEYS, B.,MORTELMANS, R., Strong ceramic foams from polyurethane templates, Adv Appl Ceram. vol. 104, 1, pp. 4-8, 2005.

[176] LUYTEN, J., MULLENS, S., COOYMANS, J., DE WILDE, A. M.,THIJS, I., New processing techniques of ceramic foams, Adv Eng Mater. vol. 5, 10, pp. 715-718, 2003.

[177] PAiva, A. E. M., SEPUlVEdA, P.,PANDOLFELLI, V. C., Processing and thermomechanical evaluation of fibre-reinforced alumina filters, $\boldsymbol{J}$ Mater Sci. vol. 34, 11, pp. 2641-2649, 1999.

[178] SHARIFI, H., DIVANDARI, M., KHAVANDI, A.,IDRIS, M. H., Effect of Al powder and silica sol on the structure and mechanical properties of Al2O3ZrO2 foams, Acta Metall Sin-Engl. vol. 23, 4, pp. 241-247, 2010.

[179] ACCHAR, W., SOUZA, F. B. M., RAMALHO, E. G.,TORQUATO, W. L., Mechanical characterization of cellular ceramics, Mat Sci Eng a-Struct. vol. 513-14, pp. 340-343, 2009.

[180] RAMBO, C. R., DE SOUSA, E., DE OliveiRA, A. P. N., HOTZA, D.,GREIL, P., Processing of cellular glass ceramics, J Am Ceram Soc. vol. 89, 11, pp. 3373-3378, 2006.

[181] PAN, J. M., YAN, X. H., CHENG, X. N., LU, Q. B., WANG, M. S.,ZHANG, C. H., Preparation of $\mathrm{SiC}$ nanowires-filled cellular SiCO ceramics from polymeric precursor, Ceram Int. vol. 38, 8, pp. 6823-6829, 2012.

[182] LIU, H. L., ZHONG, W. W., SONG, C. M.,ZHENG, Z. M., Fabrication of SiCN foam ceramic from polysilazane and polyurethane, Rare Metal Mat Eng. vol. 36, pp. 538-541, 2007.

[183] LEE, J. H., KIM, H. E., SHIN, K. H.,KOH, Y. H., Improving the strength and biocompatibility of porous titanium scaffolds by creating elongated pores coated with a bioactive, nanoporous TiO2 layer, Mater Lett. vol. 64, 22, pp. 2526-2529, 2010.

[184] YAO, X. M., TAN, S. H., ZHANG, X. Y., HUANG, Z. R.,JIANG, D. L., Lowtemperature sintering of $\mathrm{SiC}$ reticulated porous ceramics with $\mathrm{MgO}-\mathrm{Al} 2 \mathrm{O} 3-$ SiO2 additives as sintering aids, $\boldsymbol{J}$ Mater Sci. vol. 42, 13, pp. 4960-4966, 2007. 
[185] YAO, X. M., TAN, S. H., HUANG, Z. R.,JIANG, D. L., Effect of recoating slurry viscosity on the properties of reticulated porous silicon carbide ceramics, Ceram Int. vol. 32, 2, pp. 137-142, 2006.

[186] ZHU, X. W., JIANG, D. L.,TAN, S. H., Preparation of silicon carbide reticulated porous ceramics, Mat Sci Eng a-Struct. vol. 323, 1-2, pp. 232238, 2002.

[187] ZHU, X. W., JIANG, D. L.,TAN, S. H., Impregnating process of reticulated porous ceramics using polymeric sponges as the templates, $\boldsymbol{J}$ Inorg Mater. vol. 16, 6, pp. 1144-1150, 2001.

[188] ZHANG, H., LI, H. F., LI, W., MENG, S. L.,LI, D. Q., Preparation of TiO2, $\mathrm{CeO} 2$, and $\mathrm{ZrO} 2$ hierarchical structures in "one-pot" reactions, Journal of Colloid and Interface Science. vol. 333, 2, pp. 764-770, 2009.

[189] JUNG, I. C., KWON, Y. D., LEE, J.,MIN, B. K., Synthesis of B4C Nanobelts in Porous SiC Bodies, J Nanosci Nanotechno. vol. 11, 7, pp. 6555-6558, 2011.

[190] YANG, Y. B., SHI, E. Z., LI, P. X., WU, D. H., WU, S. T., SHANG, Y. Y., XU, W. J., CAO, A. Y.,YUAN, Q., A compressible mesoporous $\mathrm{SiO} 2$ sponge supported by a carbon nanotube network, Nanoscale. vol. 6, 7, pp. 35853592, 2014.

[191] LIU, Z. T., FAN, T. X., ZHANG, W.,ZHANG, D., The synthesis of hierarchical porous iron oxide with wood templates, Micropor Mesopor Mat. vol. 85, 1-2, pp. 82-88, 2005.

[192] OTA, T., IMAEDA, M., TAKASE, H., KOBAYASHI, M., KINOSHITA, N., HIRASHITA, T., MIYAZAKI, H.,HIKICHI, Y., Porous titania ceramic prepared by mimicking silicified wood, J Am Ceram Soc. vol. 83, 6, pp. 1521-1523, 2000.

[193] CAO, J., RUSINA, O.,SIEBER, H., Processing of porous TiO2-ceramics from biological preforms, Ceram Int. vol. 30, 7, pp. 1971-1974, 2004.

[194] TANG, S. K., CUI, X. L., GU, L., ZHOU, H.,ZHANG, X. W., A Novel CoTemplating Method for Hierarchical Mesoporous Alumina Monoliths Replica, Funct Mater Lett. vol. 6, 6, 2013.

[195] Guerrero, M. B., MAQuedA, L. P., CAStro, P. P.,COSP, J. P., Porous Aluminas: The biotemplate method for the synthesis of stable high 
surface area aluminas, Bol Soc Esp Ceram V. vol. 52, 6, pp. 251-267, 2013.

[196] MANDAL, P. K., MAJUMdAR, R., MUKHERJEE, K. K., CHAKRABARTI, O.,MAITI, H. S., An ultralight porous alumina ceramic in the image of jute stem, J Ceram Process Res. vol. 10, 4, pp. 457-461, 2009.

[197] RAMBO, C. R., ANDRADE, T., FEY, T., SIEBER, H., MARTINELLI, A. E.,GREIL, P., Microcellular Al2O3 ceramics from wood for filter applications, J Am Ceram Soc. vol. 91, 3, pp. 852-859, 2008.

[198] SIEBER, H., HOFFMANN, C., KAINDL, A.,GREIL, P., Biomorphic cellular ceramics, Adv Eng Mater. vol. 2, 3, pp. 105-109, 2000.

[199] SIEBER, H., KAINDL, A., SCHWARZE, D., WERNER, J. P.,GREIL, P., Light-weight cellular ceramics from biologically-derived preforms, CfiCeram Forum Int. vol. 77, 1-2, pp. 21-24, 2000.

[200] RAMBO, C. R., SIEBER, H.,GENOVA, L. A., Synthesis of porous biomorphic alpha/beta-Si3N4 composite from sea sponge, $\boldsymbol{J}$ Porous Mat. vol. 15, 4, pp. 419-425, 2008.

[201] NIU, H. X., YANG, Q., TANG, K. B., YIE, Y., Self-assembly of porous MgO nanoparticles into coral-like microcrystals, Scripta Mater. vol. 54, 10, pp. 1791-1796, 2006.

[202] ROY, D. M.,LINNEHAN, S. K., Hydroxyapatite Formed from Coral Skeletal Carbonate by Hydrothermal Exchange, Nature. vol. 247, 5438, pp. 220222, 1974.

[203] FAN, T. X., SUN, B. H., GU, J. J., ZHANG, D.,LAU, L. W. M., Biomorphic Al2O3 fibers synthesized using cotton as bio-templates, Scripta Mater. vol. 53, 8, pp. 893-897, 2005.

[204] PU, X. P., QIU, F. G., LIU, X. J.,HUANG, L. P., Development of reticulated porous ceramics by two-step centrifuging processing, J Inorg Mater. vol. 20, 6, pp. 1431-1437, 2005.

[205] LANGE, F. F.,MILLER, K. T., Open-Cell, Low-Density Ceramics Fabricated from Reticulated Polymer Substrates, Adv Ceram Mater. vol. 2, 4, pp. 827$831,1987$.

[206] PU, X. P., LIU, X. J., QIU, F. G.,HUANG, L. P., Novel method to optimize the structure of reticulated porous ceramics, J Am Ceram Soc. vol. 87, 7, pp. 1392-1394, 2004. 
[207] INTERNATIONAL COMMISSION ON ILLUMINATION, C. I. E. (2001, Lighting of Work Places Part 1: Indoor. Available: http://www.cie.co.at/index.php/Publications/index.php?i_ca_id=472

[208] MACLAREN, I., TRUSTY, P. A.,PONTON, C. B., A transmission electron microscope study of hydrothermally synthesized yttrium disilicate powders, Acta Mater. vol. 47, 3, pp. 779-791, 1999.

[209] SMOKE, E. J.,RAYNOR, G. E., Role of Microcrystalline Cellulose in Ceramic Processing, Am Ceram Soc Bull. vol. 48, 8, pp. 817-\&, 1969.

[210] BROWN,

S.

D., CARPENTE.HW,

ACCOUNTI.OE, SCHROEDE.TF,CARNIGLI.SC, Critical Evaluation of Ceramic Processing at Subconventional Temperatures, Am Ceram Soc Bull. vol. 47, 4, pp. 441-\&, 1968.

[211] NEEDHAM, J. V.,JOHNSON, W. H., Computer Control in Ceramic Processing, Am Ceram Soc Bull. vol. 47, 4, pp. 438-\&, 1968.

[212] BRUNAUER, S., EMMETT, P. H.,TELLER, E., Adsorption of gases in multimolecular layers, J Am Chem Soc. vol. 60, pp. 309-319, 1938.

[213] SYDENSTRICKER, T. H. D., MOChNAZ, S.,AMICO, S. C., Pull-out and other evaluations in sisal-reinforced polyester biocomposites, Polym Test. vol. 22, 4, pp. 375-380, 2003.

[214] ZAFEIROPOULOS, N. E., WILLIAMS, D. R., BAILLIE, C. A.,MATTHEWS, F. L., Engineering and characterisation of the interface in flax fibre/polypropylene composite materials. Part I. Development and investigation of surface treatments, Compos Part a-Appl S. vol. 33, 8, pp. 1083-1093, 2002.

[215] ROUSSEAU, R. M.,BOIVIN, J. A., The fundamental algorithm: A natural extension of the Sherman equation part I: Theory, The Rigaku Journal. vol. 15, 1, p. 15, 1998.

[216] KUMAR, S.,DRUMMOND, C. H., Crystallization of Various Compositions in the Y2o3-Sio2 System, J Mater Res. vol. 7, 4, pp. 997-1003, 1992.

[217] MCKEEVER, S. W. S., Thermoluminescence of Solids. Cambrigde: Cambrigde University Press, 1985.

[218] O'BRIEN, R. W.,HUNTER, R. J., The electrophoretic mobility of large colloidal particles, Canadian Journal of Chemistry. vol. 59, 13, pp. 18781887, 1981. 
[219] MORENO, R., SALOMONI, A.,MELLO CASTANHO, S., Colloidal filtration of silicon nitride aqueous slips. Part I: optimization of the slip parameters, $\boldsymbol{J}$ Eur Ceram Soc. vol. 18, 4, pp. 405-416, 1998.

[220] SETZ, L. F. G., DE MELlo-Castanho, S. R. H., COlOMER, M. T.,MORENO, R., Surface behaviour and stability of strontium and cobalt doped-lanthanum chromite powders in water, Solid State Ionics. vol. 180, 1, pp. 71-75, 2009.

[221] GHALI, L., MSAHLI, S., ZIDI, M.,SAKLI, F., Effect of pre-treatment of Luffa fibres on the structural properties, Mater Lett. vol. 63, 1, pp. 61-63, 2009.

[222] KLOCK, U., MUÑIZ, G. I. B., HERNANDEZ, J. A.,ANDRADE, A. S., "QUÍMICA DA MADEIRA," ed. Curitiba, Paraná (PR), Brasil.: UNIVERSIDADE FEDERAL DO PARANÁ. SETOR DE CIÊNCIAS AGRÁRIAS. DEPARTAMENTO DE ENGENHARIA E TECNOLOGIA FLORESTAL., 2005, p. 86.

[223] BROWNING, B. L., The Chemistry of Wood. New York: Interscience, 1963.

[224] TANOBE, V. O. A., SYDENSTRICKER, T. H. D., MUNARO, M.,AMICO, S. C., A comprehensive characterization of chemically treated Brazilian sponge-gourds (Luffa cylindrica), Polym Test. vol. 24, 4, pp. 474-482, 2005.

[225] BONNET, M., DELAPALME, A.,FUESS, H., Magnetic-Moment Density in Yttrium-(Yig) and Terbium Iron Garnet (Tbig) by Polarized NeutronDiffraction, Acta Crystallogr A. vol. 31, pp. S228-S228, 1975.

[226] ANTIC, B., OENNERUd, P., RODIC, D.,TEllgReN, R., The structure characteristics of the diluted magnetic semiconductor $\mathrm{Y}_{2-\mathrm{x}} \mathrm{Dy}_{\mathrm{x}} \mathrm{O}_{3}$ Powder Diffr. vol. 8, p. 216, 1993.

[227] CHRISTENSEN, A. N., Hydrothermal Preparation and Magnetic Properties of $\mathrm{Dy}_{2} \mathrm{O}_{2} \mathrm{CO}_{3}, \mathrm{Ho}_{2} \mathrm{O}_{2} \mathrm{CO}_{3}, \mathrm{Er}_{2} \mathrm{O}_{2} \mathrm{CO}_{3}$, and $\mathrm{Yb}_{2} \mathrm{O}_{2} \mathrm{CO}_{3}$., Acta Chemica Scandinavica vol. 27, 1973.

[228] BARRETT, M. F., MCDONALD, T. R. R.,TOPP, N. E., Double ammonium oxalates of the rare earths and yttrium, Journal of Inorganic and Nuclear Chemistry. vol. 26, 6, pp. 931-936, 1964.

[229] RAUKAS, M., KONRAD, A.,MISHRA, K. C., Luminescence in nano-size Y2O3:Ce, J Lumin. vol. 122-123, 0, pp. 773-775, 2007. 
[230] PARMENTIER, J., BODART, P. R., AUDOIN, L., MASSOURAS, G., THOMPSON, D. P., HARRIS, R. K., GOURSAT, P.,BESSON, J. L., Phase transformations in gel-derived and mixed-powder-derived yttrium disilicate, Y2Si207, by X-ray diffraction and Si-29 MAS NMR, J Solid State Chem. vol. 149, 1, pp. 16-20, 2000.

[231] LEONYUK, N. I., BELOKONEVA, E. L., BOCELLI, G., RIGHI, L., SHVANSKII, E. V., HENRYKHSON, R. V., KULMAN, N. V.,KOZHBAKHTEEVA, D. E., High-temperature crystallization and X-ray characterization of Y2SiO5, Y2Si2O7 and LaBSiO5, J Cryst Growth. vol. 205, 3, pp. 361-367, 1999.

[232] ChRISTENSEN, A. N., HAZELL, R. G.,HEWAT, A. W. (1997, Synthesis, Crystal Growth and Structure Investigations of Rare-Earth Disilicates and Rare-Earth Oxyapatites. Acta Chemica Scandinavica 51, 37-43.

[233] KEPINSKI, L.,WOLCYRZ, M., Nanocrystalline rare earth silicates: structure and properties, Mater Chem Phys. vol. 81, 2-3, pp. 396-400, 2003.

[234] SUN, Z. Q., ZHOU, Y. C.,LI, M. S., Low-temperature synthesis and sintering of gamma-Y2Si2O7, J Mater Res. vol. 21, 6, pp. 1443-1450, 2006.

[235] ITO, J.,JHONSON, H., Synthesis and study of yttrialite, PDF. vol. 53, 1968.

[236] SANTOS, S. C., SETZ, L. F. G., YAMAGATA, C.,MELLO-CASTANHO, S. R. H., Rheological study of yttrium oxide aqueous suspensions, Advanced Powder Technology Vii. vol. 660-661, pp. 712-717, 2010.

[237] SANTOS, S. C.,MELLO-CASTANHO, S. R. H., "Rheological behavior of yttria aqueous suspensions for impregnation method," presented at the CIMTEC- International Ceramic Congress, Proceedings. Montecatini Terme, Tuscany, 2010

[238] CROSS, M. M., Rheology of Non-Newtonian Fluids - a New Flow Equation for Pseudoplastic Systems, J Coll Sci Imp U Tok. vol. 20, 5, pp. 417-\&, 1965.

[239] FROLlinI, E., LEAO, A. L.,MATTOSO, L. H. C., Natural Polymers and Agrofibers Based Composites: Embrapa Agricultural Instrumentation, 2000.

[240] SJÖSTRÖM, E., Wood Chemistry: Fundamentals and Applications: Academic Press, 1993. 
[241] SJOSTROM, E., Wood-Chemistry-Fundamentals and Applications. San Diego, 1993.

[242] QIU, K.,HAYDEN, A. C. S., Premixed gas combustion stabilized in fiber felt and its application to a novel radiant burner, Fuel. vol. 85, 7-8, pp. 10941100, 2006.

[243] VAKHIDOV, S. A., TAVSHUNSKII, G. A., RUSTAMOV, Y., BESSONOVA, T. S., SOBOLEV, B. P.,FEDOROV, P. P., Effect of Nuclear Radiation on Mixed Fluoride-Crystals, Zh Tekh Fiz+. vol. 49, 9, pp. 1943-1949, 1979.

[244] GONZAleZ-ORTEGA, J. A., TEJEdA, E. M., PEREA, N., HiRATA, G. A., BOSZE, E. J.,MCKITTRICK, J., White light emission from rare earth activated yttrium silicate nanocrystalline powders and thin films, Opt Mater. vol. 27, 7, pp. 1221-1227, 2005.

[245] SCHMIDT, P., HAPPEK, U., COMANZO, H., SETLUR, A., SRIVASTAVA, A., BEERS, W., GARAAS, R.,LOUREIRO, S., presented at the ECS Fall Meeting, Proceedings. Los Angeles, CA, 2005

[246] STANDARDIZATION, I. O. F., "Lighting for Work Places Part 1: Indoor (ISO: 8995-1: $2002 \mathrm{E}), "$ ed, 2002. 